UNIVERSIDADE DE SAO PAULO

ESCOLA DE ENFERMAGEN

SATISFACCIÓN EN EQUIPOS INTERPROFESIONALES: RELACIONES INTERPERSONALES, LIDERAZGO TRANSFORMACIONAL Y CLIMA DE EQUIPOS EN UN HOSPITAL DE SANTIAGO, CHILE. UN ESTUDIO DE MÉTODOS MIXTOS

PILAR ALEJANDRA ESPINOZA-QUIROZ

São Paulo

2016 
PILAR ALEJANDRA ESPINOZA-QUIROZ

\section{SATISFACCIÓN EN EQUIPOS INTERPROFESIONALES: RELACIONES INTERPERSONALES, LIDERAZGO TRANSFORMACIONAL Y CLIMA DE EQUIPOS EN UN HOSPITAL DE SANTIAGO, CHILE. UN ESTUDIO DE MÉTODOS MIXTOS}

Versión corregida da la Tesis presentada al Pograma de Doctorado Interinstitucional de la Escola de Enfermagem da Universidade de São Paulo y la Escuela de Enfermería de la Pontificia Universidad Católica de Chile, para obtener el título de Doctor en Ciencias.

Programa de Pós-Graduação em Gerenciamento em Enfermagem

Área de concentración: Fundamentos e Práticas de Gerenciamento em Enfermagem e em Saúde

Prof. Orientadora: Dra. Marina Peduzzi.

\section{VERSIÓN CORREGIDA}

La versión original se encuentra disponible en la Biblioteca de la Escola de Enfermagem da Universidade de São Paulo y también en la Biblioteca digital de Tesis y Disertaciones de la Universidade de São Paulo. 
AUTORIZO LA REPRODUCCIÓN Y DIVULGACIÓN TOTAL O PARCIAL DE ESTE TRABAJO, POR CUALQUIER MEDIO CONVENCIONAL O ELECTRÓNICO, PARA FINES DE ESTUDIO E INVESTIGACIÓN, SIEMPRE QUE SE CITE DEBIDAMENTE LA FUENTE.

Firma:

Fecha:

\author{
Catálogo de Publicación (CIP) \\ Biblioteca "Wanda de Aguiar Horta" \\ Escola de Enfermagem da Universidade de São Paulo
}

Espinoza-Quiroz, Pilar Alejandra

Satisfacción en equipos interprofesionales: relaciones interpersonales, liderazgo transformacional y clima de equipos en un hospital de Santiago, Chile. Un estudio de métodos mixtos / Pilar Alejandra Espinoza Quiroz. São Paulo, 2016.

$172 \mathrm{p}$.

Tesis (Doctorado) - Escola de Enfermagem da Universidade de São Paulo.

Guía de tesis: Prof. ${ }^{a}$ Dr. ${ }^{a}$ Marina Peduzzi

Área de desarrollo: Fundamentos y Práticas de Gestión en Enfermería y Salud

Programa de Postgrado en Gestión en Enfermería

1. Investigación en administración de enfermería.. 2. Satisfacción en el trabajo. 3. Relaciones interprofesionales. 4. Liderazgo. I. Título. 
Nombre: $\quad$ Pilar Alejandra Espinoza-Quiroz

Título: Satisfacción en equipos interprofesionales: relaciones interpersonales, liderazgo transformacional y clima de equipos en un hospital de Santiago, Chile. Un estudio de métodos mixtos.

Tesis presentada al programa de Pós-Graduação em Enfermagem Doutorado Internacional Interunidades EEUSP-EEUC en la Escola de Enfermagem da Universidade de São Paulo para la obtención del Título de Doctor en Ciencias.

Aprobada en

\section{BANCA EXAMINADORA}

Prof. Dr.

Instituição:

Julgamento:

Assinatura:

Prof. Dr.

Instituição:

Julgamento:

Assinatura:

Prof. Dr.

Instituição:

Julgamento:

Assinatura:

Prof. Dr.

Instituição:

Julgamento:

Assinatura:

Prof. Dr.

Instituição:

Julgamento:

Assinatura: 


\section{DEDICATORIA}

A los profesionales que hace 30 años, en un país lejano y con un idioma diferente me mostraron con hechos lo que significa trabajar en equipo. Esa experiencia marco mi vida, nuestro trabajo trascendía mas allá de las personas y enaltecía nuestra profesión y compromiso.

Mantuve esa experiencia en mi corazón por años, buscando revivirla, hasta que comprendí que debía entenderla y luchar por replicarla.

Esta tesis es el resultado de esa experiencia y espero el comienzo en la búsqueda de encontrar los medios para que mas profesionales puedan alcanzar esa sensación de alegría y compromiso con un objetivo superior y puedan guardarlas en su corazón como yo lo hice. 


\section{AGRADECIMIENTO ESPECIAL}

Quiero agradecer por el proceso largo que finaliza con esta tesis. En primer lugar a mi compañero de vida, quien junto con mis hijas representan el eje central de todo lo que es importante para mi. Iván, gracias por creer en mis sueños, por entender lo que me motiva e impulsarme a lograrlo. Por la paciencia para escucharme cuando divagaba en relación al proyecto y mis aprendizajes a medida que avanzaba en su desarrollo, por compartir tu invaluable experiencia como líder y miembro de equipos de trabajo para darme perspectiva cuando la necesite y por último pero no menos importante por complementar mis debilidades al momento del manuscrito final. A mis niñitas Macarena y Constanza gracias por la paciencia y por obligarme a remirar mis prioridades cuando pude perderlas de vista.

Gracias a todas mis colegas y amigos de los diferentes centros de salud por creer en el proyecto y apoyarme con ideas, estrategias y escucha cuando la necesite. A mi equipo de la Dirección de Asuntos Internacionales, Lili por la paciencia y apoyo, Belén por estar siempre dispuesta a cooperar con mis otras labores cuando estaba abrumada con el proyecto, Julio por estar siempre ahí, incondicional alentando, ofreciendo ayuda y apoyo especialmente con los temas numéricos. Elisa muchas gracias por su ayuda, el estar cerca la convirtió en parte importante de este equipo.

A mis compañeras del doctorado por compartir el camino, especialmente a Francisca por convertirse con sus talentos en la compañera exacta que necesitaba para lograr salir airosa.

Para terminar una persona fundamental, mi mentora, mi compañera de equipo, mi inspiración en muchas ocasiones, especiales gracias a Marina por convertirse en la persona que ilumino este camino. Tu apoyo, actitud comprensiva y cordial, el logar comunicarnos tan bien a pesar del idioma, la cultura, porque siempre nos enfocamos en nuestras metas en común y trabajamos para ello. Solo espero que esto no sea el fin, sino el comienzo de muchas colaboraciones y de una amistad que crezca y perdure. 


\section{RESUMEN}

Introducción: Las organizaciones de salud son cada vez más complejas, la necesidad de tener numerosas profesiones para un abordaje integral de los problemas de salud se vuelve prioridad. El trabajo en equipo se presenta como el más efectivo y adaptivo para profesionales que precisan reconocer su interdependencia para el logro de metas. Objetivo: Analizar los intercambios sociales y las relaciones con el liderazgo, el clima y la satisfacción de Equipos Interprofesionales (EI) en el ámbito hospitalario. Metodología: Investigación de método mixto secuencial explicativo (CUAN-CUAL). Primera fase con dos etapas (1) observacional, transversal y correlacional incluyendo una regresión lineal para la satisfacción en el equipo (SE), el liderazgo transformacional (LT), clima en el equipo (CE) y (2) el análisis de redes sociales para identificación de la estructura y las interacciones entre los miembros del equipo. Una muestra de 409 profesionales en 53 equipos en un hospital universitario de Santiago, Chile. Segunda Fase, Cualitativa con diseño descriptivo. Se entrevistó a 15 profesionales de EI con resultados extremos y media de la fase anterior. En la primera fase se utilizó estadística descriptiva, correlación, medidas de regresión lineal, ademas de cohesión y centralidad de la red social formal e informal. Fase cualitativa con análisis de contenido tematico. Concluyend con la integración de todos los resultados anteriores. Resultados: Hubo asociaciones significativas entre SE, LT y CE. La regresión lineal con SE como variable dependiente y ajustado por edad, número de miembros y tiempo en el equipo demostró que el CE (0,256 B) puede explicar en mayor medida la SE comparado con LT $(0,168$ B). La enfermera fue reconocida como LT informal por un $72 \%(66 \%-77 \%)$ y el médico por un 15\% (10\%-19\%) de los miembros de EI. El análisis de redes formales muestra que la enfermera es la principal fuente de orientación para resolver los problemas del paciente y las redes informales que los profesionales tienden a agruparse dentro de la misma profesión. El análisis de redes de los equipos con resultados extremos en la variable SE presentó diferencias entre los de mayor y menor satisfacción en: cohesión (100\% -25\%), centralidad $(100 \%-57 \%)$ e intermediación (100\% -36\%), respectivamente. El análisis cualitativo resultó en seis temas: el trabajo en equipo con objetivos comunes para la atención centrada en el paciente; colaboración con horizontalidad en las relaciones; apoyo y reconocimiento entre los miembros y la claridad de las funciones y responsabilidades; buenas relaciones interpersonales y mayor enfoque en el paciente; innovación para el trabajo en equipo; liderazgo en el equipo y el liderazgo informal y compartido. La integración de los resultados mostró: SE requiere de la participación y la comunicación de los miembros, los 
objetivos comunes refuerzan el compromiso con una atención centrada en el paciente, roles definidos contribuyen al trabajo colaborativo y LT informal potencia el bienestar, facilita el diálogo y la innovación. Conclusión: El estudio demostró que el método mixto permitió un abordaje explicativo e integral a SE. El muestran una asociación significativa de la SE con CE y LT, pudiendo el CE explicar en mayor medida la SE, relevando ademas la importancia de la permanencia en los EI. Entre los significados atribuidos a los constructos destacan: objetivos compartidos, claridad de roles de las diferentes profesiones, horizontalidad de las relaciones y el diálogo entre los profesionales para efectivamente alcanzar los mejores resultados para el paciente.

Palabras clave: Equipos interdisciplinarios, Relaciones interprofesionales, Satisfacción con el equipo, Liderazgo, clima de equipo, Método mixto. 


\section{ABSTRACT}

Introduction: The health organizations have become increasingly complex, making necessary to have various disciplines/professions engaging in an integral view of the health problems. The team work approach appears more effective and adaptive for these professional that requires recognizing their interdependency. Objective: To analyze the social interchanges and its relation with leadership, climate and satisfaction of members in Interprofessional teams in a hospital context. Methodology: Explanatory sequential mixed method (QUANT-QUAL). First phase with two stages, (1) observational, transversal and correlational including linear regression for satisfaction with the team (TS), transformational leadership (TL) and team climate (TC) and (2) social networks analysis to identify the structure and interactions among teams members. The sample size of 409 professionals of 53 teams at a university hospital in Santiago, Chile. In the qualitative phase using a descriptive design, 15 professionals from teams with results extremes and average of TS, were interviewed. The first phase used descriptive statistics, correlation, linear regression, also cohesion and centrality measurements of the formal and informal social network. Qualitative phase used thematic content analyzes. Finalizing with all the results integrated. Results: Significant associations were verified between TS, TL and TC. Linear regression with TS as the dependent variable and adjusted for age, number of members and time with the team showed that the TC $(\mathrm{B} 0,256)$ can largely explain TS when compared to TL $(\mathrm{B} 0,168)$. The nurse was recognized for the team members as the informal TL by $72 \%(66 \%-77 \%)$ and the doctor by $15 \%$ (10\%-19\%). Analysis of the formal networks showed that the nurse is the main source of direction to solve patient problems, the informal networks showed that the professional tend to group with others of the same profession. The analysis of teams networks with extreme results in the TS variable showed differences between those with higher and lower satisfaction in: cohesion (100\%-25\%), centrality (100\%-57\%) and intermediation (100\%-36\%) respectively. The interview analysis resulted in six themes: team work with shared objectives for patient centered care; collaboration in a horizontal manner in the relations; support and recognition among the members and clarity on the roles and responsibilities; good interpersonal relations and greater focus on the patient; innovation for the team work; team leadership and informal and shared leadership. The integration of the results uncover: TS requires members participation and communication, common objective strengthen towards the commitment of patient centered care, defined roles support the collaborative work and the informal TL strengthen the wellbeing, dialogue and innovation. 
Conclusions: The study showed that a mixed method allows an explicative and comprehensive understanding of TS. Interprofessional Teams presented significant association of TS with TC and TL, also that TC explain in greater extent TS. Showing that time with the team it is important to achieve TS. The meaning related to the constructs highlights were: shared objectives, role clarity of different professions, horizontality of the relations and dialogue between the professionals to effectively achieve the best results for the patient.

Key words: Interdisciplinary teams, Interprofessionals relations, Satisfaction with the team, Leadership, team climate, Mixed method. 


\section{RESUMO}

Introdução: As organizações de saúde são cada vez mais complexas, sendo necessário contar com numerosas disciplinas/profissões na abordagem integral dos problemas de saúde. $\mathrm{O}$ trabalho em equipe apresenta-se como mais efetivo y adaptativo para os profissionais que precisam reconhecer sua interdependência. Objetivo: Analisar os intercâmbios sociais e suas relações com liderança, clima e satisfação dos profissionais de equipes Interprofissionais no contexto hospitalar. Metodologia: Pesquisa de método misto sequencial explanatório (QUANT-QUAL). Primeira fase com duas etapas, (1) observacional, transversal y correlacional incluindo regressão linear para satisfação na equipe (SE), liderança transformacional (LT) y clima de equipe (CE), e (2) análise de redes sociais para identificação da estrutura e interações entre membros das equipes. Amostra de 409 profissionais de 53 equipes em um hospital universitário de Santiago, Chile. Na fase qualitativa de desenho descritivo, foram entrevistados 15 profissionais de equipes com resultados extremos e médios. Na primeira fase utilizou-se estatística descritiva, correlação, regressão linear e medidas de coesão e centralidade da rede social formal e informal e na fase qualitativa análise de conteúdo temático, finalizando com a integração dos resultados. Resultados: Verificaram-se associações significativas entre SE, LT y CE. Regressão linear com SE como variável dependente e ajustada por idade, número de membros e tempo na equipe mostrou que o $\mathrm{CE}(\mathrm{B}$ 0,256) pode explicar em maior medida a SE comparado com LT (B 0,168). A enfermeira foi reconhecida como LT informal por 72\% (66\%-77\%) e o médico por $15 \%$ (10\%-19\%) dos membros. A análise das redes formais mostra que a enfermeira é a principal fonte de orientação para resolver problemas do paciente e a das redes informais que os profissionais tendem a se agrupar com outros da mesma disciplina/profissão. Análise de redes das equipes com resultados extremos na variável SE apresentou diferenças entre as que tinham maior e menor satisfação: coesão (100\%-25\%), centralidade (100\%-57\%) e intermediação (100\%-36\%) respectivamente. A análise das entrevistas resultou em seis temas: trabalho em equipe com objetivos compartilhados para o cuidado centrado no paciente; colaboração com horizontalidade nas relações, suporte e reconhecimento entre os membros e clareza dos papeis e responsabilidades; boas relações interpessoais e maior foco no paciente; inovação para o trabalho em equipe; liderança na equipe e liderança informal e compartilhada. A integração dos resultados evidenciou: SE requer participação e comunicação dos membros, objetivos comuns potencializa o compromisso com o cuidado centrado no paciente, papeis definidos contribui para o trabalho colaborativo e LT informal 
potencializa o bem-estar, facilita o dialogo e a inovação. Conclusão: $O$ estudo mostrou que o método misto permitiu abordagem explicativa e compreensiva da SE. Evidenciou associação significativa de SE com CE e LT e que o CE pode explicar em maior medida a SE, que os profissionais percebem as relações entre SE, CE e LT e que os significados atribuídos aos construtos destacam: objetivos compartilhados, clareza dos papéis das diferentes disciplinas/profissões, horizontalidade das relações e diálogo entre os profissionais para efetivamente produzir os melhores resultados no paciente.

Palavras chave: Equipes interdisciplinares, Relações interprofissionais, Satisfação com equipe, Liderança, clima de equipe, Método misto. 


\section{LISTA DE FIGURAS}

Figura $\mathrm{N}^{\circ}$ 1: - Equipo con mayor satisfacción: Red para solución de problemas 75 laborales

Figura $\mathrm{N}^{\circ} 2 \quad-$ Red que persigue mostrar en detalle la presencia de miembros Influyentes (mayor número de interacciones desde y hacia ellos) y de Intermediación de los flujos de información no muestra cambios en este equipo

Figura No3 - Equipo con mayor satisfacción: Red de relaciones sociales de sus miembros

Figura $\mathrm{N}^{\circ} 4 \quad-\quad$ Red que persigue mostrar en detalle la presencia de miembros Influyentes (mayor número de interacciones desde y hacia ellos) y de Intermediación de los flujos de información no muestra cambios en este equipo

Figura $N^{\circ} 5$ - Equipo con menor satisfacción: Red para solución de problemas laborales

Figura $N^{\circ} 6$ - Propiedades de la red a través del tamaño de los nodos.

Miembros Centrales en la red

Figura $N^{\circ}$ - Miembros Influyentes a través del tamaño de los nodos. (mayor interacción desde y hacia ellos)

Figura $N^{\circ} 8 \quad-$ Miembros con Alto grado de Intermediación en la red

Figura $\mathrm{N}^{\circ} 9$

- Equipo con menor satisfacción: Red de relaciones sociales de sus miembros

Figura $\mathrm{N}^{\mathrm{o}} 10$ - Propiedades de la red a través del tamaño de los nodos. Miembros Centrales en la red

Figura $\mathrm{N}^{\circ} 11$ - Miembros Influyentes (mayores interacciones desde y hacia ellos)

Figura $\mathrm{N}^{\mathrm{o}} 12$ - Miembros con Alto grado de Intermediación en la red

Figura $\mathrm{N}^{\circ} 13$ - Servicio con Equipos con alto en LT, CE y ST: Red Profesional

Figura $\mathrm{N}^{\circ} 14$

- Propiedades de la red a través del tamaño de los nodos. Miembros Centrales en la red

Figura $\mathrm{N}^{\circ} 15 \quad$ - Miembros Influyentes (mayor interacciones desde y hacia ellos) 88

Figura $\mathrm{N}^{\circ} 16$ - Miembros con Alto grado de Intermediación en la red 88

Figura $\mathrm{N}^{\circ} 17$ - Servicio con Equipos con alto en LT, CE y ST: Red de 89 relaciones sociales de sus miembros

Figura $\mathrm{N}^{\circ} 18$ - Propiedades de la red a través del tamaño de los nodos. 90 Miembros Centrales en la red

Figura $\mathrm{N}^{\circ} 19 \quad$ - Miembros Influyentes (mayor interacciones desde y hacia ellos) $\quad 90$

Figura $\mathrm{N}^{\circ} 20$ - Miembros con Alto grado de Intermediación en la red 91

Figura $\mathrm{N}^{\circ} 21$ - Servicio con Equipos con alto en LT, CE y ST: Red de 93 relaciones sociales de sus miembros 
Figura $\mathrm{N}^{\circ} 22$ - Propiedades de la red a través del tamaño de los nodos. 94 Miembros Centrales en la red

Figura $\mathrm{N}^{\circ} 23$ - Miembros Influyentes (mayor interacciones desde y hacia ellos) 95

Figura $\mathrm{N}^{\circ} 24 \quad$ - Miembros con Alto grado de Intermediación en la red 95

Figura $N^{\circ} 25$ - Servicio con Equipos con promedio en LT, CE y ST: Red social 96

Figura $N^{\circ} 26$ - Propiedades de la red a través del tamaño de los nodos. 97 Miembros Centrales en la red

Figura $\mathrm{N}^{\circ} 27 \quad$ - Miembros Influyentes (mayor interacciones desde y hacia ellos) $\quad 98$

Figura N²8 - Miembros con Alto grado de Intermediación en la red 98 


\section{LISTA DE TABLAS}

Tabla N $\mathrm{N}^{\mathrm{1}}$ - Modelo Visual de los procedimientos del diseño de estudio de 43 métodos mixtos, secuencial explicativo

Tabla N22 - Pruebas de normalidad de escalas 58

Tabla No3 - Variables sociodemográficas en Miembros de 53 Equipos 58 Interdisciplinarios

Tabla N $\mathrm{N}^{\mathrm{4}}$ - Composición de profesionales en los equipos de salud de acuerdo 60 a sus miembros

Tabla N5 - Composición de los Equipos de Trabajo Interprofesionales 61

Tabla No6 - Pruebas de confiabilidad de los instrumentos 62

Tabla No7 - Distribución de Variable Satisfacción con Equipo de Trabajo 62

Tabla N 8 - Inventario de Clima de Equipos y sus dimensiones en Equipos 63 Interprofesionales

Tabla N ${ }^{\circ} 9$ - Liderazgo Transformacional en Equipos de Trabajo 64 Interprofesionales

Tabla $N^{\circ} 10$ Liderazgo Transformacional en Equipos de Trabajo 65 Interprofesionales

Tabla N $N^{\circ} 11$ - Pruebas de correlación de las dimensiones de las variables LT y 66 CE con Satisfacción con el Equipo

Tabla No12 - Correlación de variables a nivel de Equipo de Trabajo 66

Tabla N¹3 - Regresión lineal Liderazgo Transformacional (crudo) 66

Tabla No14 - Regresión lineal Clima de Equipos (crudo) 67

Tabla Nº15 - Regresión lineal Liderazgo Transformacional y Clima de Equipo 67 (crudo)

Tabla $N^{\circ} 16$ - Regresión lineal LT y CE ajustado por edad, tiempo en el equipo y número de integrantes de los miembros de $\mathrm{EI}$

Tabla No17 ¿A quién acude cuando tiene algún problema, necesidad o 72 dificultad en el trabajo?

Tabla $\mathrm{N}^{\circ} 18 \quad$ ¿A quién acude cuando tiene algún problema personal? 73

Tabla $\mathrm{N}^{\circ} 19$ Características de la red de interacciones para solución de 74 problemas laborales y personales

Tabla $\mathrm{N}^{\circ} 20 \quad$ Características de la red de interacciones para solución de 78 problemas laborales y personales

Tabla $\mathrm{N}^{\circ} 21 \quad$ Características de la red de interacciones para solución de 85 problemas laborales y personales

Tabla N 22 Características de la red de interacciones para solución de 92 problemas laborales y personales 


\section{LISTA DE SIGLAS}

EI

SE

LT

CE
- Equipo Interdisciplinario/Interprofesional

- Satisfacción con el Equipo

- Liderazgo Transformacional

- Clima de Equipo 


\section{ÍNDICE}

1. INVESTIGACIÓN EN ADMINISTRACIÓN DE ENFERMERÍA.. 2. SATISFACCIÓN EN EL TRABAJO. 3.

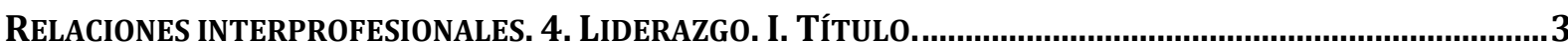

1. INTRODUCCIÓN

2. MARCO TEÓRICO

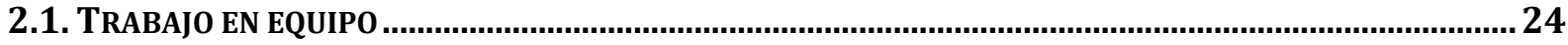

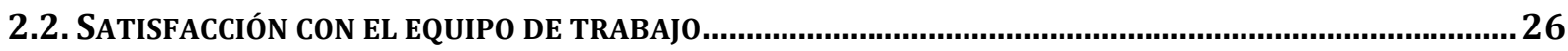

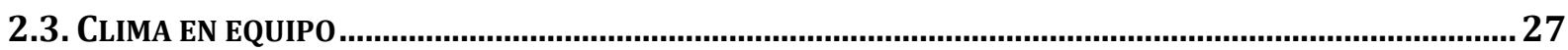

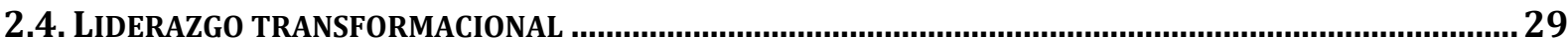

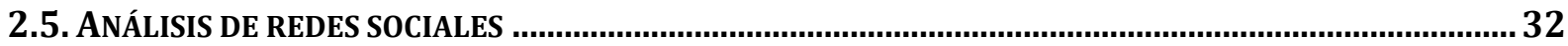

3. PREGUNTA DE INVESTIGACIÓN DE MÉTODOS MIXTOS _....................................

3.1. PREGUNTAS DE INVESTIGACIÓN CUANTITATIVA

3.2. PREGUNTAS DE INVESTIGACIÓN CUALITATIVA

4. OBJETIVOS

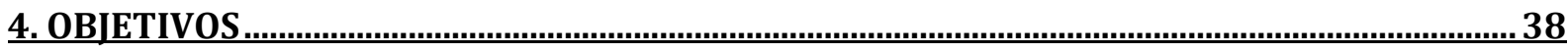

4.1. OBJETIVOS GENERALES DE LA INVESTIGACIÓN

4.2. OBJETIVOS ETAPA CUANTITATIVA

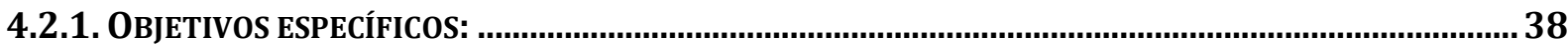

4.3. OBJETIVOS ETAPA CUALITATIVA

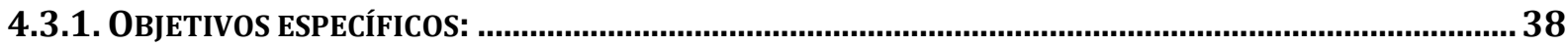

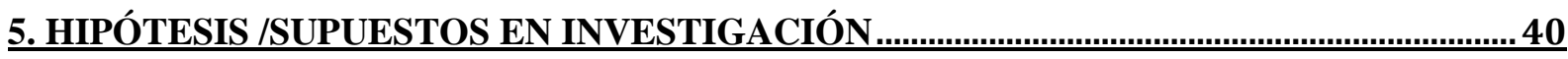

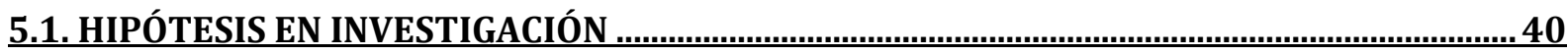

5.2. SUPUESTOS DE LA INVESTIGACIÓN

6. METODOLOGÍA

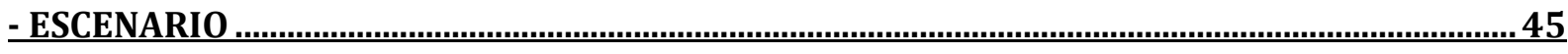

- PARTICIPANTES

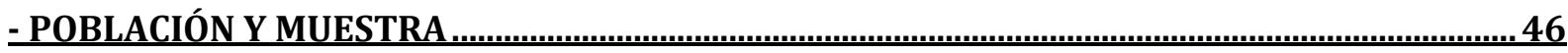

6.1. METODOLOGÍA CUANTITATIVA: 1RA FASE

6.1.1. DISEÑO OBSERVACIONAL TRANSVERSAL DESCRIPTICO CORRELACIONAL (ETAPA 1) ....................... 46

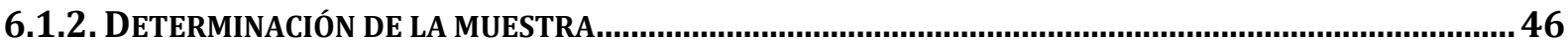

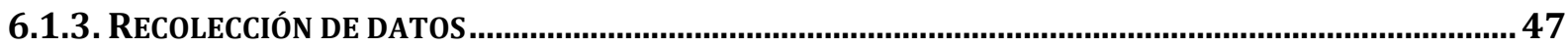




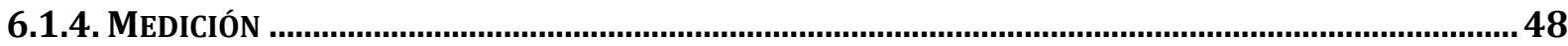

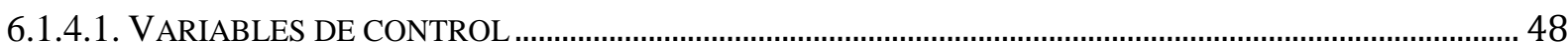

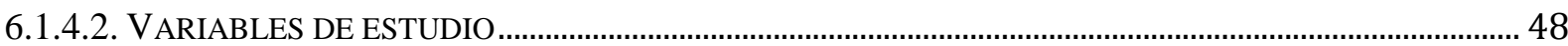

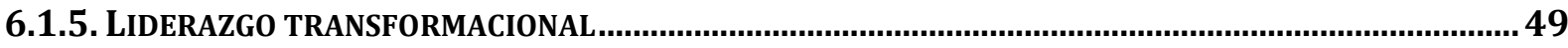

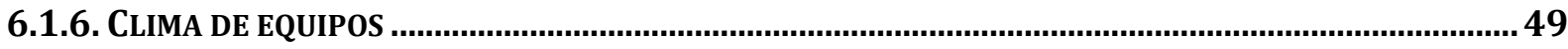

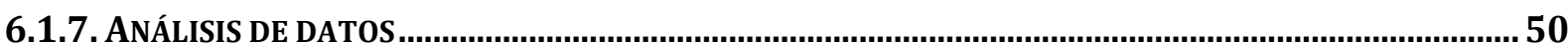

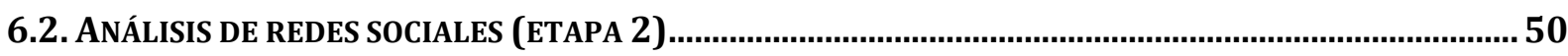

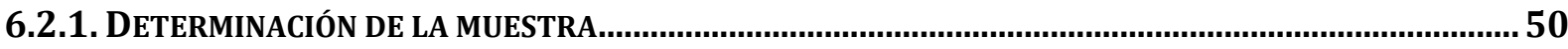

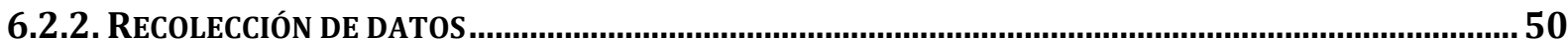

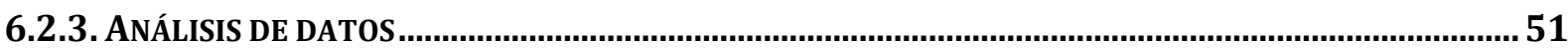

6.3. METODOLOGÍA CUALITATIVA: 2DA FASE

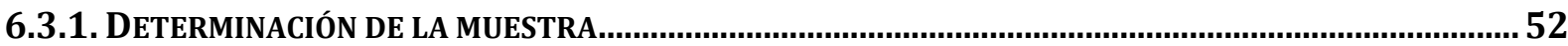

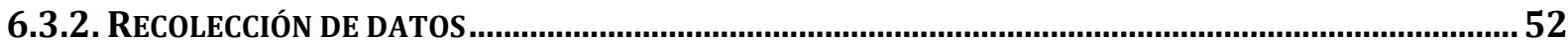

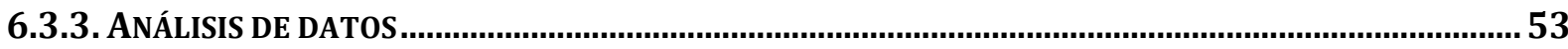

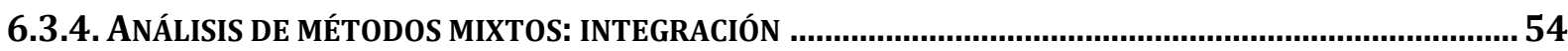

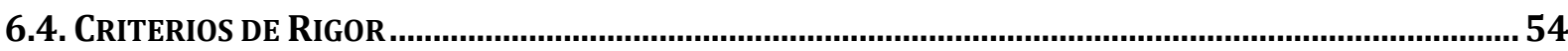

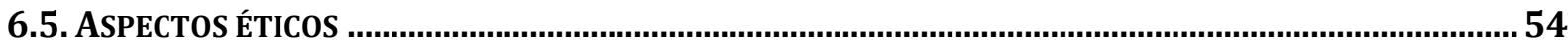

7. RESULTADOS

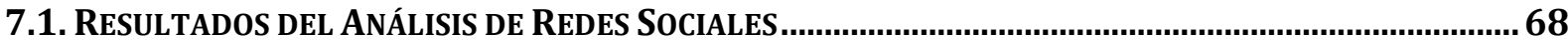

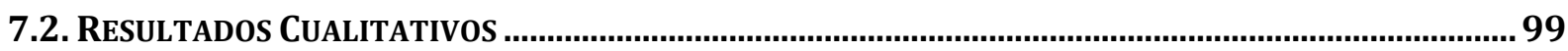

7.3. RESULTADOS INTEGRADOS

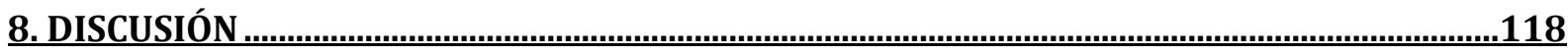

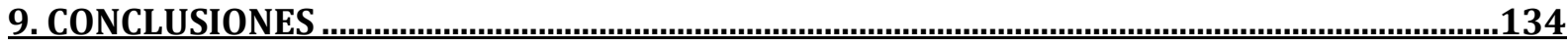

9.1. LIMITACIONES

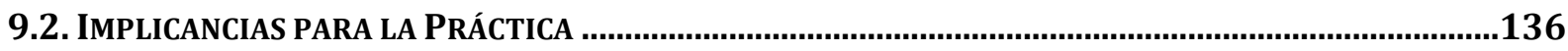

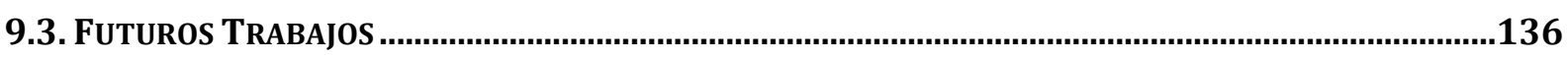

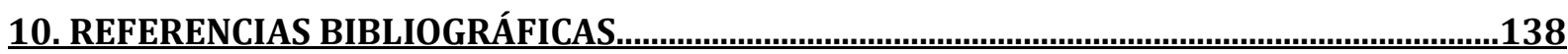

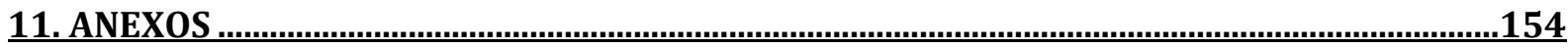

11.1. ANEXo No 1 CÁlCULO de MUESTRA............................................................................................154

11.2. ANEXo N$^{\circ} 2$ APROBACIÓN DE INVESTIGACIÓN COMITÉS DE ÉTICA BRASIL....................................155

11.3. ANEXo №3 APROBACIÓN DE INVESTIGACIÓN COMITÉ DE ÉTICA ESCUELA DE ENFERMERÍA UC ...159

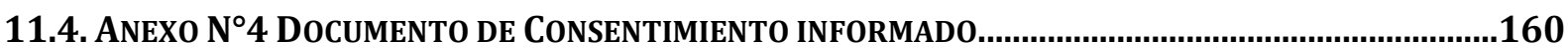

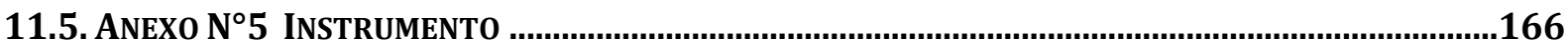

11.6. ANEXO Nº 6 GUÍA DE ENTREVISTA CON PROFESIONALES DE LOS EQUIPOS INTERDISCIPLINARIOS 172 


\section{INTRODUCCIÓN}

Las organizaciones de salud son cada vez más sofisticadas, complejas y especializadas, dentro de las cuales, los conocimientos y habilidades necesarias para cumplir efectivamente con sus metas cambian y aumentan constantemente. ${ }^{1}$ La naturaleza de estas organizaciones ha evolucionado para situarse en contextos económicos restrictivos, asociado a presiones financieras en términos de eficacia y eficiencia. ${ }^{2}$ Sumado a esto aparece la falta de profesionales a nivel mundial para cumplir con estas expectativas. ${ }^{3}$

En este escenario, es importante rescatar también la evolución en los problemas de salud de los usuarios, generando diversas necesidades asociadas a altas expectativas de satisfacción. ${ }^{4}$ Lo anterior pone de manifiesto la necesidad de contar con numerosas disciplinas que participen de la entrega de servicios, trabajando de manera interdependiente en el abordaje de los diversos problemas de salud ${ }^{5,6}$ para lo cual, el modelo de trabajo en equipo aparece como el más efectivo y adaptativo, en contraste con estructuras jerárquicas y burocráticas. ${ }^{7}$ Hoy en día, la incorporación de los resultados de la investigación, a través de la práctica basada en evidencia, han puesto de manifiesto inaceptables variaciones en la práctica clínica, lo que ha llevado a cuestionamientos en el desempeño profesional, con énfasis en responsabilidades individuales y organizacionales. ${ }^{8,9}$ En este marco complejo, aparece la figura del líder, equipado con habilidades para rediseñar los servicios y mejorar el cuidado de la salud, observando los procesos como una secuencia que debe ser evaluada con miras a eliminar etapas innecesarias, dualidad de funciones y descubrir las debilidades que limitan el alcance del estándar esperado, el cual debe estar siempre alineado con las necesidades de los usuarios. $^{10}$

Reportes de organismos internacionales reconocen problemas de calidad y seguridad en la atención sanitaria $^{11,12}$ y recomiendan la creación de ambientes laborales que potencien el bienestar y desarrollo del personal de salud, comenzando por el desarrollo de liderazgos transformadores dentro de las instituciones. ${ }^{12,13}$

En los ambientes dinámicos actuales es imperativo contar con equipos y liderazgos de alto desempeño que guíen en los complejos cambios necesarios para unir calidad y eficiencia en la nueva generación del cuidado, utilizando enfoques que integren variables organizacionales y estructurales. $^{14}$ 
Entre los miembros de estos equipos, destaca enfermería, disciplina que entrega el $70 \%$ de los cuidados otorgados a pacientes hospitalizados. ${ }^{15}$ Considerando esta información y situándola en el contexto nacional, donde el déficit de profesionales alcanza un $47 \%$ en diferentes ambientes sanitarios, ${ }^{16,17,18}$ sumado a una alta rotación de ellos, tanto en el área pública como privada, explicándose por la búsqueda de mejores rentas, incentivos y beneficios profesionales, ${ }^{18,19}$ además de insatisfacción en su ambiente laboral. ${ }^{20,21}$ Reconocen que los factores que podrían estar incidiendo en esta realidad, son, la falta de apoyo desde las personas que ostentan puestos relevantes dentro de la organización, la falta de socialización de la información desde la administración a los subalternos o su transmisión incorrecta, falta de trabajo en equipo, por último pero no menos importante, la falta de autonomía en la realización de sus tareas. $^{21,22}$

Basado en lo expuesto, aparece como primordial desarrollar una mejor comprensión de las prácticas de comunicación y relaciones de intercambio social dentro de los equipos interdisciplinarios de salud, a través del estudio de la satisfacción de sus miembros con el trabajo colaborativo, el estilo de liderazgo, formal o compartido, que reconozca y potencie el desarrollo de sus miembros y un clima dentro del equipo que entregue seguridad participativa y objetivos compartidos. Además, es necesario profundizar en la estructura y contenido de las relaciones interpersonales, formales e informales para el trabajo compartido, esto, con miras a lograr un conocimiento y comprensión profunda de la interacción de estas variables dentro de los equipos interpersonales. Todas ellas reconocidas ampliamente por su asociación a permanencia laboral, compromiso, motivación, crecimiento personal y profesional entre otros.

Se espera con los resultados y contribuciones de esta tesis fundamentar la creación de programas de formación y capacitación que integren herramientas administrativas enfocadas en relaciones laborales satisfactorias que pueden incidir directamente en la estabilidad y permanencia laboral e indirectamente en resultados de excelencia en el cuidado de la salud, facilitando la habilidad de los equipos para enfrentar las demandas de un sistema de salud en cambio constante. 


\section{MARCO TEÓRICO}

Mundialmente los sistemas de salud son consideradas como grandes organizaciones, donde un trabajo en equipo efectivo puede optimizar el cuidado del paciente ${ }^{23}$, promoviendo satisfacción laboral y retención de sus miembros. ${ }^{24,25}$ Las investigaciones que persiguen un cuidado de calidad y seguro, han aumentado en las ultimas décadas ${ }^{26}$, reconociendo en el trabajo en equipo el potencial para aumentar la productividad, creatividad, adaptabilidad 26,27,28 y la solución de problemas complejos de manera innovadora. A pesar de lo anterior, los resultados de sus procesos no siempre son exitosos, ${ }^{29,30}$ lo cual estaría asociado a las relaciones interpersonales al interior ellos, específicamente a aspectos comunicacionales y de cooperación, limitando así el desarrollo de su máximo potencial. ${ }^{29,} 30$ Por el contrario, relaciones interpersonales positivas ayudarían a generar un ambiente de trabajo estimulante, comunicación efectiva y resultados eficaces. ${ }^{31}$

Estrategias para generan un clima de trabajo positivo y mayor satisfacción incluyen, amistad con los colegas, ${ }^{34}$ apoyo del supervisor, compañerismo (calidez), responsabilidad (autonomía) y recompensas. ${ }^{32}$ Equipos efectivos se conforman desde una visión y motivación compartida, confianza y respeto entre sus miembros. ${ }^{33}$ La satisfacción laboral aparece asociada también a la colaboración con el profesional médico, ${ }^{35}$ apoyo y comunicación con los supervisores y compañeros de trabajo, ${ }^{34}$ reconocimiento, trato justo ${ }^{36}$ y compromiso profesional. ${ }^{37}$ Situaciones todas, que pueden ser potenciadas por la presencia de líderes proactivos ${ }^{38}$ que orientan su comportamiento a aspectos relacionales, ayudando a la efectividad percibida por el equipo. ${ }^{39,40,41}$ Entre ellos destaca el líder transformacional, relacionado con la satisfacción de los seguidores a nivel individual y de equipo a través de la confianza depositada en él y en los miembros del equipo. ${ }^{42,43}$

Otro aspecto relevante para comprender los procesos sociales al interior de los equipos, es observar las redes sociales, su estructura social y profesional, lo cual ilustraría sobre aspectos como, interacción, comunicación y trabajo colaborativo, permitiendo explicar sus relaciones interpersonales en términos de trasmisión de la información dentro del equipo. ${ }^{44,45,46}$

La presente investigación busca profundizar en el conocimiento y comprensión de la satisfacción percibida por los miembros de equipos interdisciplinarios con el trabajo compartido, esto, a través de explorar variables de reconocido impacto en contextos 
organizacionales, como son, el estilo de liderazgo, en este caso liderazgo transformacional y el clima percibido por los miembros al interior del equipo. Además, se pretende ahondar en la comprensión de los procesos a través de la descripción de la estructura y contenido de las relaciones de intercambio social entre sus miembros durante el trabajo conjunto.

\subsection{Trabajo en equipo}

La organización de las personas dentro de las instituciones de salud, específicamente de las unidades más pequeñas, reconocidas también como equipos de trabajo, se ha convertido en un componente esencial para el éxito organizacional, si se considera su complejidad y entorno, logrando que múltiples habilidades se potencien más allá de la suma del trabajo individua. ${ }^{147}$ El equipo se define como el grupo al cual las personas son asignadas, se identifican e interactúan con regularidad, con el fin de realizar tareas comunes. ${ }^{47}$ Las personas tienden a identificarse con su grupo y a desarrollar un compromiso con su estructura social, independiente de si son de carácter permanente o semi-permanente. ${ }^{33}$ Los individuos normalmente pueden pertenecer a más de un grupo de trabajo, pero el enfoque es sobre el grupo en el que las tareas y las actividades cotidianas se llevan a cabo y se dividen de acuerdo al abordaje que utiliza cada uno para alcanzar los objetivos organizacionales. ${ }^{47}$ Esta conceptualización no impide asociaciones puramente sociales en el lugar de trabajo, sin embargo, la interdependencia en la tarea es considerada como un elemento esencial. ${ }^{47} \mathrm{El}$ equipo se define como el grupo al cual las personas son asignadas, se identifican e interactúan con regularidad, con el fin de realizar tareas comunes y compartir el mismo objetivo o producto final. Su participación es estable en el tiempo e interaccionan con cierta frecuencia. Su trabajo puede ser analizado en términos del objetivo compartido (cuidado de los mismos pacientes) y su apreciación del rol interdependiente que cada uno cumple, traduciéndose en un sentido de pertenencia, conocimiento de los valores compartidos y confianza mutua. Cuentan con una estructura administrativa que permite atestiguar de los resultados esperados y los comportamientos necesarios para lograrlo. ${ }^{48}$ Además se cuenta con una función de liderazgo que apoya el trabajo colaborativo entregando dirección de funciones.

Dimensiones cruciales al momento de identificar los equipos son: habilidades diferentes, que habla del grado en el cual sus miembros tienen conocimientos especializados o capacidades funcionales que hace difícil ser sustituidos. ${ }^{47,48}$ Diferencias en el grado de autoridad para la toma de decisiones, en que puede recaer en individuos o grupos de individuos y por último la 
estabilidad temporal, que incluye el grado en que sus miembros tienen una historia de trabajo compartido y sus expectativas de continuar haciéndolo.

De las taxonomías utilizadas al momento de describir los equipos se rescatan los tres constructos subyacentes o dimensiones cruciales explicitadas más arriba ${ }^{48}$. La importancia de contar con una estructura conceptual común además de implicancias teóricas y empíricas podría tener un valor práctico para diagnóstico y predicción, ya que la evidencia sugiere que ciertos tipos de equipos son propensos a ciertas fortalezas y debilidades. ${ }^{48}$

Existen otras taxonomías de trabajo en equipo que contribuyen a reconocer que los equipos no pueden ser caracterizados de forma homogénea, sin embargo, la literatura apunta a la necesidad de diferenciar equipos efectivos, aquellos que producen buenos resultados en atención de pacientes, y los menos efectivos llamados pseudo-equipos ${ }^{48}$. Estudios destacan la necesidad de colaboración entre sus miembros, e identifican tres variedades en ese sentido: con potencial de colaboración, colaboración en desarrollo y colaboración activa. ${ }^{44}$ Algunos distinguen equipos que tienden a la integración, aunque son en realidad un mero agrupamiento de profesionales ${ }^{49,50}$ y los equipos realmente integrados. En esa línea aparecen también los fragmentados y los denominados central-periférico, que cuentan con un núcleo de profesionales integrados en torno al cual se agrupan los demás profesionales. ${ }^{51}$

Un tipo específico dentro de la organización para el trabajo está representado por el equipo multidisciplinario o interprofesional, que serán utilizados en esta investigación como equivalentes. En estos equipos todos los profesionales trabajan con claras definiciones de funciones, tareas y líneas jerárquicas de autoridad. ${ }^{52}$ En el caso de un equipo de salud, el médico ocupa frecuentemente una posición nuclear como responsable del tratamiento del enfermo y coordina su plan de trabajo con los otros profesionales en el equipo. ${ }^{52,53} \mathrm{El}$ nivel de autonomía profesional es alta para los médicos y menor para los otros profesionales, tendiendo cada área a crear sus propios objetivos individuales y planes de cuidado para el paciente. ${ }^{49,50}$ En general el médico se comunica con los profesionales del equipo para transmitir órdenes y puede haber poca o ninguna comunicación entre los demás profesionales. ${ }^{52,53,54}$

Investigaciones en relación a equipos interdisciplinarios (multiprofesional, interdisciplinar e multiprofesionales) y unidisciplinarios, proviene mayoritariamente de Europa, América Norte 
y Oceanía, aunque es posible observar un desarrollo incipiente en países como Brasil. Una revisión sistemática integrativa realizada en Australia el año 2006 que buscaba determinar el efecto de las características del equipo, enfatiza en que estas deben incluir, responsabilidad individual, compromiso, entusiasmo y motivación ${ }^{55}$ y que el apoyo social entregado por un supervisor o los colegas aumenta los niveles de satisfacción con el trabajo. ${ }^{55}$ Estudios realizados en unidades de cuidado intensivo indican que una mayor auto-identificación con el equipo disminuiría las tasas de mortalidad $^{56}$ y las caídas con lesiones en los pacientes. ${ }^{57}$ Equipos multidisciplinarios de cuidados paliativos confirman la importancia de la claridad de roles, el compromiso, el intercambio cercano y positivo entre los miembros para lograr el éxito. ${ }^{58,59}$ Miembros de equipos unidisciplinarios se perciben como beneficiados con mejores relaciones interpersonales, mayor efectividad y sentido de responsabilidad, disponibilidad de apoyo y compromiso. ${ }^{59}$ Por último el profesional más cercano al cuidado directo del paciente no se percibe como participante de la toma de decisiones en los equipos interdisciplinarios, donde solo quienes cumplen roles más complejos se involucran en ella. ${ }^{58,59}$

Aparece también la importancia de un número adecuado de profesionales para otorgar un cuidado de calidad y seguro a los paciente. ${ }^{60}$ y se sugiere la existencia de una relación significativa entre la estructura del equipo, sus procesos y los resultados de salud a ser alcanzados. $^{60}$ Un estudio en servicios médico-quirúrgicos basado en principios de la investigación-acción, con la mitad de las unidades empleando un modelo de atención en equipo y el resto un modelo de asignación individual de pacientes ${ }^{60,61}$ concluye a los 12 meses, que la satisfacción profesional y retención del personal fue mayor con el trabajo en equipo. $^{61}$

\subsection{Satisfacción con el equipo de trabajo}

La satisfacción laboral se ha definido como un estado emocional positivo o placentero resultante de una percepción subjetiva de las experiencias laborales del sujeto ${ }^{62}$. En general, las distintas definiciones reflejan la multiplicidad de variables que pueden incidir en ella, las circunstancias y características del propio trabajo y las individuales de cada trabajador, condicionando la respuesta afectiva de éste hacia los diferentes aspectos del trabajo. ${ }^{62}$ 
La satisfacción en el trabajo es importante no sólo en términos del bienestar deseable de las personas, donde quiera que trabajen, sino también, en términos de productividad y calidad. ${ }^{63}$ La percepción de la calidad del cuidado del paciente y las relaciones colaborativas aparecen como los predictores más importantes de la satisfacción para los trabajadores de la salud. ${ }^{64}$ Esto reviste singular importancia desde el ámbito de la gestión de los equipos al interior de la organización ${ }^{65}$ pudiendo influir en la calidad del servicio prestado. ${ }^{66}$ La insatisfacción por otro lado ha aparecido como un predictor significativo de conductas disfuncionales, como el ausentismo, el cambio de puesto y el abandono de la organización. ${ }^{67}$ Cuando se estudia la satisfacción laboral, se profundiza en las percepciones acerca de la tarea, los compañeros, los líderes, las conductas individuales y grupales en un contexto social. ${ }^{67}$

En el marco del trabajo en equipo, el interés radica en la satisfacción de los miembros con el trabajo desarrollado al interior del equipo, ya que su ausencia puede traducirse en procesos deficientes $^{68}$ resultados inconsistentes ${ }^{69,70}$, dificultad para interactuar y alcanzar acuerdos, generando frustración ${ }^{71}$ emociones negativas y transformándose finalmente, en un elemento disruptivo de los procesos organizacionales. ${ }^{72}$

La satisfacción con el equipo, es un marcador de que tan efectivamente los miembros creen que el equipo puede lograr sus metas, ${ }^{68}$ donde sienten que pueden hacer contribuciones valiosas y ser escuchados durante la toma de decisiones, ${ }^{71}$ generando sentimientos positivos y bienestar, lo que incentiva a desear seguir trabajando juntos a futuro. ${ }^{73}$

En el caso de profesionales de la salud en equipos interprofesionales, la satisfacción se traduce en intenciones de permanecer en el equipo y menor stress laboral. ${ }^{74,75}$ Por lo anterior, al evaluarla es necesario utilizar indicadores que distingan la dimensión que rescata específicamente la satisfacción con los miembros del equipo. ${ }^{76}$

\subsection{Clima en equipo}

Una forma de profundizar en la comprensión de los procesos internos de los equipos, es explorar el concepto de clima de equipos, reconocido como, la descripción basada en lo que las personas ven y reportan de lo sucedido con ellos en una situación organizacional o grupal especifica. ${ }^{77}$ Anderson y West $^{46}$ definen el clima interno del equipo, como las percepciones compartidas relativas al grupo de trabajo próximo, esto representa al equipo permanente o 
semipermanente al que son asignados los sujetos, con los cuales se identifican e interaccionan de forma regular para realizar las tareas asignadas en su medio laboral. Para entender el clima en los equipos de trabajo, Anderson y West (1998) proponen 3 condiciones necesarias, pero no suficientes, para compartir percepciones de un clima determinado dentro de un grupo: (a) que sus miembros tengan que interactuar, (b) que sus miembros tengan un objetivo en común que los predisponga a tomar una acción colectiva y (c) que exista la suficiente interdependencia en la tarea para desarrollar un entendimiento compartido. ${ }^{46,78}$

Un factor determinante para el desempeño de un grupo de trabajo y su posición competitiva dentro de la organización y en su entorno, es su propensión a la innovación, que ha sido durante mucho tiempo un área de interés para los científicos sociales y los psicólogos que trabajan en contextos organizacionales. ${ }^{77}$ Esta se define como "la introducción intencional y aplicación dentro de un rol, grupo u organización, de ideas, procesos, productos y procedimientos nuevos a la unidad competente para su adopción", diseñados para beneficiar significativamente a la persona, el grupo o la sociedad en general, ${ }^{78,79} \sin$ embargo, se reconocen múltiples factores que pueden incidir en su aplicación, como son, las relaciones interpersonales en el trabajo, las características propias de la tarea y la oportunidad de ser mejorada a través de la innovación, la diversidad de conocimiento y competencias de sus miembros ${ }^{80,81}$ y factores externos como, la competencia, los cambios y exigencias del entorno. ${ }^{81}$ Miembros de equipos de trabajo, reconocidos como tales, revisan regularmente y sistemáticamente su desempeño y adaptan sus procesos y objetivos de cuidado en relación a ello. Grupos de trabajo, por otro lado, no se relacionan frecuentemente para intercambiar información y reflexionar sobre su desempeño, resultando en muy poca o nada de innovación en los procesos de cuidado. ${ }^{52}$

El clima de equipo para la innovación, en el modelo propuesto por West en $1990^{82}$ y medido a través de TCI (Team Climate Inventory), cuenta con cuatro dimensiones, la visión, seguridad participativa, orientación a la tarea y el apoyo a la innovación. Según el cual, los equipos con objetivos y visión claramente definidos y compartidos son más propensos a desarrollar métodos de trabajo mas eficaces, ya que sus esfuerzos tienen un enfoque y dirección clara. La participación en la toma de decisiones podría aumentar la probabilidad de que los miembros puedan influir, manifestándose dispuestos a ofrecer nuevas ideas, al sentir que las relaciones interpersonales dentro del equipo son seguras y no amenazantes. Por último, es necesario al 
momento de innovar el compromiso del equipo, para conseguir así, el más alto nivel de rendimiento, ofreciendo un apoyo articulado a las nuevas ideas. ${ }^{82,83}$

$\mathrm{Su}$ evaluación alrededor del mundo en diferentes equipos y contextos sanitarios, ha evidenciado mejores resultados de clima en equipos interdisciplinarios, asociándolo a una mayor calidad en los resultados de salud. ${ }^{83-87}$,lo que orienta en la necesidad de seguir profundizando en la comprensión de esta relación la cual podría impactar en el mejoramiento de la calidad de la atención. ${ }^{88-90}$ El clima de los equipos para la innovación, una dimensión del TCI ha sido asociado positivamente con la satisfacción del paciente y del equipo de salud. ${ }^{88,89} \mathrm{Al}$ evaluar el clima de los equipos, se observa una asociación positiva con el bienestar personal y negativa con el stress laboral..$^{90,91}$

\subsection{Liderazgo transformacional}

“El Liderazgo Transformacional motiva a otros a realizar más....más de lo que ellos creían posible. Autoimponiéndose expectativas más desafiantes y alcanzado en la mayoría de los casos mejores resultados. ${ }^{92}$

El Liderazgo transformacional intenta influir en las creencias y actitudes de sus seguidores y alinearlas con las propias, y así, dirigirlos a través de convicciones comunes hacia el logro del éxito organizacional. ${ }^{45,93,94}$ Dentro de este liderazgo transformacional se han identificado cuatro dimensiones: la Motivación Inspiradora, que aspira a influir en los seguidores a través de comunicación persuasiva y motivadora de un conjunto de metas que se consideran como universalmente valiosas de lograr; Consideración-Individualizada, que se produce cuando el líder ayuda al seguidor para alcanzar sus necesidades internas más deseadas; InfluenciaIdealizada, subdividida en: Influencia Idealizada Atribuida, en la cual el líder es respetado, admirado y tiene la confianza de sus subordinados, siendo modelo de identificación e imitación para ellos, lo que puede fomentar fuertes vínculos emocionales positivos con los seguidores. El Comportamiento Idealizado Influenciado, en el cual el líder muestra conductas que sirven como modelos de rol para los subordinados o colegas, demuestra consideración por las necesidades de los otros por sobre sus propias necesidades, comparte riesgos con los seguidores, y es consistente entre lo que dice y hace; por último, la Estimulación Intelectual, que incita a los seguidores a pensar de forma creativa en el desarrollo de nuevas ideas para desenvolver su labor. 93,94 
Este líder transformacional es caracterizado como alguien capaz de articular una visión de futuro, que puede ser compartida con otros, que estimula intelectualmente a su entorno, prestando atención a las diferencias individuales ${ }^{45}$ y orientándose a una mayor efectividad en el desempeño de los seguidores. ${ }^{94}$ En los servicios de salud ha recibido creciente atención en los últimos decenios y ha sido promovido como un estilo de liderazgo que facilita el cambio, incrementa el compromiso en el trabajo, la satisfacción laboral y el bienestar dentro de los equipos. ${ }^{95-99}$ Esto último muy relevante en contextos con una falta creciente de profesionales lo cual potenciaría su contratación y retención en las organizaciones. ${ }^{100-105}$ Además, este bienestar laboral se asocia generalmente a una disminución del desgaste físico y psicológico, ${ }^{106}$ promoviendo paralelamente prácticas de autoeficacia individual y colectiva, que actuarían como predictores motivacionales del bienestar en las organizaciones. ${ }^{107-110}$ considerando que el sector sanitario es especialmente estresante. ${ }^{111}$

Los líderes transformacionales potencian un ambiente de trabajo saludable para los equipos, a través de un mayor sentido de auto-eficacia, percepción de dominio de la situación, claridad en la orientación del rol y mayor confianza en la administración. ${ }^{112}$ Investigaciones realizada en países de América del Norte y Europa, asocian el liderazgo transformacional con un mejor desempeño laboral, ${ }^{113-115}$ en enfermería esto se traduciría en cuidados eficaces más allá de lo esperado, a través de entregar un sentido o motivación que aumentaría los niveles de compromiso con su desempeño. ${ }^{114-116}$ A diferencia de los resultados encontrados en Sudamérica, que apuntan a una falta de conocimientos en relación a liderazgo y sus beneficios en los profesionales. ${ }^{114-117}$

Al integrar elementos cognitivos y psicológicos al estudio de la forma en que líderes y seguidores interpretan su relación, aparecen las capacidades, motivaciones, valores, emociones y desafíos compartidos con sus seguidores ${ }^{94,112}$ jugando un rol relevante en la forma como los individuos responden a los diferentes estilos de liderazgo ${ }^{101,118}$ Bajo esta mirada, los seguidores aparecen como potenciales moderadores de la relación entre el estilo de liderazgo y los resultados de desempeño organizacional, especialmente en instituciones de salud. ${ }^{118-122}$ En los últimos años, se ha reconocido la importancia del trabajo en equipo para alcanzar los objetivos de calidad y seguridad en los pacientes ${ }^{16,123,124}$ asociado a satisfacción laboral en los profesionales. ${ }^{104} \mathrm{Se}$ hace necesario avanzar en el conocimiento de las características de esta asociación, si se pretende explicar en mayor profundidad los vínculos entre el líder, seguidores y resultados de desempeño. ${ }^{101,120}$ El empoderamiento psicológico, la 
distancia estructural con el líder y la percepción de eficacia individual y grupal de los seguidores, actuarían como mediadores de la relación para lograr compromiso, bienestar y satisfacción en los seguidores. $^{45,120,121,125}$

Una revisión sistemática realizada por Wong \& Cummings el $2007^{126}$ que buscaba determinar cuantitativamente el impacto del Liderazgo Transformacional en resultados de paciente, concluye que existe una asociación significativa entre el comportamiento del líder y mayor satisfacción de los pacientes, reducción de eventos adversos, ambientes clínicos orientados en agendas de calidad y compromiso con los equipos. Dierckx de Casterle et al el $2008^{127}$ reconoce que el equipo de enfermería se beneficia en una comunicación más eficaz, mayor responsabilidad, autonomía, claridad del rol, colaboración, comunicación con el paciente y continuidad de la atención.

Al relacionar el líder transformacional y un equipo de salud, se concluye que se reafirma el compromiso con el cuidado centrado en el paciente y la búsqueda de alcanzar las metas organizacionales. ${ }^{128}$ Es un estilo que se percibe como familiar, que enfatiza en la importancia de las relaciones interpersonales y el apoyo a los integrantes del equipo, por lo cual es reconocido, valorado y respetado. ${ }^{129} \mathrm{El}$ equipo percibe los beneficios del liderazgo transformacional en una comunicación efectiva, responsabilidad, empoderamiento y claridad del rol entre sus integrantes. ${ }^{129}$

Una segunda revisión realizada por Cummins et al el 2010 sobre estilos de liderazgo y satisfacción laboral en enfermería, reconocen que los estilos enfocados en las personas y sus relaciones se asocian a un mayor grado de satisfacción laboral que los estilos enfocados en la tarea. ${ }^{130}$ Concluyen que el liderazgo enfocado en la tarea por sí solo, no es suficiente para alcanzar óptimos resultados, por lo cual, es necesario realizar esfuerzos en las organizaciones y estimular el desarrollo de liderazgos transformacionales y de esta manera aumentar la satisfacción laboral de enfermería, su contratación y retención, además de ambientes de trabajo saludables, particularmente importante por la falta de este profesional en organizaciones sanitarias. ${ }^{130}$ 


\subsection{Análisis de redes sociales}

La perspectiva teórica para profundizar en la estructura social de los equipos es el Análisis de las Redes Sociales (ARS). Esta perspectiva establece que la vida social y las relaciones están condicionadas por la posición que se ocupa dentro de la estructura social y pueden ser explicadas analizando los patrones de distribución de estas diferentes posiciones y las redes que se forman a través de las relaciones que se establecen entre ellas, dentro de grupos y sociedades. ${ }^{131}$ Bajo esta premisa las personas se clasifican de acuerdo a su rol o posición dentro la red social y de su asociación con otras personas de manera equivalente. La suposición implícita del modelo es que las relaciones sociales están delineadas por el rol y la posición dentro del grupo. ${ }^{131}$

El ARS utiliza un método de orientación cuantitativo para describir y analizar la estructura inherente al mundo de las relaciones sociales, utilizando para este fin la construcción de representaciones visuales de las relaciones llamadas redes. ${ }^{132}$ Una red es un conjunto de relaciones sociales que vinculan a los actores dentro de una estructura social, la cual se entiende como las regularidades en los patrones de relaciones entre las diferentes entidades. ${ }^{133}$ El ARS se diferencia de otros métodos de investigación estructuralista en que sus fundamentos epistemológicos no están impulsados por una estrategia deductiva, ya que considera que la estructura de las relaciones se entienden mejor cuando se investigan los patrones de relaciones entre los miembros de un grupo, más allá de los atributos y acciones de cada uno ${ }^{134}$. El ARS es además una herramienta metodológica que busca describir y analizar los patrones de relaciones sociales a través de su capacidad para describir sistemáticamente la composición, estructura y contenido general de los vínculos sociales en su ambiente natural, usando imágenes visuales de conjuntos de relaciones (redes) y las medidas asociadas a ellas. 133,134

En el ARS la estructura social se describe en términos de nodos (personas) y lazos (las relaciones entre ellos) formando eventualmente esta red de relaciones. ${ }^{133} \mathrm{El}$ análisis de las características de las redes se lleva a cabo mediante la aplicación de diferentes medidas de conexión, por ejemplo, la cohesión o densidad de la red representada por el número de lazos entre los nodos; el aislamiento o cómo se separan o segregan los nodos; la centralidad o que nodo tiene la mayoría de las conexiones, de entrada (el número de vínculos dirigidos a un

individuo) y de salida (el número de vínculos dirigidos desde un individuo). ${ }^{134}$ Una medida 
relevante es la centralidad de intermediación representada por el nodo por el cual pasan la mayoría de las relaciones, convirtiéndolo en alguien importante e influyente; se puede medir también el grado de separación o cuántos lazos se encuentran entre las personas y por último, la reciprocidad o que tan bidireccional son las interacciones entre los nodos. ${ }^{134,135}$ Los datos necesarios para la confección de la red son obtenidos de los mismos sujetos utilizando preguntas cerradas en un cuestionario diseñado en relación al objetivo del estudio.

En las redes que representan organizaciones más tradicionales, la presencia de una alta densidad, indicaría una actividad social altamente coordinada con normas y valores arraigados. Por el contrario, las medidas de densidad inferior representan muchas veces comunidades más fragmentadas. La centralidad por otro lado representa la distribución de los lazos en torno a ciertos nodos. ${ }^{136}$ Una red se considera centralizada cuando la mayoría de sus enlaces (lazos) están dispersos en torno a un solo elemento o nodo (individuo) y si estos nodos principales se eliminan esta se fragmentaría en subredes desconectadas, la centralidad de un nodo hablaría de su importancia o relevancia dentro de la red y es considerado clave dadas sus amplias relaciones con los demás. ${ }^{132,133}$ En las redes informales esta centralidad reflejaría la popularidad, mientras que en las redes formales representa el traspaso de información. Una red descentralizada, presenta poca variación entre los enlaces que cada nodo posee, sin embargo, son consideradas más resistentes, ya que sufren menos cambios estructurales cuando se quitan nodos. ${ }^{132}$

La literatura ha establecido una diferencia clara entre la estructura formal y la informal en una organización caracterizándose por las posiciones que las personas ocupan dentro de los grupos de la misma, sucediendo ambas de manera paralela y, aunque, no son completamente independientes es posible diferenciarlas claramente, por la posición que cada persona ocupa en el grupo y por los canales de interacción que se establecen ${ }^{132,134}$. La estructura informal y sus relaciones podrían incidir en el patrón de trabajo de los grupos, creando normas propias para la división del trabajo, además de la aparición de jerarquías no reconocidas por la organización. ${ }^{137}$ Según el modelo de redes sociales ambas estructuras se desarrollan en base a la proximidad que experimentan con los otros, la cual puede estar dada por cercanía física, profesional, de tarea o actividad, social y la creada por la estructura formal de la organización. ${ }^{138}$ Esas diferencias podrían explicar los patrones de relaciones que subyacen a la estructura social de los equipos. 
En el contexto específico de las instituciones de salud, el trabajo se caracteriza por su variabilidad y complejidad en relación al ambiente y a los usuarios, en esa perspectiva, la racionalidad implícita en la formación de los equipos interdisciplinarios es la necesidad de contar con personal con las habilidades y el conocimiento necesario para responder a estas demandas, y las estructuras que emergen en esta situación necesitan compartir información relevante para la tarea desarrollando así una red de influencias sociales. ${ }^{139,140}$

El referencial teórico del ARS aplicado a la presente investigación, busca describir los patrones de relación entre los miembros del equipo interdisciplinario, definiendo de esta manera la estructura social del equipo, basado en las redes de relaciones que se establecen entre sus miembros, más allá de las categorías o roles predeterminados por la organización. Es importante recalcar que el ARS muestra las estructuras sociales, profesionales y sus características, pero no revela el tenor de la comunicación o interacción. ${ }^{141}$

Toda la información expuesta justifica la necesidad de investigar en organizaciones de salud, especialmente en sus equipos de trabajo, satisfacción de sus miembros, especialmente si se considera su relación con resultados de salud en los usuarios. Los constructos subyacentes a la satisfacción con el equipo de trabajo, liderazgo transformacional, clima de equipo y análisis de redes sociales constituyen el referencial teórico del estudio. Complementado con la utilización de diferentes abordajes metodológicos que permitan una aproximación más integrada del fenómeno. 


\section{PREGUNTA DE INVESTIGACIÓN DE MÉTODOS MIXTOS}

¿Cómo los intercambios sociales entre los miembros de equipos interdisciplinarios y con su líder, influencian la satisfacción en el equipo, en contextos hospitalarios?

\subsection{Preguntas de investigación cuantitativa}

¿Cuál es la influencia que tiene el liderazgo transformacional y el clima percibido en la satisfacción en equipos interdisciplinarios en contextos hospitalarios?

¿Cuáles son los patrones de interacción social entre los miembros de los equipos interdisciplinarios en contextos hospitalarios?

\subsection{Preguntas de investigación cualitativa}

¿Cómo las relaciones interpersonales y patrones de comunicación entre los miembros y con el líder de equipos interdisciplinarios explican la satisfacción de sus miembros en contextos hospitalarios? 
4. OBJETIVOS

-




\section{OBJETIVOS}

\subsection{Objetivos generales de la investigación}

Analizar los intercambios sociales y sus relaciones con liderazgo, clima y satisfacción de los profesionales en equipos interprofesionales en contextos hospitalarios.

\subsection{Objetivos etapa cuantitativa}

4.2.1 Analizar la influencia del liderazgo transformacional y clima de equipos en la satisfacción de los miembros de equipos interprofesionales

4.2.2 Analizar las redes sociales de los miembros de equipos interprofesionales en un hospital de Santiago.

\subsubsection{Objetivos específicos:}

1. Describir la estructura y composición de los equipos interprofesionales de diferentes servicios en un hospital de Santiago.

2. Identificar la influencia del clima de equipo en la satisfacción con el equipo percibida por sus miembros en equipos interprofesionales en un hospital de Santiago.

3. Identificar la influencia del liderazgo transformacional en la satisfacción con el equipo percibida por sus miembros en equipos interprofesionales en un hospital de Santiago.

4. Examinar las medidas de densidad y centralidad de las redes sociales de trabajo y personales de los miembros de los equipos interprofesionales en un hospital de Santiago.

\subsection{Objetivos etapa cualitativa}

Comprender las relaciones interpersonales, patrones y contenido de comunicación entre los miembros de equipos interprofesionales y con su líder, en contextos hospitalarios.

\subsubsection{Objetivos específicos:}

1. Analizar el contenido y la forma de las relaciones interpersonales y la satisfacción experimentada por los miembros de los equipos interprofesionales.

2. Analizar los comportamientos y relación entre los miembros de equipo interprofesionales.

3. Analizar las características de la relación entre el líder y los miembros de equipos interprofesionales.

4. Analizar el contenido, temporalidad y contexto del intercambio de información entre los miembros de equipos interprofesionales. 


\section{HIPÓTESIS /SUPUESTOS EN INVESTIGACIÓN}

\subsection{Hipótesis en investigación}

1. Una mayor Satisfacción con el equipo interprofesional percibida por sus miembros se ve influenciada por:

a. Una mayor percepción del estilo de Liderazgo Transformacional en el equipo.

b. Una percepción positiva del Clima del Equipo.

c. Una mayor Densidad y Centralidad en la red de relaciones sociales laborales y personales entre los miembros de equipos interprofesionales.

\subsection{Supuestos de la investigación}

Las relaciones interpersonales satisfactorias entre los miembros de equipos interprofesionales contribuyen a la producción de un mejor clima de equipo, percepción de liderazgo transformacional y satisfacción con el equipo. 
6. METODOLOGÍA 


\section{METODOLOGÍA}

El presente estudio utilizó un diseño de método mixto CUAN-CUAL, secuencial y exploratorio. Este consiste en dos fases distintivas; cuantitativa seguida por una cualitativa, ambas siendo igual de relevantes para los objetivos del estudio. ${ }^{142,143}$ En este diseño el investigador primero recolecta y analiza los datos numéricos, para proseguir con la recolección y análisis de los datos cualitativos, esta secuencia ayuda a explicar y/o elaborar los resultados de la primera etapa. Ambas fases están conectadas en el estado intermedio del estudio.

La racionalidad subyacente a esta aproximación es que el análisis de los datos cuantitativos entrega una comprensión general del fenómeno bajo investigación, el análisis de los datos cualitativos por su parte refina y explica los resultados estadísticos, explorando la visión de los participantes y su comportamiento en profundidad. ${ }^{142,144,145}$ La tabla 1 muestra como se desarrolló cada una de estas etapas, como se conectaron a través del estudio y como sus resultados se integraron al finalizar del mismo. 
Tabla 1. Modelo Visual de los procedimientos del diseño de estudio de métodos mixtos, secuencial explicativo

\begin{tabular}{|c|c|c|}
\hline Fases & Procedimientos & Productos \\
\hline $\begin{array}{l}\text { CUANTITATIVA } \\
\text { Recolección de datos }\end{array}$ & $\begin{array}{l}\text { Etapa 1: transversal, descriptivo y } \\
\text { correlacional. } \\
4 \text { cuestionarios auto aplicados ( } \mathrm{n}= \\
\text { 53) equipos interdisciplinarios de } \\
\text { servicios de alta y baja } \\
\text { complejidad. }\end{array}$ & $\begin{array}{l}\text { 1.-Datos numéricos } \\
\text { individuales agrupados a } \\
\text { nivel de equipos. }\end{array}$ \\
\hline $\begin{array}{l}\text { CUANTITATIVA } \\
\text { Análisis de los datos }\end{array}$ & $\begin{array}{l}\text { Estadística descriptiva } \\
\text { Frecuencias } \\
\text { Correlaciones } \\
\text { Regresión lineal } \\
\text { SPSS software }\end{array}$ & $\begin{array}{l}\text { Normalidad de la } \\
\text { distribución } \\
\text { Perdida de datos. } \\
\text { Pruebas de confiabilidad de } \\
\text { los instrumentos. } \\
\text { Perfil de los equipos y } \\
\text { Asociaciones } \\
\text { Influencia de variables } \\
\text { independientes sobre } \\
\text { dependientes. }\end{array}$ \\
\hline $\begin{array}{l}\text { CUANTITATIVA } \\
\text { Recolección de datos }\end{array}$ & $\begin{array}{l}\text { Etapa 2: Análisis de redes sociales } \\
2 \text { preguntas cuestionarios auto } \\
\text { aplicados }(n=53) \text { equipos } \\
\text { interdisciplinarios de servicios de } \\
\text { alta y baja complejidad }\end{array}$ & $\begin{array}{l}\text { 2.- Datos de las relaciones } \\
\text { interpersonales de la red de } \\
\text { afiliación profesional y social } \\
\text { de los miembros de equipos } \\
\text { interprofesionales en sus } \\
\text { servicios clínicos. }\end{array}$ \\
\hline $\begin{array}{l}\text { CUANTITATIVA } \\
\text { Análisis de los datos }\end{array}$ & software Ucinet & $\begin{array}{l}\text { Diagrama de densidad y } \\
\text { centralidad de la red } \\
\text { profesional y social de los } \\
\text { Equipos Interprofesionales. }\end{array}$ \\
\hline $\begin{array}{l}\text { Conectando las } \\
\text { fases cuantitativa } \\
\text { y cualitativa }\end{array}$ & $\begin{array}{l}\text { Selección intencional de los } \\
\text { equipos interprofesionales de } \\
\text { servicios de alta y baja } \\
\text { complejidad, basada en la } \\
\text { variación de la respuesta de } \\
\text { satisfacción con el equipo. } \\
\text { Desarrollo y ajuste de la guía de } \\
\text { entrevistas. }\end{array}$ & Equipos: $\mathrm{n}=5$ \\
\hline $\begin{array}{l}\text { CUALITATIVA } \\
\text { Recolección de datos }\end{array}$ & $\begin{array}{l}\text { Entrevista con miembros de } \\
\text { equipos profundizando en la } \\
\text { comprensión de los resultados de } \\
\text { la etapa cuantitativa y sus teorías } \\
\text { subyacentes. }\end{array}$ & $\begin{array}{l}\text { Entrevistas: grabación y } \\
\text { trascripción }\end{array}$ \\
\hline
\end{tabular}




\begin{tabular}{|c|l|l|}
\hline CUALITATIVA & $\begin{array}{l}\text { Análisis de contenido temático de } \\
\text { los relatos utilizando los } \\
\text { referenciales teóricos de los } \\
\text { fenómenos en estudio. } \\
\text { software Nvivo }\end{array}$ & $\begin{array}{l}\text { Modelo visual de los temas, } \\
\text { categorias y códigos, sus } \\
\text { similitudes y diferencias. }\end{array}$ \\
\hline $\begin{array}{c}\text { INTEGRACión de los } \\
\text { resultados Cuantitativos }\end{array}$ & $\begin{array}{l}\text { Integrar, interpretar y contrastar } \\
\text { los resultados de ambas fases. }\end{array}$ & $\begin{array}{l}\text { Modelo visual de los } \\
\text { resultados de ambas fases } \\
\text { Discusión y reflexión } \\
\text { Implicancias laborales } \\
\text { Investigaciones futuras }\end{array}$ \\
\hline
\end{tabular}




\section{- Escenario}

Hospital Clínico en Santiago de Chile, recinto privado dependiente en un porcentaje importante de una Universidad y el resto de fondos internacionales, siendo casi completamente autofinanciado. Ubicado en Santiago Centro y dotado de la más moderna tecnología. Centro de salud con más de 20 mil metros cuadrados que contempla plantas de mucha accesibilidad, posibilidad de circulación e interrelación de las distintas áreas críticas permitiendo una mejor coordinación entre ellas y sobre 700 camas de paciente. Con un modelo para el manejo de pacientes complejos, contando en un mismo lugar con procedimientos diagnósticos y terapéuticos. Con servicios de baja y alta complejidad, estos últimos reciben sólo pacientes con patología aguda con riesgo actual o potencial a su vida y que presenta condiciones de reversibilidad que hacen necesaria la aplicación de técnicas de monitorización, vigilancia, manejo y soporte vital avanzado, solamente disponible en este tipo de unidad. Durante el periodo de la investigación año 2015, el hospital se encontraba desde el 2014 en proceso de cambio asociado al ingreso de un socio estratégico internacional, sin embargo, en los servicios clínicos no se percibía diferencias en las rutinas de trabajo, de acuerdo a los profesionales.

\section{- Participantes}

Universo compuesto por médicos de las diferentes especialidades, enfermeras universitarias, nutricionistas, matronas, kinesiólogos y técnicos en enfermería. Entregando atención secundaria y terciaria de salud en todas las especialidades médicas y quirúrgicas, del adulto y pediatría, con diferentes grados de complejidad.

Antes de comenzar el estudio los participantes fueron agrupados en equipos interprofesionales para cada uno de los diferentes servicios clínicos, esto de acuerdo a la distribución organizacional, estructural y la percepción de pertenecía al equipo de sus miembros basado en la nomenclatura internacional para investigación del fenómeno. Finalmente, estos equipos representaron la unidad de análisis del estudio.

Criterios de inclusión: Profesionales con formación universitaria. Técnicos de nivel superior en enfermería de todos los servicios hospitalarios y que tuvieran como mínimo seis meses de antigüedad en sus equipos. 
Criterios de Exclusión: Estudiantes de pre y post grado en pasantías clínicas y profesionales cursando diplomas de especialidad. Todo el personal administrativo y de apoyo que no trabajaba en el cuidado directo del paciente.

\section{- Población y muestra}

Estuvo conformada por todos los equipos interdisciplinarios identificados en el hospital y que accedieron participar en el estudio. A través de un muestreo intencionado que representó a los diferentes servicios del hospital, se finalizó con una muestra de los equipos que aceptaron participar en el estudio (95\%) constituida por 53 equipos.

\subsection{Metodología cuantitativa: $1^{\text {ra }}$ Fase}

6.1.1. Diseño observacional transversal descriptico correlacional (etapa 1)

A través de un diseño Descriptivo Correlacional de las variables Satisfacción con el Equipo, Liderazgo Transformacional y Clima de Equipos, medidas a nivel individual y analizadas a nivel grupal. Los cuestionarios fueron aplicados al mismo tiempo, analizados independientemente y considerados simultáneamente al interpretar los resultados.

\subsubsection{Determinación de la muestra}

El cálculo de muestra para el proyecto arrojó la necesidad de contar con 54 Equipos Interdisciplinarios (Anexo 1) y posterior a la autorización del comité de Ética en Chile y Brasil, se solicitó reunión al hospital para informar en profundidad los objetivos del estudio y solicitar autorización para su ejecución. Se socializó el proyecto personalmente por el investigador y se notificó formalmente vía mail, haciendo extensiva la invitación a participar a todo el personal clinico. El equipo interdprofesional se definió como el grupo al cual las personas son asignadas, se identifican e interactúan con regularidad, con el fin de realizar tareas comunes y compartir el mismo objetivo (cuidado de los mismos pacientes). $\mathrm{Su}$ participación es estable en el tiempo e interaccionan con frecuencia (mínimo de tres días a la semana). Cuentan con una estructura administrativa que permite atestiguar de los resultados esperados y los comportamientos necesarios para lograrlo (cuidados y resultados de los paciente). Cuenta con una función de liderazgo que apoya el trabajo colaborativo entregando dirección en funciones (liderazgo o supervisión). Cuentan con habilidades diferentes y sus miembros tienen conocimientos especializados o capacidades funcionales que hace difícil 
sustituirlos (interactuando al menos dos disciplinas) y por ultimo cuentan con una historia de trabajo compartido (al menos seis meses).

Los miembros de los equipos fueron identificados en base a la definición anterior, primero indagando en la estructura administrativa y dotación de todos los grupos profesionales, de esta manera se desarrolló un mapa de la distribución de los profesionales en los diferentes servicios del hospital y su agrupación en los diferentes sistemas de turnos.

Su agrupamiento como equipos comenzó identificando los equipos de enfermería (unidisciplinarios) que compartían turnos de trabajo, solicitando su participación sólo cuando reconocían cumplir con los criterios para ser considerados miembros de equipos multidisciplinarios, en muchos casos no continuaron el proceso, pues reconocieron sólo trabajar como equipos uniprofesionales.

\subsubsection{Recolección de datos}

Con estos primeros miembros de equipos interprofesionales identificados se les invitó a participar del proyecto completando los instrumentos, posteriormente sus respuestas fueron agrupadas físicamente por equipo, a la espera de ser completados con los otros miembros (profesionales).

En segundo lugar se solicitó una reunión con la totalidad de profesionales kinesiólogos y nutricionistas separadamente, en esa ocasión se explicó el objetivo de la investigación y basado en la definición de equipo de trabajo se invitó a los que se consideraban miembros de equipos multidisciplinarios a permanecer y ser parte del proyecto completando los instrumentos, al entregar los instrumentos completos al investigador, se les preguntaba en privado que indicaran el servicio y equipo profesional (nombre de un integrante) en el cual debían ser agrupados sus datos. Vale la pena mencionar que los que no continuaron, reconocían trabajar en equipo solo con sus colegas (unidisciplinarios). El proceso anterior fue replicado con los profesionales nutricionistas.

Por último, se abordó a los médicos de todos los servicios en que enfermería, kinesiología y nutrición declararon trabajar en equipo, invitándolos a participar y elegir el equipo profesional donde deseaban ser incluidos, en el caso de trabajar con múltiples equipos se les solicitó 
imaginar que podían elegir con quien trabajar al otro día, si así fuera ¿a quién elegirían? Con esa información se pudo determinar en qué equipo incluirlos y se terminó de completar 53 equipos interdisciplinarios de servicios de alta y baja complejidad, de cuidado adulto y pediátrico.

Todos los profesionales invitados a participar, tuvieron instancias para declinar sin ninguna explicación. Los equipos con $20 \%$ de ausencias o rechazo a participar pasaron a una recolección posterior. Ausencias permanentes, hicieron que el equipo no fuera incluido, registrando las razones.

Los instrumentos fueron empaquetados y entregados a los miembros de cada estamento profesional de manera individual por el investigador, retirado en sobre cerrado y guardado en un compartimento con llave portado al momento de retirar, de manera de asegurar el anonimato de la información. Se contó siempre con un lugar privado para completar los instrumentos individualmente, esto tomaba alrededor de $15 \mathrm{~min}$. Este proceso se realizó siempre acompañado por el investigador del proyecto, como una forma de asegurar las mismas instrucciones y manejo. Los instrumentos no tenían nombres o números que permitieran identificar a los participantes. La recolección fue por estamentos profesionales, servicio y fecha. La información organizada fue siempre conocida sólo por el investigador del proyecto.

\subsubsection{Medición}

\subsubsection{Variables de control}

Aspectos socio-demográficos incluyeron edad, género, profesión u actividad, antigüedad en la organización (el hospital), en el equipo y número de integrantes de cada equipo.

\subsubsection{Variables de estudio}

Satisfacción de los miembros del equipo:

La satisfacción con el equipo de trabajo fue medida usando una escala de 5 ítems con respuesta de tipo Likert con siete opciones de respuesta. Adaptado por Gladstein (1984) y validada en español por Torre-Ruiz, $2014^{71}$ en un estudio con equipos de trabajo (sanitarios entre otros), con valores de consistencia interna de alfa crombach 0.9. y análisis factorial de 
una dimensión, con cargas entre 0,74-0,86. Sus preguntas evaluaron en los miembros del equipo aspectos como: satisfacción con los compañeros de trabajo, (Pregunta 1) Con los procesos al interior del equipo (Preguntas 3 y 5) y con los resultados obtenidos (preguntas 2 y 4). Valorada en una escala de acuerdo de 1 (completamente en desacuerdo) a 7 (completamente de acuerdo). Anexo 5

\subsubsection{Liderazgo transformacional}

El instrumento inquiere sobre la presencia y profesión de un líder (definición explicita) dentro del equipo (formal y/o informal). Se utilizó el Cuestionario Multifactorial de Liderazgo (MLQ), creado por Bass y Avolio (1994), basado en el Modelo de Liderazgo de Rango Total. $^{94}$ La versión corta de este instrumento tiene un total de 45 ítems y los ítems de Liderazgo Transformacional usados en esta investigación suman 20, incluyendo cuatro factores: influencia idealizada (8 ítems); motivación inspiradora (4 ítems); estimulación intelectual (4 ítems); y consideración individual (4 ítems) medidos con una escala Likert del 0 (nunca) al 4 (siempre). ${ }^{113}$ Los puntajes altos y bajos en cada sub-escala representan niveles de comportamiento de estilo de liderazgo Transformacional. Su validación local alcanzo un alfa de cronbach de $0,97 .{ }^{146}$

\subsubsection{Clima de equipos}

Evaluado usando el Inventario de Clima en Equipos, TCI en español (Team Climate Inventory de Anderson y West). ${ }^{82}$ Este instrumento es una medida sólida de las dimensiones del clima de los equipos de trabajo. ${ }^{85-86} \mathrm{El}$ TCI en su formulación original consiste en 38 ítems y cuatro sub-escalas: objetivos o visión, seguridad participativa, orientación a la tarea y apoyo en la innovación, reportando un alpha de Cronbach de $0,91{ }^{81}$

Para esta investigación, se utilizó la versión reducida desarrollada por Kivimaki y Eloviano (1999) en español de 14 ítems, conservando las cuatro dimensiones de la versión original ${ }^{147}$. Claridad en los objetivos, incluye 4 afirmaciones (alpha Cronbach $=0,86$ ). Seguridad Participativa con 4 afirmaciones (alpha Cronbach $=0,86$ ). Orientación a la tarea tiene 3 afirmaciones (alpha Cronbach $=0,85$ ). Apoyo a la innovación tiene 3 afirmaciones (alpha Cronbach $=0,86$ ). Los miembros de los equipos respondieron a cada una de las afirmaciones o descripciones indicando si están de acuerdo o no en referencia a su propio equipo. 


\subsubsection{Análisis de datos}

Para el análisis de los datos cuantitativos se utilizó el programa estadístico SPSS versión 16.0. con estadística descriptiva (frecuencia, medidas de tendencia central y dispersión). Se realizó correlaciones y regresiones lineales entre Satisfacción con el Equipo, Liderazgo Transformacional y Clima de los Equipos, todas ellas agregadas a nivel de equipos (53). El modelo que consideraba la Satisfacción con el Equipo como variable dependiente y el Liderazgo y Clima como independientes, fue ajustado por número de integrantes del equipo, edad y tiempo de permanencia en el mismo. La distribución de los datos fue normal lo que permitió utilizar estadísticos paramétricos con un nivel de significancia del 95\%.

\subsection{Análisis de redes sociales (etapa 2)}

Este tipo de análisis ha obtenido cada vez mayor aceptación en contextos sanitarios. ${ }^{148,149} \mathrm{Su}$ aplicación ha sido principalmente para indagar en servicios de salud buscando entregar una mayor comprensión de la red y sus patrones de colaboración entre los distintos profesionales. ${ }^{148}$ En este proyecto se exploró la afiliación profesional, el intercambio de información y la proximidad entre los miembros de EI. Utilizando el marco de referencia de las redes sociales se examinaron las relaciones formales e informales entre los miembros de EI y su líder, buscando aportar a la comprensión de la satisfacción de sus miembros con sus equipos, en contextos hospitalarios.

\subsubsection{Determinación de la muestra}

Se utilizó la muestra explicitada en la etapa 1, de 53 equipos interprofesionales para describir las respuestas generales y posteriormente se continuó el análisis con los equipos con resultados extremos y promedios de la variable SE.

\subsubsection{Recolección de datos}

Las redes sociales se midieron con dos preguntas adaptadas al contexto del equipo de salud y fueron incluidas en el cuestionario en la etapa 1. Se solicitó a los miembros del equipo responder ¿Con que profesional del equipo de trabajo y con que frecuencia en una semana usted habla sobre temas y/o actividades relacionados con el trabajo? utilizando una escala de 1 a 5 veces. En segundo lugar, para la red de amistad se utilizó la pregunta ¿Con cuál de los 
miembros de su equipo consulta o recibe ayuda en asuntos personales? Debiendo marcar a un profesional elegido de una lista que aparecía bajo la pregunta, con una $X{ }^{149}$ Dado que los elementos de red representan los patrones e intensidad de las interacciones entre todos los miembros, es importante que la mayoría de las personas llenen el cuestionario. La tasa de respuesta fue cercana a $100 \%{ }^{150}$.

\subsubsection{Análisis de datos}

Para analizar la densidad de la red social fue necesario dicotómizar la red profesional en términos de frecuencia, entre 1 y 3 reciben valor 0 ; entre 4 y 5 reciben el valor 1 , la red de amistad no fue necesario dicotómizar pues se indicaba solo una persona por una vez. Luego se define la red de interés mediante la identificación de sus límites, utilizando dos estrategias: posicionales y relacionales ${ }^{148}$. La estrategia posicional determina límites de la red sobre la base de criterios específicos de afiliación por la responsabilidad del cuidado de los mismos pacientes en este caso equipos de servicios clínicos. Las redes sociales se midieron como redes completas con cada miembro y su afiliación en términos profesionales y esta relacionada con todos los demás miembros del equipo, lo mismo para la red profesional y de amistad o personal. Posteriormente los equipos fueron agrupados por servicio.

En la estrategia relacional, los participantes identifican a aquellos con quienes comparten información y responsabilidad en el cuidado del paciente, para el estudio, los participantes fueron todo el tiempo identificados por sus roles profesionales, en donde se les pidió identificar a otros profesionales con quienes se relaciona para realizar de manera conjunta actividades o compartir información relevante para el cuidado del paciente o personal.

La densidad, que determina la cohesión del equipo, se calculó mediante la suma de todos los lazos entre miembros de equipos y dividido por el número máximo posible de estos vínculos. ${ }^{160}$ Este coeficiente puede variar entre 0 y $1^{149}$. La centralidad para entender hasta que punto participan de manera igualitaria los miembros, ${ }^{150}$ para lo cual se calculó con el índice de Freeman (1979) ${ }^{149}$, que mide las redes de comunicación y de amistad relacionadas con miembros individuales en la red, es decir, cuántos han elegido a este miembro o grupo profesional en el caso de afiliación, como su amigo o colega para comunicarse. La centralización puede variar desde 0 , cuando todos los agentes tienen el mismo índice de centralidad (la misma cantidad de lazos), a un máximo de 1 si un miembro domina 
completamente los otros. ${ }^{150}$ La centralidad de intermediación representando el profesional o grupo profesional (afiliación) por el cual pasan la mayoría de las relaciones. Antes de realizar los análisis fue necesario agrupar todas las respuestas como matriz de adherencia de cada uno de los miembros a los diferentes grupos profesionales para posteriormente convertirlos en una matriz de adyacencia que permitiera diagramarlos y observar la interacción formal e informal de los miembros en los equipos y en sus servicios clínicos. Se utilizó el software Ucinet para Windows para calcular y diagramar los diferentes parámetros. ${ }^{148,151}$

\subsection{Metodología cualitativa: $2^{\text {da }}$ Fase}

Con los datos obtenidos de la primera fase se desarrolló una representación visual de las interacciones de los miembros y los resultados cuantitativos en las variables estudiadas en la fase 1, para los 53 equipos. Este fue el insumo para un estudio cualitativo, descriptivo, el cual permitió relatar, explorar y comprender el fenomeno de la satisfaccion con el equipo en su contexto real, entregando un abordaje comprensivo para las caracteristicas significativas de la percepcion de los participantes. ${ }^{152,153}$

\subsubsection{Determinación de la muestra}

Se incluyeron todos los miembros (enfermera, médico, técnico en enfermería, kinesiólogo y nutricionista) de los equipos interprofesionales con resultados extremos y promedio de la variable satisfacción con el equipo de trabajo, mismos equipos del ARS. El contar con mas de un equipo en los valores extremos y promedios de los resultados de la variable satisfacción en la primera fase, fue posible elegir entre un número amplio de miembros de equipos para invitar a participar y responder a la entrevista. Los miembros de los equipos elegidos fueron abordados personalmente por el investigador para invitarlos a participar en esta segunda fase, explicando el objetivo y las razones de haber sido elegidos. El número de participantes fue determinado usando el criterio de saturación de la muestra, incorporando participantes hasta que la inclusión de un nuevo caso no aportara con nueva información, ${ }^{153}$ quedando finalmente con 15 participantes.

\subsubsection{Recolección de datos}

En esta etapa se utilizaron entrevistas semiestructuradas, las cuales permitieron profundizar, comprender y complementar los resultados de la primera fase, buscando de esta manera obtener una visión o descripción profunda de cómo se organizan, relacionan, comunican, 
interactúan y coordinan los miembros de los equipos para el cuidado del paciente. Esta etapa permitió profundizar en las practicas e interacciones sociales, demostrando ser un camino consistente para comprender la distancia entre los datos y las practicas concretas de los involucrados en la cotidianidad de los servicios clínicos. ${ }^{152,154}$

La entrevista semiestructurada utilizó una guía basada en los referenciales teóricos subyacentes a las variables medidas anteriormente, se incluyó aspectos del Trabajo en Equipo, Clima de Equipo y Liderazgo Trasformacional. La variable satisfacción con el equipo estaba considerada desde los resultados cuantitativos al elegir la muestra, por lo tanto, el foco fue indagar en las variables de estructura y proceso para complementar la comprensión de la satisfacción con el equipo, y aspectos de los resultados cuantitativos que ameritaban clarificación. Se inquirió acerca de los patrones de relaciones interpersonales y comunicación, el propósito de los intercambios, su contenido y canal de comunicación, las personas involucradas y se estimuló al entrevistado para compartir lo que deseara en relación a la temática en estudio.

\subsubsection{Análisis de datos}

El análisis de contenido temático, es usado ampliamente para desarrollar inferencias objetivas acerca de un tema de interés en cualquier tipo de comunicación. ${ }^{153}$ Este análisis permitió realizar un estudio del contenido aparente y latente del discurso, ambos se relacionan con la interpretación, pero se diferencian en profundidad y nivel de abstracción ${ }^{155}$. Se decidió analizar el contenido de las entrevista, utilizando un enfoque inductivo en el cual el investigador comienza examinando las entrevistas en busca de palabras, conceptos y temas que ayuden a responder a los objetivos de la investigación, este proceso consiste en organizar los mensajes originales de acuerdo a un esquema de clasificación basado en el referencial teórico, esencialmente se organiza el texto de manera de permitir una fácil identificación, indexado y recuperación de contenido relevante. ${ }^{153,155}$

Utilizando el software Nvivo, cada entrevista fue ingresada, analizada y los temas principales extraídos. Se aseguró la confiabilidad del análisis utilizando más de un codificador, quienes revisaron independientemente el material llegando a consenso en los resultados. Se buscó con esto garantizar que las categorías estuvieran lo suficientemente definidas para que cualquier otro codificador pudiera alcanzar las mismas conclusiones. ${ }^{156}$ 


\subsubsection{Análisis de métodos mixtos: integración}

Los datos del componente cuantitativo que han sido recogidos y analizados previamente, son usados para ser complementados, interpretados y explicados a través de los resultados del componente cualitativo. El análisis de métodos mixtos es un proceso interactivo, los datos de ambas etapas son analizados dentro del marco ofrecido por los referenciales teóricos y por la consistencia e inconsistencia comparativa de sus resultados. Finalmente, el equipo de investigación revisa los resúmenes de los análisis realizados para cada una de las variables, temas, categorías y concluye en respuesta a la pregunta que guio la investigación. ${ }^{142,145}$

\subsection{Criterios de Rigor}

Se tomaron medidas para asegurar la calidad de los datos. En primer lugar, el uso de métodos múltiples aumento la validez interna, proporcionando múltiples perspectivas/ medidas sobre un mismo fenómeno. ${ }^{154}$ En segundo lugar, mientras que la investigación espera comprender la singularidad y no generalizar, la transferibilidad puede ser establecida cuando los resultados se generalizan a la luz de los referenciales teóricos, mediante la comparación de los hallazgos con las dimensiones de un marco teórico, en este estudio del modelo de satisfacción con el equipo, Clima de Equipo y Liderazgo transformacional. ${ }^{154} \mathrm{Si}$ los hallazgos se refieren a algunas de las dimensiones de los modelos, su transferibilidad a otros entornos se justifica debido a que son compatibles con el marco teórico. En tercer lugar, un cuaderno del investigador para acompañar el proceso y monitorear pensamientos, sentimientos, reacciones y expectativas y que puede ser utilizada para el análisis de los datos. ${ }^{154}$ La introspección en la investigación cualitativa es crucial para saber de qué manera las posiciones del investigador y su predisposición podrían haber influido en la comprensión del fenomeno. ${ }^{154}$

Por último, se estableció la fiabilidad mediante el uso de un protocolo de investigación y la documentación exacta de cada paso del proceso de manera de facilitar la trazabilidad para las personas externas. ${ }^{153}$ Una base de datos bien estructurada en el software NVivo se utilizó para la gestión de datos y como prueba de las conclusiones.

\subsection{Aspectos éticos}

Según Emmanuel, Wendler \& Grady (2000) ${ }^{157}$ existen requerimientos éticos que sintetizan los códigos y declaraciones tradicionales con las que se evalúan los planteamientos éticos de las investigaciones en sujetos humanos. A continuación, se analizan los ocho principios éticos 
planteados por Emmanuel et al. (2004) en relación a este estudio. De la misma manera, se respetan los principios éticos de investigación da Resolução 466 do ano de 2012, Conselho Nacional de Pesquisa, Conselho Nacional de Saúde, Ministério da Saúde Brasil. ${ }^{158}$

Relación de Sociedad Colaborativa: Considerando la importancia de gestionar un proyecto que considere las necesidades de la comunidad local, esta propuesta emana de la falta de investigación local en el tema considerando la importancia y relevancia para el bienestar de los trabajadores de la salud e indirectamente de la población en general.

Valor Social: Esta investigación busca Analizar la satisfacción laboral y su relación con liderazgo, transformacional, clima percibido y análisis de redes sociales en equipos multidisciplinarios en un hospital de Santiago. Como una manera de reconocer la percepción de los clientes internos de las fortalezas y debilidades de estas herramientas administrativas, en la búsqueda de mejorar a futuro aspectos claves de la gestión de calidad, como disminuir los efectos adversos derivados de la atención y satisfacer las necesidades biopsicosociales del cliente interno e indirectamente del externo.

Validez científica: El estudio sigue un proceso de investigación rigurosa, orientándose por una pregunta de investigación en base a la que se desarrolla las hipótesis, los objetivos y la revisión literaria de forma concordante, así como también el método de análisis a utilizar, El diseño propuesto parece el más apropiado para cumplir el objetivo planteado, ya que, explorará desde las percepciones de las personas que participan de los procesos organizacionales y al finalizar el estudio serán participes de la evaluación de los resultados.

Selección justa de los sujetos: En este estudio, el principio de justicia se refleja en la selección justa de los sujetos para esta investigación. Cualquier equipo de salud tendrá la posibilidad de participar en este estudio. Esta investigación no será ofrecida solamente a equipos que estén a favor de la investigación.

Riesgo/beneficio favorable: El proyecto no contempla riesgos conocidos por participar. En cambio, el generar estrategias basadas en herramientas organizacionales de probada efectividad podría mejorar las relaciones interpersonales dentro de equipo de salud. Y el cuidado de los pacientes. 
Revisión independiente: para poder ser desarrollado el estudio debe ser aprobado por el comité de ética de la Escuela de Enfermería de la universidad de Sao Paulo y de la Pontificia Universidad Católica de Chile.

Consentimiento Informado: Asegura que los participantes a través de su firma acepten participar de la investigación, informa del objetivo, los riesgos, las ventajas y alternativas de la investigación, se aclaren sus dudas y pueda tomar una decisión libre y consciente. Se asegura la confidencialidad de la información y la posibilidad de retirarse del estudio o negarse a responder una pregunta en cualquier momento. (Se adjuntan formulario de aprobación y consentimientos informados en anexo 2 y 3 ).

Respeto por los sujetos de investigación potencialmente incluidos en el estudio: toda la información proporcionada debe ser tratada respetando la confidencialidad; además de la voluntariedad en el retiro de la investigación sin consecuencias. 
7. RESULTADOS 


\section{RESULTADOS}

Los resultados serán descritos en el orden en el cual los análisis fueron realizados. Primero se reporta las pruebas de normalidad de distribución de los datos en las escalas, para continuar con las características de los participantes, todos ellos miembros de equipos interprofesionales de diferentes servicios del hospital universitario, seguido por una descripción de los análisis agregados por equipos. Por último, se testean las hipótesis y se responde a los objetivos planteados para el proyecto.

\section{Tabla 2. Prueba de normalidad de escalas}

\begin{tabular}{l|c|c}
\hline & \multicolumn{2}{|c}{ Kolmorogov-Smirnov } \\
\hline & Estadístico & Sig. \\
\hline Liderazgo Transformacional & $\mathbf{0 . 1 2 0}$ & $\mathbf{0 . 0 5 4}$ \\
\hline & & \\
\hline Clima de Equipos & $\mathbf{0 . 0 7 8}$ & $\mathbf{0 . 2 0 0}$ \\
\hline & & \\
\hline Satisfacción con el Equipo & $\mathbf{0 . 7 7 0}$ & $\mathbf{0 . 5 9 4}$ \\
\hline
\end{tabular}

Los resultados de significancia estadística que estiman la normalidad de la distribución de los datos para las tres escalas $(>0,05)$ permiten determinar el uso de pruebas paramétricas para todos los análisis y pruebas de hipótesis.

Tabla 3. Características sociodemográficas miembros de 53 Equipos

\begin{tabular}{l|c|c}
\hline & $\mathbf{N}$ & $\mathbf{\%}$ \\
\hline Sexo & $\mathbf{4 0 9}$ & $\mathbf{1 0 0 , 0}$ \\
\hline Femenino & & \\
\hline Masculino & 343 & 83.9 \\
\hline Rol profesional & 66 & 16.1 \\
\hline Técnico en Enfermería & 190 & \\
\hline Enfermero/a & 132 & 46.5 \\
\hline Médico & 45 & 32.3 \\
\hline Kinesiólogo/a & 18 & 11.0 \\
\hline Matrón/a & 12 & 2.4 \\
Nutricionista & 12 & 2.9 \\
\hline Edad & Media & SD \\
\hline Tiempo trabajando en el Hospital (en meses) & 34.30 & 10.348 \\
\hline
\end{tabular}

Los miembros de EI provienen de servicios de alta y baja complejidad del hospital. Enfermería como disciplina alcanza casi un $80 \%$ de los miembros entre profesionales y 
técnicos, realidad observada en todos los servicios de la organización, representando el grupo más numeroso, permanente en el servicio y responsable del cuidado del paciente, compuesto casi en su totalidad por población femenina (78\%). Los otros profesionales no médicos, como Kinesiología y Nutricionión reconocen responsabilidades en diferentes áreas del hospital, actuando como consultores, aun así, un $10 \%$ de ellos se consideran parte de un EI. Los médicos aparecen como participantes de múltiples equipos, relacionado con su experticia clínica, sin embargo, su pertenencia es mayor cuando sus horarios son similares al resto de los miembros, como en ciertas áreas de alta complejidad, coincidiendo con los turnos de los demás profesionales al momento de tratar al paciente. Al considerar su antigüedad en los servicios se incluyó especialistas y becados de especialidad (dos años en el servicio). Se observa una variabilidad importante en la edad y antigüedad en los equipos de los diferentes profesionales, sobre todo si se considera la oferta abundante de trabajo, para los profesionales de enfermería en los últimos años lo que facilitaba su migración en busca de mejores oportunidades. 


\begin{tabular}{|c|c|c|c|c|c|c|c|c|c|}
\hline & & \multicolumn{8}{|c|}{ Según su opinión ¿Quiénes de los siguientes profesionales son miembros de su equipo de trabajo? } \\
\hline & & $\begin{array}{l}\text { Técnico en } \\
\text { Enfermería }\end{array}$ & Enfermera & Médico & Kinesiólogo & Matrona & Nutricionista & $\begin{array}{l}\text { Fonoaudi } \\
\text { ólogo }\end{array}$ & $\begin{array}{c}\text { Químico } \\
\text { farmacéutic } \\
\text { o }\end{array}$ \\
\hline \multirow{6}{*}{ 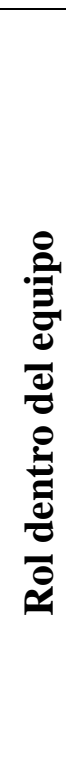 } & $\begin{array}{c}\text { Técnico en } \\
\text { Enfermería }\end{array}$ & $95.3 \%(181)$ & $92.1 \%(175)$ & $62.6 \%(119)$ & $46.3 \%(88)$ & $\begin{array}{c}12.1 \% \\
(23)\end{array}$ & $30 \%(57)$ & $3.2 \%(6)$ & $2.6 \%(5)$ \\
\hline & Enfermera & $96.2 \%(127)$ & $90.9 \%(120)$ & $88.6 \%$ (117) & $61.4 \%(81)$ & $9.8 \%(13)$ & $54.5 \%(72)$ & $\begin{array}{c}24.2 \% \\
(32)\end{array}$ & $22.7 \%(30)$ \\
\hline & Médico & $93.3 \%(42)$ & $97.8 \%(44)$ & $97.8 \%(44)$ & $62.2 \%(28)$ & $\begin{array}{c}22.2 \% \\
(10)\end{array}$ & $51.1 \%(23)$ & $\begin{array}{c}31.1 \% \\
(14)\end{array}$ & $24.4 \%(11)$ \\
\hline & Kinesiólogo & $77.8 \%(14)$ & $94.4 \%(17)$ & $94.4 \%(17)$ & $83.3 \%(15)$ & $0 \%(0)$ & $55.6 \%(10)$ & $38.9 \%(7)$ & $11.1 \%(2)$ \\
\hline & Matrona & $100 \%(12)$ & $91.7 \%(11)$ & $75 \%$ (9) & $16.7 \%(2)$ & $\begin{array}{c}91.7 \% \\
(11)\end{array}$ & $8.3 \%(1)$ & $0 \%(0)$ & $0 \%(0)$ \\
\hline & Nutricionista & $83.3 \%(10)$ & $91.7 \%(11)$ & $33.3 \%(4)$ & $33.3 \%(4)$ & $8.3 \%(1)$ & $33.3 \%(4)$ & $16.7 \%(2)$ & $0 \%(0)$ \\
\hline
\end{tabular}


Llama la atención observar lo resultados de la tabla 4 desde una concepción basada en el modelo biomédico, y considerar que algún profesional de salud no incluya al médico como participe permanente de sus equipos, sin embargo, el profesional de nutrición lo considera sólo un $33 \%$ y a enfermería casi el triple $92 \%$. Esto posiblemente porque se relacionan cerca de la cama del paciente para compartir información cada vez que nutrición acude a los servicios. Medicina se considera en casi un $100 \%$ como parte del equipo y lo central para ellos es contar con enfermería (98\%), así técnicos en enfermería (93\%). Para enfermería lo central es su disciplina (profesionales $91 \%$ y técnicos 96\%) núcleo central al momento de satisfacer las necesidades del paciente, especialmente los técnicos que se encuentran al lado de la cama del paciente, la mayoría del tiempo.

Tabla 5. Composición de los Equipos de Trabajo Interprofesionales

\begin{tabular}{l|c|c|c}
\hline \multirow{2}{*}{ Tiempo trabajando con su equipo actual (en meses) } & $\mathrm{N}$ & mínimo & máximo \\
\cline { 2 - 4 } Complejidad del Servicio al que pertenecen & 397 & 6 & 240 \\
\hline \multirow{2}{*}{ Número de integrantes por equipo } & & Alta & Baja \\
\cline { 2 - 4 } & & 35 & 18 \\
\cline { 2 - 4 } & 409 & 9 & $\mathrm{~min} / \mathrm{máx}$. \\
\hline
\end{tabular}

\begin{tabular}{l|c|c|c|c}
\hline Rol dentro del equipo & $\mathbf{N}$ & $\begin{array}{c}\text { Media } \\
\mathbf{\%}\end{array}$ & $\begin{array}{c}\text { Min/máx. } \\
\mathbf{\%}\end{array}$ & $\begin{array}{c}\text { SD } \\
\mathbf{\%}\end{array}$ \\
\hline Técnico en Enfermería & 53 & 43.40 & $0 / 75$ & 18.38 \\
\hline Enfermero/a & 53 & 32.87 & $0 / 83$ & 15.27 \\
\hline Médico & 53 & 14.23 & $0 / 67$ & 16.67 \\
\hline Kinesiólogo/a & 53 & 4.27 & $0 / 20$ & 6.81 \\
\hline Matrón/a & 53 & 2.39 & $0 / 33$ & 7.84 \\
Nutricionista & 53 & 2.84 & $0 / 20$ & 5.87 \\
\hline
\end{tabular}

Los EI se distribuyen en los diferentes servicios del hospital entregando atención a adultos y niños, con problemas de salud de alta complejidad como Unidad de Cuidados intensivos, Servicio Coronario, Pabellones Quirúrgicos, Neonatología, entre otros y baja complejidad como Médico-Quirúrgico, Oncología, pediatría, maternidad, por nombrar algunos. Se incluyó también EI de especialidades que entregan servicio de consultoría a los diferentes servicios. El número de integrantes estuvo determinado por la estructura y dotación de los turnos en el caso de enfermería y por afinidad del resto de los profesionales, quedando con números pequeños como el caso de pabellones quirúrgicos o especialidad (4) y numerosos como 
servicios de recuperación quirúrgica (20). En relación a la permanencia en los equipos esta presentó una variación importante, incluso profesionales con antigüedad de años en el hospital presentaban muy poca en su equipo, pudiendo mostrar que los profesionales rotan en diferentes equipos y no acumulan permanencia. Fue posible encontrar también en servicios de baja complejidad equipos conformados por dos disciplinas no médicas (5), por ejemplo, enfermería y kinesiología o enfermería y matrona, quienes reconocen el rol del médico, pero no lo consideran parte del equipo bajo la definición utilizada para el presente estudio.

Tabla 6. Prueba de confiabilidad de los instrumentos

\begin{tabular}{l|c}
\hline Instrumentos & $(\propto)$ \\
\hline Satisfacción con el Equipo & .808 \\
\hline Clima de Equipo (TCI) & .935 \\
\hline Liderazgo Transformacional (MLX) & .964 \\
\hline
\end{tabular}

En el análisis de confiabilidad, sólo el instrumento de la SE (5 items), mostró que el último item que preguntaba en negativo sobre la satisfacción con el equipo y por lo tanto se codificaba inverso de los otros 4, resultó en una corelacion inter-item de 0.151 , comparado con los demas (0.744-0.794), por lo cual se decidio retirarlo para análisis posteriores. De esta manera el alfa de Crombach del instrumento aumento de 0.725 a $0.940 .{ }^{159}$

Tabla 7. Satisfacción con el Equipo de Trabajo Interprofesionales

\begin{tabular}{l|c|c|c|c}
\hline & N & Media & Min/máx. & SD \\
\hline Satisfacción con el Equipo & 53 & 22.71 & $11.5 / 28$ & 3.05 \\
\hline
\end{tabular}

La satisfacción de los miembros con sus equipos de trabajo, fue evaluada en relación a su percepción de las relaciones interpersonales que se establecen para organizarse y decisiones consensuadas para el logro de los objetivos. Es posible observar variabilidad en los resultados, sin embargo, el promedio tiende a una percepción positiva. Vale la pena mencionar que en un análisis detallado por equipo mostro que estas diferencias se distribuyen entre los equipos sin relación con la complejidad del servicio o tipo de paciente a su cargo (adulto o pediátrico). Es importante mencionar que el equipo con mayor satisfacción trabaja 
en una especialidad, entregando cuidado como consultores a múltiples pacientes dentro del hospital, cuenta con 6 miembros que incluye solo medicina y enfermería. Han trabajado como equipo 60 meses en promedio. El equipo con menor percepción de satisfacción estaba compuesto por profesionales matronas, enfermeras, técnicos en enfermería y medicina, y su permanencia en el equipo va entre 8 a 18 meses en promedio.

Tabla 8. Clima de Equipos en Equipos Interprofesionales

\begin{tabular}{l|c|c|c|c}
\hline & $\mathbf{N}$ & Media & Min/máx. & SD \\
\hline Inventario Clima de Equipos & $\mathbf{5 3}$ & $\mathbf{5 4 . 1 3}$ & $\mathbf{4 0} / \mathbf{6 9}$ & $\mathbf{5 . 6 2}$ \\
\hline 1.-Claridad Objetivos & 53 & 16.71 & $13.6 / 20$ & 1.37 \\
\hline 2.-Seguridad Participativa & 53 & 15.36 & $10.2 / 19.8$ & 1.88 \\
\hline 3.-Orientación a la Tarea & 53 & 11.27 & $7.8 / 14.8$ & 1.40 \\
\hline 4.-Apoyo Innovación & 53 & 10.79 & $7.3 / 14.3$ & 1.42 \\
\hline
\end{tabular}

Al revisar los resultados de la percepción de los miembros de los 53 EI sobre el clima de sus equipos y profundizando en sus dimensiones, es posible observar que el puntaje promedio habla de una percepción que tiende mas bién positiva, lo que podría deberse a trabajar con un mismo grupo de profesionales frecuentemente y lograr un sentido de pertenencia. Fue posible identificar puntajes cercanos al máximo en un equipo compuesto por profesionales y técnicos en enfermería y un médico (4) trabajando en un servicio de baja complejidad para el cuidado de pacientes con patologías oncológicas y con una antigüedad en el equipo alrededor de 12 meses. El segundo equipo con el puntaje más alto es el mismo que alcanzó el puntaje más alto de satisfacción con el equipo. Los puntajes más bajos estaban también en los equipos con puntajes más bajos de satisfacción con el equipo. 


\section{Tabla 9. Liderazgo Transformacional en Equipos Interprofesionales}

\begin{tabular}{|c|c|c|c|c|c|c|c|c|c|c|}
\hline & & \multicolumn{9}{|c|}{ Según su opinión ¿A quién considera un líder transformacional en su equipo de trabajo interprofesional? } \\
\hline & & $\begin{array}{c}\text { Técnico en } \\
\text { Enfermería }\end{array}$ & Enfermera & Médico & Kinesiólogo & Matrona & Nutricionista & Fonoaudiólogo & $\begin{array}{c}\text { Químico } \\
\text { farmacéutico }\end{array}$ & Ninguno \\
\hline \multirow{6}{*}{ 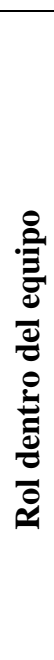 } & $\begin{array}{l}\text { Técnico en } \\
\text { Enfermería }\end{array}$ & $28.7 \%(54)$ & $77 \%(146)$ & $12.2 \%(23)$ & $4.3 \%(8)$ & $4.3 \%(8)$ & $0.5 \%(1)$ & $0.5 \%(1)$ & $0.5 \%(1)$ & $10.6 \%(20)$ \\
\hline & Enfermera & $10.6 \%(14)$ & $87.1 \%(115)$ & $32.6 \%(43)$ & $2.3 \%(3)$ & $3 \%(4)$ & $0.8 \%(1)$ & $0.8 \%(1)$ & $0.8 \%(1)$ & $8.3 \%(11)$ \\
\hline & Médico & $6.7 \%(3)$ & $66.7 \%(30)$ & $86.7 \%$ (39) & $2.2 \%(1)$ & $6.7 \%(3)$ & $0 \%(0)$ & $0 \%(0)$ & $2.2 \%(1)$ & $8.9 \%(4)$ \\
\hline & Kinesiólogo & $5.6 \%(1)$ & $38.9 \%(7)$ & $55.6 \%(10)$ & $27.8 \%(5)$ & $0 \%(0)$ & $0 \%(0)$ & $0 \%(0)$ & $0 \%(0)$ & $27.8 \%(5)$ \\
\hline & Matrona & $0 \%(0)$ & $41.7 \%(5)$ & $8.3 \%(1)$ & $0 \%(0)$ & $\begin{array}{c}58.3 \% \\
(7)\end{array}$ & $0 \%(0)$ & $0 \%(0)$ & $0 \%(0)$ & $25 \%(3)$ \\
\hline & Nutricionista & $8.3 \%(1)$ & $75 \%(9)$ & $8.3 \%(1)$ & $8.3 \%(1)$ & $8.3 \%(1)$ & $0 \%(0)$ & $0 \%(0)$ & $0 \%(0)$ & $8.3 \%(1)$ \\
\hline
\end{tabular}

Al observar los resultados aparece en primer lugar la figura del profesional de enfermería, elegido por la mayoría de los técnicos en enfermería y los profesionales no médicos como el líder transformacional del EI, situándose como líder informal. El médico, líder formal desde la organización es reconocido mayoritariamente por los propios médicos. Al analizar posteriormente las diferencias porcentuales con sus desviaciones estándar entre médico y enfermera fue posible encontrar una diferencia estadísticamente significativa entre ambos puntajes, situando a enfermería como el líder transformacional para el EI. 
Tabla 10. Liderazgo Transformacional en Equipos Interprofesionales

\begin{tabular}{l|c|c|c|c}
\hline & $\mathbf{N}$ & Media & Min/máx. & SD \\
\hline Liderazgo Transformacional total & 53 & $\mathbf{6 5 . 6 7}$ & $\mathbf{4 1 / 7 7 . 3}$ & $\mathbf{7 . 1 9}$ \\
\hline 1.-Influencia Idealizada & 53 & 26.99 & $17.3 / 31.7$ & 2.80 \\
\hline 2.-Motivación Inspiradora & 53 & 13.10 & $8.3 / 16.0$ & 1.51 \\
\hline 3.-Estimulación Intelectual & 53 & 12.67 & $6.8 / 15.6$ & 1.59 \\
\hline 4.-Consideración Individualizada & 53 & 12.93 & $8.8 / 16.0$ & 1.75 \\
\hline
\end{tabular}

Al revisar los resultados de la percepción de los miembros de los 53 EI sobre el Liderazgo Transformacional en sus equipos y profundizando en sus dimensiones, es posible observar que el puntaje promedio indicaría una percepción que tiende a reconocer la presencia de este estilo en sus equipos y al considerar los resultados de la tabla anterior podría deberse a la presencia permanente de enfermería en los equipos. En relación a los equipos que ostentan la manifestación más clara de estos comportamientos en sus líderes, uno es un servicio de baja complejidad de 7 miembros entre profesionales de enfermería y nutrición (no hay médico) todas de sexo femenino, con antigüedad promedio en el equipo de 36 meses. El segundo equipo es el mismo que aparece entre los puntajes más altos del clima de equipo de un servicio de cuidados oncológicos. Los equipos con líderes con escasos comportamientos transformacionales son los mismos que presentaron los menores puntajes en satisfacción y clima de equipo.

Tabla 11. Correlación de las dimensiones de LT y CE con Satisfacción con el Equipo

\begin{tabular}{l|c}
\hline Variables y sus dominios & Satisfacción Equipo \\
\hline Influencia Idealizada (II) &, $778<0.05$ \\
\hline Motivación Inspiradora (MI) &, $732<0.05$ \\
\hline Estimulación Intelectual (EI) &, $779<0.05$ \\
\hline Consideración Individualizada (CI) &, $708<0.05$ \\
\hline Liderazgo Transformacional (total) &, $806<0.05$ \\
\hline Claridad Objetivos (CO) &, $621<0.05$ \\
\hline Seguridad Participativa (SP) &, $795<0.05$ \\
\hline Orientación a la Tarea (OT) &, $772<0.05$ \\
\hline Apoyo a la Innovación (AI) &, $711<0.05$ \\
\hline Clima de Equipos (total) &, $789<0.05$ \\
\hline p=0,05 &
\end{tabular}


La asociación entre las dimensiones de LT y CE con la Satisfacción con el Equipo se observa como positiva en todos los casos y fuerte en la mayoría de ellos. Lo que podría deberse a que los constructos teóricos tienden a observar dimensiones similares de un fenómeno que se construye socialmente.

Tabla 12. Correlación de SE, LT y CE a nivel de Equipo

\begin{tabular}{l|c|c|c}
\hline & $\mathbf{N}$ & $\mathbf{R}$ & Sig. \\
\hline Clima de Equipo - Satisfacción con Equipo & 53 & 0.789 & $<0.05$ \\
\hline Liderazgo Transformacional - Satisfacción con Equipo & 53 & 0.806 & $<0.05$ \\
\hline Clima de Equipo- Liderazgo Transformacional & 53 & 0.737 & $<0.05$ \\
\hline
\end{tabular}

$\overline{\mathrm{p}=0,05}$

Al analizar los puntajes de las tres variables y su correlación en los 53 equipos es posible observar asociaciones positivas y estadísticamente significativas en cada uno de los casos, lo que se sustenta por los resultados de cada una de ellas separadamente.

Adicionalmente y buscando explicar más específicamente la relación entre la satisfacción con el equipo como una variable de resultado y el clima y liderazgo como procesos tendientes a potenciarla o limitarla, se decide continuar con una regresión lineal, para la cual la SE actuaría como variable dependiente del CE y LT ambas independientes. Explorando en primer lugar las asociación crudas de cada variable con SE separadamente, para continuar con ambas en un mismo análisis. Para terminar con el análisis de un modelo que consideró las tres variables y se ajustó por número de integrantes del equipo, edad y tiempo de permanencia en el mismo, estas últimas variables, reconocidas en la literatura de equipos de trabajo por su influencia en las variables del estudio.

Tabla 13. Regresión lineal con Liderazgo Transformacional (crudo)

\begin{tabular}{l|c|c}
\hline \multirow{2}{*}{ Parámetro } & \multirow{2}{*}{ B } & Contraste de hipótesis \\
\cline { 3 - 3 } $\begin{array}{l}\text { Liderazgo } \\
\text { Transformacional }\end{array}$ & \multirow{2}{*}{, 342} & Sig. \\
\hline $\begin{array}{l}\text { p }=0,05 \\
\text { Bondad de Ajuste: Akaike (AIC) } 217\end{array}$
\end{tabular}


El resultado muestra una asociación significativa en donde el aumento de un punto en la medición del LT aumenta 0.3 puntos en la SE.

Tabla 14. Regresión lineal con Clima de Equipos (crudo)

\begin{tabular}{l|c|c}
\hline \multirow{2}{*}{ Parámetro } & \multirow{2}{*}{ B } & Contraste de hipótesis \\
\cline { 3 - 3 } Clima de Equipo &, 428 & Sig. \\
\hline $\mathrm{p}=0,05$ \\
Bondad de Ajuste: Akaike (AIC) 221
\end{tabular}

El analisis muestra una asociación significativa en donde el aumento de un punto en la medición del CE aumenta 0.4 puntos en la SE.

Tabla 15. Regresión lineal con Liderazgo Transformacional y Clima de Equipo (crudo)

\begin{tabular}{l|c|c}
\hline \multirow{2}{*}{ Parámetro } & \multirow{2}{*}{ B } & Contraste de hipótesis \\
\cline { 3 - 3 } $\begin{array}{l}\text { Liderazgo } \\
\text { Transformacional }\end{array}$ &, 209 & Sig. \\
\hline $\begin{array}{l}\text { Clima de equipo } \\
\text { P=0,05 }\end{array}$ &, 230 &, 000 \\
Bondad de Ajuste: Akaike (AIC) 205
\end{tabular}

La tabla 15 muestra una asociación significativa en donde el aumento de un punto en la medición del LT aumenta 0.20 puntos en la SE y un punto del CE 0.23. En donde ambas son significativas y explican en cierta medida la percepción de la variable SE. Es interesante como este tipo de variables parecen compartir una interfaz en el fenómeno social en estudio ya que ambas parecen ajustar su influencia al estar juntas.

Tabla 16. Regresion lineal con LT y CE ajustado

\begin{tabular}{l|c|c}
\hline Parámetro & B & Contraste de hipótesis \\
\cline { 3 - 3 } $\begin{array}{l}\text { Liderazgo } \\
\text { Transformacional }\end{array}$ &, 168 & Sig. \\
\hline Clima de equipo &, 259 &, 000 \\
\hline Edad &,- 103 &, 073 \\
\hline Tiempo en equipo &, 016 &, 026 \\
\hline Numero de integrantes &,- 015 &, 812 \\
\hline
\end{tabular}


$\mathrm{P}=0,05$

Bondad de Ajuste: Akaike (AIC) 206

Se muestra una asociación significativa con el LT y CE, en donde el aumento de un punto en la medición del LT y CE aumenta 0.20 y 0.23 puntos respectivamente en la SE. En donde el clima explica en mayor medida la percepción de la variable dependiente. De las variables de ajuste sólo el tiempo en el equipo resulto significativo y estaría explicando también, aunque en menor medida la SE. Esto es especialmente interesante en la realidad local, pues se tiende a rotar a las personas en diferentes equipos como una manera de ampliar su espectro de habilidades.

\subsection{Resultados del Análisis de Redes Sociales}

La encuesta fue aplicada a todos los miembros (409) de los equipos identificados (53) para el estudio, cuyo objetivo era identificar las interacciones entre los miembros dentro de sus equipos. Estos equipos incluían Técnico en Enfermería (TE), Médico (M), Enfermera (E), Matrona (MT), Nutricionista (N) y Kinesiólogo (K). Los resultados serán expuestos en el orden en que fueron analizados, en primer lugar, se presentarán sus respuestas generales acerca de las interacciones sociales al momento de buscar asesoría o apoyo ante dificultades del trabajo y luego ante un problema de índole personal (tabla 11 y 12). Posteriormente y como una forma de complementar y dar seguimiento a los resultados cuantitativos se indagará en las características de las redes sociales de equipos interprofesionales con resultados extremos de la variable satisfacción con el equipo incluyendo su representación gráfica. Adicionalmente y como una forma de entregar una visión de los equipos en sus servicios, se exponen estos resultados también. El primero es un servicio de baja complejidad que contiene dos de los equipos con mejores resultados de la variable Liderazgo Transformacional y Clima de Equipo. El segundo servicio de alta complejidad incluye 8 equipos con resultados promedio de las tres variables en estudio.

Es relevante explicar que al responder las preguntas en torno a profesiones y no profesionales específicos, se buscaba facilitar la participación y mantener el anonimato. Por lo tanto las relaciones expresadas en este análisis son de afiliación a un grupo profesional, no de relación directa entre dos profesionales, sin embargo, la concepción teórica implícita del análisis de afiliación en redes sociales establece que cuando un individuo participa de un grupo, las posibilidades de interactuar con sus miembros es alta, sobre todo si los equipos no son numerosos. 
Por ejemplo, al responder a quien acudirías en caso de precisar ayuda profesional para resolver un problema de trabajo, todos los profesionales que respondieron enfermería aparecerán como relacionándose entre ellos dentro de red, porque existe una posibilidad alta que su afiliación al grupo lo permita, lo mismo para los que responden médico, matrona, etc.

Los profesionales están representados por nodos o figuras de diferentes formas y colores para diferenciar su profesión y facilitar su identificación dentro de la red. Cada uno de estos profesionales tienen una etiqueta adosada, con información de su profesión (letra inicial), edad, género y antigüedad en el equipo (meses) y el color de esa etiqueta indica específicamente a que grupo profesional eligieron en la red de trabajo y lo mismo en la red personal.

Se realizaron dos mediciones en la red, las primeras a la red completa, como es la cohesión o densidad de las interacciones, determinadas por el número de personas que aparecen relacionadas dentro de la red de todas las posibles interacciones, dependiendo del número de integrantes de la red (equipo) completa. Otra medida de la red es la centralidad o cercanía entre los miembros para determinar la posibilidad de interactuar entre ellos, entendiendo que esto aplica a las personas que comparten afiliación solamente.

Las mediciones asociados a los nodos (profesionales) de manera específica incluyeron; Centralidad del profesional en términos de la posibilidad de conexiones o interacciones, al ser red de afiliación, estaría determinado por el número de lazos (interacción) que llegan y salen desde el. La centralidad de intermediación por otro lado, se refiere a miembros situados en posición de conectar con otros miembros a través del flujo de información o interacciones dentro de la misma, por último se identificó la presencia de sub-grupos dentro de la red, determinado por su afiliación a diferentes grupos profesionales o a sus propios colegas. Los resultados de los análisis para la red de solución de problema laboral y personal para cada equipo serán presentados en tablas, una para cada equipo. Posteriormente los dos servicios tendrán tablas independientes para presentar la información.

En primer lugar las tablas 13 y 14 para el equipo con mayor y menor puntaje en satisfacción con el equipo respectivamente, la tabla 15 presenta los resultados del servicio con equipos con valores altos de LT y CE. Finalmente la tabla 16 presenta los análisis de los 8 equipos con resultados promedios de las tres variables del estudio en su servicio. 
Los análisis de cada red incluyen:

\begin{tabular}{|l|l|l|}
\hline Medición & Nivel & Descripción \\
\hline Cohesión /densidad & Red & $\begin{array}{l}\text { Número de relaciones entre los } \\
\text { profesionales con respecto al máximo } \\
\text { posible. }\end{array}$ \\
\hline Centralidad/Cercanía & Red & $\begin{array}{l}\text { Número de relaciones con el camino más } \\
\text { corto posible de un miembro a otro. }\end{array}$ \\
\hline Centralidad/ Grado total & Miembro & $\begin{array}{l}\text { grado de conexión, vínculos que salen y } \\
\text { llegan para cada profesional dentro del } \\
\text { equipo }\end{array}$ \\
\hline Intermediación & Miembro & $\begin{array}{l}\text { Miembros situados entre cada par de otros } \\
\text { miembros del equipo, actuando como } \\
\text { puente. }\end{array}$ \\
\hline Sub-grupos & Miembros & $\begin{array}{l}\text { Grupos que se forman dentro de los equipos } \\
\text { o servicios. }\end{array}$ \\
\hline
\end{tabular}

Las figuras, representan gráficamente la red de interacciones y afiliación de los profesionales utilizando la siguiente simbología.

\begin{tabular}{|l|l|}
\hline Símbolo & Cuadrado Morado - Un/a Profesional Nutricionista \\
\hline Tinesiólogo & Triangulo Verde - Un/a Profesional Kinesiólogo/a \\
\hline Mécnico en Enfermería & Circulo Azul - Un/a Profesional Enfermero/a \\
\hline Matrona & Rombo Calipso - Un/a Técnico/a en Enfermería \\
\hline Color ttıquetas & Cuadrado Rojo - Un/a Profesional Médico \\
\hline Consulta a Enfermera & Circulo Rosado y Fondo Negro - Un/a Profesional Matron/a \\
\hline Consulta a Kinesiólogo & Azul acude a Profesional Enfermera \\
\hline Consulta a Técnico & Verde acude a Profesional Kinesiólogo/a \\
\hline Consulta a Médico & Calipso acude a Técnico/a en Enfermería \\
\hline Consulta a Nutricionista \\
\hline Consulta a Matrona \\
\hline
\end{tabular}




\section{Finalmente el orden de presentación de los resultados incluye:}

- Resultados generales de las dos preguntas de la red.

- Resultados numéricos y gráficos de la red del equipo con mayos satisfacción

- Resultados numéricos y gráficos de la red del equipo con menor satisfacción

- Resultados numéricos y gráficos de la red del servicio con equipos con mejores resultados de liderazgo transformacional y clima de equipos.

- Resultados numéricos y gráficos de la red del servicio con equipos con resultados promedios de satisfacción con el equipo, liderazgo transformacional y clima de equipo. 
Tabla 17. ¿A quién acude cuando tiene algún problema, necesidad o dificultad en el trabajo?

\begin{tabular}{|c|c|c|c|c|c|c|c|c|}
\hline & & \multicolumn{7}{|c|}{ Profesional } \\
\hline & & $\begin{array}{c}\text { Técnico en } \\
\text { Enfermería }\end{array}$ & Enferme & Médico & Kinesiólogo & Matrona & Nutricionista & A nadie \\
\hline \multirow{6}{*}{ 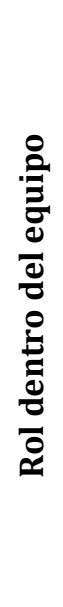 } & Enfermera & $6.6 \%(8)$ & & $21.3 \%(26)$ & $0.8 \%(1)$ & $0.8 \%(1)$ & $0.8 \%(1)$ & $3.3 \%(4)$ \\
\hline & Kinesiólogo & $0 \%(0)$ & $33.3 \%(6)$ & $16.7 \%(3)$ & $50 \%(9)$ & $0 \%(0)$ & $0 \%(0)$ & $0 \%(0)$ \\
\hline & Médico & $2.2 \%(1)$ & $20 \%(9)$ & $77.8 \%$ (35) & $0 \%(0)$ & $0 \%(0)$ & $0 \%(0)$ & $0 \%(0)$ \\
\hline & Matrona & $8.3 \%(1)$ & $41.7 \%(5)$ & $0 \%(0)$ & $0 \%(0)$ & $50 \%(6)$ & $0 \%(0)$ & $0 \%(0)$ \\
\hline & Nutricionista & $0 \%(0)$ & $83.3 \%(10)$ & $0 \%(0)$ & $0 \%(0)$ & $0 \%(0)$ & $8.3 \%(1)$ & $8.3 \%(1)$ \\
\hline & $\begin{array}{l}\text { Técnico en } \\
\text { Enfermería }\end{array}$ & $24.3 \%(42)$ & & $3.5 \%(6)$ & $0 \%(0)$ & $4 \%(7)$ & $0 \%(0)$ & $3.5 \%(6)$ \\
\hline
\end{tabular}

La tabla muestra que un mayor porcentaje de los miembros de los equipos considera al enfermero/a al momento de resolver una duda, cuestionamiento o dificultad en el cuidado de los pacientes, excepto el médico quien en la mayoría de los casos busca un colega para asesoría. 
Tabla 18. ¿A quién acude cuando tiene algún problema personal?

\begin{tabular}{|c|c|c|c|c|c|c|c|c|}
\hline & & \multicolumn{7}{|c|}{ Profesional } \\
\hline & & $\begin{array}{l}\text { Técnico en } \\
\text { Enfermería }\end{array}$ & Enfermera & Médico & Kinesiólogo & Matrona & Nutricionista & A nadie \\
\hline \multirow{6}{*}{ 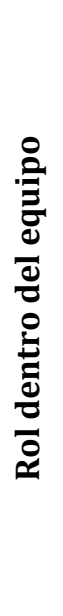 } & Enfermera & $4.9 \%(6)$ & 71.3\% (87) & $4.1 \%(5)$ & $1.6 \%(2)$ & $0.8 \%(1)$ & $0 \%(0)$ & $16.4 \%(20)$ \\
\hline & Kinesiólogo & $0 \%(0)$ & $11.1 \%(2)$ & $0 \%(0)$ & & $0 \%(0)$ & $0 \%(0)$ & $22.2 \%(4)$ \\
\hline & Médico & $0 \%(0)$ & 6. $7 \%(3)$ & $60 \%(2$ & $0 \%(0)$ & $0 \%(0)$ & $0 \%(0)$ & $33.3 \%(15)$ \\
\hline & Matrona & $8.3 \%(1)$ & $8.3 \%(1)$ & $0 \%(0)$ & $0 \%(0)$ & $\%$ & $0 \%(0)$ & $33.3 \%(4)$ \\
\hline & Nutricionista & $0 \%(0)$ & $25 \%(3)$ & $0 \%(0)$ & $8.3 \%(1)$ & $0 \%(0)$ & $58.3 \%(7)$ & \\
\hline & $\begin{array}{c}\text { Técnico en } \\
\text { Enfermería }\end{array}$ & $44.5 \%(77)$ & $30.6 \%$ & $1.2 \%(2)$ & $0 \%(0)$ & $1.7 \%(3)$ & $0 \%(0)$ & $21.4 \%$ (37) \\
\hline
\end{tabular}

La tabla muestra que un mayor porcentaje de los miembros de los equipos considera a sus colegas al momento de resolver un problema de índole personal, los Técnicos en Enfermería se apoyan en sus colegas pero también en la enfermera, posiblemente por cercanía física y de tarea. 


\begin{tabular}{|l|l|l|}
\hline \multirow{2}{*}{ Tabla 19. Características de la red de interacciones para solución de problemas laborales y personales } \\
\hline & \multicolumn{2}{|c|}{ Equipo Interprofesional con alta satisfacción } \\
\cline { 2 - 3 } & Red para Solución de Problema en el trabajo & Red para resolver problema personal \\
\hline Cohesión /densidad & $100 \%$ & $40 \%$ \\
\hline Centralidad/Cercanía & $\begin{array}{l}\text { Promedio } 1 \\
\text { Compacto: } 1 \\
\text { Amplitud: } 0\end{array}$ & $\begin{array}{l}\text { Promedio 1 } \\
\text { Compacto: } 0.40 \\
\text { Amplitud: } 0.60\end{array}$ \\
\hline Centralidad/ Grado total & $\begin{array}{l}\text { Todos (5-100\% ) in/out . } \\
\text { Media 5 (SD 0) Centralización Índex :0 }\end{array}$ & $\begin{array}{l}\text { Todos (2-40\%) in/ out. } \\
\text { Media 2 (SD 0) } \\
\text { Centralización Índex: } 0\end{array}$ \\
\hline Centralidad/ Intermediación & 0 & 0 \\
\hline Sub-grupos & Todos un grupo & 2 subgrupos \\
\hline
\end{tabular}




\section{Figura 1.-Equipo con mayor satisfacción: Red para solución de problemas laborales}
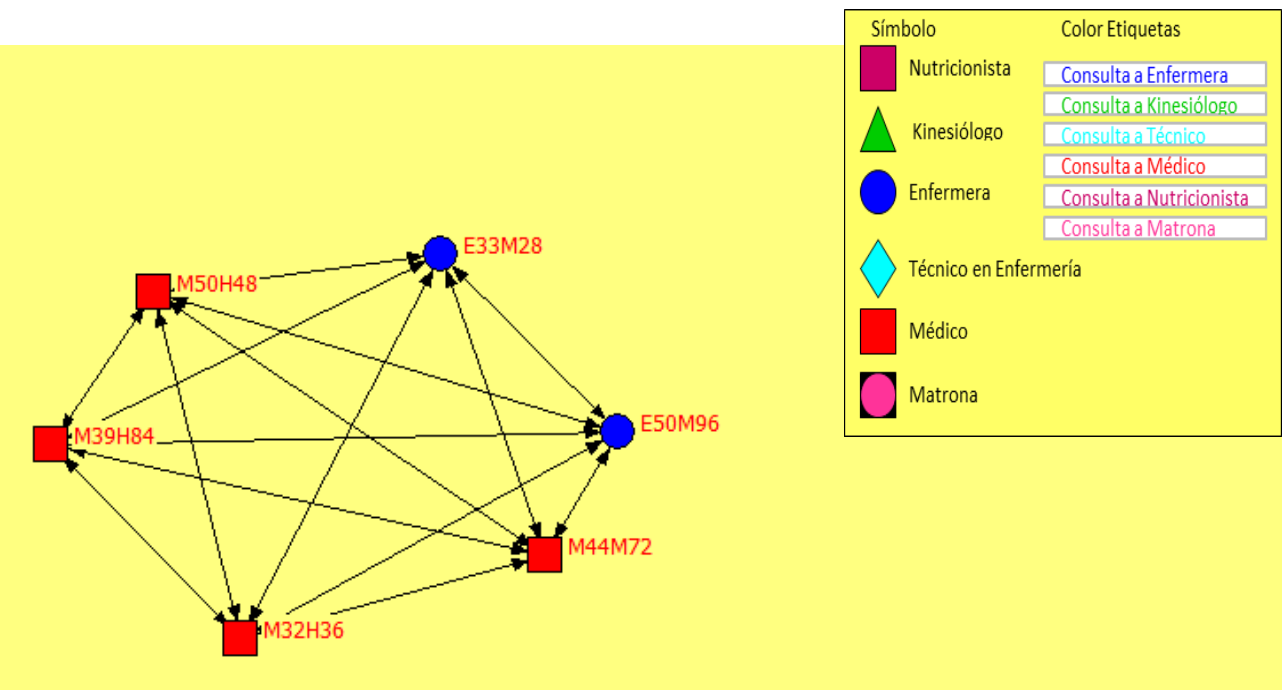

El equipo con mayor satisfacción de sus miembros son profesionales especialistas, enfermeras y médicos que se desempeña consultando pacientes con diagnostico especifico en los diferentes servicios del hospital. Sus miembros cuentan con vasta experiencia clínica, edad promedio de 41 años y pertenencia al equipo entre 24 y 96 meses. La red representa la búsqueda de solución de problema laborales entre los miembros del equipo basado en las redes de interacción que establecen, apareciendo como altamente cohesionada (densidad 100\%) todos sus miembros están directamente conectados (1 grado de separación) mostrando conexiones fuertes facilitando responder con rapidez y efectividad y presentando una estructura horizontal que permite abordar a cada miembro y ser abordado con la misma facilidad para intercambiar información que facilite el desempeño de sus labores. El flujo de información profesional hacia los miembros del equipo se genera mayoritariamente en el profesional médico (etiquetas rojas) y las interacciones pueden usar diferentes caminos y alcanzar la red completa rápidamente, sin ser controlada o intermediada por nadie en particular. Los equipos se presentan como una unidad altamente integrada. 
Figura 2: Propiedades de la red a través del tamaño de los nodos
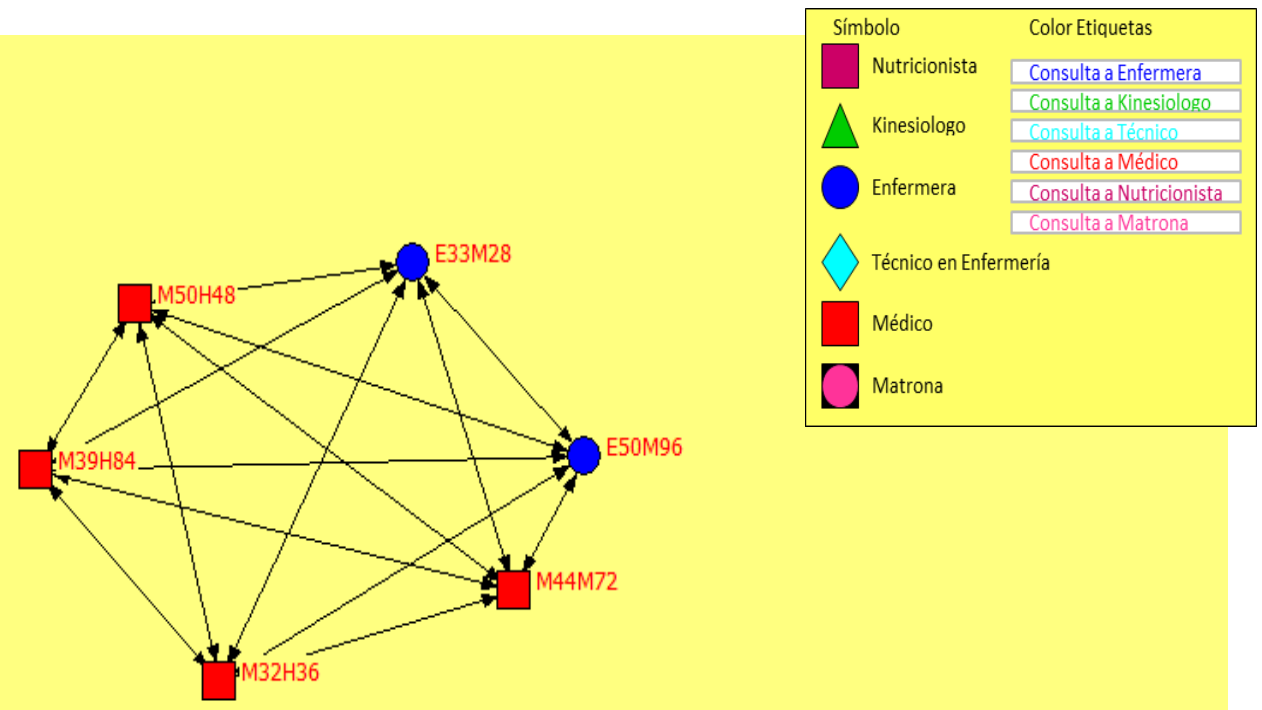

La representacion grafica que persigue mostrar en detalle la presencia de miembros Influyentes (mayor número de interacciones desde y hacia ellos) y de Intermediación de los flujos de información a través de diferencias en el tamaño de los nodos, no muestra cambios en esta red.

Figura 3: Equipo con mayor satisfacción: Red de relaciones sociales de sus miembros

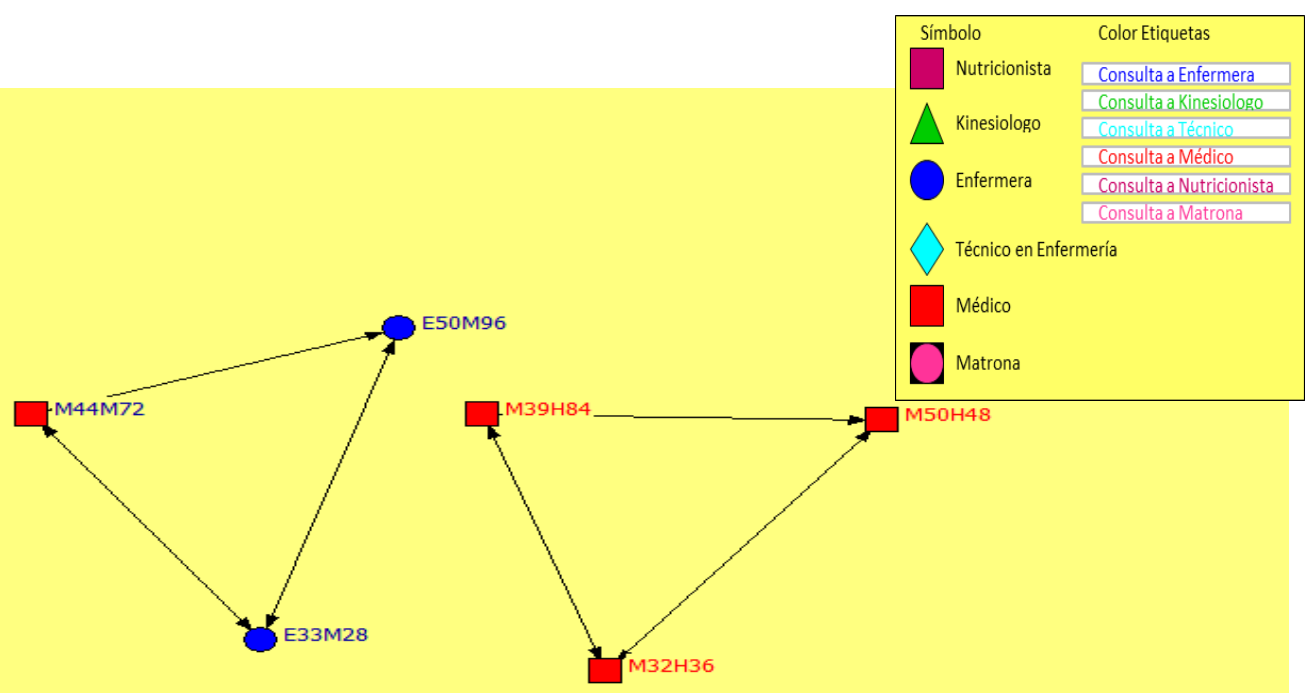


La red creada por afinidad personal que responde a una búsqueda de apoyo en aspectos personales de sus miembros presenta un grado menor de cohesión (densidad 40\%), ya que se separan en dos grupos de tres miembros cada uno, el primero representado por un médico experimentado y dos colegas más jóvenes (uniprofesional) y el segundo interdisciplinario incluyendo dos enfermeras y un médico (genero femenino). Esta estructura con dos triadas centralizadas en sí mismas divide la red de interacciones en 50\% para cada una, a pesar de eso, la distancia entre cada miembro se mantiene (1 grado), presentando conexiones fuertes y caminos pequeños lo que les permite ser solidarios y no depender de otros para alcanzar a quien necesitamos o que nos necesite. Las interacciones desde y hacia cada uno dentro de su grupo se reparte de manera igualitaria, 2 para cada uno (40\%), sin embargo, es interesante observar como esta separación obedece también a si decides establecer relaciones personales con enfermería o solo con profesionales pares (etiquetas rojas y azules).

\section{Figura 4: Propiedades de la red a través del tamaño de los nodos}

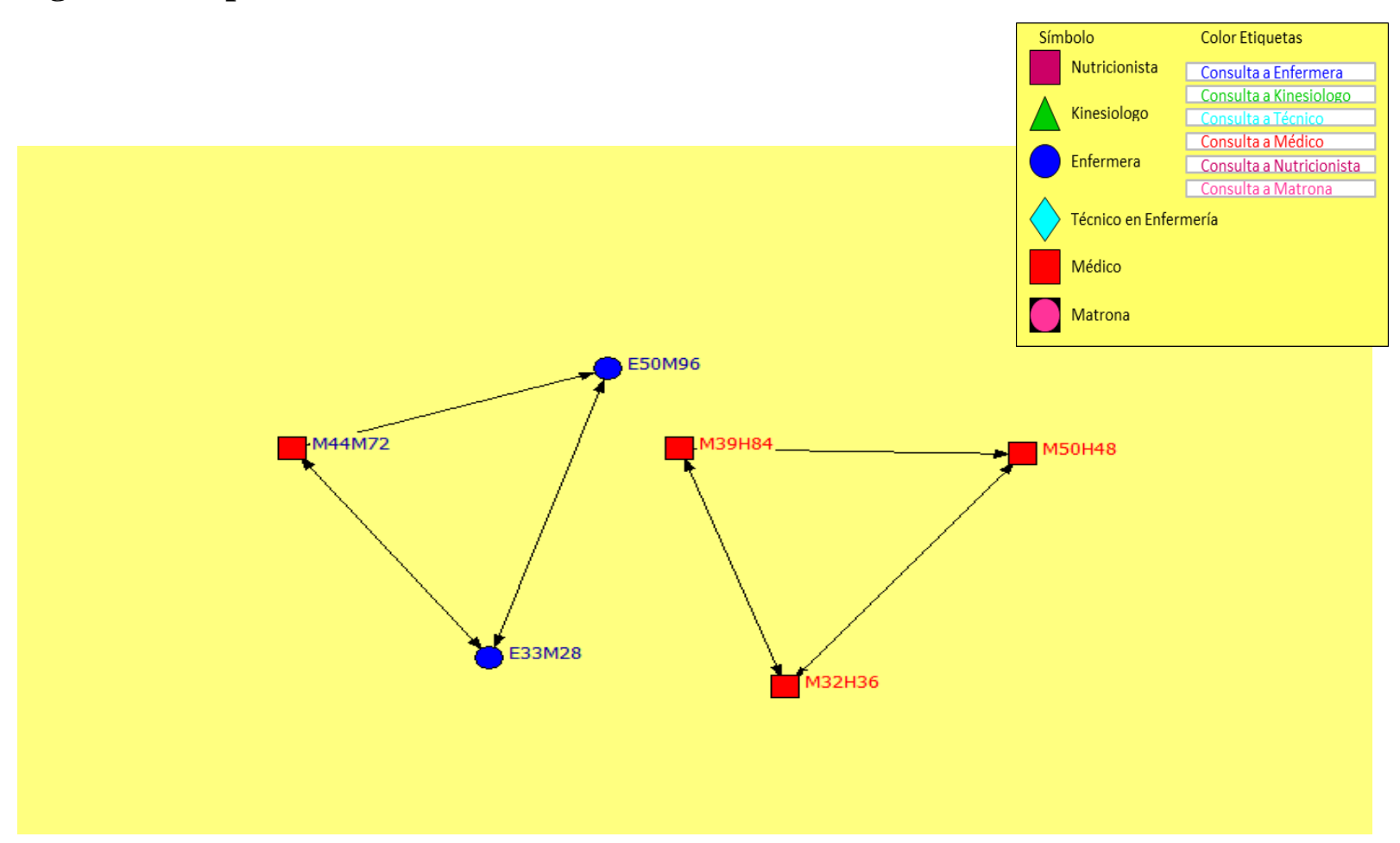

La representacion grafica que persigue mostrar en detalle la presencia de miembros Influyentes (mayor número de interacciones desde y hacia ellos) y de Intermediación de los flujos de información a través de diferencias en el tamaño de los nodos, no muestra cambios en esta red. 
Tabla 20. Características de la red de interacciones para solución de problemas laborales y personales

\begin{tabular}{|c|c|c|}
\hline & \multicolumn{2}{|l|}{ Equipo Interprofesional con baja satisfacción } \\
\hline & Red para Solución de Problema en el trabajo & Red para resolver problema personal \\
\hline Cohesión /densidad & $25 \%$ & $9 \%$ \\
\hline Centralidad/Cercanía & $\begin{array}{l}\text { Promedio } 1 \\
\text { Compacto: } 0.25 \\
\text { Amplitud: } 0.74\end{array}$ & $\begin{array}{l}\text { Promedio } 1 \\
\text { Compacto: } 0.61 \\
\text { Amplitud: } 0.93\end{array}$ \\
\hline Centralidad/ Grado total & $\begin{array}{l}\text { Los } 8 \text { juntos con } 57 \% \text { (out e in), las } 4(21 \%) \text { y } 2 \text { ( } \\
7 \%) \text {. } \\
\text { Network índex. } 17 \% \text { media: } 5.7 \text { (SD 2.8). }\end{array}$ & $\begin{array}{l}\text { Los } 3(18 \%) 2(9 \%) \text { resto }(0 \%) \text { Media: } \\
0.66 \text { (SD 0.85). Network centralización } \\
13 \%\end{array}$ \\
\hline Centralidad/ Intermediación & Los 6 (3.63). índex: $1.983 \%$. media 2 (SD 2) & $\begin{array}{l}\text { Los } 3 \text { de arriba (1- 0.909) media: } 0.250 \\
\text { (SD 0.433). }\end{array}$ \\
\hline Subgrupos & $1(6)$ & $1(3)$ \\
\hline
\end{tabular}




\section{Figura 5: Equipo con menor satisfacción: Red para solución de problemas laborales}

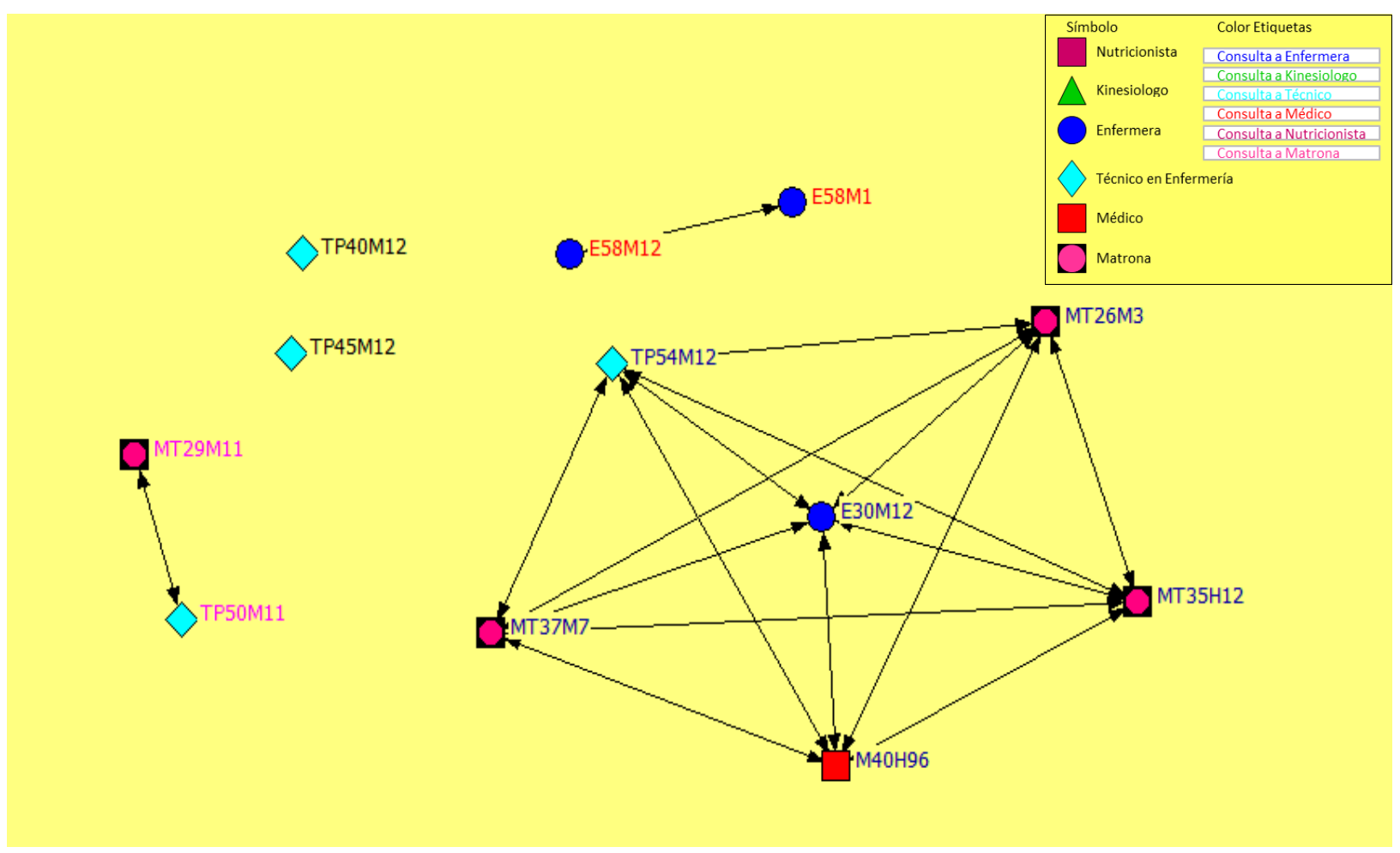

El equipo incluye profesionales matronas (4) enfermeras (3) Técnicos en Enfermería (4) y médico (1), se desempeñan en un servicio de alta complejidad, la antigüedad de sus miembros en el equipo no supera los 12 meses, excepto el médico con 96 meses. La red que representa la búsqueda de apoyo para solución de problemas laborales entre los miembros del equipo aparece con una cohesión de un $25 \%$ representando las interacciones realizadas entre sus miembros de todas las posibles de manifestarse. La distancia entre sus miembros en promedio es de un paso (1 grado), habiendo especial cercanía en parejas de miembros ya que su relación es más directa. Su estructura, representada por la organización de sus miembros dentro del equipo aparece como fragmentada y no sólo estructuralmente porque algunos de sus miembros se reúnen en grupo, diadas incluso un par de ellos completamente aislados, si no, por lo que dice relación con la búsqueda de apoyo profesional para compartir información que ayude en la entrega de un mejor cuidado a sus pacientes, aspecto que también los divide claramente. Hay 6 miembros de diferentes disciplinas que se presentan agrupados dentro de la red y que adscriben a enfermería (etiqueta azul) para la solución de problemas controlando el 57\% de todas las interacciones realizadas, hay dos parejas también, una de ellas de enfermeras, ambas con amplia experiencia que acuden al equipo médico para resolver dudas alcanzando un $16 \%$ del traspaso de información. Un 16\% también alcanza la diada del Técnico en Enfermería y Matrona, ambas adscriben al equipo de matronas para encontrar 
orientación profesional y en la cual basado en su experiencia profesional, el TP actuaría como mentora y la matrona como principiante. Se presentan aisladamente de los otros miembros de la red dos TP con amplia experiencia profesional, pero con una permanencia en este equipo que no supera los 12 meses (8,3\% de las interacciones) y que podría explicarse por la dificultad de incorporarse a un grupo nuevo o tal vez por aspectos generacionales.

Lo miembros de este grupo (6) que adscriben a enfermería como reciben y generan el $50 \%$ de las interacciones de la red, actuando además como mediadores de gran parte del flujo (36\%) de comunicación entre los otros miembros del equipo (incluso algunos podrían depender de ellos para informarse), están conectados entre sí muchas veces, utilizando diversos caminos y pudiendo por lo mismo desarrollar lazos más fuertes y una conexión menos sujeta a interrupciones, haciéndola más estable. Comparten además años de experiencia profesional y generación similares lo que podría facilitar su entendimiento y apoyo mutuo, parecen no sentir la necesidad de buscar profesionales más experimentados. Lo mismo sucede con las profesionales de enfermería que aparecen como una diada aislada compartiendo profesión, experiencia y su favoritismo por guía experta médica.

Figura 6: Propiedades de la red a través del tamaño de los nodos.

Miembros Centrales en la red

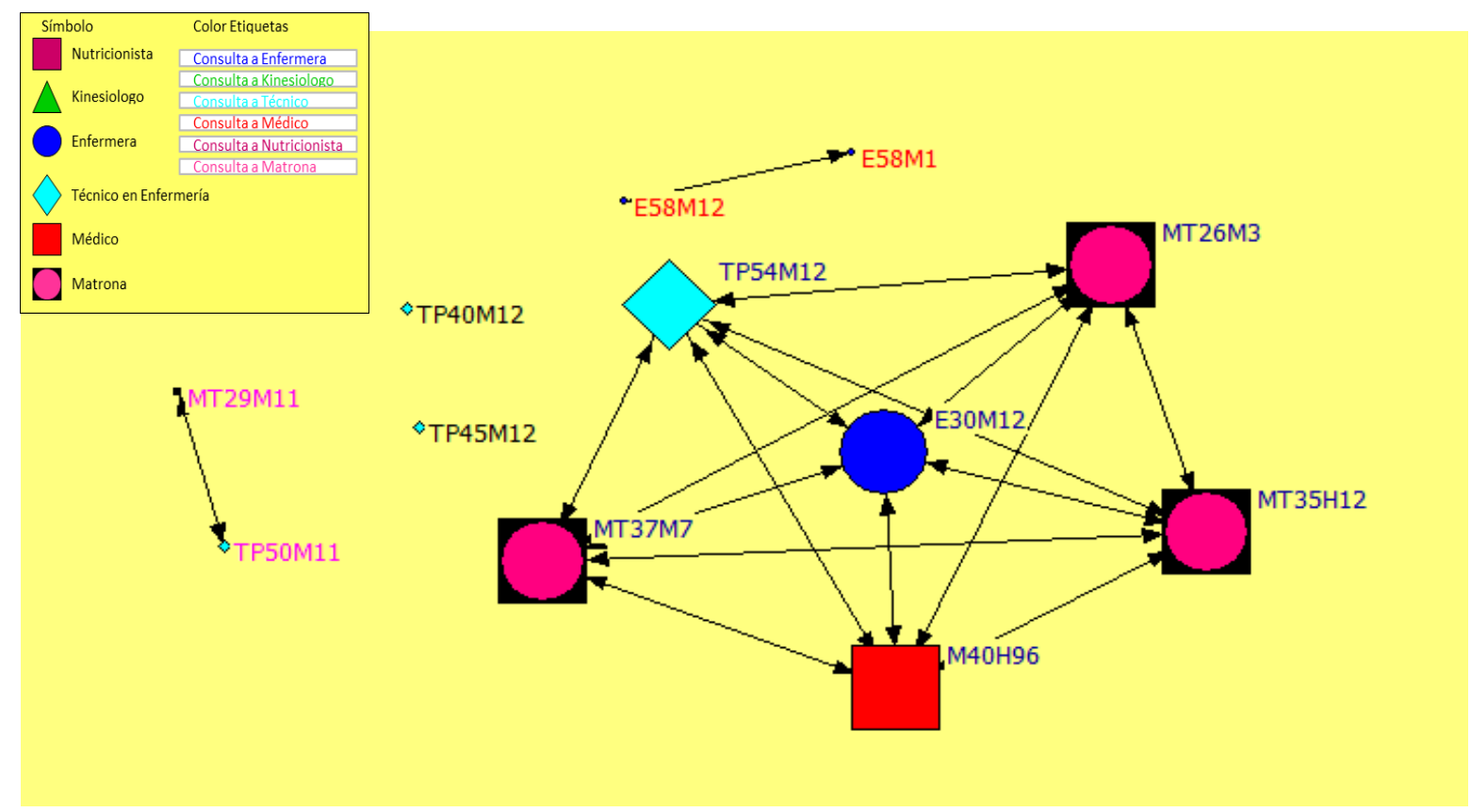


Figura 7: Miembros Influyentes a través del tamaño de los nodos. (mayor interacción desde y hacia ellos)
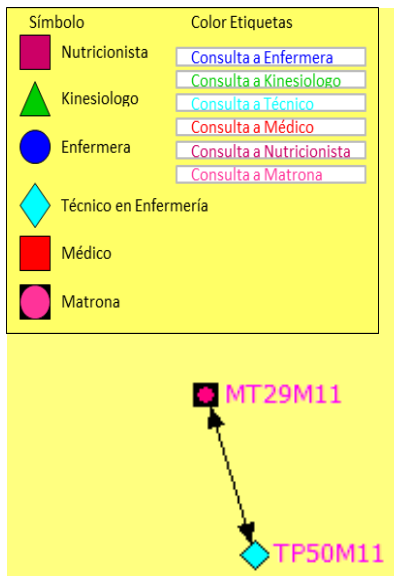
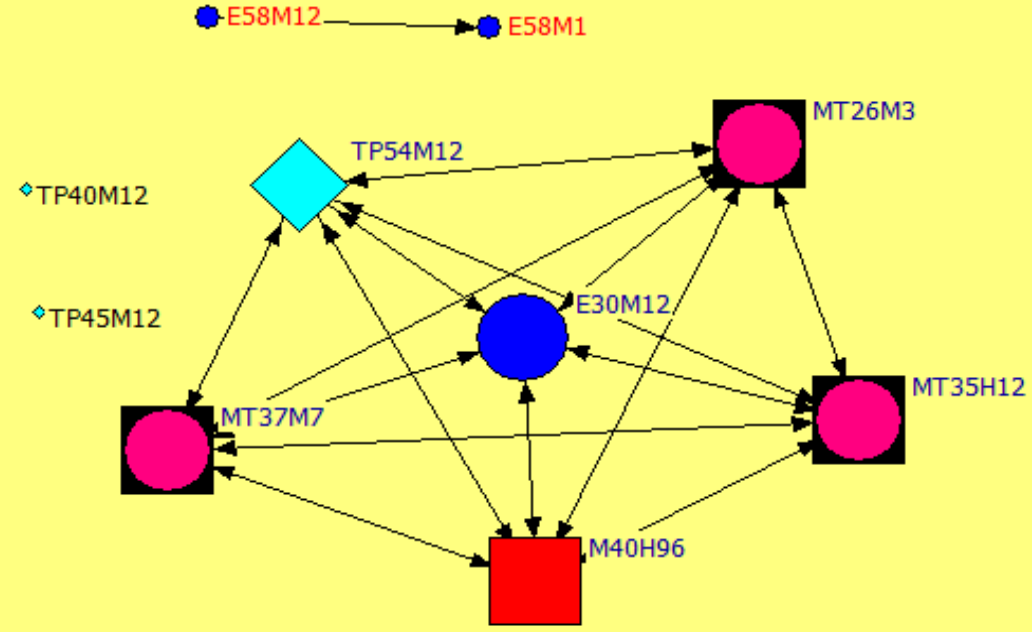

Figura 8: Miembros con Alto grado de Intermediación en la red
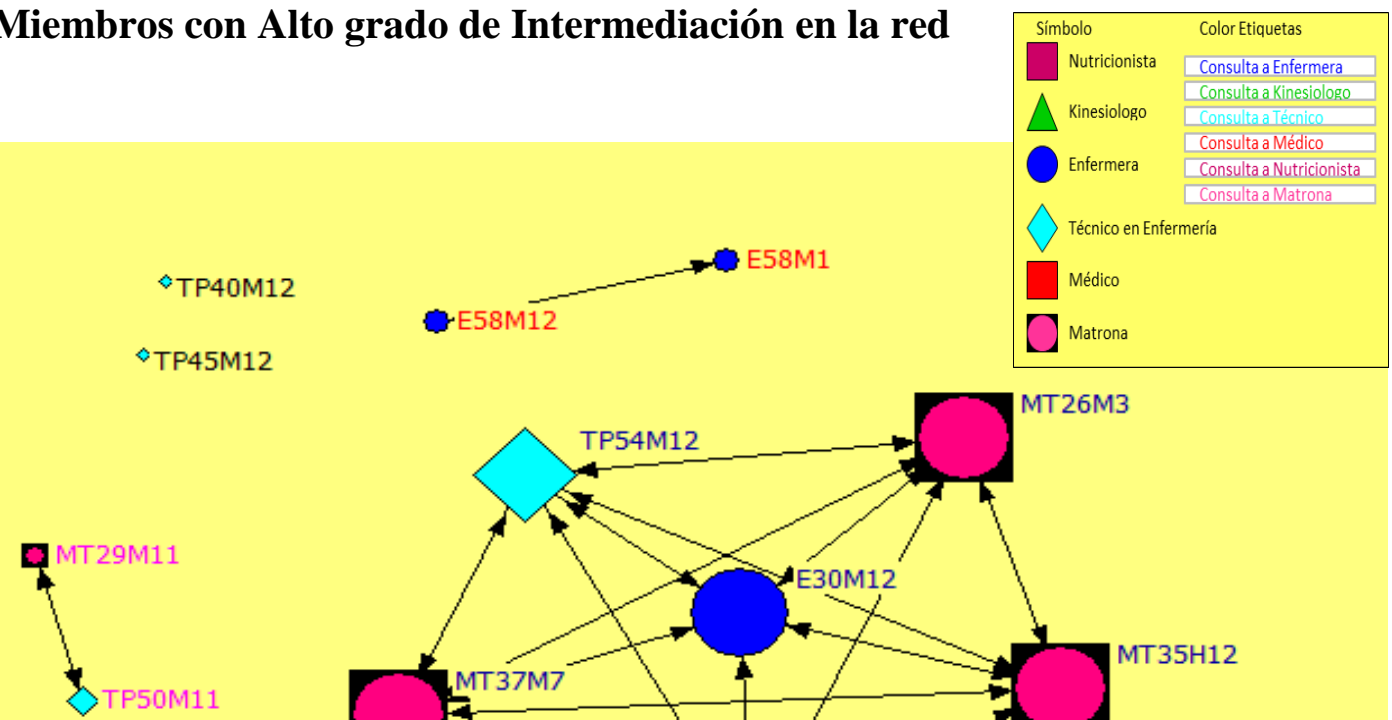

$\diamond$ TP45M12

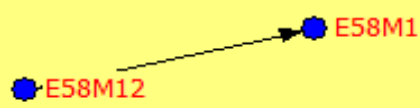

MT26M3

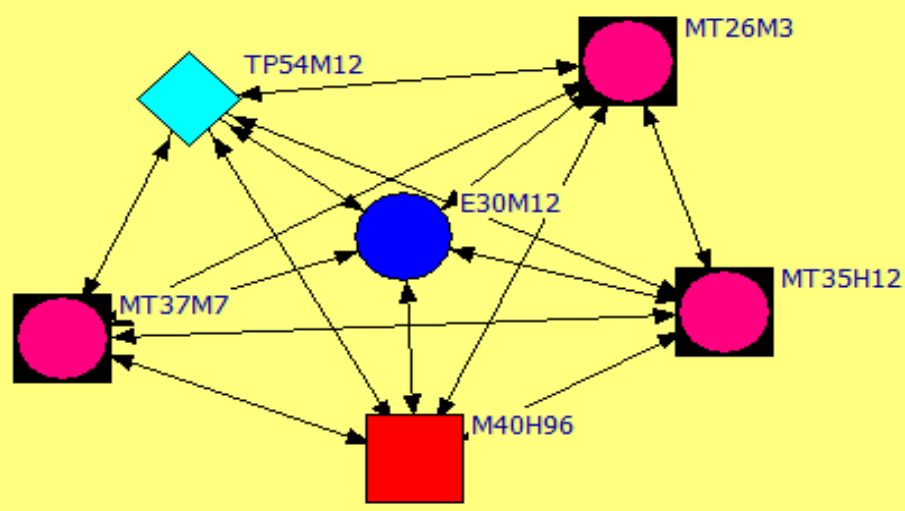




\section{Figura 9: Equipo con menor satisfacción: Red de relaciones sociales de sus miembros}
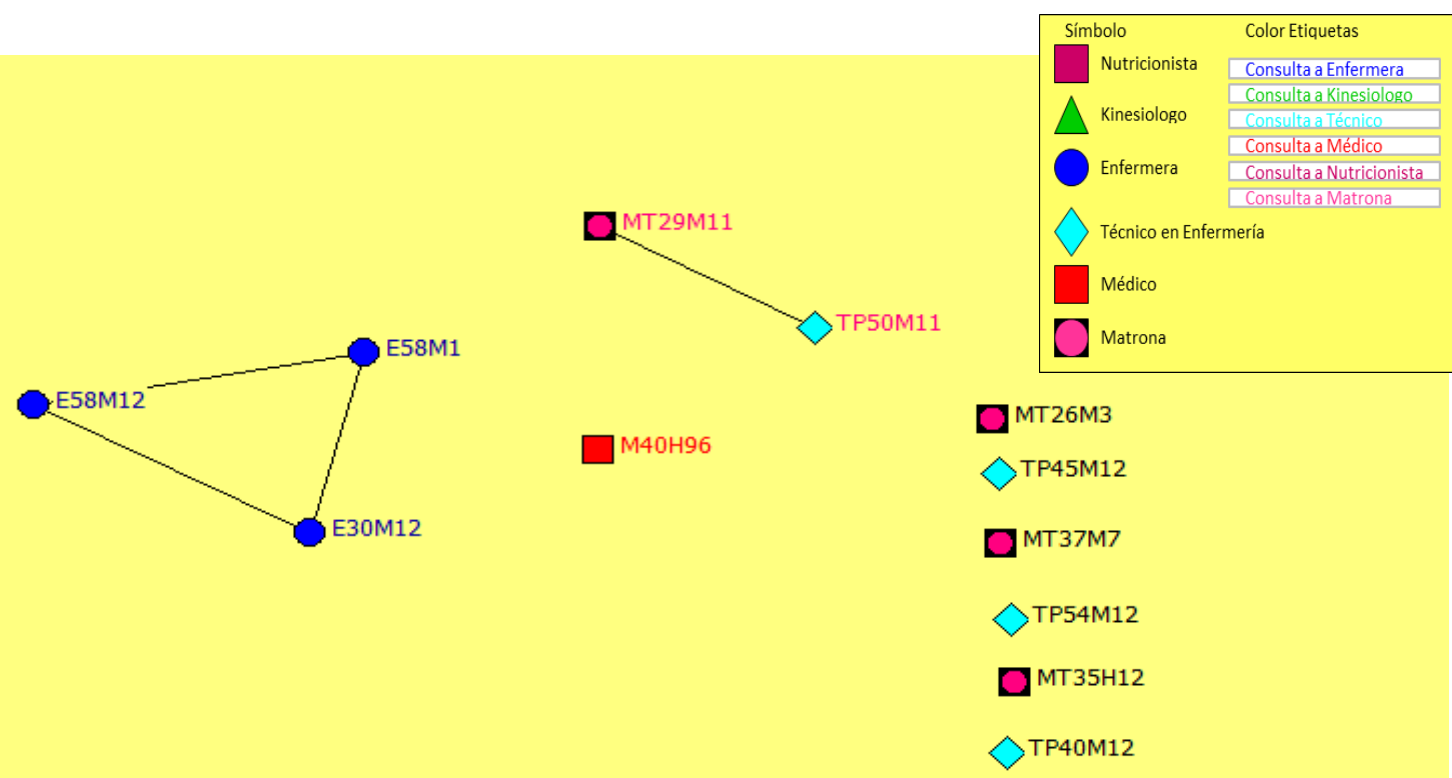

La red de afinidad personal para apoyar temas particulares entre sus miembros presenta un grado aún menor de cohesión solo un $9 \%$ de todas interacciones posibles. Los miembros se organizan de manera diferente cuando puedes elegir a tus compañeros para tratar temas personales o simplemente no te relacionas más allá de aspectos laborales (6 aislados). Aparece sólo una triada de enfermeros presentando una estructura más tribal con limitado tiempo como equipo, pero variada experiencia laboral, dos de ellas altamente experimentadas, llama la atención que ellas laboralmente adscriben al equipo médico, pero personalmente lo hacen a enfermería, sólo la enfermera más joven mantiene su afiliación. Están ubicados centrales en la red con un $18 \%$ de las interacciones entre ellas, la diada MT y TP de la red laboral trasciende a una relación personal (9\%) centralizando una parte reducida de las limitadas interacciones que se establecen dentro de la red, el resto de los miembros aparecen con $0 \%$ interacciones personales desde y hacia ellos. Por último, el grupo de Enfermería interviene en el flujo de información de la red, situándolos entre los otros miembros y entregándole la capacidad de negociar frente a aspectos personales en que deben organizarse como equipo para, por ejemplo, facilitar acuerdos, aislarlos y/o limitar contactos. En el caso del médico él no se relaciona de manera personal con ninguno de los integrantes del equipo y si lo hiciera el preferiría hacerlo con otro profesional de su misma profesión. 
Figura 10: Propiedades de la red a través del tamaño de los nodos.

Miembros Centrales en la red
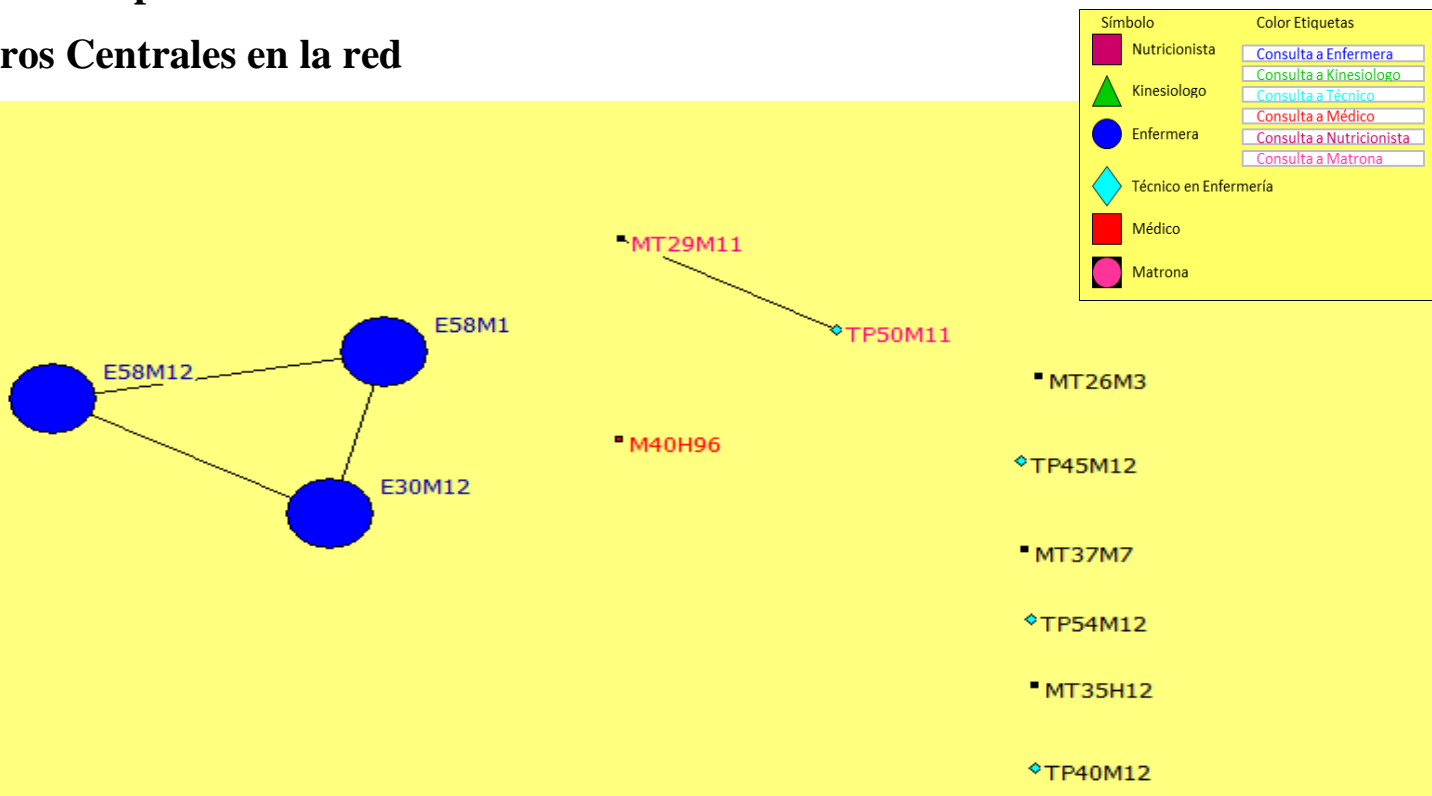

Figura 11: Miembros Influyentes (mayores interacciones desde y hacia ellos)
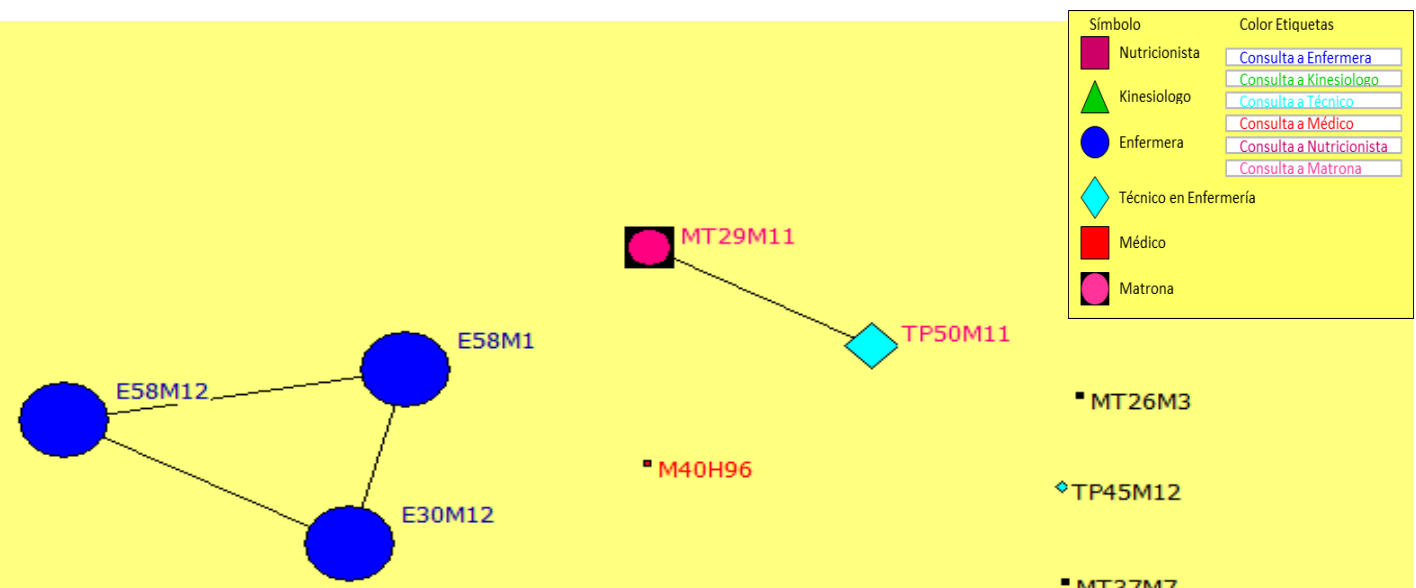

- MT26M3

$\diamond \mathrm{TP} 45 \mathrm{M} 12$

- MT37M7

$\diamond$ TP54M12

- MT35H12

$\diamond \mathrm{TP} 40 \mathrm{M} 12$ 
Figura 12: Miembros con Alto grado de Intermediación en la red

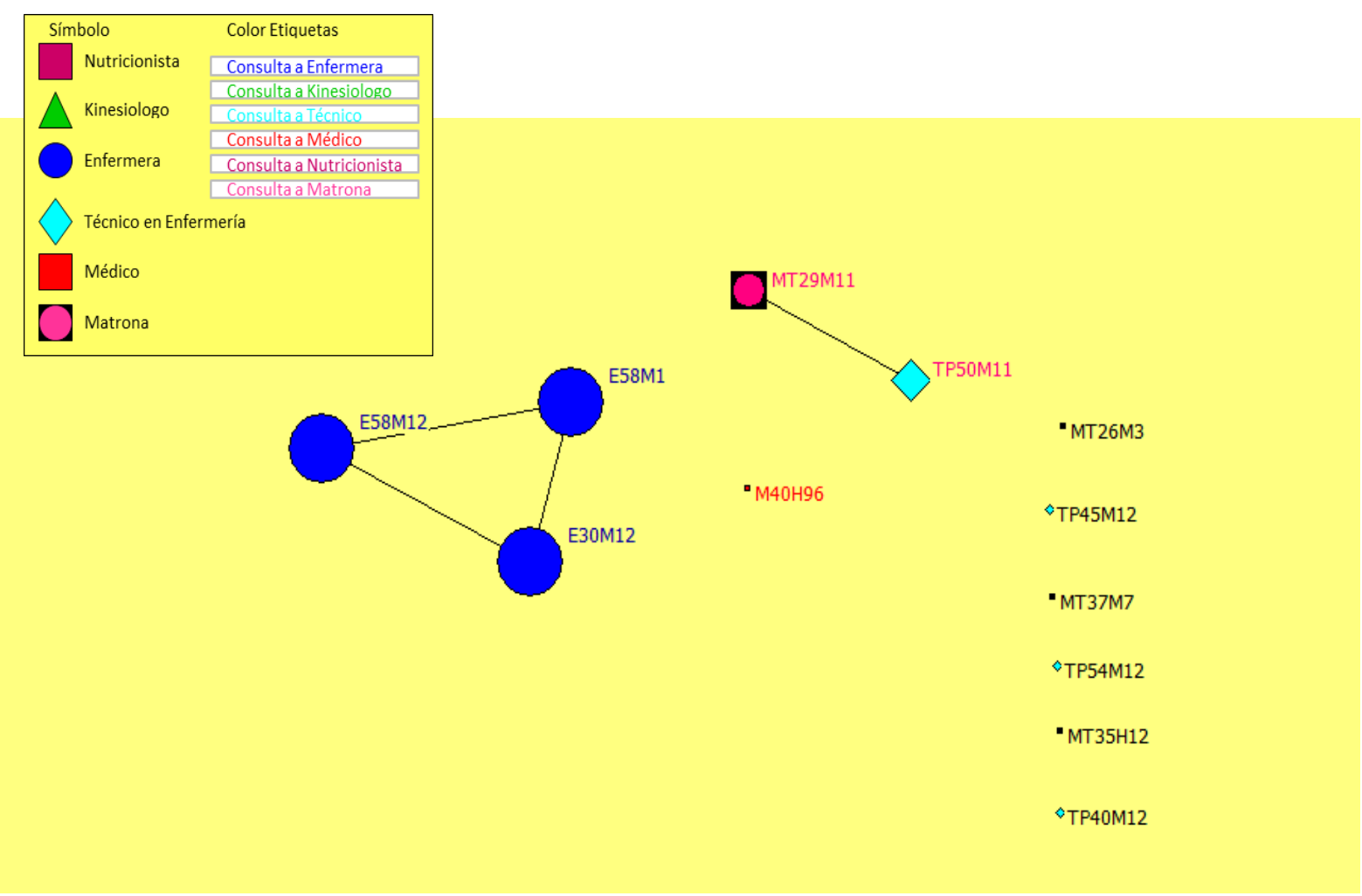


Tabla 21. Características de la red de interacciones para solución de problemas laborales y personales

\begin{tabular}{|c|c|c|}
\hline & \multicolumn{2}{|l|}{ Servicio con Equipos con alto en LT, CE y ST } \\
\hline & Red para Solución de Problema en el trabajo & Red para resolver problema personal \\
\hline Cohesión /densidad & $44 \%$ & $20 \%$ \\
\hline Centralidad/Cercanía & $\begin{array}{l}\text { Promedio } 1 \text { grado } \\
\text { Compacto } 0,41 \\
\text { Amplitud } 0,59\end{array}$ & $\begin{array}{l}\text { Promedio } 1 \text { grado } \\
\text { Compacto } 0,16 \\
\text { Amplitud } 0,8\end{array}$ \\
\hline Centralidad/ Grado total & $\begin{array}{l}\text { Centralidad media: } 5.73 \text { (SD 2.8). Índex (in/out): } \\
17 \% \\
9(57 \%), 4(21 \%) \text { y } 2(7 \%) \text {. }\end{array}$ & $\begin{array}{l}\text { Centralización media de } 2.2 \text { (SD 1.6) } \\
\text { Índex (in/out) } 13 \% .5(28 \%), 4(21 \%), 2 \\
(7 \%) \text { y } 24(0 \%) .\end{array}$ \\
\hline Centralidad/ Intermediación & $\begin{array}{l}\text { Centralización Índex: 1,3\%, media: } 4.73 \text { (SD } \\
\text { 2.8) } 9(38 \%) .3(10 \%)\end{array}$ & $\begin{array}{l}\text { Centralización índex: } 0.86 \\
\text { Media: } 1.5 \text { (SD 1.3). } 5(16 \%), 4(10 \%) \text { y } \\
\text { resto }(0 \%) \text {. }\end{array}$ \\
\hline Subgrupos & $2(9,4)$ & $2(5 \mathrm{y} 4)$ \\
\hline
\end{tabular}




\section{Figura 13: Servicio con Equipos con alto en LT, CE y SE: Red Profesional}

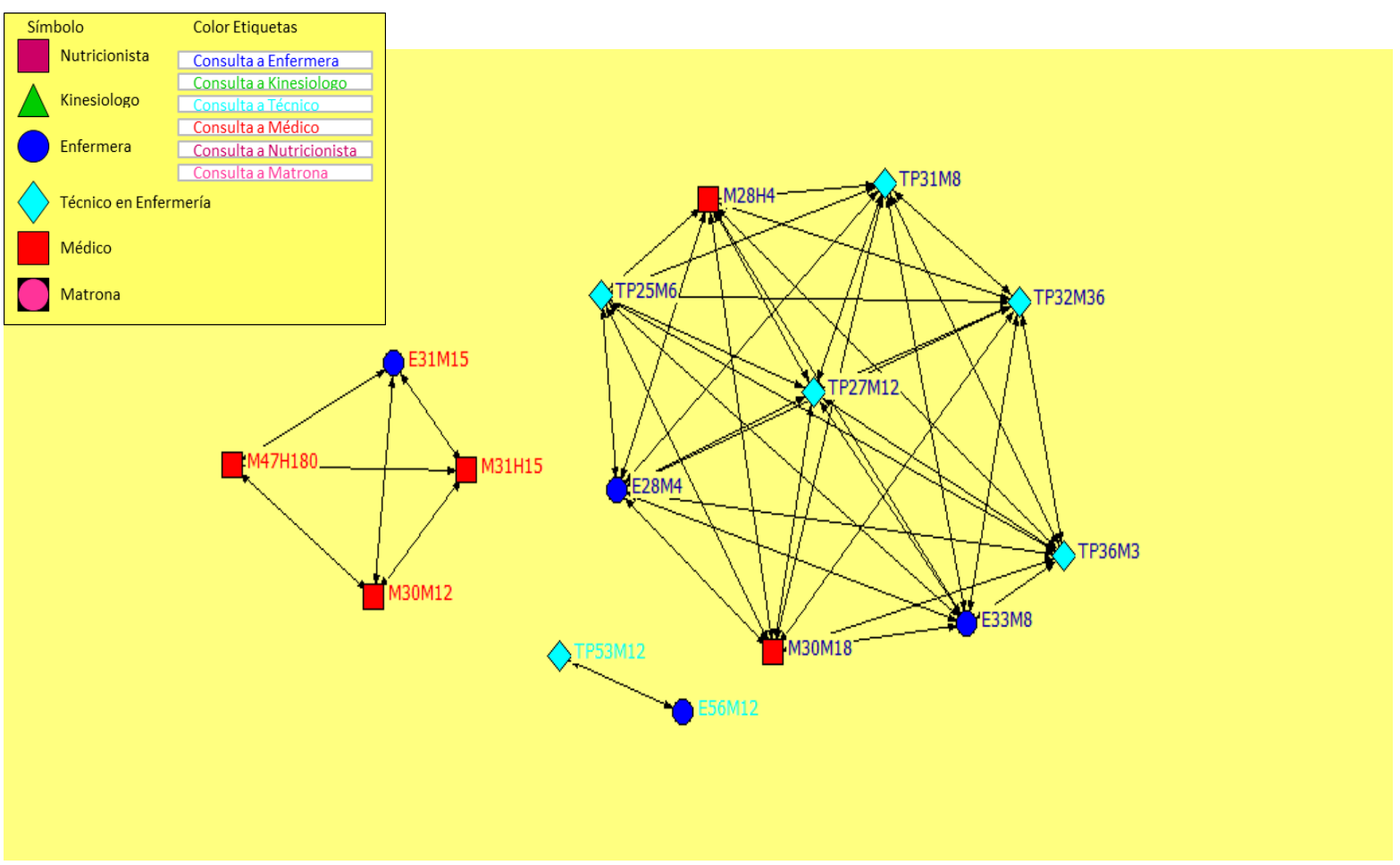

Los equipos con mayores niveles de liderazgo transformacional y mejores resultados de Clima de Equipo pertenecen a un servicio (representado en gráfico) de baja complejidad con atención clínica de especialidad. Cuentan con 5 M especialistas o en formación de especialidad con rangos de edad de 28-50 años. 4 E de entre 28 y 56 años y 6 TP entre 25 y 53 años. Todos ellos con una amplia variedad de tiempo en sus respectivos equipos (6- 96 meses). La red que representa la búsqueda de solución de problema de trabajo entre los miembros del equipo basado en las de interacción que establecen, presenta una estructura que incluye dos grupos interprofesionales y una pareja, es posible observar con claridad como el grupo más numeroso se concentra alrededor de los profesionales de enfermería para buscar orientación y apoyo profesional, el grupo de 4 profesionales adscribe a la orientación y guía médica y la diada de E y TP con gran experiencia lo hacen vinculándose a los TP. La red alcanza una densidad de cohesión del $40 \%$ de todas las interacciones posibles, a pesar de que todos sus integrantes están a 1 grado de distancia los unos de los otros, lo que facilita las interacciones y conexión entre sus miembros.

El grupo de 9 profesionales (más numeroso) comparten similitudes en edad, experiencia profesional, pero su antigüedad en sus respectivos equipos es variada. Todos ellos concentran lugares de centralidad en el servicio (50\% de las interacciones), convirtiéndolos desde el punto de vista de la información que manejan al momento de tomar decisiones profesionales como los miembros más influyentes de la red, sobre todo si se consideran las interacciones 
que emergen desde cada uno de ellos y las que reciben desde los otros (57\%) facilitando así la solución de problemas laborales. Además, el 38\% de toda la información que fluye dentro de la red pasa por ellos. Hay un segundo grupo más pequeño (4) que incluye $3 \mathrm{M}$ y $1 \mathrm{E}$ con experiencia moderada tres de ellos y más jóvenes que se relacionan directamente con un médico más experimentado, la posición de centralidad del grupo en términos de sus interacciones alcanza un 16\% y su grado de intermediación de las interacciones para participar o influenciar las decisiones alcanza sólo un 21\% limitando su capacidad de mediar. Por ultimo aparecen como separadas de la red una diada de TP y E ambas experimentadas, pero con solo un año en este equipo y que se acercan más al grupo de TP para buscar apoyo.

Figura 14: Propiedades de la red a través del tamaño de los nodos.

Miembros Centrales en la red
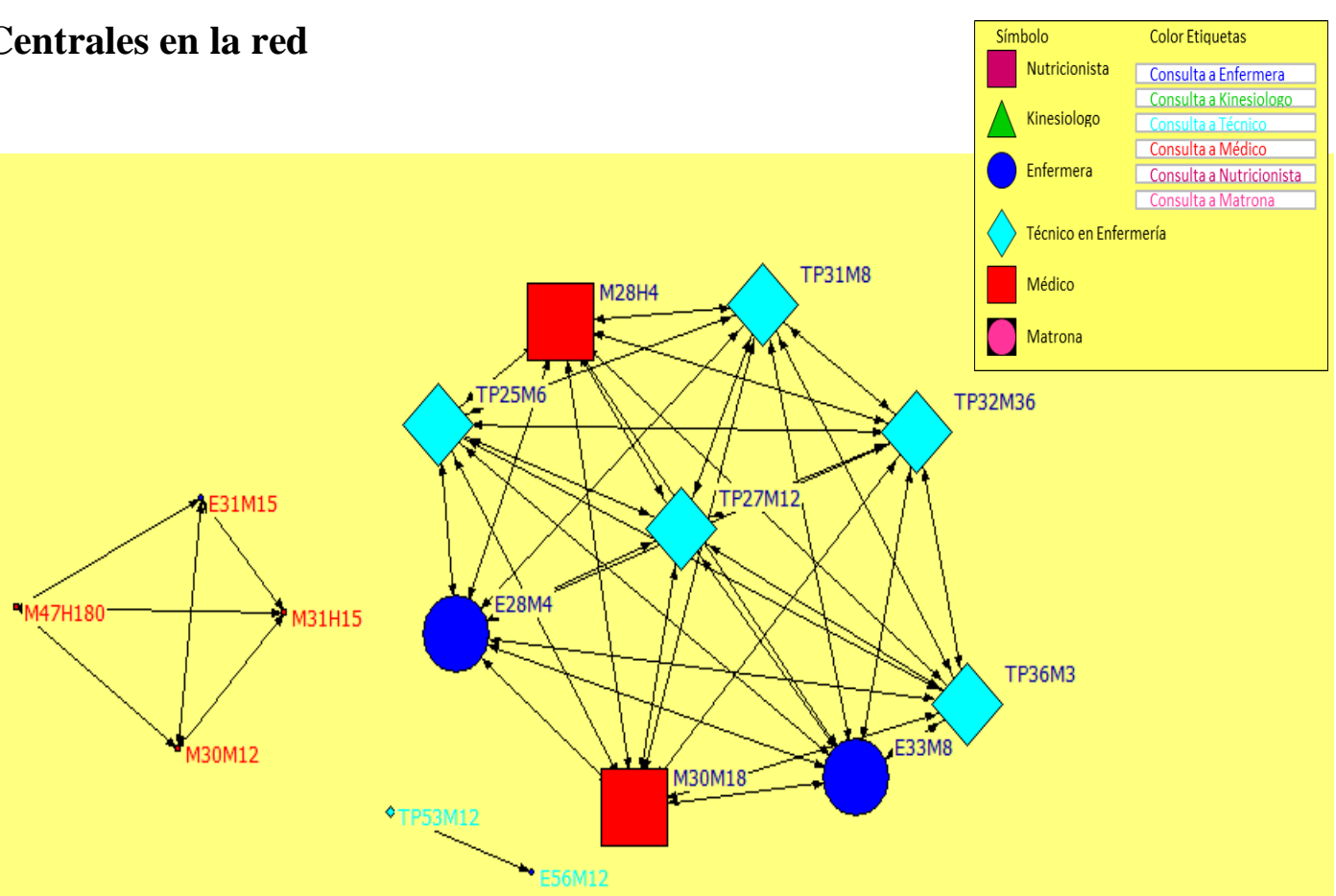
Figura 15: Miembros Influyentes (mayores interacciones desde y hacia ellos)

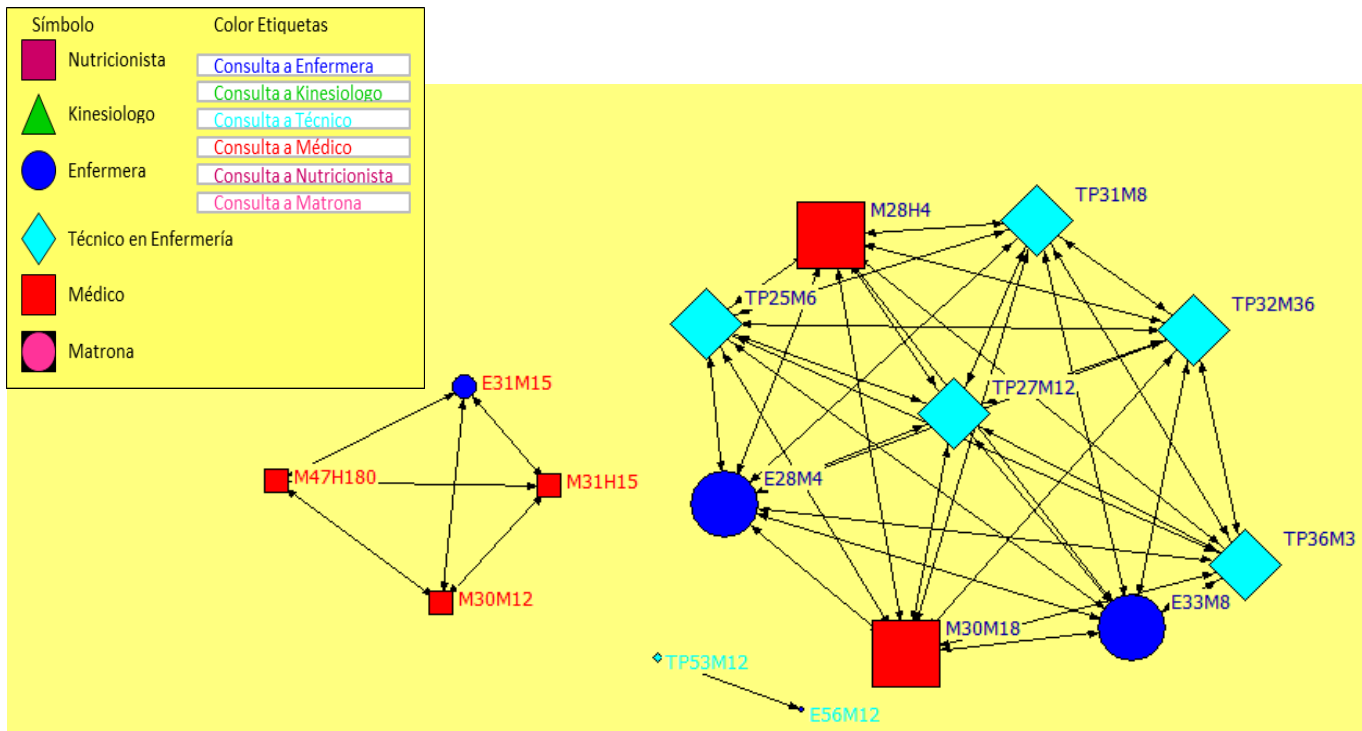

Figura 16: Miembros con Alto grado de Intermediación en la red

\begin{tabular}{|c|c|}
\hline Símbolo & Color Etiquetas \\
\hline Nutricionista & Consulta a Enfermera \\
\hline & Consulta a Kinesiologo \\
\hline Kinesiologo & Consulta a Técnico \\
\hline & Consulta a Médico \\
\hline Enfermera & Consulta a Nutricionista \\
\hline & Consulta a Matrona \\
\hline Técnico en En & mería \\
\hline Médico & \\
\hline Matrona & \\
\hline
\end{tabular}
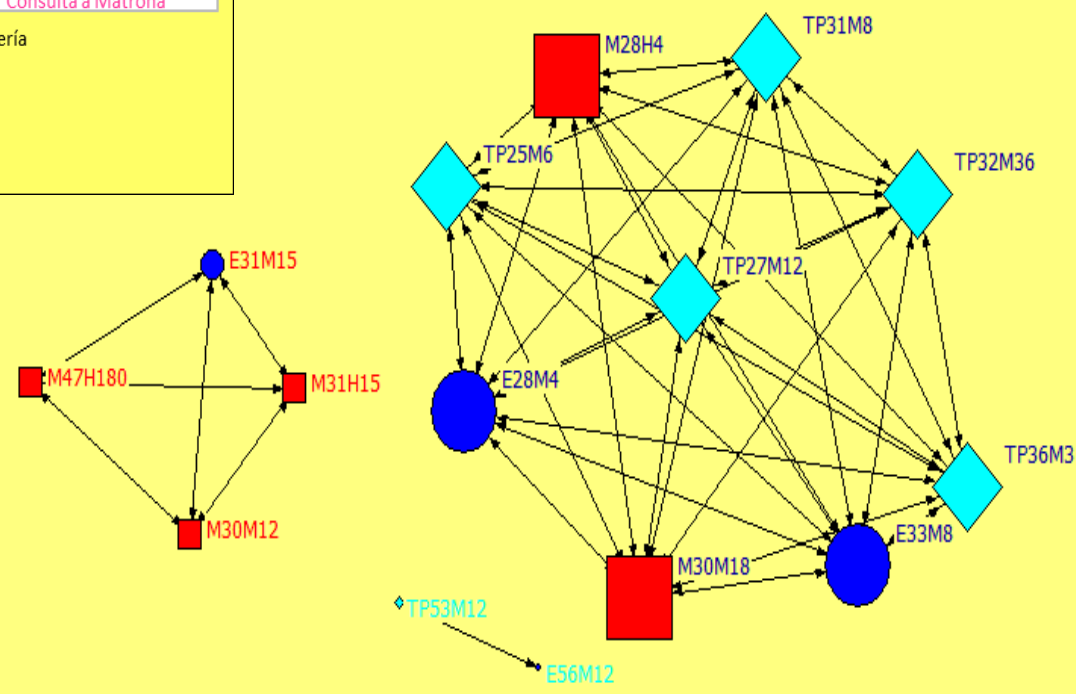
Figura 17: Servicio con Equipos con alto en LT, CE y ST: Red de relaciones sociales de sus miembros

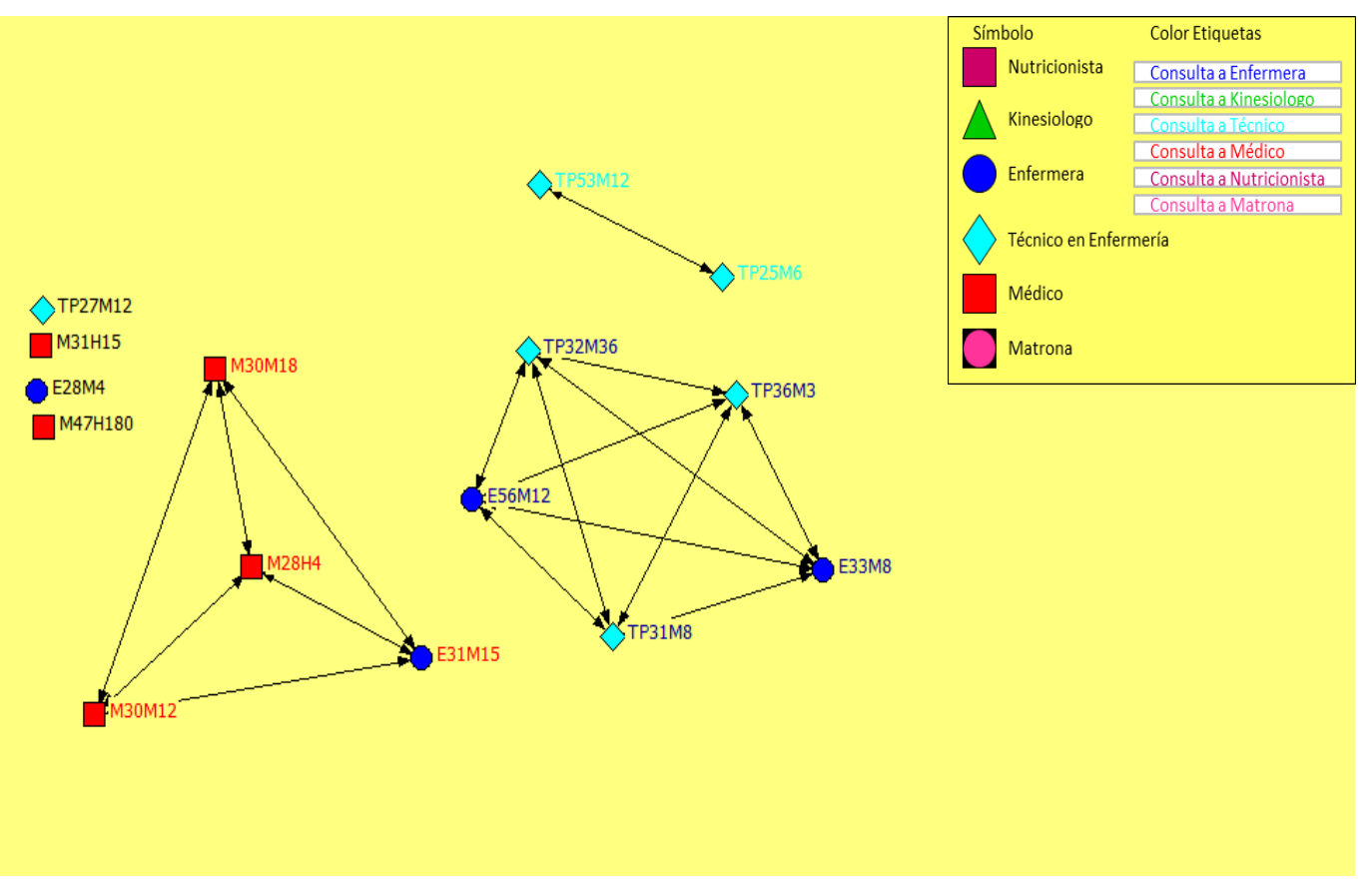

La red social de los equipos en el servicio basado en la búsqueda de apoyo en temas personales presenta solo un $20 \%$ de densidad, mostrando las interacciones posibles dado el número de miembros del equipo, a pesar de lo anterior, la distancia entre cada uno es cercana, en promedio 1 grado. Es posible observar dos grupos y una diada, su agrupación parece obedecer en términos generales a afinidad profesional (tribal). El grupo con mayor número de integrantes (5), no comparte importantes similitudes en términos generacionales, experiencia y/o permanencia en el equipo, pero todas eligen relacionarse con profesionales afines. Este grupo es el más influyente basado en su centralidad en la red y su mediación del flujo de comunicación ( $28 \%$ y $16 \%$ respectivamente). En relación al segundo grupo que incluye $3 \mathrm{M}$ y $1 \mathrm{E}$ en términos de vinculación personal es definitivamente a medicina (etiqueta roja) comparten aspectos generacionales y su permanencia en sus equipos en el servicio no supera los 18 meses. En términos de prominencia en la red su centralidad y facultad de mediar las interacciones personales entre el resto de los miembros alcanza un $36 \%$ y $21 \%$ respectivamente. Por último, la diada de TPs aparece de acuerdo a su edad y antigüedad como una relación de apoyo y consejería como las que se establece entre una mentora y aprendiz, pero llevado al plano personal. Por ultimo aparecen 4 integrantes de equipos que prefieran que su relación no trascienda aspectos laborales. 
Figura 18: Propiedades de la red a través del tamaño de los nodos.

Miembros Centrales en la red

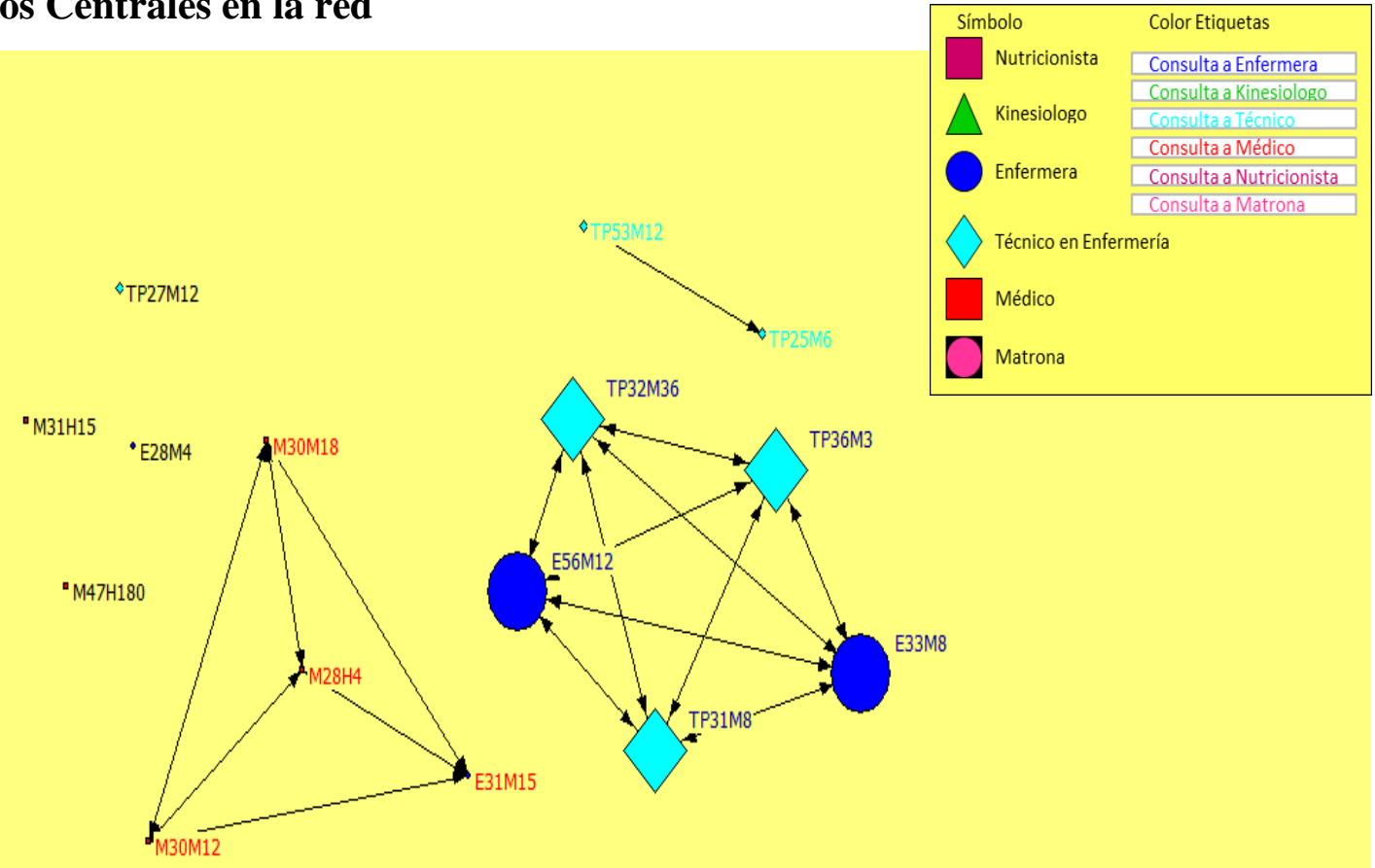

Figura 19: Miembros Influyentes (mayores interacciones desde y hacia ellos)

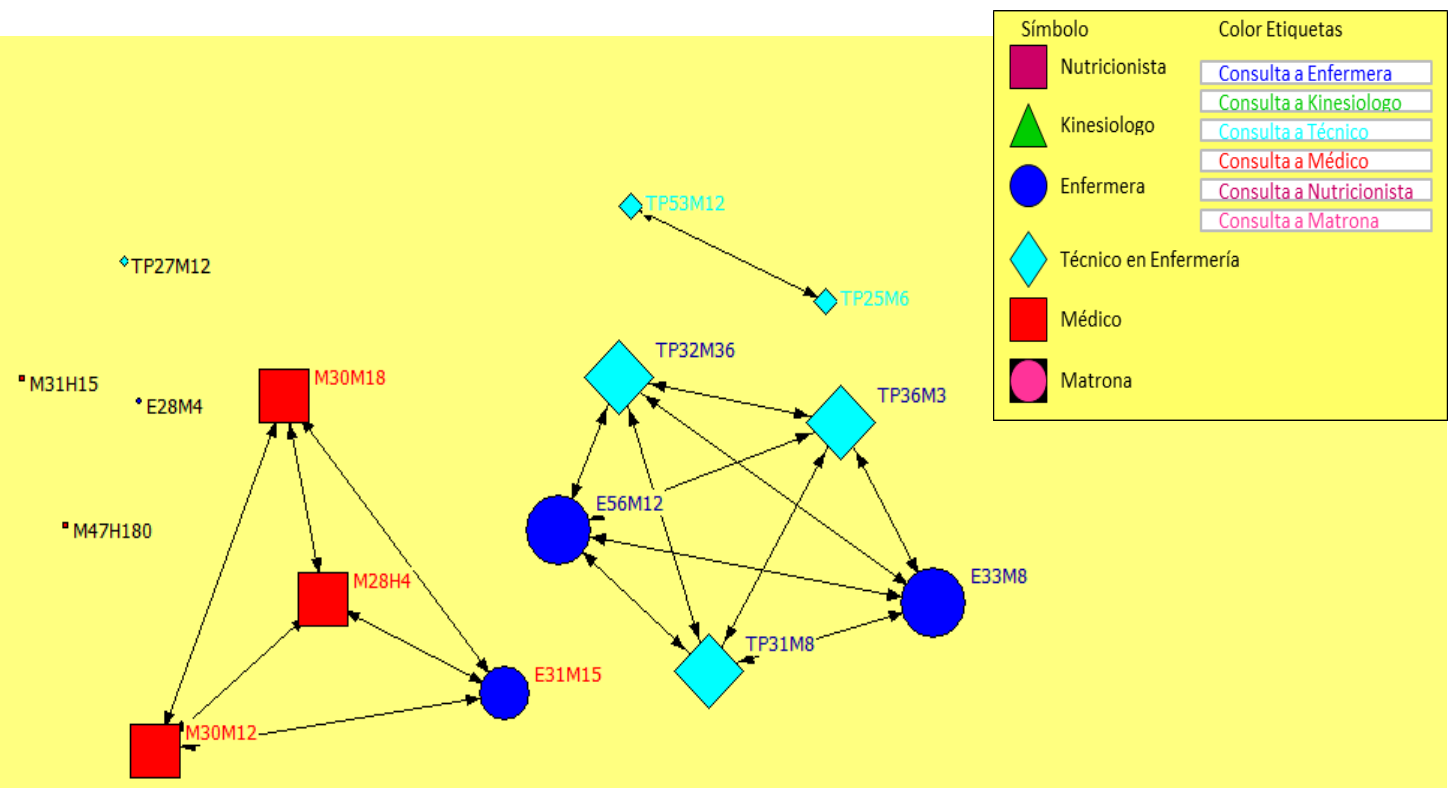


Figura 20: Miembros con Alto grado de Intermediación en la red

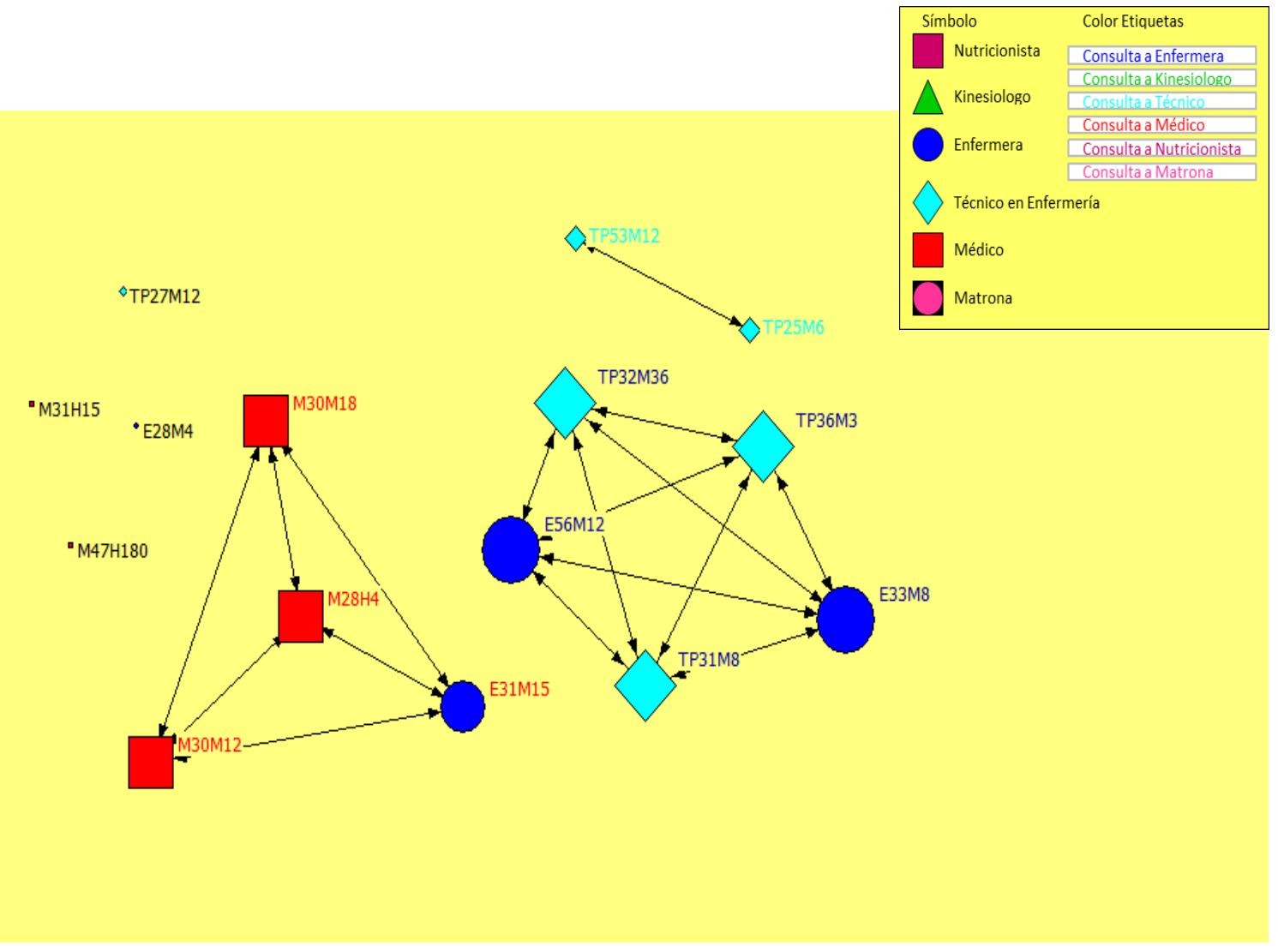


Tabla 22. Características de la red de interacciones para solución de problemas laborales y personales

\begin{tabular}{|c|c|c|}
\hline & \multicolumn{2}{|l|}{ Servicio con Equipo resultados medios de LT, CE y ST } \\
\hline & Red para Solución de Problema en el trabajo & $\begin{array}{l}\text { Red para resolver problema } \\
\text { personal }\end{array}$ \\
\hline Cohesión /densidad & $37 \%$ & $29 \%$ \\
\hline Centralidad/Cercanía & $\begin{array}{l}1 \text { grado } \\
\text { Compacto: } 0.36 \\
\text { Amplitud: } 0.63\end{array}$ & $\begin{array}{l}1 \text { grado } \\
\text { Compacto: } 0.28 \\
\text { Amplitud: } 0.71\end{array}$ \\
\hline Centralidad/ Grado total & $\begin{array}{l}\text { Centralización Índex in/out: 17\%, Media } 20 \text { (SD } \\
\text { 11), } 32(54 \%), 12(19 \%), 10(15 \%) \text { y 1-1 (1.7\%) } 2 \\
\text { aislados . }\end{array}$ & $\begin{array}{l}\text { Centralización Índex in/out: } 20 \% \\
\text { Media: } 16 \text { (SD 12) } 29 \text { (49\%), } 12 \\
(19 \%), 3(3.5 \%) \text { y } 4(1.7 \%) .\end{array}$ \\
\hline Centralidad/ Intermediación & $\begin{array}{l}\text { Media: } 20 \% \text { (SD 11) Centralidad Índex: } 0.319 \% .32 \\
(30 \%-0.940) .\end{array}$ & $\begin{array}{l}\text { Centralidad índex: } 0.36 \\
\text { Media: } 15 \% \text { (SD 11) } 29 \text { (27- 0.84).12 } \\
(10-0.31)\end{array}$ \\
\hline Subgrupos & $3(32,12$ y 10$)$ & $3(29,12,3)$ \\
\hline
\end{tabular}




\section{Figura 21: Servicio con Equipos con promedio en LT, CE y ST:}

\section{Red Profesional}

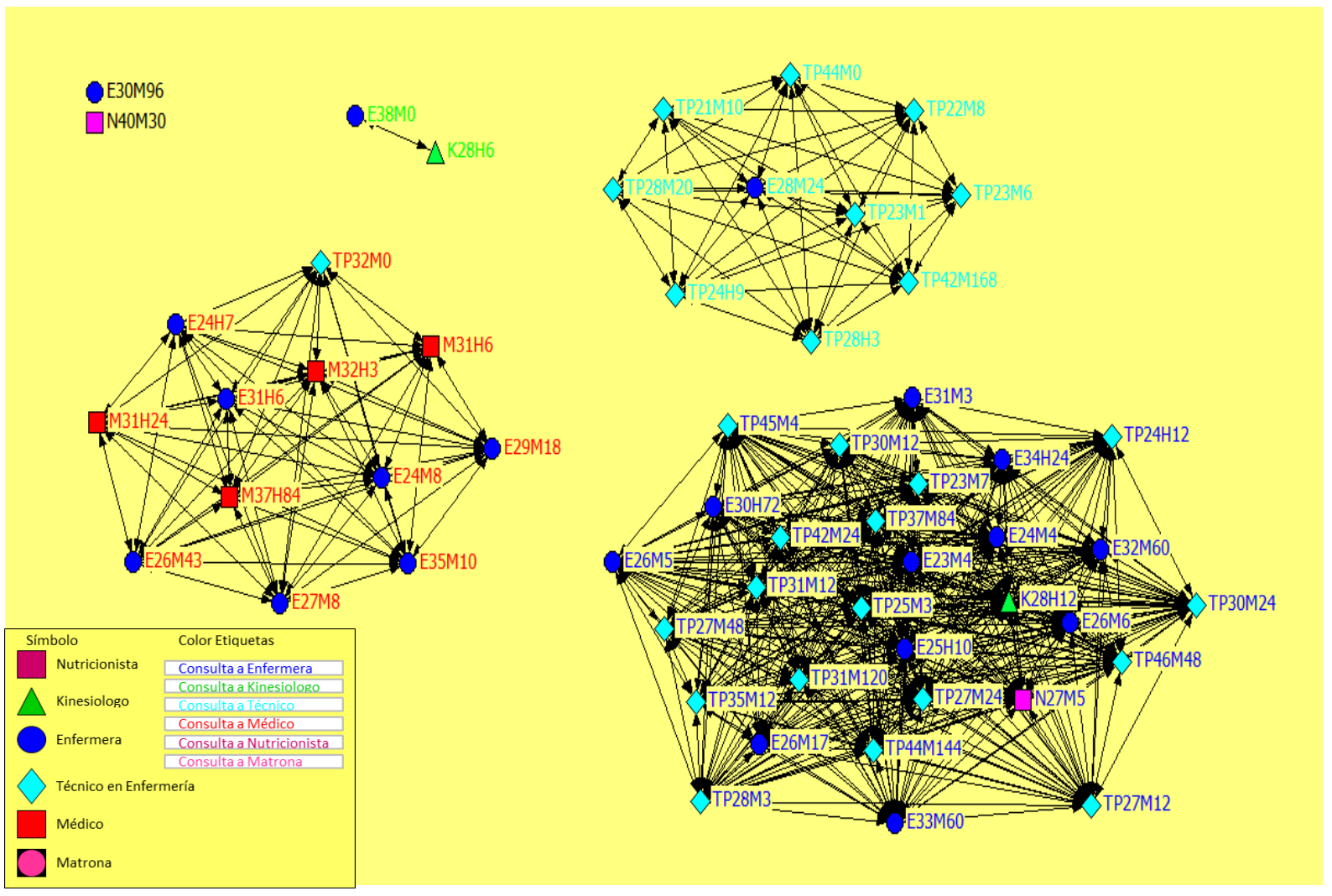

Un servicio que contiene múltiples equipos con valores promedio de las tres variables en estudio, es una unidad de alta complejidad donde confluyen diferentes especialidades médico-quirúrgicas en términos de cuidados requeridos por los pacientes y con profesionales de diferentes disciplinas compartiendo tiempo en la unidad, esto, permitido por la estructura de dotación establecido por la organización. La red profesional presenta una densidad de cohesión de 37\% de todas las interacciones posibles, sin embargo, sus integrantes están a 1 relación de distancia los unos de los otros en sus grupos de afiliación. Están agrupados al momento de solicitar apoyo y asesoría profesional en tres grandes conglomerados dependiendo del grupo profesional al que adhieren para buscar asesoría, el más numeroso y central en todas las mediciones de la red es enfermería. Este subgrupo incluye 32 miembros en su mayoría profesionales de enfermería (11), Técnicos en enfermería (19) y un Kinesiólogo y una Nutricionista. Todos ellos concentran y centralizan la comunicación (57\%) $\mathrm{y}$ donde sus miembros influyen en el resto apoyando y guiando o indagando en los otros miembros para buscar asesoramiento y capacitación en temas que influyen en la entrega de un mejor cuidado del paciente (54\% de las relaciones de entrada y salida). La intermediación que realizan de las comunicaciones en la red alcanza un 30\%. La segunda agrupación de 12 
miembros incluye 7E, 1 TP y 4M con edades cuyo rango va entre los 24 y 37 años y antigüedad 6-84 meses. Los une que su primera alternativa al momento de solicitar asesoría profesional para la solución de problemas laborales es el profesional médico, sus integrantes parecen apoyarse mutuamente para suplir su falta de experiencia profesional y para eso son muy cohesionados con una distancia no mayor de 1 conexión entre ellos, sus 12 miembros exhiben el $21 \%$ de las interrelaciones, un $19 \%$ de las interacciones emanan o son recepcionadas por ellos, sin embargo su poder de intermediación entre sus miembros no es relevante como el de enfermería. La tercera agrupación de 10 miembros incluye 9 TP y 1 E y se acerca a las primeras (TP) cada vez que requieren orientación y apoyo, sus edades y experiencia presenta una variabilidad marcada, con extremos de 21 años a 44 y antigüedad de 6 a 168 meses. Los resultados del análisis de redes le reconocen una centralidad de interacciones del 17\%, de un $19 \%$ de todas las realizadas en la red y su intermediación es desestimable en una red que comparte información de trabajo. Por último, aparece una diada de enfermera y kinesiólogo, los cuales aparecen como cercanos, pero su influencia y capacidad de participar del traspaso de información o toma de decisiones es muy baja. Estan aislados en términos de relaciones para apoyo profesional una enfermera con gran antigüedad en su equipo (96 meses) y una Nutricionista (30 meses) pero con amplia experiencia profesional.

\section{Figura 22: propiedades de la red a través del tamaño de los nodos.}

\section{Miembros Centrales en la red}

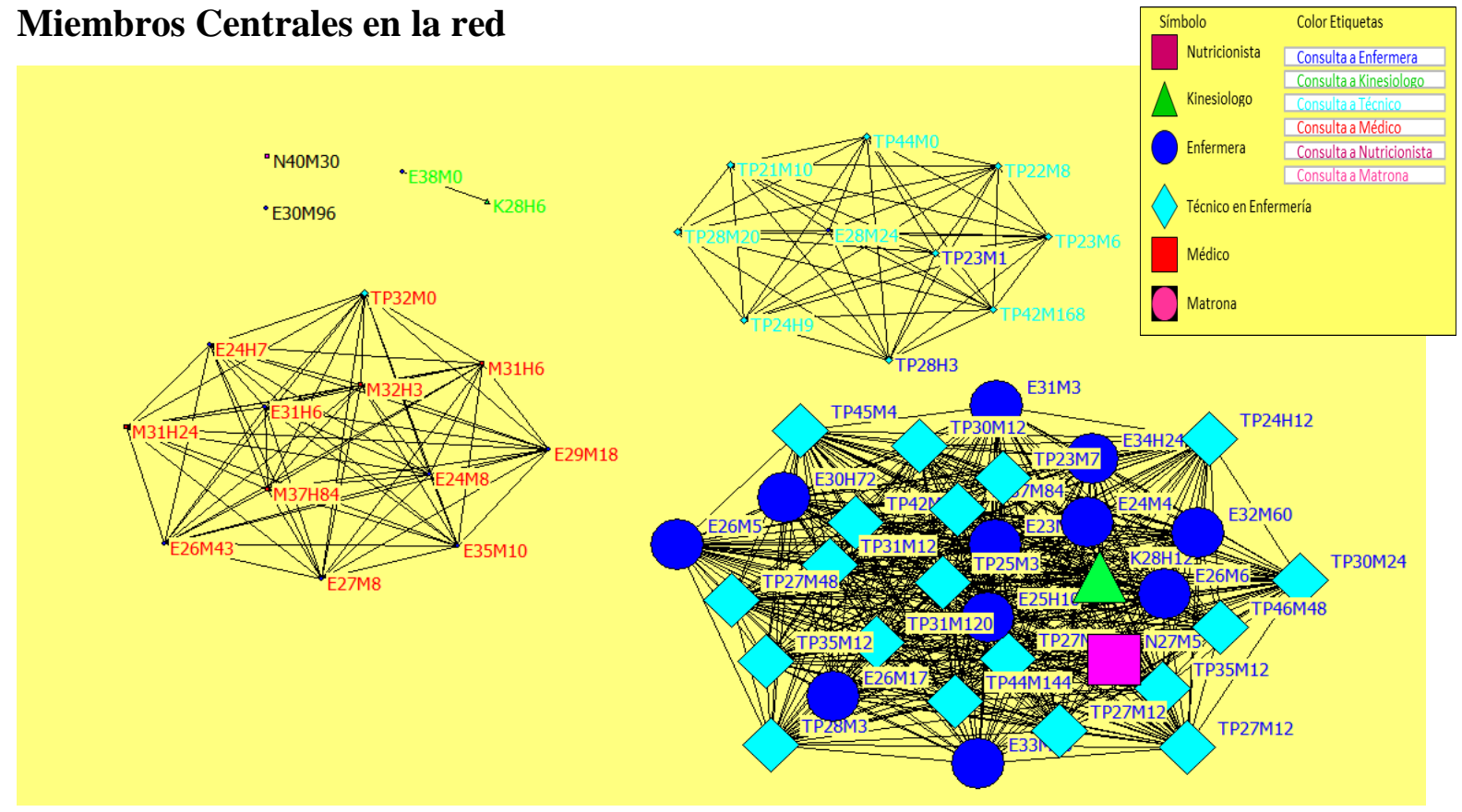


Figura 23: Miembros Influyentes (mayores interacciones desde y hacia ellos)

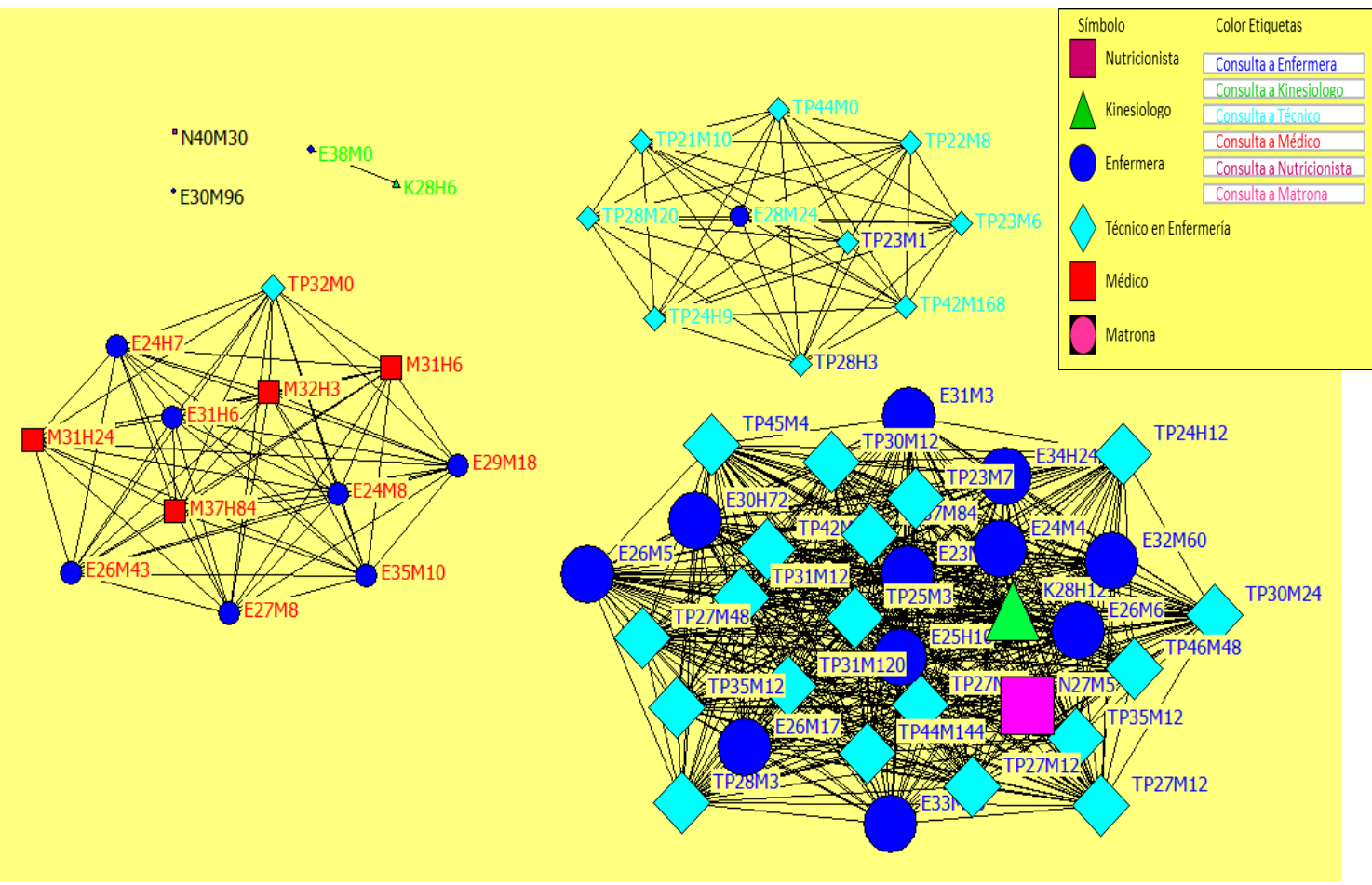

Figura 24: Miembros con Alto grado de Intermediación en la red

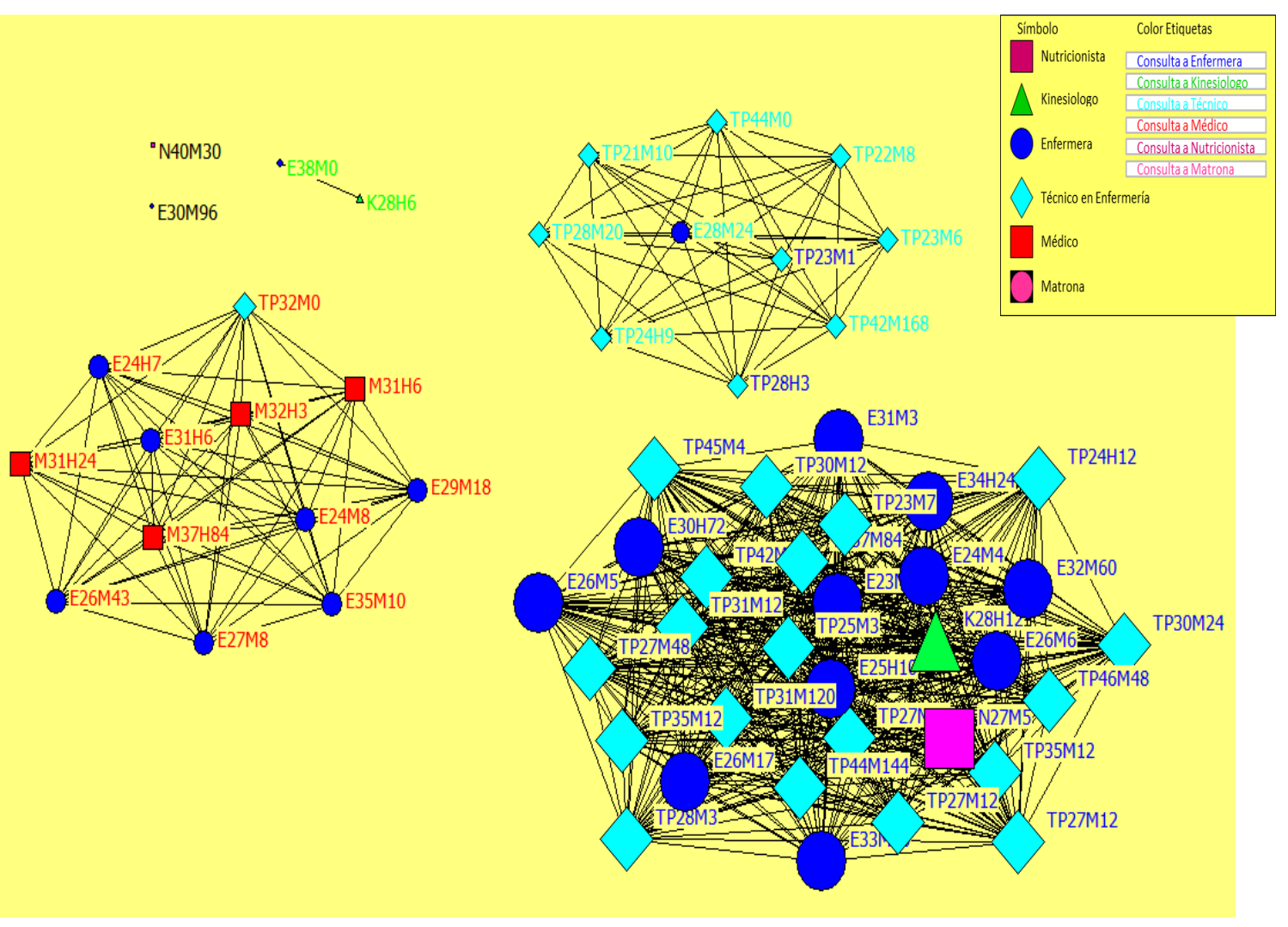




\section{Figura 25: Servicio con Equipos con promedio en LT, CE y ST: Red social}

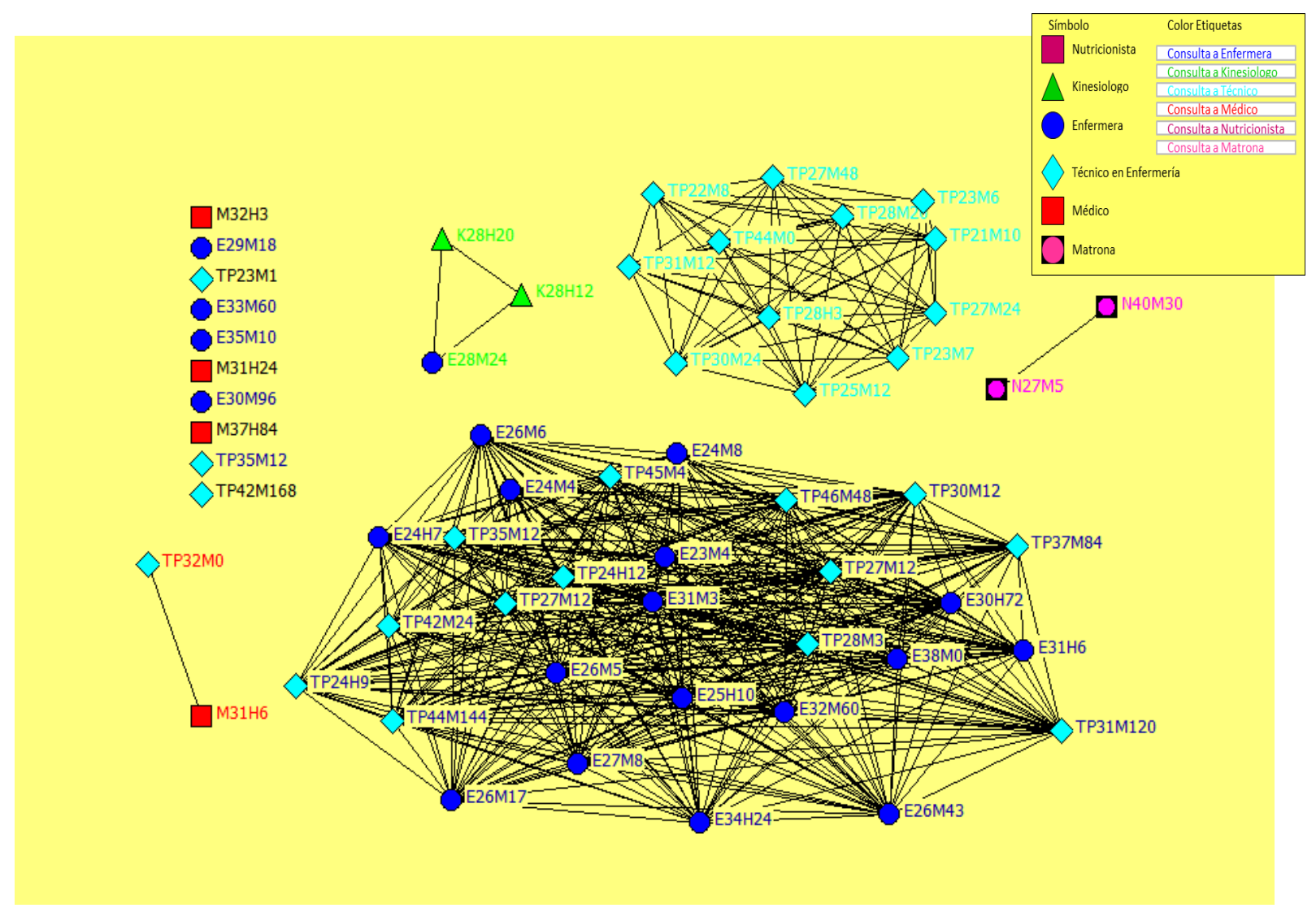

Al observar las relaciones personales en múltiples equipos con valores promedio de las tres variables en estudio, contenidos en esta una unidad de alta complejidad, la red desde lo profesional cambia de manera importante sufriendo la desaparición completa de un grupo de 10 profesionales y dejando en su lugar un trio y dos diadas y 10 profesionales que declaran no tener relaciones personales con ningún miembro de su círculo laboral. Esta red alcanza una densidad del $15 \%$ de todas las interacciones posibles basado en el número de miembros que contiene. El grupo más numeroso (29) y que adhiere a enfermería al momento de establecer relaciones personales incluye sólo enfermeras y técnicos en enfermería muy cercanos entre ellos (1 grado), siendo centrales en la red y concentrando el $60 \%$ de las interacciones, sus miembros participan con receptor y emisor de interacciones (49\%) además de ser puentes de comunicación en $84 \%$ de las interacciones entre dos miembros de la red. El segundo grupo de profesionales (12) incluye sólo técnicos en enfermería que se eligen entre ellas por afinidad para compartir sus problemas y dificultades personales, ellos también están muy cohesionados y si observamos su centralidad, comunicación (recibe y entrega) e intermediación (entre las interacciones) sus resultados son, $255, \quad 19 \% \quad \mathrm{Y} \quad 31 \%$ respectivamente. 
La triada que se manifestó sólo a nivel personal e incluye 2 Kinesiólogos y un profesional de enfermería quienes a pesar de aparecer como cercanos y cohesionados su impacto en relación a la red del punto de vista de la amistad, no se extiende más allá de sus confines, lo mismo sucede con la diada de TP y M. Llama la atención como una de las Nutricionista que adhería a enfermería y la otra estaba aislada en la red profesional, al momento de apoyarse de manera personal aparecen como una unidad.

Figura 26: Propiedades de la red a través del tamaño de los nodos.

\section{Miembros Centrales en la red}

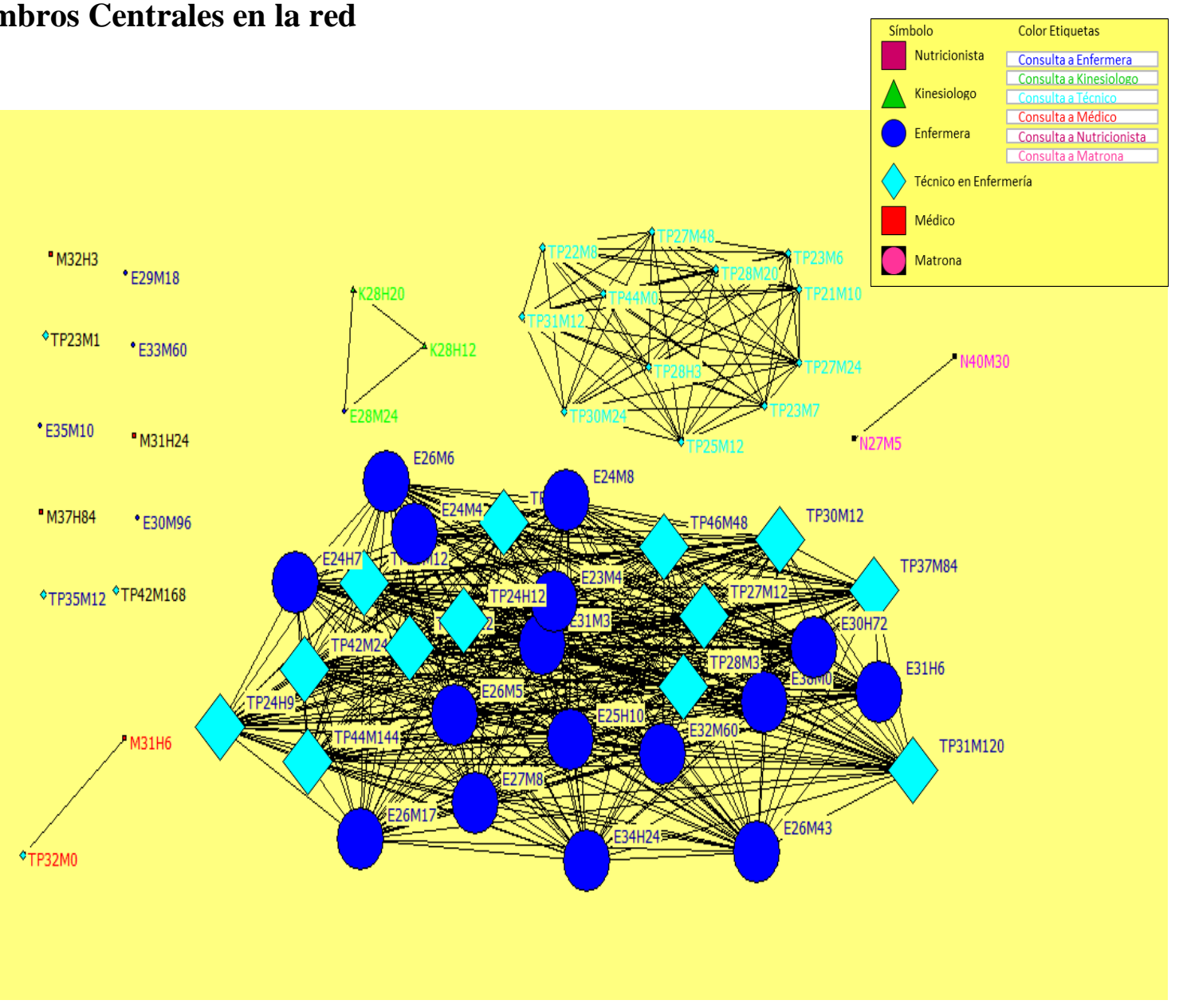


Figura 27: Miembros Influyentes (mayores interacciones desde y hacia ellos)

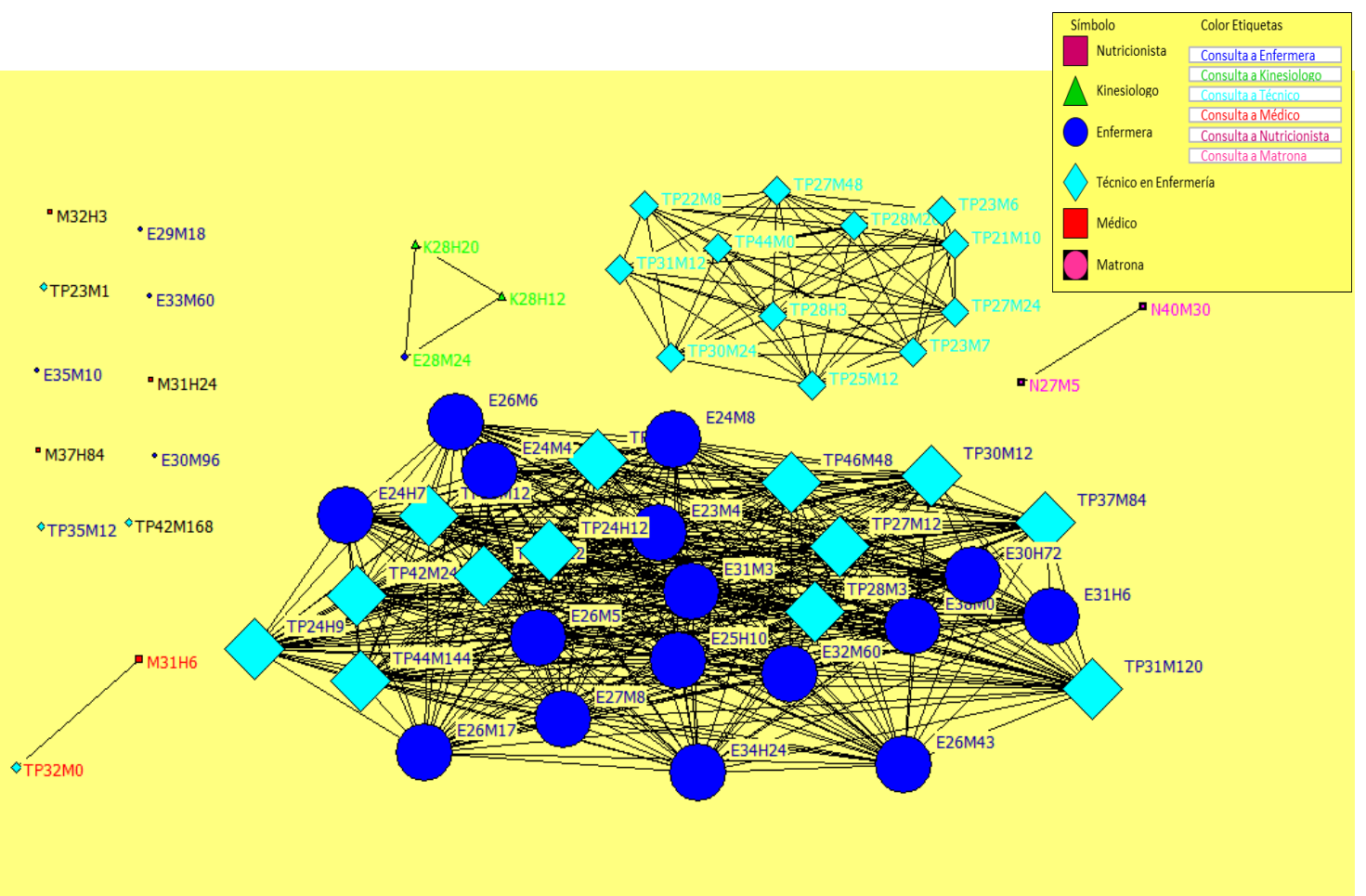

Figura 28: Miembros con Alto grado de Intermediación en la red

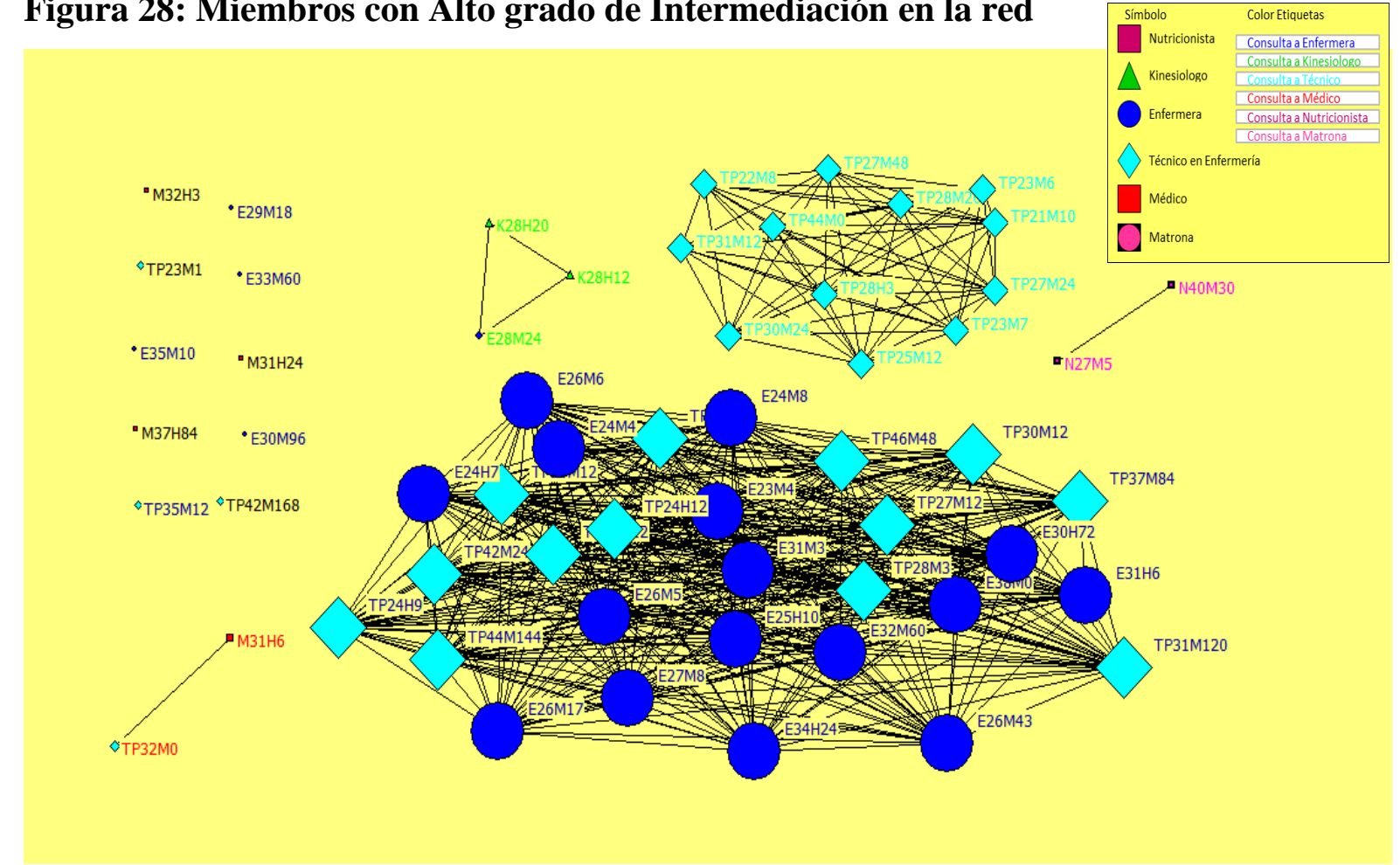




\subsection{Resultados Cualitativos}

Se realizaron 15 entrevistas semiestructuradas a profesionales pertenecientes a 4 equipos interdisciplinarios con resultados extremos y promedio de la variable Satisfacción con el Equipo, basado en los resultados de la fase 1 de la investigación. Se incluyen 3 Médicos, Técnicos en Enfermería, 2 Nutricionistas, 2 Kinesiólogos y 3 Enfermeras, cuyas edades fluctúan entre 25 y 45 años y su antigüedad en el equipo va desde los 6 a 68 meses aproximadamente.

El análisis de contenido temático de las narraciones utilizó los referenciales teóricos de la satisfacción con el Equipo (SE), Clima de Equipo (CE ) y Liderazgo Transformacional (LT) permitiendo describir 19 categorías representados por códigos narrativos (voz de los participantes), las cuales finalmente fueron agrupadas generando 6 temas representativos, los cuales serán descritos en detalle más adelante.

Los resultados se presentan por tema, y las categorías (destacadas en negrito) que lo componen irán emergiendo en la narración junto con extractos de los relatos de los participantes.

\section{Tema 1: Trabajo en Equipo: características y atributos}

Lo primero que llama la atención al comenzar la entrevista es la reacción de la mayoría de los entrevistados al escuchar la primera pregunta, que indaga en su percepción del Trabajo en Equipo (TE), llevándolos a rememorar una situación percibida como positiva, no siendo siempre su situación actual y recociéndola como una excepción más que la regla en contextos de salud, sin embargo, para los que han tenido la fortuna de vivirla es una experiencia que recuerdan con cariño.

Comienzan por reconocer que el foco del TE en salud es entregar un cuidado centrado en el paciente, para que este se manifieste debe existir una visión compartida por todos los miembros, para traducirlo en acciones es preciso un objetivo común, compromiso y comunicación de todos los miembros del equipo y no por cada estamento profesional por separado, si se aspira al logro de los resultados del paciente. Cuando lo anterior no ocurre el trabajo del equipo se complejiza y el logro de los objetivos se dificulta. Un Médico lo reconoce como....." un grupo de personas con roles, con funciones distintas...y cada uno 
tiene un objetivo en común, el ayudar a un paciente”... la profesional de Nutrición agrega la importancia del compromiso... "Remamos todo para el mismo lado??.. depende del compromiso de la gente ... Me toca ver gente que no le interesa si el paciente volvió o no volvió, donde va, si come, si no come, entonces finalmente eso entorpece el trabajo " La TE reafirma su postura.. "Que seamos comprometidos y velar por un bien en común, que es ver al paciente, mantenerlo bien “... Compartir información debe ser parte del compromiso. La Nutricionista reconoce "...No tienen problema en responderme ninguna pregunta, no responden de mala forma porque saben que uno está preocupada del paciente"

Insisten que el cuidado centrado en el paciente debe ser el foco de su accionar y estar por sobre las diferencias personales, manifestadas por las relaciones entre los miembros, sin embargo, reconocen que las emociones negativas asociadas a algunas relaciones interpersonales pueden dificultar la concentración para alinearse en torno a este Objetivo Común al momento de cuidar al paciente y alcanzar los resultados esperados. Un Técnico en Enfermería lo explica." a las otras personas les cuesta entender que al fin y al cabo igual tienen que trabajar juntas ... itienen que hacerlo! iipor el paciente!! no por ellas....enfocarse en el paciente, no en las relaciones.... si se llevan bien o se llevan mal”.

Agregan que la Permanencia para compartir objetivos y claridad de función de todos los miembros en el equipo facilita el trabajo, pues permite reconocer con claridad expectativas de rol propio y el de sus compañeros logrando alcanzar más fácilmente los objetivos y fidelizando a las personas con la organización. Los kinesiólogos consideran que... “ incluye saber lo que está haciendo el otro.....Equipos que recién se están armando y que no tienen claro los objetivos del quehacer..... y no todos tienen claro sus roles...iiino funcionan!!!........ Una Enfermera agrega “ (el equipo) hacen que uno logre hacer cosas buenas y las personas valoran y se quedan... más allá del sueldo ..... eso lo fideliza en la unidad"

Los miembros del equipo reconocen la necesidad de compartir el espacio físico y horarios de turnos facilitando el poder establecer relaciones, comunicarse, compartir información, puntos de vista, etc. Necesario al momento de coordinarse y apoyarse, reconocen que esto sucede más frecuentemente entre profesionales no médicos, es así como enfermería aparece como un núcleo cercano de tarea, pues comparten frecuentemente y se organizan para realizar el cuidado del paciente, un profesional Kinesiólogo lo expresa así... "Yo no estoy en tantas 
reuniones .... Los equipos de enfermería y Técnicos es ijel núcleo más fuerte!!, se juntan mucho. Quizás el núcleo de médicos, kinesiólogos, no se junta tantas veces”.

Por último reconocen la importancia de aspectos normativos comunes entre los miembros de los equipos como son, comportamientos y valores compartidos para el TE, estos actuarían como facilitadores de las interacciones, relaciones, y respeto mutuo entre sus miembros... un profesional Médico indica .. "Depende mucho cómo te reciba tu entorno laboral...Hay ciertos códigos que uno tiene que ir eh manejando y son bastantes universales .... son normas ... casi de buena conducta y de respeto mutuo"

\section{Tema 2: Colaboración en Equipos interdisciplinares}

Este tema surge al indagar para comprender como se organizan los miembros dentro del equipo para realizar sus labores y cumplir con sus responsabilidades de manera conjunta. Indagar en el proceso dinámico que involucra el desarrollo de tareas entre sus miembros, buscando relevar factores o situaciones que facilitan el trabajar juntos en la búsqueda de un mejor desempeño. Los entrevistados muchas veces recuren a experiencias clínicas concretas para ejemplificar lo que sucede entre los miembros del equipo en la búsqueda de una atención segura, profundizando en las interacciones o prácticas relevantes.

Al igual que en el tema anterior lo primero que establecen es el foco común de su cuidado, el paciente, agregando aquí otro elemento importante, la horizontalidad profesional y apoyo con foco en los resultados, relevante si se busca trabajar juntos en pro del paciente. Para que esta horizontalidad se manifieste es preciso valorar equitativamente los aportes de cada profesional al logro de los objetivos, apareciendo aspectos generacionales como un factor positivo dentro del equipo, aportando distintos enfoques, habilidades y posturas frente a aspectos del trabajo. Una característica es el apoyo y ayuda mutua entre los miembros del equipo, en unidades más integradas, aparece especialmente en profesionales que permanecen en los servicios (no médicos) y que reconocen posiciones similares dentro de él en términos de poder para la toma de decisiones, los médicos por su parte aportan a través de visitas esporádicas a los servicios. Reconocen que lograr este apoyo, no es usual y la mayor barrera estaría representada por profesionales que no se movilizan más allá de su rol, independiente de las necesidades del paciente, una Enfermera del equipo expresa ..."Todos cumplen una labor y todas las labores son valiosas. ....tenemos distintas generaciones los baby bummer cierto (ríe) ....los milenium entonces eso enriquece más el trabajo y el clima laboral”. Un 
Técnico en Enfermería lo expresa así..."Los médicos pasan visita......los que más nos afiatamos día a día somos técnicos, enfermero, kinesiólogo, auxiliares de apoyo también, con ellos trabajamos a la par y el que necesita ayuda ise va ayudar!! un Kinesiólogo apoya sus palabas...” no solamente hago lo mío...... i i ¿Unidades bien integradas realmente funcionan!! ayudo a los demás y lo demás cuando yo estoy medio afligido ii ime ayudan a mi i; ...eso no creo que se dé en muchos servicios!!! Refieren además la importancia del apoyo mutuo entre profesionales, especialmente médico y enfermera, sin embargo, profesionales médicos pueden observar este apoyo de los miembros del equipo como ayuda para su labor y a ellos como facilitadores de su desempeño, por ejemplo una enfermera explica. "Los médicos acá tienen una posición ....... más bien transversal, .... eso facilita que cada uno tenga su rol y pueda hacerlo bien..i i; no es vertical!!!.... las enfermeras tienen mayor experiencia ..... y es como filtro de las indicaciones, un filtro real que es respetado, un Médico agrega “ "Tienes que apoyarte en tú enfermero, en tu kinesiólogo y muchas veces incluso en tú paramédico porque hay cosas que se te van, por qué pasan más tiempo con el paciente”

Una vía para lograr esta relación de apoyo para el trabajo es a través del Dialogo e interacciones que reconocen y consideran al otro, para eso se insta la participación de los miembros en la toma de decisiones, comunicándose y dialogando para trabajar coordinadamente, reconociendo labores destacadas en el cuidado del paciente, y también labores esenciales como son la higiene del paciente, todas importantes y necesarias para su bienestar. Estas interacciones incluyen escucha activa que valide la opinión y aporte de cada uno, aunque sea divergente, para finalmente hacer propios los resultados del equipo. El aprendizaje de los miembros dentro del equipo requiere humildad para aceptarlo, reconociendo que esta relación puede darse en un sentido inverso al de la estructura organizacional, por ejemplo, cuando un miembro experto del equipo entrega confianza y guía a un profesional más joven pero con mayor formación académica Una profesional Nutricionista lo explicita ..."Preguntan la opinión, la toman en cuenta ... ¿cambio? primero le preguntan a uno, ijasí que súper bien!! ... iүyo creo que es una cosa fundamental sentirse parte de algo!!!" El Médico secunda esta postura con más elementos...”Decisiones compartidas, escuchar al otro y la libertad de decir ... tomar decisiones compartidas...lo hemos trabajado y i¡lo hacemos!!....practicamos.... hacemos escenario de simulación .... crítico y corto, 5 minutos y después retroalimentación una hora.....y ii se empieza a amalgamar todo!!!” el Kinesiólogo insiste.. "iijes súper importante!!! no importa que me caiga bien, mal, que sea mi amiga , da lo mismo.. pero... si yo sé lo que hace el otro....lo voy 
a respetar...aunque sea que el caballero que saca la basura ... que todos sepan lo que nosotros hacemos y que es importante y que de repente me tienen que ayudar...lo principal de mi objetivo todos lo entienden y por eso todos me ayudan!! “ El Técnico en Enfermería reconoce la relación entre experiencia y confianza... "Nos complementamos hay tanto enfermero nuevo, a veces ellos dicen, "ooh me gusta trabajar con usted, porque usted me da confianza, porque lleva años, tiene experiencia" y esas cosas, yo creo que es como viceversa entre enfermera y nosotros”. Un Médico reconoce la humildad en relaciones de confianza "Cuando uno duda mucho o da pie atrás de tus indicaciones...jtú equipo deja de creer en ti!!! Si te equivocas sistemáticamente y no te das cuenta que te estás equivocando y i no pides ayuda!!! quien te va a tener confianza?.....!! confianza que tú te vas a hacer responsable de esa indicación después??”.

Los miembros enfatizan que para lograrlo es imprescindible sentirse parte del equipo, reconocido en su aporte sin necesidad de explicitarlo, ser valorado en su dimensión humana, sentirse seguro y libre para expresarse, logrando así sentir confianza y generándose un clima de respeto con sus compañeros de trabajo, sin embargo, el médico agrega que esta dimensión personal no parece relevante a la luz de las habilidades técnicas con que cuenta para ayudarlo. Palabras del Médico.. "Este clima de respeto y confianza se van dando independiente que haya distintos caracteres .... hay gente que te puede caer ijsúper mal!! pero si los respetas como profesional, lo que me interesa es que haga bien la pega y que técnicamente sea calificado para ayudarme". ... La enfermera dice "Cuando te valoran como persona y como profesional yo creo que eso es iisúper importante!!! uno no necesita estar demostrando lo que sabe..... porque la gente conoce el trabajo que uno hace y valora a la personas también" Un médico secunda." Cuando la gente se siente valorada, se siente querida, y se siente respetada.... se siente con la confianza necesaria como para poder trabajar juntos”.

Un tercer elemento que los entrevistados reconocen para potenciar la colaboración es Reconocer rol propio y ajeno para potenciar Sinergia entre los miembros, para lo cual es importante compartir tiempo trabajando en equipo para reconocer con claridad los roles individuales y lograr complementarlos para realizar la tarea requerida. Reconocer el rol propio permite potenciarlo y desarrollarlo siempre manteniéndolo alineado con los otros miembros del equipo. Barreras para trabajar surgen desde la ignorancia de la labor de los otros miembros y esperar que los demás realicen ciertas tareas relacionadas con el paciente y no involucrarse personalmente o asegurarse que serán realizadas. ...Un kinesiólogo refiere “ iiyo 
sé que trabajo en equipo!! se la función del técnico en enfermería y sé que mi función i¡no puede interferir con la suya!! ... ii iyo vivo ahí con ellos! se lo que hace el paramédico, lo que hace el médico, quien tiene la facultad profesional y todo eso" El Médico Agrega...." Claridad de rol, o sea la claridad y la expectativa de rol, porque por un lado la persona sabe exactamente lo que tiene que hacer pero el otro profesional también sabe que esperar de esa persona.. absolutamente, ijsi!" ... Otro Médico ...” hay personas que no tienen claro los roles y piensan que el otro tiene que hacerlo Teniendo claro los roles, los objetivos, la disposición para trabajar y reconocer a los otros en la importancia de su rol ..........el sentir que uno está teniendo un rol que es importante para el objetivo ... que uno tenga claro cual es el rol, valorar ese rol y potenciarlo y darle la importancia que corresponde “

La sinergia entre los miembros del equipo, como resultado superior a la suma de los aportes individuales se explicita en su máxima expresión en situaciones de urgencia vital para el paciente, la mayoría de los profesionales están de acuerdo que.. "Cada uno se ajusta a su rol.....en una entubación de urgencia las enfermeras van al carro de paro, una la vía aérea, las drogas, el médico la entubación y el kinesiólogo el ventilador mecánico, la TENS la ventilación, el auxiliar trae los medicamentos que le piden, y están todos ordenaditos para que resulte, cada uno sabe su rol y su complemento y cada uno fundamental en lo suyo.... como en la guerra i i iayudémonos!!! y itodos por un bien común!!

\section{Tema 3: Relaciones interpersonales, comunicación e interacción social}

Este tema incorpora la organización de personas que trabajan con personas y donde las interacciones y relaciones ente ellos aparecen como imprescindibles para el desarrollo de la tarea y el alcance de los resultados del paciente. Es interesante observar como los profesionales clarifican la presencia de una interface entre relaciones personales y laborales, siendo el cuidado centrado en el paciente lo que permite que ambas se integren para lograr un trabajo participativo. Hay momentos donde es posible observar una tensión entre los dos niveles de relación y en esos casos la mejor solución es centrar el foco en lo que los convoca, el cuidado del paciente.

Se declara la importancia de contar con instancias en el trabajo que potencien una Interacción cordial y comunicación personal facilitan relaciones laborales entre los miembros de los equipos, esto permite compartir información, experiencias y puntos de vista en un contexto de respeto mutuo. Circunstancias que faciliten esta comunicación afable aportan al desarrollo de la tarea, como son la empatía y expresión de emociones positivas, 
sucediendo especialmente entre profesionales no médicos. Nutrición lo ve así.. "Ayuda la comunicación, la empatía, que en general... en pediatría i la mayoría anda alegre!!!... iisúper buenas experiencias!!! donde yo he trabajado eeh, tengo ijsúper buena comunicación con las enfermeras!!! i!incluso con algunos médicos!!! los auxiliares.... hay una relación personal con muchos, entonces el trabajo se hace mucho más fácil”.

Otra profesional Nutricionista lo refiere así..."El equipo.... son súper comunicativos....entonces se puede lograr un trabajo como ijsúper en equipo!!...porque preguntan, ayudan, avisan, todo y saben también donde recurrir o preguntar, a quien dirigirse ; a la persona adecuada!” ...Un Kinesiólogo agrega la importancia de contar con interacciones positivas para lograr los mejores resultados...." Si hay una persona, que puede ser una manzana podrida que este interfiriendo ...ver si uno puede cambiarla a un equipo en donde ella se sienta mas cómoda, porque a lo mejor el grupo funciona mal porque uno solo es el que está generando problemas".

Es interesante notar en el primer testimonio la necesidad de contar con equipos comunicativos porque su falta puede llevar a fragmentación, en donde sólo encontrando a la persona adecuada permitiría acceder a ella. En el segundo testimonio, reconocen que la manera de manejar el conflictos entre los miembros al interior del equipo es cambiando a la persona que consideran fuente de él a otro equipo, sin enfrentar el problema de comunicación de base.

Un elemento que es preciso develar en mayor profundidad, por la frecuencia de aparición en los relatos, es la percepción de dos niveles de relaciones interpersonales entre los miembros de los equipos. Reconociendo que no es posible escoger las personas con quienes trabajas, es necesario establecer buena comunicación y lazos de confianza a través de la libertad y tranquilidad de poder expresarte y de esta manera alcanzar los resultados esperados para el paciente. Las interacciones estrictamente profesionales entre los miembros del equipo, diferentes de las relaciones sociales que nacen entre personas individuales en contextos laborales asociada a afinidad personal y que son diferentes a su vez, de relaciones de parentesco o amistad. Aunque distintas en su espectro y profundidad ambas son reconocidas como importantes en contextos laborales, aún más se considera que la presencia de una relación social entre sus miembros facilita las interacciones laborales y ambas potencian la creación de un Clima de confianza facilita la participación y Seguridad. Un médico indica.." (En las relaciones interpersonales) yo creo que hay harto tema personal, lo que uno 
trae, experiencias positivas y negativas ... y ponerlo en práctica en la realidad, es como... insisto..... ensayo y error.. viendo que funciona y que no!!” Nutrición agrega..... "Se hace mucho mas fácil cuando tienes una relación interpersonal mas que solamente laboral.. iihay más confianza para preguntar!!!, a la enfermera, o incluso al médico para estar más preparada" ....El Técnico en enfermería acota..."Nosotros a veces hacemos cosas como turno (sociales) y ayuda a crear otros lazos, a conocernos mas, o reuniones ......nos decimos “no me gusta esto de usted, me gustaría que lo cambiara”, ...Sentirse con la libertad, decir o comunicar, y la otra persona dar su punto de vista, a lo mejor podrían haber mejor relaciones".

Esta confianza se manifiesta también en relaciones interpersonales en el equipo en la búsqueda de entregar un cuidado seguro, a través del intercambio de información, compartir el desarrollo de la tarea y responsabilizarse por los resultados. Tranquilidad para compartir los resultados positivos y errores manteniendo el foco en las necesidades del paciente. Una profesional Nutricionista lo expresa..El personal de enfermería, auxiliares, a nosotros nos invitan y se hace una reunión para conocer las cosas nuevas por ejemplo.... un paciente con sonda, pacientes de alta...... iiiPara que todos manejemos la misma información!!! Un médico agrega su experiencia........En una UCI iijes imposible que sepas qué pasa a cada momento con cada paciente!!! ..... por eso tienes tú equipo i i iconfiar cien por ciento en lo que está haciendo tú gente!! Y muchas veces es en tomar decisiones en el momento con la información que ellos te dan. Un segundo Médico Agrega .. "Cuando uno duda mucho o da pie atrás de tus indicaciones...jtú equipo deja de creer en ti!!! Si te equivocas sistemáticamente y no te das cuenta que te estás equivocando y ijno pides ayuda!!! quien te va a tener confianza?.....!! confianza que tú te vas a hacer responsable de esa indicación después?? Interesante en los relatos, es la posibilidad de inferir que la comunicación no siempre es compartida entre todos los miembros, además los médicos enfatizan en la confianza que tienen en los miembros de su equipo al momento de tomar decisiones y la importancia de reconocer sus propias inquietudes y errores sistemáticos como si esto representara una conducta excepcional en su relación con el equipo.

Por último hay entrevistados que explicitan que el flujo de datos dentro del equipo se asocia al profesional de Enfermería como centro de recepción y divulgación de la información y las interacciones entre los miembros, en la mayoría de los casos participando en la Mediación de la información. Enfermería facilita la articulación de la información entre los Médicos y el 
resto de los profesionales de salud, rol de influencia en las redes de interacciones entre los diferentes miembros del equipo es reconocido, una Nutricionista lo explica.. "El personal de enfermería, auxiliares, a nosotros nos invitan y se hace una reunión para conocer las cosas nuevas por ejemplo.... un paciente con sonda, pacientes de alta..... iijPara que todos manejemos la misma información!!! Otra colega Nutricionista agrega “Varias veces querer hablar con...el (médico) .. yo lo llamo por teléfono...porque las enfermeras manejan todos los números de ahí, entonces cuando es algo de nutrición les pido el teléfono....porque ellas tienen esa facilidades de tener todos los números de los médicos y ellas llaman...."

\section{Tema 4: Innovación en el trabajo en equipo}

Este tema aparece como respuesta de los profesionales a los cambios y avances desarrollados en el cuidado de la salud en las últimas décadas, las investigaciones, tecnologías de la información, participación de diferentes generaciones que aportan desde su cultura. El reconocimiento y la búsqueda de las contribuciones de cada miembro a la solución de problemas a través de la innovación para entregar el mejor cuidado al paciente. La otra mirada de este tema y que aparece antagonizándolo es la resistencia al cambio, manifestado sobre todo por profesionales con mayor experiencia en el trabajo y que se sienten confortables con el statu quo.

Lo primero que facilita la innovación es potenciar las Oportunidades, Incluir, crear y apoyar para mejorar a todos los miembros que promueven nuevas miradas y formas de hacer las cosas, la generación de un clima de seguridad para expresarse y escucharlos, permitiendo la participación de todos en el desarrollo de respuestas originales para solucionar problemas, apoyar su implementación y seguimiento, potenciando así su compromiso pues aumenta la responsabilidad con los resultados, una Enfermera relata ... "Actualmente la gente está concentrada en las oportunidades que uno les da.. escucharlos es valioso para ellos.... a veces hay personas muy nuevas ... que tienen muy buenas ideas y trabajan en darle forma a ese proyecto".. otra profesional de enfermería lo fundamenta..."en la práctica clínica ijson ellos!!! (el equipo) de ahí tiene que nacer la solución del problema ...si las infecciones aumentaron ..... de ahi mismo surgen con las respuestas y hay que escucharlos

porque es más fácil que puedan adherir" Un médico agrega ......"iiihemos hecho innovación!!. van surgiendo ideas, tratamos de implementarla.... se da el ambiente ..... si uno tiene una idea y quiere compartirla el resto la acoge, y si todos están de acuerdo ......se trata de poner en practica". 
A pesar del apoyo y oportunidades para desarrollar mejoras, muchas veces la necesidad de incurrir en esfuerzos adicionales para aprender algo nuevo, prepararse para realizar sus actividades de manera diferente u observar con nuevos ojos la misma realidad, es más de lo que los miembros están dispuestos a invertir para lograrlo. Pudiendo generar rechazo y tensión entre la intención de Reformular y la Resistencia al cambio, lo que puede dividir al equipo y frenar el desarrollo y la búsqueda de mejores resultados para el paciente, sin embargo, llama la atención la dicotomía expresada en términos de los sentimientos negativos que puede generar la resistencia al cambio y en la misma frase reconocer que es preciso convencer al equipo del mérito de la innovación. un Médico lo ejemplifica...";ah mira...... hizo esto! yi ifuncionó!! ah que interesante.......... en un principio puede ser iijaberrante!!.. después no se vuelve tan rara”... Otro Médico agrega “ hacíamos esto siempre así! iijes de las cosas que más me perturban! iy me enoja! es que nunca hemos hecho esto acá iijesa no es una respuesta razonable!!! hay alguna razón por la que no lo hagan? " Enfermería también aporta...” si dicen ißno es que hace veinticinco años que lo hacemos así!! !! Uno dice, mira ahora están estas ideas, si lo hacemos así puede que resulte, uno tiene que i; tener la capacidad de hacer que te crean!!!

La desigualdad en edad, formación y experiencia de los miembros de equipos interdisciplinarios, puede hacer que algunos se presenten reservados y cautos frente a las diferencias generacionales y otros aceptar el Aporte de las nuevas Generaciones, las cuales han crecido y se han educado en un contexto de cambios y adaptación constante en todos los ámbitos, obligándolos a desarrollar habilidades y talentos los que, en el área de la salud pueden ponerse al servicio del cuidado del paciente. Es importe el énfasis en reconocer estas diferencias generacionales si se quiere mantener la motivación e interés de los miembros del equipo. Una Enfermera refiere que "hay mucha gente joven ..... con ganas de querer hacer cosas..... como es de un hospital clínico hay muchas eh personas que tienen ijmuchas ganas de aprender y de hacer cosas!! por lo tanto el interés que tiene permite también que no sé frustren" .. un Médico reconoce que "Si con un paciente ..... pasaste tres o cuatro ideas y iino te funciona ninguna!!! y somos tres personas tienes que preguntarles a los otros ¿que les parece? ¿hacemos algo más? viste algo más? se les ocurre algo?, sugerencias? ¡me gusta lo que dice! ipongámosle!! Es interesante en este último relato como es preciso ensayar y errar cuatro veces al entregar cuidado al paciente antes de solicitar apoyo del resto del equipo con el riesgo que puede significar para su salud. 


\section{Tema 5: Liderazgo en el equipo}

En respuesta a la pregunta sobre su percepción del liderazgo en su equipo de trabajo surgen dos aspectos relevantes que permiten aumentar y complementar los temas anteriores. Las expectativas de los miembros en relación al líder del equipo incluye aspectos relativos a la tarea como son la comunicación, que muestra la visión de la meta al equipo de una manera que hace sentido y motiva a trabajar para alcanzarla, en donde la participación individual y el reconocimiento de sus aportes es importante para el logro colectivo y eso lo trasmite el líder. Además el líder del equipo debe ser capaz de reconocer la dimensión personal en los miembros considerando su bienestar a través de una comunicación que considera aspectos importantes de la vida de las personas más allá del trabajo como su familia por ejemplo y que ayuda a generar un clima acogedor.

Lo primero que esperan de un líder es Comunicación motivadora que reconoce al otro, manifestada como una capacidad de motivar compartiendo una visión de futuro que entrega sentido al trabajo, pero además reconociendo el valor de la participación de cada miembro para alcanzarlo. Llama la atención que la mayoría de las respuestas en esta categoría son entregados por médicos en donde se aprecia su propio reconocimiento como líder del equipo, dentro del cual su responsabilidad estaría en impedir que los miembros se desmotiven, potenciando el valor de la retroalimentación positiva, en este aspecto incluyen al resto de los miembros. Un Médico lo explica... "Es la capacidad de motivar..... que la gente se sienta motivada, acogida y el líder logra transmitir eeh... la importancia del objetivo, y la importancia del rol de cada uno para lograrlo ........ yo lo veo como esa capacidad de poder hacer sentir que el otro es valioso para el trabajo que estamos haciendo". Un segundo Médico aporta... "Sentirse valorado y va mucho la mano del reconocimiento del líder, eso es muy importante. Hay gente que no se siente valorada y ahí está el problema, se desmotiva y no se sienten valorados .....cuando la gente no tiene refuerzos positivos de saber que lo que está haciendo es importante, la gente se desmotiva”"

Un tercer médico lo explicita "Estamos buscando dar felicitaciones, ...... para las dos cosas .....porque tampoco puede quedar en todo positivo, iiiiinos equivocamos a cada rato!!!! importante que el error i itampoco sea punitivo!!! que la gente no tenga miedo a reportar los errores, .....que sea una cosa para mejorar ....pero cuando hay cuestiones positivas, cosas que son útiles y reales reconocerlas .......la gente lo valora harto .... Reconocimiento del equipo, sus pares y las jefaturas, es importante para ellos “. 
Hay dos testimonios que observan este líder desde una postura menos conciliadora más vertical en que le exigen reconocer el aporte de los miembros al logro de los objetivos. Una Nutricionista lo expresa "las personas que tienen (posiciones) jefaturas ... i ino se sientan con el poder!! todos hacen (cosas) ...... (ellos) deben transmitir que todo están avanzando para algo.... todos vamos para el mismo lado “ Un Médico reconoce que esta postura no da los resultados esperados “.... tomar una postura dictatorial!! Oh .......iijincluir al resto de la gente!!!!, funciona más i icuando uno incluye!!”.

Un líder debe velar y Considerar el bienestar individual y colectivo de los miembros del equipo, para lograrlo, debe ir más allá de lo laboral e interesarse en la dimensión más personal, aspectos de sus vidas relevante para ellos, sus historias, sus seres queridos, saber que le entrega sentido a su vida, en resumen interesarse en el otro. Un médico lo explica .. "Cosas simples como saludar en la mañana ; así basta! ehm tratar de aprenderse el nombre de las personas eh y pedir ayuda cuando es necesario y con eso por lo general está bien siempre en todas las unidades “ una Enfermera agrega “... se van formando vínculos a través de la hora de café cierto y más bien personal...........también las emergencias hacen que la gente pueda generar lazos de compañerismo” una Nutricionista aporta “.....yo lo que siempre he hecho es saludar, preguntarle a las auxiliares sobretodo .....cómo están? su familia? sus hijos? tratar de interiorizarme más en su vida, i ii isaber si están bien!! .......ii de su vida!!!, en el fondo saber si están mal por algo...Una segunda Nutricionista agrega “ Cuando uno identifica las personas con las que trabajo y me voy a percatar de que algunas necesitan apoyo.." Un Kinesiólogo reconoce.." hay personas que no son tan fáciles, algunas son mas introvertidas extrovertidas" Vale la pena observar el énfasis de los profesionales en indagar en aspectos del bienestar especialmente en miembros en posiciones jerárquicamente inferiores y en la necesidad de identificar personalmente a todos los miembros del equipo, independientemente de sus personalidades o facilidad para relacionarse con ellos, como si esto fueran conductas excepcionales.

\section{Tema 6: Liderazgo informal y Compartido}

El último tema surge de la inquietud de los entrevistados por explicitar su percepción de un liderazgo que se escapa a la estructura establecida desde la organización, uno que puede ser ostentado por cualquier miembro del equipo, o puede cambiar de un miembro a otro, que se relaciona más con las preferencias de los miembros del equipo y como son ellos quienes 
enaltecen a uno de sus miembros a esta posición. Reconocen el liderazgo como un fenómeno dinámico, que puede cambiar de acuerdo a las necesidades del momento o los diferentes requerimientos del paciente, asociado a las competencias necesarias para realizar su cuidado y donde cada uno donde sea capaz de asumir un papel más activo para el logro de las metas. Agregan que muchas veces el supervisor elegido desde la organización no cuenta con las competencias necesarias para desarrollar el liderazgo requerido por esta.

El liderazgo observado por los miembros muchas veces se manifiesta como Situacional y Compartido por los miembros, declaran que hay situaciones en que las habilidades, competencias y talentos de algunos de los miembros del equipo aparecen como relevantes para solucionar una situación referida al cuidado del paciente o problemas del equipo y es ahí donde los otros miembros deberían dar un paso al costado y permitir la guía experta de la persona más preparada. Un médico reconoce .." El líder no puede ser una sola persona, en los equipos todos deberíamos tener capacidad de liderazgo, ... o sea eso va a ser demasiado pasivo y no va a resultar ......... probablemente van haber personas que adquieren mayor visión” Un segundo Médico agrega.. “se le atribuye mucho rol de líder al médico siendo que probablemente no tenga rol de liderazgo en un equipo ¡ihay un profesional que está a cargo!! pero esa capacidad .......todos deberían ser líderes además en su quehacer “

Rescatan que un líder necesita ciertas habilidades y características más allá de su categoría profesional y de si es reconocido por la organización para coordinar el trabajo. Establecen la presencia de un segundo líder, capaz de conectar con las personas, manifestándose como un Facilitador del dialogo y comunicación entre los miembros del equipo, un mediador del flujo de información relevante para el cuidado del paciente, potenciando la comunicación y relaciones interpersonales entre los miembros del equipo a través de un dialogo cordial y respetuoso. Un kinesiólogo indica. "Tiene un líder establecido que manda... eeh que hace la coordinación y probablemente hayan lideres más informales que van bajando la presión ....van liberando ...van lubricando este sistema para que...sea más amigable en el día a día" , un segundo Kinesiólogo agrega..” Tiene que haber un lider......no importa que sea ni joven, ni vieja, ni muchos estudios, tiene que ser una persona que sea conciliadora y que sepa comunicarse con la gente.. que tenga llegada ...... lideres informales ... tienen un valor agregado que quizás la jefatura debería darle ...un poco más de atribuciones dentro del esquema laboral..." 
Aparecen testimonios que consideran al líder como alguien con aptitudes, habilidades y rasgos de personalidad que facilita su liderazgo en el equipo, reconocen a enfermería como poseedora de este rol, que aunque no está formalizado desde la organización, el profesional lo desarrolla en el trabajo con los demás miembros del equipo en la cotidianidad. Es interesante como este rol se facilita por la seguridad y confianza con que enfermería se relaciona con el líder formal. El liderazgo y sus competencias se consideran también como habilidades que pueden ser aprendidas y desarrolladas por todos los miembros del equipo, dando lugar a la categoría Innato versus aprendido, dentro de los relatos Nutricionista lo expresa.. ........ “hay lideres innatos.. jsi!!, se nota en personalidades... algunas enfermeras, tienen más facilidad para delegar funciones, tienen un aspecto de líder, pero no son líderes... formales....son más bien informales, se les nota en la personalidad al momento de hablar con ellos.... saben todo lo que pasa, no tienen problema en hablar fuerte, en acercarse a un médico.... mucha otra gente tiene como pánico al hablarle a un médico, pero (ellas) no tienen problemas" y donde un médico describe así el proceso para desarrollarlo "Hay actitudes y capacidades, como herramientas comunicacionales, de manejo de persona, recursos humanos que yo creo se puede adquirir... tal vez talleres, escenarios, role playing....yo creo que uno puede adquirir, aprender y potenciar”.

En la misma línea de la categoría anterior una dicotomía se manifiesta dentro del equipo entre el líder Elegido versus Impuesto por la organización. Si algunos profesionales creen que el liderazgo es innato, eso significa que no debería ser impuesto desde la organización sin considerar a personas con ciertas características intrínsecas y potenciarlas para asignarles este rol dentro de los equipos. Por otro lado si considera que es posible desarrollar habilidades y competencias de liderazgo a través del aprendizaje, la organización al asignar el rol debería asegurare que el profesional cuenta con la formación necesaria para desarrollarlo en sus equipos de la mejor manera posible. Es interesante como el testimonio del líder formal apunta a competencias y experiencia que permiten hacerse cargo de situaciones en el trabajo, sin embargo, el líder informal (de acuerdo a testimonios anteriores) enfatiza en la presencia y accesibilidad, facilitando el establecimiento de relaciones interpersonales a través de las relaciones habituales dentro del trabajo. El Médico, considerado líder formal lo explicita.. "Es la persona que tiene más experiencias, más capacitadas, y hace evidente el liderazgo y se hace notar, i ino es impuesta!!! ... ...por un papel que sea asignada, pero en las situaciones mismas se desenvuelven como líderes y sus pares las reconocen como tal, en el fondo como lider"... Enfermería indaga en sus características.." uno le pregunta porque lo reconocen 
como líder??..... quizás más asequible, más terrenal, está más a mano, porque...... uno come con las enfermeras, se ríe, comparte con ellas..... nos juntamos, o con los paramédicos, la misma cosa y muchas veces también eso hace que sea más cercano ..... están más a la mano, por una cosa por edad, por tradición.. “

\subsection{Resultados Integrados}

\begin{tabular}{|c|c|}
\hline Resultados Cuantitativos & $\begin{array}{l}\text { Resultados Cualitativos de las entrevistas para } \\
\text { seguimiento a miembros de EI intencionados y que } \\
\text { complementan los resultados cuantitativos }\end{array}$ \\
\hline $\begin{array}{l}\text { 1. Composición de los equipos } \\
\text { interdisciplinarios (EI)según sus miembros: } \\
50 \% \text { incluía E, M y TP. } \\
\text { 33\% incluían MT/ K , E y M. } \\
\text { 33\% de ellos consideraba sólo E y TP. }\end{array}$ & $\begin{array}{l}\text { Enfermería incluyendo profesionales y Técnicos es } \\
\text { considerado un Núcleo cercano de tarea, pues } \\
\text { trabajan coordinadamente y permanecen los mismos } \\
\text { horarios al cuidado del paciente. } \\
\text { Kinesiólogos y Nutricionistas se consideran como } \\
\text { equipos monoprofesionales, aunque en posición de } \\
\text { elegir entre los profesionales de salud consideran a } \\
\text { enfermería como parte de su EI. }\end{array}$ \\
\hline $\begin{array}{l}\text { A mayor Satisfacción con el Equipo, mejor } \\
\text { Clima de Equipo percibido por sus } \\
\text { miembros }\end{array}$ & $\begin{array}{l}\text { Facilita la Satisfacción de Los miembros con el } \\
\text { clima del EI: } \\
\text { 1.-Si se consideran ciertas características y atributos } \\
\text { necesarios para trabajar en equipo. } \\
\text { 2.-Colaboración entre los miembros de Equipos } \\
\text { interdisciplinares } \\
\text { 3.-Relaciones interpersonales, comunicación e } \\
\text { interacción social entre todos sus miembros. } \\
\text { 4.-Potenciar la Innovación en el trabajo del equipo }\end{array}$ \\
\hline $\begin{array}{l}\text { A mayor Satisfacción con el equipo, mejor } \\
\text { percepción de una visión compartida } \\
\text { percibida por sus miembros. }\end{array}$ & $\begin{array}{l}\text { Facilita la Satisfacción de Los miembros: } \\
\text { 1.-Contar con objetivos compartidos entre todos los } \\
\text { miembros del equipo. } \\
\text { 2.-Compromiso con el quehacer para entregar un } \\
\text { Cuidado Centrado en el Paciente. } \\
\text { 3.-Permanencia en el tiempo. } \\
\text { 4.-Posibilidad de reunirse y compartir. } \\
\text { 5.-Contar con valores compartidos. } \\
\text { Limita la Satisfacción: } \\
\text { 1.-Recambio de miembros sin contar con tiempo } \\
\text { necesario para conocerse y compartir. } \\
\text { 2.-Falta de compromiso de los miembros. } \\
\text { 3.-No tener claridad de los roles y responsabilidades } \\
\text { individuales. } \\
\text { 4.-No contar con instancias para reunirse como EI } \\
\text { Presencia de subgrupos que fragmentan el EI }\end{array}$ \\
\hline
\end{tabular}


A mayor Satisfacción con el equipo, mejor percepción de Seguridad Participativa percibida por sus miembros.

A mayor Satisfacción con el equipo, mejor percepción de Orientación a la Tarea percibida por sus miembro.
Facilita la Satisfacción de Los miembros:

1.-Interacción cordial y comunicación personal para compartir información, experiencias y puntos de vista en un contexto de respeto mutuo que facilita relaciones laborales.

2.-Clima de confianza que entregue libertad y tranquilidad para compartir los resultados positivos y errores facilitando las interacciones de trabajo.

3.-Dialogo e interacciones que reconocen y respetan al otro .

4.-Escucha activa que valide la opinión y aporte de cada uno.

\section{Limita la Satisfacción:}

1.-Falta de comunicación ente los miembros

2.-Necesidad de profesionales mediadores de la información ente los miembros de los EI.

3.-Conflictos entre las personas al interior del equipo.

4.-No sentirse parte del equipo, ni reconocido en su aporte

\section{Facilita la Satisfacción de Los miembros:}

1.-Horizontalidad profesional que permite la valoración equitativa de los aportes de los miembros. 2.-Valorizacion del aporte de las diferentes generaciones.

3.-Apoyo con foco en los resultados de un cuidado centrado en el paciente.

4.-Reconocer el rol propio y responsabilidades personales y también de los otros miembros del equipo, para potenciar la sinergia.

5.-Presencia más permanente de los miembros del equipo para interactuar y compartir información. 6.-Participación en la toma de decisiones, comunicándose y dialogando para trabajar coordinadamente.

\section{Limita la Satisfacción:}

1.-Presencia de EI fragmentados por la presencia de subgrupos de disciplinas especialmente no medicas. 2.-Profesionales de equipos centrados en objetivos de su labor especifica, sin apoyar al resto en la búsqueda de resultados de pacientes.

3.-Profesionales médicos están cerca del paciente de manera espóradica, los demas profesionales no médicos están más cerca del paciente temporalmente. 
A mayor Satisfacción con el equipo, mejor percepción de Apoyo a la Innovación percibido por sus miembros.

La mayoría (75\%) de los miembros de Equipos Interdisciplinarios perciben a Enfermería como el Líder Transformacional en el equipo.

A mayor Satisfacción con el Equipo, mayor percepción de comportamientos de Liderazgo Transformacional percibido por sus miembros.
Facilita la Satisfacción de Los miembros:

1.-Contar con oportunidades, incluir, crear y apoyar para mejorar los procesos de atención al paciente.

2.-Participar de un clima de seguridad para expresarse y ser escuchado.

3.-Participar activamente de la solución de problemas, implementación y seguimiento.

4.-Oportunidades para aportar desde las diferentes habilidades asociadas a las distintas generaciones.

Limita la Satisfacción:

1.-No participar en la resolución de problemas limitando la identificación y compromiso.

2.-Percepción de falta de interés y compromiso de los otros miembros para salir de su zona de confort y aprender cosas nuevas.

3.-Observar que hay ensayo y error sin buscar participación de los otros miembros para entregar soluciones.

\section{La Enfermera es reconocido con el líder informal} de los EI por:

1.-Considerar el bienestar individual y colectivo de los miembros del equipo.

2.-Conoce y reconoce a los miembros del equipo en sus talentos y habilidades.

3.-Se interesa por la dimensión personal de los miembros del EI.

4.-Genera lazos de confianza con los miembros a través de instancias formales e informales.

Facilita la Satisfacción del los miembros de EI, un Líder que:

1.-Utiliza comunicación que motiva y reconoce al otro.

2.-Considera el bienestar individual y colectivo.

3.-Permite que dependiendo de la situación que el rol de líder pueda ser asumido por los miembros del equipo.

4.-Facilitador del dialogo y la comunicación

5.-Elegido por su preparación y características intrínsecas para liderar y no impuesto.

\section{Limita la Satisfacción:}

1.-Pocisión vertical del líder por sobre los miembros.

2.-Lider impuesto por la organización.

3.-Lider sin competencias y habilidades para liderar. 
A mayor Satisfacción con el Equipo, mayor percepción de comportamientos de Influencia Idealizada del LT percibido por sus miembros.

A mayor Satisfacción con el Equipo, mayor percepción de comportamientos de Motivación Inspiradora del LT percibido por sus miembros.

A mayor Satisfacción con el Equipo, mayor percepción de comportamientos de Estimulación Intelectual del LT percibido por sus miembros.

A mayor Satisfacción con el Equipo, mayor percepción de comportamientos de Consideración Individualizada del LT percibido por sus miembros.
Facilita la Satisfacción de Los miembros:

1.-Demuestra interés en conocer a los miembros del equipo en sus diferentes dimensiones.

2.-Comparte para potenciar la motivación con los objetivos y la visión de los resultados del trabajo del EI.

3.-Se comunica personalmente con los miembros de equipo.

\section{Limita la Satisfacción:}

1.-Pocisión vertical del líder por sobre los miembros.

2.-Hablar del trabajo sólo cuando se comenten errores.

Facilita la Satisfacción de Los miembros:

1.-Capacidad del líder de motivar compartiendo una visión de futuro que entrega sentido al trabajo

2.-Reconoce el valor de la participación de cada miembro para alcanzarlo.

3.-Retroalimenta positivamente a los miembros del EI.

4.-Posee y utiliza las habilidades y competencias que la posición en el equipo amerita.

\section{Limita la Satisfacción:}

1.-Postura dictatorial del líder por sobre los miembros.

\section{Facilita la Satisfacción de Los miembros:}

1.-Permite que los miembros del equipo asuman un papel activo liderando en situaciones en que estén mejor equipados para hacerlo.

2.-Reconoce y valora la experticia y experiencia de los miembros del equipo.

Limita la Satisfacción:

1.-Postura de superioridad intelectual que no reconoce las competencias en los otros miembros.

Facilita la Satisfacción de Los miembros:

1.-Reconoce la dimensión personal en los miembros 2.-Considera su bienestar a través de comunicación personalizada.

3.-Es capaz de generar un clima acogedor para los miembros del equipo

4.-Reconoce y potencia las cualidades individuales de los miembros del equipo.

\section{Limita la Satisfacción:}

1.-Postura de superioridad que no reconoce a los miembros de su equipo de trabajo

2.-Falta de interés en la dimensión personal de los miembros del equipo. 
A mayor Satisfacción con el Equipo, mayo Cohesión y Centralidad compartida entre sus miembros en la red de relaciones formales e informales.
Facilita la Satisfacción de Los miembros:

1.-Contar con un núcleo cercano y de tarea

2.-Horizontalidad profesional

3.-Diálogos entre los miembros

4.-Interacciones cordiales y comunicación entre los miembros.

Limita la Satisfacción:

1.-Mediación de la información solamente por algunos miembros

2.-Presencia de subgrupos de las diferentes disciplinas. 


\section{DISCUSIÓN}

La pregunta que guío este estudio fue: ¿Cómo los intercambios sociales entre los miembros de equipos interdisciplinarios y con su líder, influencian la satisfacción en el equipo, en contextos hospitalarios?.

Las Organizaciones de Salud, especialmente los hospitales presentan un gran dinamismo en sus procesos, cada día alrededor del mundo se está innovando o creando maneras de optimizar estos procesos con miras a entregar el mejor resultado de salud a los usuarios. Para enfrentarse a esta realidad compleja es necesario potenciar los aportes individuales de manera de entregar un valor agregado al servicio ofrecido al paciente y para lograrlo es necesario un compromiso implícito de los profesionales a cargo de su cuidado. La presente investigación surge de la necesidad de contar con información actualizada y local de las relaciones de trabajo de los profesionales que conforman las unidades más pequeñas y cercanas al paciente, como son los equipos de trabajo multiprofesionales. Al abordar un fenómeno social complejo como este, es necesario buscar una comprensión profunda de las interacciones entre los involucrados, indagando en variables de reconocida impacto en resultados de paciente y miembros de equipos. Se presentan y discuten los resultados en la misma secuencia que fueron recolectados para terminar integrándolos con miras a comprender en profundidad las dinámicas de los equipos multiprofesionales en el contexto local.

Se comenzó por identificar los Equipos de Trabajo multiprofesionales, basado en criterios internacionales de pertenencia temporal y responsabilidades compartidas. Cerca del $50 \%$ de los profesionales de los servicios hospitalarios de cuidado directo al paciente refiere que si para trabajar es preciso compartir y comunicarse con miembros de otras disciplinas para convenir el cuidado del paciente, entonces ellos no trabajan en equipo, lo cual es concordante con realidades internacionales que hablan de una falta de comunicación en los equipos, lo que podría disminuir la calidad de $\operatorname{los}$ procesos ${ }^{68}$ aumentando la variabilidad en los resultados, ${ }^{69,71}$ con limitada interacción para alcanzar acuerdos ${ }^{125}$ y transformándose finalmente en un elemento que interfiere negativamente en los procesos al interior de la organización. ${ }^{72}$

Esto se aprecia especialmente en profesionales no médicos, que refieren pertenecer a equipos, pero de su propia disciplina (unidisciplinarios) y donde cada uno tiene una labor definida y cumple solo con los objetivos asociados a su rol para el cuidado del paciente. ${ }^{33,49,50}$ La 
literatura internacional reconoce en este tipo de equipos mejores relaciones interpersonales, de afecto, mayor compromiso y empatía al momento de apoyar al otro. ${ }^{59}$

Finalmente fue posible identificar 53 equipos multiprofesionales pertenecientes a diferentes servicios del hospital, especialmente de alta complejidad, en los cuales se facilita la permanencia diaria de diferentes disciplinas cerca del paciente por las necesidades más compleja que estos presentan, también se rescata información de equipos de especialidad, quienes están a cargo de problemas de salud específicos del paciente, estos equipos son conocidos como, de consulta de especialidad. ${ }^{56}$

Se comienza por identificar la satisfacción con el equipo de trabajo a través de un instrumento específico que indaga sobre la relación con sus compañeros de trabajo. ${ }^{76}$ Los resultados presentan puntajes extremos (alta y baja satisfacción), pero la mayoría tiende a una percepción positiva, investigaciones lo asocian con una mejor comunicación ${ }^{31}$ más soporte de los jefes y compañeros de trabajo, ${ }^{34}$ mayor colaboración con el médico. ${ }^{35}$ Esta satisfacción con el equipo, entrega confianza en el logro de los objetivos ${ }^{68}$, se sienten reconocidos en sus aportes y participan de la toma de decisiones ${ }^{71}$, aumentando su sensación de bienestar y deseos de seguir trabajando con sus compañeros. ${ }^{73}$

Para intentar explicar esta satisfacción desde áreas más especificas relacionadas con las interacciones entre los miembros del equipo, se procede a indagar en el clima del equipo, sus diferentes dimensiones y asociación positiva con la satisfacción con el equipo, en el contexto local. La literatura internacional asocia fuertemente el clima con la satisfacción del paciente y el bienestar personal del equipo de salud ${ }^{88-90}$ y negativamente con burn out. ${ }^{91}$ Esto puede verse reflejado en el desarrollo de relaciones de amistad en el trabajo ${ }^{34}$, mayor apoyo del superior jerárquico, calidez, autonomía y percepción de recompensas por su trabajo. ${ }^{32}$ Equipos más efectivos se generan al compartir una visión y motivación, confianza y respeto entre sus miembros. ${ }^{33}$ La primera dimensión del clima estaría representada por la visión del equipo, manifestada por acuerdos e identificación con los objetivos al momento de entregar cuidados al paciente y que aumentan el compromiso con las metas. Estas metas en común logran una interdependencia en la tarea al desarrollar un sentido o significado compartido. $47,48,52,53$ 
En segundo lugar el Clima indaga en la percepción de los miembros de poder participar de manera segura y activamente en el equipo, poder aportar en las decisiones, desde la seguridad de ser reconocido como parte del equipo, ser escuchado y sentirse segurao del apoyo de los miembros y del líder, la literatura habla de una necesidad de reconocimiento desde los pares y el líder, trato equitativo ${ }^{36}$ y compromiso desde lideres proactivos. ${ }^{37,38}$ El tercer dominio indaga en la orientación a la tarea precisando de relaciones entre los miembros para coordinarse, colaborar, compartir información y reconocer el rol y responsabilidad de cada uno para alcanzar un cuidado centrado en el paciente. La literatura asocia esta dimensión con relaciones colaborativas entre los miembros y la sensación de haber entregado una atención de la mejor calidad ${ }^{64}$ pudiendo llevarlo a materializarse,${ }^{65,66}$ también aparece como relevante la claridad del rol, el compromiso, relaciones cercanas y cordiales que generen sentimientos positivos en la búsqueda del éxito. ${ }^{58,59} \mathrm{El}$ énfasis estaría dado por las responsabilidades individuales y colectivas. ${ }^{8,9}$ La poca claridad de funciones pueden limitar el alcance de la calidad precisa para satisfacer las necesidades de los pacientes. ${ }^{10}$. El cuarto y último dominio es transversal al constructo teórico subyacente y corresponde al apoyo a la innovación, el cual se manifiesta por participación en la creación y desarrollo de ideas para solucionar problemas del paciente, sentirse con la libertad de opinar, intervenir y saber que será escuchado, tener seguridad que si la solución propuesta es la adecuada será instado a desarrollarla. Este dominio, en la literatura aparece en diferentes escenarios y se relaciona con el desarrollo de ideas, procesos y productos distintos para su incorporación en diferentes escenarios, que buscan beneficiar a los involucrados ${ }^{80-82}$ y donde las relaciones interpersonales y la característica del trabajo pueden determinar o afectar su adopción y aplicación, limitando la mejora y aprovechamiento de las habilidades y talentos individuales. ${ }^{82,83}$ Lo anterior llevado a contextos clínicos puede aumentar la producción, y mejoramiento continuo de los procesos, y generar mayor identificación y compromiso de quienes participan. ${ }^{26,27,28} \mathrm{El}$ apoyo a la innovación aumenta el compromiso con los miembros del equipo y la labor de cada uno, ${ }^{29,30}$ así también aparece como importante incluir y buscar los aportes de las diferentes generaciones y sus habilidades especiales y únicas para alcanzar las metas de salud.

La segunda variable que permite indagar en los procesos y estructura al interior del equipo para comprender su relación con la satisfacción el equipo es el estilo de liderazgo, en este caso se utilizó el liderazgo transformacional, reconocido por su impacto positivo directo en contextos sanitarios tanto para el profesional como indirectamente en resultados de pacientes, recomendándose para la creación de ambientes que potencien el bienestar y desarrollo del personal de salud, partiendo por el desarrollo de liderazgos transformadores. ${ }^{12,13}$ Apareciendo 
como un estilo de liderazgo que facilita el cambio, aumenta el compromiso, la satisfacción laboral y el bienestar de los miembros dentro de sus equipos. ${ }^{95-99}$ Aumentando la contratación y retención de las personas en las organizaciones. ${ }^{100-105}$ Aumentando la percepción de bienestar en el trabajo y disminución del desgaste físico y psicológico, ${ }^{106}$ a través del desarrollo de autoeficacia individual y colectiva y llevando finalmente al bienestar en la organización. ${ }^{108-110}$

Se inicia por identificar al líder transformacional de los equipos de acuerdo a la percepción de sus miembros, reconociendo la presencia de un liderazgo compartido e informal como es el de Enfermería. Llama la atención este liderazgo claramente simultáneo entre el líder determinado por la estructura organizacional y el percibido por los profesionales que interactúan permanentemente para trabajar en equipo. A pesar de que el profesional médico reconoce el liderazgo de enfermería, él se considera profesionalmente como el líder del equipo. En estos casos la literatura reconoce que en ciertos escenarios se manifiesta una insatisfacción con el líder reconocido desde la organización, ${ }^{20,21}$ ya que perciben falta de apoyo, falta de comunicación, socialización y traspaso de la información, dificultad para trabajar en equipo, y falta de autonomía y reconocimiento, entre otros. ${ }^{21,22}$ Por otro lado, el líder reconocido por el equipo, como informal, la literatura realza sus competencias para facilitar el desarrollo de la tarea a través de las relaciones interpersonales, la comunicación, traspaso de información, reconociéndole habilidades relacionales, empatía e identificación como un par, por sus compañeros ${ }^{55}$ en donde comparten valores y convicciones, potenciando finalmente mejores resultados. ${ }^{45,93,94}$

Este estilo se asocia también con un mejor desempeño en el trabajo ${ }^{113-115}$ en el caso del enfermero/a entregaría cuidados mas eficaces, estaría mas motivado, se sentiría identificado con los objetivos, llevando finalmente a un mayor compromiso con su ejercicio profesional. ${ }^{114,116}$ Resultados en Sudamérica, apuntan a una falta de conocimientos en relación a liderazgo y los beneficios. ${ }^{118-122}$

El primer dominio del liderazgo transformacional es representado por el carisma del líder al considerar las necesidades del otro, manteniendo siempre la consistencia de sus actos, y ganándose el respeto de los miembros del equipo, resultados de investigaciones lo perciben como cercano, pues enfatiza en la importancia de las relaciones interpersonales y apoyo a los integrantes del equipo siendo retribuido con reconocimiento, apoyo y respeto. ${ }^{129} \mathrm{El}$ segundo 
dominio está representado por la motivación inspiradora que busca generar una visión atractiva del futuro, compartiéndola de manera de motivar y entusiasmar a los seguidores para trabajar en su cumplimiento, empleando los sentimientos para acompañarlos en la búsqueda de las metas. Resultados hablan de que este líder espera lograr los mejores resultados a través del compromiso logrado por la motivación. ${ }^{52,53,54} \mathrm{Al}$ relacionarlo con el equipo de salud, se reafirma el compromiso con el cuidado centrado en el paciente y la búsqueda de alcanzar las metas de la organización. ${ }^{128}$ La dimensión estimulación intelectual por su parte, estimula la creatividad de los profesionales, solicitando ideas y soluciones que ayuden al logro de los objetivos, buscando mantener la creación constante, para proyectar en ellos la visión del logro de las metas. Otros resultados indican que ayuda a pensar de forma original, más allá de su zona de confort, siendo creativo para desarrollar su labor. ${ }^{93,94}$ Por último la dimensión consideración individualizada, referido a un líder que piensa en cada integrante del equipo como una persona única, con características propias, siendo capaz de reconocer las cualidades y talentos individuales para potenciarlos. Resultados reconocen que establece relaciones interpersonales positivas en un ambiente estimulante, comunicándose efectivamente para lograr resultados. ${ }^{31}$ Los profesionales lo perciben como cercano, con énfasis en las relaciones interpersonales y apoyo al equipo. ${ }^{129}$

Como una forma de comprender en mayor profundidad la satisfacción con el equipo, se indago en el poder explicativo del clima de equipo y liderazgo transformacional, considerando ademas variables de la organización que podría intervenir en esta relación, encontrándose que el clima explica más efectivamente la satisfacción que el liderazgo, sin embargo ambas variables parecen relacionarse dentro del contexto social del trabajo en equipo. Adicionalmente emerge el tiempo en el equipo como una variable que también es capaz de explicar aunque en menor medida esta satisfacción, lo que aparece como importante en el contexto local donde se considera que la movilidad profesional es un valor.

Como una forma de continuar indagando en la Satisfacción con el Equipo de trabajo y complementando los resultados anteriores, se realizó un análisis de las redes de comunicación entre los miembros de equipos con resultados extremos y promedio de la variable SE. Estas redes explicaban como los profesionales se agrupan en relación a afinidad profesional (con que profesión) para resolver temas del trabajo (red formal) y personales (red informal). Los resultados de los miembros que perciben una mayor satisfacción con su equipo, son 6 profesionales con una antigüedad en el equipo superior a los 24 meses y que conforman una 
red de interacciones para el trabajo muy densa e integrada, investigaciones se refieren estos equipos como en proceso de colaboración activa. ${ }^{44}$ Con una cohesión del 100\%, todos sus miembros están conectados entre si, y cada uno puede ser abordado con facilidad para intercambiar información, sin necesidad de intermediarios, con una organización entre ellos más bien horizontal para responder con rapidez a las demandas de su trabajo, a diferencia de la literatura, que sitúa al médico ocupando frecuentemente una posición central como responsable del tratamiento del paciente. ${ }^{52,53}$ trabajando siempre con líneas de autoridad. ${ }^{52}$

Por otro lado los resultados del equipo con baja satisfacción incluyen múltiples profesionales, con una antigüedad como equipo que no supera los 12 meses. La red presenta una cohesión de un $25 \%$ y su estructura para el trabajo aparece como dividida, la literatura la llamaría descentralizada, y es considerada más resistente, ya que sufren menos cambios en su estructura cuando alguna persona abandona la red. ${ }^{132}$ Hay un subgrupo reunido alrededor de enfermería que pertenecen a una generación similar y que concentran la mayoría de las interacciones y la intermediación de gran parte de la información. Según estudios, su centralidad hablaría de la importancia, relevancia e influencia ya que pueden relacionarse más fácilmente con los demás miembros de la red. ${ }^{132,133}$ Hay dos parejas, una cercana al equipo médico y otro al de matronas e incluso dos profesionales aparecen completamente aislados, quienes a pesar de su experiencia llevan solo un año en el equipo. Investigaciones indican que las estructuras que emergen en este tipo de red necesitan compartir información relevante para su tarea, para lo cual precisan generar una red aparte de influencias sociales entre ellos y en este caso sería el estamento de enfermería quién la ostenta. ${ }^{139,140}$ La literatura sobre colaboración interprofesional los define como equipos fragmentados, que no cuentan con un núcleo único de profesionales integrados en torno al cual se agrupan los demás profesionales. $^{51}$

La red del equipo más satisfecho creada en términos de afinidad personal (informal) presenta un grado menor de cohesión que la profesional, y se separan en dos grupos cerrados de tres miembros cada uno, sus interacciones se reparten de manera igualitaria, sin embargo, es interesante como esta separación obedece a establecer relaciones personales con el estamento de enfermería o solo con profesionales pares de medicina y lo otro es que estan separados por genero. La red del segundo equipo, con baja satisfacción (informal) presenta un grado aún más bajo de cohesión, sus miembros se organizan de manera diferente, incluso ahora 6 de ellos están aislados (red profesional eran 2). Aparece sólo una trio de enfermeros, cercano a su 
grupo profesional, llama la atención en estos profesionales que laboralmente adscriben a medicina, pero personalmente a enfermería y aparecen nuevamente como centrales por las interacciones que reciben, emanan y fluyen a través de ellas. En el caso del médico no se relaciona de manera personal con ninguno de los integrantes del equipo y si lo hiciera es sólo con otro profesional médico. La literatura reconoce que ambas estructuras (formal e informal) no son completamente independientes entre sí, aunque es posible diferenciarlas por la posición que cada persona y por las rutas de interacción que forman ${ }^{132,134}$. La estructura informal y sus relaciones podrían incidir en el patrón de trabajo de los integrantes, creando normas propias para organizarse en el trabajo, además de surgir jerarquías informales, com el caso de enfermería, , no reconocidas por la organización. ${ }^{137}$

En una tercera etapa de la investigación y persiguiendo el mismo objetivo de complementar profundizando, se realizaron entrevistas a profesionales pertenecientes a los equipos con resultados extremos y promedio de la variable satisfacción con el equipo, posterior al análisis de redes sociales, lo que permitió aumentar la comprensión de los resultados cuantitativos, su manifestación en el contexto local y entregar elementos concretos para desarrollar estrategias de mejora donde sea pertinente.

Los resultados arrojaron seis temas los cuales se irán desarrollando y contrastando con resultados de otras investigaciones si fuera relevante.

En primer lugar, el tema relativo al Trabajo en Equipo, donde los entrevistados reconocen desde el comienzo que el foco estaría en entregar un Cuidado Centrado en el Paciente (CCP) y para lograrlo es necesario contar con una visión compartida, relativa a los objetivos a alcanzar como equipo, los cuales precisan ser consensuados y que van más allá de los objetivos individuales de cada disciplina. Es preciso contar con el compromiso de todos los miembros para convertirlos en mejoras para el paciente, en donde estudios reconocen la importancia de la participación en el desarrollo de los objetivos para lograr identificación y compromiso. ${ }^{33}$ Esto puede verse limitado por la falta de comunicación entre los miembros y diferencias personales que dificulten y complejicen el trabajo pudiendo limitar su logro. Como base para relacionarse es necesario que sus miembros coincidan en aspectos valóricos y normativos, que constituyan una base que facilite las interacciones en un marco de respeto mutuo. Otro elemento facilitador es contar con tiempos y espacios comunes que permitan compartir y en este caso enfermería aparece con favorecido pues cuenta con un núcleo 
cercano de tarea representado especialmente por profesionales no médicos, donde se organizan para realizar el cuidado del paciente. Estos equipos más cercanos, la literatura los percibe como favorecidos con mejores relaciones interpersonales, más efectivos y con mayor sentido de responsabilidad, apoyo con sus compañeros y compromiso. ${ }^{59}$

El segundo tema se refiere a la colaboración entre los miembros de equipos interprofesionales, como ellos se organizan para realizar sus labores y cumplir con sus responsabilidades. Para entregar un Cuidado Centrado en el Paciente es importante la horizontalidad entre los diferentes profesionales, manifestada por una valoración equitativa de los aportes de cada uno al logro de los objetivos, esto desde sus distintas competencias, habilidades y talentos. Investigaciones atestiguan la importancia de entregar contribuciones importantes y ser escuchados y reconocidos para la toma de decisiones, ${ }^{71}$ logrando sentimientos positivos y bienestar en los profesionales queriendo permanecer en el equipo. ${ }^{73}$ Un aspecto importante para los miembros es el apoyo y ayuda mutua, manifestada especialmente entre profesionales no médicos, los cuales se reúnen alrededor de la cama del paciente y cuya única barrera estaría representada por profesionales que se limitan a cumplir con objetivos individuales o que muestran una falta de humildad para pedir o aceptar apoyo, aun cuando las necesidades del paciente lo ameriten. En el caso del médico, ellos perciben su apoyo con visitas esporádicas y él mismo reconoce el apoyo de los otros miembros como facilitadores de su propio desempeño. La literatura científica en general reconoce al médico como comunicándose con los profesionales del equipo en general para transmitir indicaciones y ordenar con limitada o ninguna interacción social entre ellos. ${ }^{52-54}$ En este contexto los resultados no siempre son exitosos ${ }^{29,30}$ y estaría asociado a las limitadas oportunidades para comunicarse, compartir información, ayudarse mutuamente, limitando el potencial de los miembros. ${ }^{29,30}$

El vehículo que moviliza esta colaboración estaría dado por el dialogo y las interacciones entre sus miembros, las cuales precisan reconocer la labor y el aporte de cada uno al cuidado del paciente, determinado según investigaciones por el grado en el cual sus miembros tienen competencias o habilidades que hace difícil reemplazarlos ${ }^{47,48}$ y para lo cual es necesario encarecer su participación en la toma de decisiones, comunicando información relevante para un trabajo coordinado y haciendo propios los resultados, mientras se potencia la responsabilidad individual con las metas colectivas, compromiso, pasión y motivación por el exito $^{55}$. La exploración de una dimensión más humana en las relaciones entre los miembros 
del equipo les ayuda a sentirse seguros y libres para expresarse, pues genera un clima de confianza y respeto entre ellos. Para el médico esta dimensión personal no parece relevante si se compara con las habilidades técnicas requeridas para apoyar su labor. Un tercer elemento, reiterativo en la realidad local, es el reconocimiento del rol propio y de los otros miembros si se espera lograr sinergia dentro del equipo. Investigaciones en equipos de salud confirman la importancia de contar con claridad de roles desde lo administrativo y disciplinar, potenciando el compromiso, intercambio cercano y positivo entre los miembros para el logro de los objetivos. $^{58,59}$ Para lograrlo es preciso reconocer roles y responsabilidades individuales, compartir tiempo para lograr complementarse y alinear los roles individuales para la tarea requerida. Barreras surgen desde la ignorancia y expectativas erróneas en torno al rol de cada miembro, lo que significa muchas veces no involucrarse o asegurarse de la realización de las tareas. La sinergia entre los miembros del equipo, se explicita con frecuencia sólo en situaciones de urgencia vital para el paciente, en done los profesionales trabajan con claras definiciones de funciones, tareas y líneas jerárquicas de autoridad. ${ }^{52}$

El tercer tema referido a las buenas relaciones interpersonales y laborales con foco en el paciente, profundiza en las interacciones y relaciones entre los miembros para el desarrollo de la tarea y el alcance de los resultados del paciente. Es interesante como en este tema se clarifica la presencia de una interface entre las relaciones personales y laborales, siendo el cuidado centrado en el paciente lo que permite que se integren para lograr un trabajo participativo, buscando según investigaciones, relaciones interpersonales positivas que ayuden a generar un ambiente de trabajo estimulante, comunicación efectiva y finalmente resultados eficaces ${ }^{31}$. Si ambas son capaces de influenciarse entre si, es necesario considerarlas y potenciarlas a través de la generación de instancias para interacciones cordiales y comunicación, buscando compartir experiencias, puntos de vista, experimentar empatía y sentirse con la libertad para expresar opiniones y emociones en un contexto de confianza y respeto mutuo, facilitando finalmente sus relaciones laborales. Lo anterior según estudios internacionales, no limita que se desarrollen relaciones de amistad en el lugar de trabajo, ${ }^{34}$ sin embargo, la interdependencia en la tarea es considerada como el elemento más importante y central. ${ }^{47}$ Se reconoce la importancia del flujo de información para tomar decisiones en torno al cuidado del paciente y como enfermería estaría al centro de la recepción y divulgación de esta red de interacciones entre los diferentes miembro del equipo. El resultado de la falta de relaciones interpersonales puede manifestarse en un equipo fragmentado y con conflictos entre sus miembros, dificultando la comunicación y 
coordinación para entregar un cuidado seguro. La confianza entre los miembros del equipo, por otro lado, se manifiesta por el intercambio de información, tranquilidad y seguridad para compartir resultados positivos y errores. Los médicos relacionan la confianza en su equipo con la información que le entregan para tomar decisiones y donde el reconocimiento de sus propias inquietudes o errores es considerado excepcional en su relación con ellos. La literatura enfatiza que la dificultad para interactuar, comunicarse y alcanzar acuerdos, puede generar frustración, desapego ${ }^{71}$ emociones negativas, siendo finalmente un elemento que coharta los procesos al interior de la organización. ${ }^{72}$

El cuarto tema representado por la innovación en el trabajo del equipo, se reconoce en la búsqueda de las contribuciones de sus miembros a la solución de problemas que permitan entregar el mejor cuidado al paciente y donde las oportunidades para expresarse, ser escuchado y apoyado por el equipo estimularía su creatividad e interés en participar. En este contexto el reconocimiento del aporte individual y especialmente de las generaciones más jóvenes, quienes se sienten más cómodos en ambientes de cambios y adaptación constante, es relevante, si se espera mantener su interés y compromiso con el equipo. Por otro lado aparece la resistencia al cambio, donde miembros del equipo se sienten confortables con el statu quo y no desean incurrir en esfuerzos adicionales, aprender o capacitarse para realizar sus actividades de manera diferente.

El quinto tema relevado por los miembros del equipo, se refiere al Liderazgo en el Equipo y se ve representado por las expectativas de los miembros en torno a él y que incluye por un lado aspectos relativos a la coordinación y supervisión de la tarea, en donde la comunicación entre los miembros, un líder motivador, que reconoce al otro y comparte una meta con sentido puede significar la participación activa de cada uno de los profesionales. La literatura en contextos clínicos, sin embargo, considera al médico como líder formal, en una posición jerárquica, responsable del enfermo y que comunica su plan a los otros profesionales. ${ }^{52,53}$ Por otro lado, el líder debe ser capaz de reconocer la dimensión personal de los miembros si considera el bienestar individual y colectivo, interesarse en aspectos particulares, relativo a sus vidas, independiente de la afinidad personal que tenga con ellos, para lograrlo precisa de dialogo e interacciones que involucren aspectos más allá del trabajo y que generen un clima acogedor para todos. La mayoría de los testimonios son entregados por médicos en donde se aprecia su propio reconocimiento como líder del equipo y que busca motivar a través de la retroalimentación positiva a los miembros, sin embargo, algunos miembros del equipo lo 
reconocen a él como vertical en sus relaciones interpersonales y le exigen al menos conocer a los miembros de su equipo y reconocer sus aportes al logro de los objetivos.

El sexto tema que se relaciona con el Liderazgo informal dentro del equipo, los entrevistados reconocen el liderazgo como un fenómeno dinámico basado en las necesidades del paciente y desde ahí surge este liderazgo fuera de la estructura de la organización y que puede ser ostentado por cualquier miembro o rotar entre ellos dependiendo de la situación del paciente y que habilidades, competencias y talentos de sus miembros son necesarias y relevantes en ese momento, las cuales en muchas ocasiones el líder formal no las tiene. Establecen la presencia de este segundo líder, informal, elegido por los miembros, enaltecido por ellos a esta posición y que es capaz de conectar con las personas, facilitar la comunicación dentro del equipo, mediar el flujo de información y potenciar las relaciones interpersonales a través de un dialogo cordial y respetuoso. Se le reconoce también como poseedor de aptitudes, habilidades y rasgos de personalidad que facilitan su desempeño como líder y a enfermería como poseedora de estos atributos y aunque no está formalizado en la organización, el liderazgo es desarrollado por ellas en la cotidianidad y que se vería facilitado también por la seguridad y confianza con que enferm se relaciona con el líder formal, en este caso el médico. De acuerdo a lo expresado, enfermería favorece, según la literatura, este estilo de liderazgo transformacional, que potencia la creatividad para el cambio, aumenta el compromiso en el trabajo, la satisfacción laboral y el bienestar de los miembros con sus equipos. ${ }^{95-99}$ Estilo que se percibe como familiar, que releva la importancia de las relaciones interpersonales y el apoyo entre los integrantes del equipo, siendo reconocido, y respetado ${ }^{129}$. El equipo percibe los beneficios del liderazgo transformacional a través de una comunicación efectiva, responsabilidades claras, empoderamiento para el crecimiento y claridad del rol entre sus integrantes. $^{129}$

Un aspecto relevante es la necesidad de contar con competencias y habilidades para ser el líder del equipo, las cuales según algunos profesionales pueden ser aprendidas y desarrolladas por todos los miembros y para otros son inherentes a unos pocos. Esta dicotomía se manifiesta con más claridad al comparar el líder elegido e impuesto desde la organización y el informal. Si el liderazgo fuera innato, se recomendaría considerar a personas con las características necesarias y potenciarlas, pero, en el caso que no las tuviera debe ser apoyado para desarrollarlas contando con formación antes de asumir el rol en el equipo. Finalmente en sus propios testimonios, el líder formal apunta a la necesidad de competencias y experiencia para 
ser líder, sin embargo, el informal a la accesibilidad para facilitar el establecimiento de relaciones interpersonales.

Para finalizar y con la información recabada de las tres fases anteriores se analizan los resultados de manera integrada para entregar una mirada comprensiva del fenómeno del trabajo en equipos interdprofesionales en contextos hospitalarios, que entregue elementos que permitan potenciar la satisfacción de sus miembros e indirectamente mejores resultados de paciente. Cabe en este punto destacar que la búsqueda de la literatura sobre el estado del arte en lo referente al fenómeno desde una mirada que integra diferentes aproximaciones paradigmáticas incluyendo las variables del estudio, no fue fructifera en identificar o rescatar algún artículo o tesis, que permitiera contrastar la discusión que sigue.

En primer lugar, en relación a la composición de los equipos, de acuerdo a la percepción de los profesionales, no existe una concepción generalizada de equipo de trabajo que incluya más allá del médico, enfermera y técnico de enfermería, solo en casos particulares los otros profesionales se consideran parte de este equipo, dado por la posibilidad de interactuar atendiendo las necesidades específicas del paciente. Incluso muchos de ellos se consideran parte de equipos monodisciplinarios, conformados por afinidad profesional y personal. Estos equipos incluyen en primer lugar a enfermería y técnicos, quienes comparten horario de trabajo y se coordinan para entregar el cuidado del paciente, en el caso de kinesiólogos o nutricionista, reconocen que pueden ampliar su equipo para incluir a enfermería, quien los recibe en los servicios y se relaciona con ellos más frecuentemente. La satisfacción en los equipos de trabajo desde el punto de vista estructural requiere de un núcleo cercano de miembros que interactúen personalmente, dialoguen y se comuniquen entre ellos sin necesidad de intermediarios (otras personas o tecnología).

En relación al clima de trabajo dentro del equipo, su percepción positiva se ve influenciado en primer lugar por aspectos organizacionales que facilitan las relaciones interpersonales entre sus miembros, por ejemplo, que sus respectivos horarios de trabajo lo permitan, su permanencia en el tiempo con el mismo equipo, contar con instancias para conciliar en equipo los objetivos de un cuidado centrado en el paciente, que potencie la identificación y el compromiso de alcanzarlos, compartir información relevante que permita coordinar los esfuerzos individuales y alcanzar los mejores resultados para los pacientes. Esto se facilita por la comunicación entre sus miembros, escuchar las opiniones y puntos de vista divergentes 
para la toma de decisiones compartida. Reconociendo todos los aportes como igualmente valiosos e importantes en un clima de confianza que entregue seguridad para opinar, libertad para crear e innovar, especialmente a las nuevas generaciones, en un ambiente de respeto y apoyo mutuo. Esto se facilita por un trato cordial y respetuoso entre sus miembros, que reconozca al otro en su dimensión profesional y personal. En este contexto es imperativo una clara definición del rol de cada uno de ellos, lo que facilitaría el reconocimiento y responsabilidades, facilitando el trabajo colaborativo y la sinergia entre sus miembros para alcanzar las metas de paciente.

En relación a la satisfacción experimentada por los miembros de los equipos interdprofesionales con el estilo de liderazgo transformacional en sus equipos, este aparece como compartido entre dos miembros, por un lado, un liderazgo formal que organiza y da dirección y uno que favorece la coordinación de los profesionales al interior del equipo para alcanzar los resultados.

En relación al primero, formal y reconocido desde la organización, ocupa una posición más bien vertical para relacionarse, no cuenta siempre con preparación formal para realizar labores administrativas y de gestión de personas, las instancias de comunicación se limitan a visitas esporádicas a los servicios por su labor como profesional de salud, más que como líder del equipo. No se relaciona de manera frecuente con los miembros, por lo cual sus interacciones son mas bien enfocadas en el cumplimiento de la tarea y no demuestra interés en la dimensión personal de ellos.

El líder informal, por otro lado, es reconocido por los miembros del equipo y su contribución es potenciar el bienestar individual, demuestra interés en conocer y reconocer a los miembros en su dimensión profesional y personal, generando lazos con ellos a través de instancias formales e informales. Facilita el dialogo y la comunicación entre los miembros, los motiva e inspira para crecer y desarrollarse, escucha sus inquietudes profesionales y personales, potencia ambientes creativos que entreguen seguridad para participar, ser escuchado y reconocido en su aporte. Conoce y reconoce las competencias y talentos de los miembros del equipo, los retroalimenta positivamente y los estimula a asumir el rol de líder del equipo si el cuidado del paciente lo amerita. Aunque no cuenta siempre con una preparación formal para liderar, cuenta con ciertas características de personalidad innatas que facilitan que lo ejerza. 
Para concluir es importante considerar que las variables estudiadas parecen compartir ciertos elementos o aproximaciones al fenómeno desde sus constructos teóricos similares, sin embargo, el clima de equipo como proceso que se construye entre los miembros presenta una influencia mayor en la satisfacción, en segundo lugar y de manera cercana, estaría la presencia de un liderazgo transformacional y por último pero no menos importante, la permanencia en el tiempo de los integrantes. 
9. CONCLUSIONES 


\section{CONCLUSIONES}

La presente investigación utiliza una mirada comprensiva para explicar la satisfacción experimentada por los miembros de equipos interprofesionales en contextos clínicos. Explorando en profundidad procesos de construcción social al interior de los mismos, como son el clima y la relación con el líder, en un marco de relaciones interpersonales que permiten su generación y desarrollo. El clima del equipo, generado a través de las relaciones interpersonales y comunicación entre sus miembros explicaría en importante medida su satisfacción, siempre y cuando considere aspectos como, el desarrollo de interacciones en torno a un objetivo compartido, como es el cuidado del paciente, el mantener constante esta meta en los intercambios sociales entre sus miembros facilita el trabajo colaborativo más allá de las diferencias personales, ya que sitúa la relación en un acuerdo común. Aspectos como, un ambiente de confianza y seguridad manifestado por relaciones profesionales equitativas en cuanto al valor y reconocimiento de los aportes individuales al trabajo y donde la permanencia en el tiempo de sus miembros, aparece como relevante para lograrlo. Un tema recurrente y que podría responder a una realidad local es la claridad de roles y definición de responsabilidades, como marco de referencia para el trabajo interprofesional.

Adicionalmente, un liderazgo de estilo transformacional en el equipo ayuda explicar la satisfacción, en este caso reconocido como un liderazgo compartido entre sus miembros, por un lado el líder formal con una orientación hacia las competencias que aportan los miembros del equipo para la realización de la tarea y un liderazgo informal que facilita la sinergia de estas competencias a través del establecimiento de relaciones interpersonales que conocen y reconocen al otro en todas sus dimensiones. En este último punto es importante enfatizar en el reconocimiento de la dimensión profesional y personal de sus miembros, y como su interdependencia pueden influenciar las relaciones orientadas al desarrollo de la tarea y limitar el logro de los objetivos. Es importante destacar que el clima del equipo aparece explicando en mayor medida la satisfacción con el equipo.

La utilización del análisis de redes sociales en esta investigación permitió observar los patrones de comunicación y traspaso de información de los profesionales en sus respectivos equipos interprofesionales. Fue posible comparar visualmente agrupaciones para solucionar problemas laborales y personales y fue muy interesante contrastar equipos con resultados extremos de satisfacción, identificando con claridad diferencias en la cohesión entre sus 
miembros, agrupaciones uni-profesionales dentro de los equipos interprofesionales y profesionales completamente aislados del resto en términos de interacciones sociales. Estos resultados apoyaron el análisis, explicación y contraste de los resultados anteriores, entregando una mirada novedosa y llena de matices.

\subsection{Limitaciones}

Dentro de las limitaciones del estudio se encuentran el tamaño de la muestra, restringida por el número de profesionales que declaran trabajar en equipos de salud multiprofesionales y por lo tanto, la generalización de los resultados puede verse limitada. A pesar de utilizar un enfoque de recolección riguroso, la tasa de respuesta de la encuesta puede haber sido influenciado por el período de transición que vive la organización debido a la incorporación de un socio estratégico internacional, por lo cual la participación en el estudio pudo no haber sido prioridad para ellos. Es posible que los profesionales que se sienten motivados por el trabajo en equipo estuvieran más dispuestos a participar y sus respuestas pueden no reflejar los niveles reales de las variables en el trabajo con su equipo.

El investigador es enfermera, por tanto, establecer una buena relación con los profesionales de enfermería podría ser más fácil que con los demás miembros del equipo, esto podría haber influido en los resultados de la entrevista, sin embargo, las grabaciones, notas del investigador y reuniones periódicas de supervisión con otro investigador (supervisor del doctorado), ayudaron en la prevención de puntos de vista sesgados y su identificación temprana en caso de existir. En la exploración cualitativa, se pidió a los participantes entregar sus percepciones y recordar interacciones con miembros de su equipo, y no siempre es posible recordar con claridad las circunstancias o eventos que rodean las experiencias.

Existen limitaciones inherentes al diseño del estudio, dado su carácter descriptivo, ninguna relación causal puede deducirse de sus conclusiones. A pesar de lo anterior la utilización de métodos mixtos generó una descripción enriquecida de la práctica de trabajo interprofesional y sus circunstancias, permitiendo una mayor comprensión de la satisfacción de sus miembros. Al mismo tiempo, los generosos datos de las narraciones se reflejan en las mediciones cuantitativas para complementar y explicar sus resultados. Este estudio es importante en la promoción del uso de métodos mixtos en investigación como una manera de absorber al máximo las diferentes aristas del fenómeno investigado. 


\subsection{Implicancias para la Práctica}

La presente investigación presenta resultados que contribuyen al proceso de planificación y toma de decisiones en el ámbito de los Recursos Humanos en Salud, entregando elementos para potenciar la generación y gestión de equipos de salud, contar y retener recursos humanos suficientes, competentes y comprometidos. Ayudando a fortalecer el desarrollo de compromisos y motivación resultando en permanencia y retención laboral especialmente donde las necesidades son más urgentes (sector público y regiones).

Una gestión eficiente en el area de la salud, facilita la habilidad de los equipos para enfrentar las demandas de un sistema en cambio e innovación constante, mejorando sus resultados, aportando colaborativamente desde cada profesión/disciplina, generando sinergia hacia un cuidado integral, efectivo, eficiente, centrado en la necesidades del paciente, mejorando así su calidad de vida y la de sus familias.

Se busca con estos resultados apoyar con elementos de transferibilidad para intervenciones basadas en evidencia, reportados por la literatura al contexto y cultura local. Se espera fundamentar la creación de programas de formación y capacitación profesional que integren herramientas administrativas enfocadas en relaciones laborales satisfactorias en sus equipos de trabajo, incidiendo en la estabilidad y permanencia laboral e indirectamente en resultados de excelencia en el cuidado de la salud de la población.

\subsection{Futuros Trabajos}

Se sugiere continuar en esta línea de investigación, explorando barreras para el trabajo en equipo, profundizar en la comprensión de la interface entre las dimensiones profesional y personal y su impacto en aspectos laborales. Se sugiere explorar las emociones experimentadas, su regulación y contagio por los miembros de equipos de salud, adoptando una aproximación comprensiva utilizando diferentes paradigmas. Los resultados derivados de este estudio servirán de conocimiento base para expandir teoría e informar a la investigación y la práctica. Una mejor comprensión de la satisfacción de los miembros en sus equipos contribuirá al trabajo interdisciplinario e interprofesional e indirectamente a mejorar el cuidado del paciente. 


\section{REFERENCIAS BIBLIOGRÁFICAS}

1. Weinberg D, Cooney-Miner D, Perloff JN, Babington L, Avgar A. Building Collaborative Capacity: promoting interdisciplinary teamwork in the absence of formal teams. Med Care. 2011 Aug;49(8):716-23.

2. Lemieux-Charles L, McGuire WL. What do we know about health care team effectiveness? A review of the literature. Med Care Res Rev. 2006 Jun;63(3):263-300.

3. WHO. Global Shortage of Health Workers and its Impact; 2006:1- 4.

4. Committee on Quality of Health Care in America, Institute of Medicine. Crossing the Quality Chasm: A New Health System for the 21st Century. Washington, DC: The National Academies Press; 2001.

5. Shortell SM, Singer SJ. Improving patient safety by taking systems seriously. JAMA. 2008 Jan;299(4):445-7.

6. Hackman JR, Leading Teams: Setting the Stage for Great Performances. Boston: Harvard Business School Press; 2002.

7. Cott C. Structure and meaning in multidisciplinary teamwork. Sociol Health Illn. 1998 Nov; 20(6):848-73.

8. Joint Commission on Accreditation of Healthcare Organizations. Sentinel events: evaluating cause and planning improvement. Oakbrook Terrace, IL: Joint Commission on Accreditation of Healthcare Organizations; 1998.

9. Kohn L, Corrigan J, Donaldson M. To erris human: building a safer health system [Institute of Medicine Report]. Washington, DC: National Academy Press; 1999.

10. Schei E. Doctoring as Leadership: the power to heal. Perspect Biol Med. 2006 Summer; 49(3):393-406.

11. Institute of Medicine (IOM) (2000) To Err is Human: Building A Safer Health System. National Academy Press, Washington, D.C. 
12. Committee on the Work Environment for Nurses and Patient Safety, Institute of Medicine. Keeping Patients Safe - Transforming the Work Environment of Nurses. Washington DC: The National Academy Press; 2004.

13. Baker GR, Norton PG, Flintoft V, et al. The Canadian adverse events study: the incidence of adverse events among hospitals patients in Canada. CMAJ. 2004 May;170(11):1678-86.

14. Weller J, Boyd M, Cumin D. Teams, tribes and patient safety: overcoming barriers to effective teamwork in healthcare. Postgrad Med J [Internet]. 2014 Mar [cited 2015 Dic 14];90(1061):149-154. Available from: http://www.ncbi.nlm.nih.gov/pubmed/24398594.

15. Institute of Medicine. The Future of Nursing: Leading Change, Advancing Health. Washington DC: National Academies Press; 2010. p.56.

16. Lu H, While AE, Barriball KL. Job satisfaction among nurses: a literature review. Int J Nurs Stud. 2005 Feb;42(2):211-27.

17. Anthony MK, Standing TS, Glick J, Duffy M, Paschall F, Sauer MR, et al. Leadership and Nurse Retention. J Nurs Adm. 2005 Mar;35(3):146-55.

18. Columna digital. [internet]. Puerto Montt, Chile; 2011. Déficit de enfermeros: una realidad preocupante; 2011 Jan 04 [cited 2013 May 17]. Available from: http://www.columnadigital.cl/dficit-de-enfermeros-una-realidad-preocupante-parte-i/

19. Brady-Germain P, Cummings GG. The influence of nursing leadership on nurse performance: a systematic literature review. J Nurs Manag. 2010 May;18(4):425-39.

20. Siebens K, Casterle' BD, Abraham I, et al. The professional self-image of nurses in Belgian hospitals: a crosssectional questionnaire survey. Int J Nurs Stud. 2006 Jan:43(1),7182.

21. Milisen K, Abraham I, Siebens K, Darras E, Dierckx de Casterlé B. Work environment and workforce problems: a cross-sectional questionnaire survey of hospital nurses in Belgium. Int J Nurs Stud. 2006 Aug;43(6):745-54.

22. West MA, Borrill CS, Dawson JF, Brodbeck F, Shapiro DA, Haward B. Leadership clarity and team innovation in health care. Leadersh Q. 2003 August;14:393-410. 
23. Griffin MA, Patterson MG, West M.A. Job satisfaction and teamwork. Journal of Organisational Behaviour. 200; 22: 537-50.

24. John S. Heywood; Uwe Jirjahn Teams, Teamwork and Absence. Scandinavian Journal of Economics. 2004 Dec;106(4): 765-782.

25. Fletcher J. "The paradox of post heroic leadership: gender, power and the 'new' organization", Academy Management Research Conference, Denver and Colorado; 2002.

26. Gladstein DL. Groups in context: a model of task group effectiveness. Adm Sci Q. 1984; 29(4):499-517.

27. Allen NJ, Hecht, TD. The "romance of teams": Toward an understanding of its psychological underpinnings and implications. J Occup Organ Psychol. 2004; 77:439-61.

28. Dieleman SL, Farris KB, Feeny D, Johnson JA, Tsuyuki RT, Brilliant S. Primary health care teams: team members' perceptions of the collaborative process. J Interprof Care. 2004 Feb;18(1):75-8.

29. Lester S, Meglino B, Korsgaard M. The antecedents and con- sequences of group potency: A longitudinal investigation of newly formed work groups. Academy of Management Journal. 2002;45: 352-368. doi:10.2307/3069351

30. Allen NJ, Hecht TD. The "romance of teams": Toward an understanding of its psychological underpinnings and implications. J Occup Organ Psychol. 2004; 77: 439-461.

31. Körner M, Wirtz MA, Bengel J, Göritz A. Relationship of organizational culture, teamwork and job satisfaction in interprofessional teams. BMC Health Services Research [Internet]. 2015 Jun [cited 2015 Dic 13];15 : 243. Available from: http://www.biomedcentral.com/1472-6963/15/243/

32. Rosenman ED, Shandro JR, Ilgen JS, Harper AL, Fernandez R. Leadership Training in Health Care Action Teams: A Systematic Review. Academic Medicine [Internet]. 2014 Sep [cited 2015 Dic 14];89(9):1295-1306. Available from: http://www.ncbi.nlm.nih.gov/pubmed/25006708

33. Stewart GL. A meta-analytic review of relationships between team design features and team performance. Journal of Management. 2006; 31: 319-35. 
34. Kovner C, Brewer C, Wu YW, Cheng Y, Suzuki M. Factors associated with work satisfaction of registered nurses. Journal of Nursing Scholarship. 2006;38(1):71-79. [PubMed: 16579327]

35. Chang WY, Ma JC, Chiu HT, Lin KC, Lee PH. Job satisfaction and perceptions of quality of patient care, collaboration and teamwork in acute care hospitals. J Adv Nurs. 2009 Sep; 65(9): 1946-55.

36. Blegen M. Nurses' job satisfaction: A meta-analysis of related variables. Nursing Research. 1993; 42(1):36-41. [PubMed: 8424066]

37. Fang Y. Turnover propensity and its causes in Singapore nurses: An empirical study. International Journal of Human Resource Management. 2001; 12(5):859-71.

38. Clegg A. Leadership: Improving the quality of patient care. Nursing Standard. 2000; 14(30):43-5

39. Burke CS, Stagl KC, Klein C, Goodwin GF, Salas E, Halpin SM. What type of leadership behaviors are functional in teams? A meta-analysis. Leadersh Q. 2006;17:288-07.

40. Cummings GG, Hayduk L, Estabrooks CA. Mitigating the impact of hospital restructuring on nurses: the responsibility of emotionally intelligent leadership. Nurs Res. 2005 Jan-Feb;54(1):2-12.

41. Chen HS, Baron M. Nursing directors' leadership styles and faculty members' job satisfaction in Taiwan. J Nurs Educ. 2006;45(10):404-11.

42. Bass B, Avolio B. Improving organizational effectiveness. Through transformational leadership. USA: SAGE Publications; 1994.

43. Braun S, Peus C, Weisweiler S, Frey D. Transformational leadership, job satisfaction, and team performance: A multilevel mediation model of trust. Leadersh Q. 2013;24:270-83.

44. D’Amour D, Goulet L, Labadie J-F, San Martin-Rodriguez L, Pineault R. A model and typology of collaboration between professionals in healthcare organizations; 2008. Rescatado en 2014 de: http://www.ncbi.nlm.nih.gov/pmc/articles/PMC2563002/pdf/1472-6963-8188.pdf 
45. Braithwaite: Between-group behaviour in health care: gaps, edges, boundaries, disconnections, weak ties, spaces and holes. A systematic review. BMC Health Services Research 2010;10:330.

46. Anderson NR, West MA. Measuring climate for work group innovation: development and validation of the Team Climate Inventory. J Organ Behav. 1998 May;19(3):235-58.

47. Hollenbeck JR, Beersma B, Schouten ME. Beyond team types and taxonomies: a dimensional scaling conceptualization for team description. Acad Manage Rev. 2012 Jan;37(1),82-106.

48. West M, Lyubovnikova J. Illusion of team working in health care. Journal of Health Organization and Management. 2013; 27(1):134-142.

49. Peduzzi M. Equipe multiprofissional de saúde: conceito e tipologia. Rev Saúde Pública. 2001; 35(1):103-9.

50. Peduzzi M, Carvalho B, Mandu E, Souza G, Silva J, Alcântara M. Trabalho em equipe na perspetiva da gerência de serviços de saúde: instrumentos para a construção da prática interprofissional. Physis (UERJ. Impresso) 2011; 21: 629-646.

51. Miller C, Freeman M, Ross N. Interprofessional practice in health and social care: challenging the shared learning agenda. London: Arnold; 2001.

52. Peduzzi M, Sangaleti C, Aguiar C, Souza G, Silva, j. Trabalho em equipe sob a perspectiva interprofiissional. Proenf Gestao, 2012; 1(13):9-39.

53. Canelotti B. Trabalho em equipe de saúde e de enfermagem: Análise sistemática da literatura [dissertation]. São Paulo: Universidad de São Paulo; 2008. p.127.

54. McCallin A. Interdisciplinary team leadership: ¿a revisionist approach for an old problem? J Nurs Manag. Nov 2003; 11(6): 364-70.

55. Pearson A, Porritt KA, Doran D, Vincent L, Craig D, Tucker D, et al. A comprehensive systematic review of evidence on the structure, process, characteristics and composition of a nursing team that fosters a healthy work environment. Int J Evid Based Healthc. 2006 Jun; 4(2):118-59. 
56. Wheelan SA, Burchill CN, Tilin F. The link between teamwork and patients' outcomes in intensive care units. Am J Crit Care. 2003 Nov; 12(6):527-34.

57.Brewer BB. Relationships Among Teams, Culture, Safety, and Cost Outcomes. West J Nurs Res. 2006 Oct; 28 (6);641-53.

58. Jünger S, Pestinger M, Elsner F, Krumm N, Radbruch L. Criteria for successful multiprofessional cooperation in palliative care teams. Palliat Med. 2007 Jun; 21(4):347-54.

59. Cioffi J, Fergurson L. Team nursing in acute care settings: nurses experiences. Contemp Nurse. 2009 Aug; 33(1):2-12.

60. Kalisch BJ, Lee KH. Nurse Staffing Levels and Teamwork: A Cross-Sectional Study of Patient Care Units in Acute Care Hospitals. J Nurs Scholarsh. 2011 Mar; 43(1):82-8.

61. Fairbrother G, Jones A, Rivas K. Changing model of nursing care from individual patient allocation to team nursing in the acute inpatient environment. Contemp Nurse. 2010 Jun; 35(2):202-20.

62. Locke E, Lathamb G. Work Motivation and Satisfaction: Light at the End of the Tunnel. Psychol Sci . 1990 Jul; 1(4):240-46.

63. Fernández M, Moinelo A, Villanueva A et all. Satisfacción Laboral de los Profesionales de Atención Primaria del área 10 de linsal de Madrid. Rev Esp Salud Publica, 2000; 74:13947.

64. Amos $\mathrm{M}, \mathrm{Hu} \mathrm{J}$, Herrick $\mathrm{C}$. The impact of team building on communication and job satisfaction of nursing staff. Journals of Nursing Staff Development. 2005; 21(1):10-16.

65. Chiang MM, Salazar CM, Martín MJ, Nuñez A. Clima organizacional y satisfacción laboral. Una comparación entre hospitales públicos de alta y baja complejidad. Salud de Trabajadores. 2011 Jan; 19 (1):5-16.

66. Peiró J, González-Romá V, Zurriaga R et al. El cuestionario de satisfacción laboral de los profesionales de la salud de Equipos de Atención Primaria. Revista de Psicología de la salud. 1989;1(2):135-74. 
67. Alcover de la Hera CM, Rodríguez FG. Potencia en grupos: Un constructo entre la autoeficacia y la motivación colectiva. = Group potency: A construct between self-efficacy, and group motivation. Apunt Psicol. 2000; 18(1): 123-143.

68. Walumbwa FO, Bruce J, Avolio B, Zhu W. How transformational leadership weaves its influence on individual job performance: the role of identification and efficacy beliefs. Pers Psychol. 2008 Jan; 61:793-825.

69. Wall V, Nolan L. Small Group Conflict A Look at Equity, Satisfaction, and Styles of Conflict Management. Small Group Research 1987 May; 18(2):188-211.

70. Lester Scott, Meglino B, Korsgaard A. The Antecedents and Consequences of Group Potency: A Longitudinal Investigation of Newly Formed Work Groups. Acad Manage J. 2002 vol. 45. 2. p. 352-368.

71. Torre-Ruiz JM, Ferrón-Vílchez V, Ortiz-de-Mandojana N. Team Decision Making and Individual Satisfaction With the Team. BMJ Open. 2014; 45:198.

72. Shaw JD, Duffy MK, Stark EM. Interdependence and Preference for Group Work: Main and Congruence Effects on the Satisfaction and Performance of Group Members. Journal of Management. 2000 April; 26 (2):259-79.

73. Peeters M, Rutte C, Van Tuijl H, Reymen I. The big five personality traits and individual satisfaction with the team. Small Group Research.2006; 37:187-211. doi: $10.1177 / 1046496405285458$.

74. Rafferty AM, Ball J, Aiken LH. Are teamwork and professional autonomy compatible, $¿$ and do they result in improved hospital care? Quality in Health Care. 2001;10(2):32-7.

75. Chang WY, Ma JC, Chiu HT et all. Job satisfaction and perceptions of quality of patient care, collaboration and teamwork in acute care hospitals. J Adv Nurs. 2009 Sep;65(9):194655.

76. Brunetto Y, Sherry M, Shriberg A, et al. The impact of workplace relationships on engagement, well-being, commitment and turnover for nurses in Australia and the USA. J Adv Nurs. 2013Dec;69(12):2786-99. 
77. Tse HM, Dasborough MT, Ashkanasy NM. A multi-level analysis of team climate and interpersonal exchange relationships at work. Leadersh Q. 2008 April;19(2):195-211.

78. West MA, Anderson NR. Innovation, cultural values and the management of change in British hospitals. Work Stress. 1992; 6(3):293-310.

79. West MA, Anderson NR. Predicting management team innovation: individual and structural factors; 1994.

80. West MA, Farr JL. Innovation at work: psychological perspective. Soc Behav. 1989 March;4:15-30.

81. West MA. Leadership clarity and team innovation in health care. Leadersh Q. 2003; 14(4-5):393-410.

82. West MA. Innovation and Creativity at work: Psychological and Organizational Strategies. John Wiley \& Sons: 1990. The social psychology of innovation in goups; p. 30933.

83. Ouwens M, Hulscher M, Akkermans R, Hermens R, Grol R, Wollersheim H. The Team Climate Inventory: application in hospital teams and methodological considerations. Qual Saf Health Care. 2011 Aug;17(4):275-80.

84. Strating MM, Nieboer AP. Psychometric test of the Team Climate Inventory-short version investigated in Dutch, K. S. BMS Health Serv Res. 2009 Jul; 9:126.

85. Mathisen GE, Einarsen S, Jørstad K, Brønnick KS. Climate for work group creativity and innovation: Norwegian validation of the team climate inventory (TCI). Scand J Psychol. 2004 Nov;45(5):383-92.

86. Proudfoot J, Jayasinghe UW, Holton C, Grimm J, Bubner T, Amoroso C, et al. Team climate for Innovation: ¿what difference does it make in general practice? Int J Qual Health Care. 2007 Jun; 19(3):164-9.

87. Hsu-Min T, Feng-Chuan L, West MA. The Team Climate Inventory (TCI). A Psychometric Test on a Taiwanese Sample of Work Groups. Small Group Research. 2009 Aug;40(4):465-82. 
88. Goh TT, Eccles MP. Team climate and quality of care in primary health care: a review of studies using the Team Climate Inventory in the United Kingdom. BMC Res Notes. 2009 Oct; 29(2):222.

89. Chang WY, Ma JC, Chiu HT, Lin KC, Lee PH. Job satisfaction and perceptions of quality of patient care, collaboration and teamwork in acute care hospitals. J Adv Nurs. 2009 Sep;65(9):1946-55.

90. Hann M, Bower P, Campbell S, Marshall M, Reeves D. The association between culture, climate and quality of care in primary health care teams. Fam Pract. 2007 Sep;24(4):323-9.

91. Dackert I. The impact of team climate for innovation on well-heing and stress in elderly care. J Nurs Manag. 2010 Apr; 18, (3):302-10.

92. Avolio BJ, Bass BMMultifactor Leadership Questionnaire. 3rd ed. Menlo Park, CA: Mind Garden Inc; 2004.

93. Horwitz I, Horwitz S, Daram P, Brandt M, Brunicardi C, Awad S. Transformational, Transactional, and Passive-Avoidant Leadership Characteristics of a Surgical Resident Cohort: Analysis Using the Multifactor Leadership Questionnaire and Implications for Improving Surgical Education Curriculums. J Surg Res. 2008 Jul;148(1):49-59.

94. Bass BM, Avolio BJ. Transformational leadership and organizational culture. Public Adm Q. 1993 spring;17(1):112-21.

95. Havig AK, Skogstad A, Veenstra M, Romøren TI. The effects of leadership and ward factors on job satisfaction in nursing homes: a multilevel approach. J Clin Nurs. 2011 Dec; 20(23-24):3532-42.

96. Utley R, Anderson R, Atwel, J. Implementing Transformational Leadership in LongTerm Care. Geriatr Nurs. 2011 May;32(3):212-9.

97. Furtado LC, Batista Mda G, Silva FJ. Leadership and job satisfaction among Azorean hospital nurses: an application of the situational leadership model. J Nurs Manag. 2011 Nov;19(8):1047-57.

98. Malloy T, Penprase B. Nursing leadership style and psychosocial work environment. J Nurs Manag. 2010 Sept; 18(6):715-25. 
99. Nielsen K, Yarker J, Brenner SO, Randall R, Borg V. The importance of transformational leadership style for the well-being of employees working with older people. J Adv Nurs. 2008 Sep; 63(5):465-75.

100. Raup GH. The impact of ED Nurse manager leadership style on staff nurse turnover and patient satisfaction in academic health center hospitals. J Emerg Nurs. 2008 Oct;34(5):403-9.

101. Cummings GG, MacGregor T, Davey M, Lee H, Wong CA, Lo E, et al. Leadership styles and outcome patterns for the nursing workforce and work environment: A systematic review. Int J Nurs Stud. 2010 Mar; 47(3):363-85.

102. Schwartz DB, Spencer T, Wilson B, Wood K. Transformational Leadership: Implications for Nursing Leaders in Facilities Seeking Magnet Designation. AORN J. 2011 Jun; 93(6):737-48.

103. Mahmoud A. A Study of Nurses' Job Satisfaction: The Relationship to Organizational Commitment, Perceived Organizational Support, Transactional Leadership, Transformational leadership and level of education. Eur J Sci Res. 2008;22(2):286-95.

104. Van Knippenberg D, Van Knippenberg B, De Cremer D, Hogg M. Leadership, self, and identity: A review and research agenda . Leadersh Q. 2004 Dec;15(6):825-56.

105. Walumbwa F, Lawler J, Avolio B. Leadership, Individual Differences, and Workrelated Attitudes: A Cross-Culture Investigation. Applied Psychology. 2007 Apr; 6 (2):212-30.

106. Nemanich LA, Keller RT. Transformational leadership in an acquisition: a field study of employees. Leaders Q. 2007 Feb; 18(1):49-68.

107. Spence Laschinger HK, Leiter MP. The impact of nursing work environments on patient safety outcomes: the mediating role of burnout/engagement. J Nurs Adm. 2006 May; 36(5):259-67.

108. Salanova M, Lorente L, Chambel MJ, Martínez IM. Linking transformational leadership to nurses' extra-role performance:the mediating role of self-efficacy and work engagement. J Adv Nurs. 2011 Oct; 67(10):2256-66. 
109. Munir F, Nielsen K. Does self-efficacy mediate the relationship between transformational leadership behaviours and healthcare workers' sleep quality? A longitudinal study. J Adv Nurs. 2009 Sep; 65(9):1833-43.

110. Le Blanc PM, Schaufeli WB, Salanova M, Llorens S, Nap RE. Efficacy beliefs predict collaborative practice among intensive care unit nurses. J Adv Nurs. 2010 Mar; 66(3):583-94.

111. McVicar A. Workplace stress in nursing: a literature review. J Adv Nurs. 2003 Dec; 44(6): 633-42.

112. Avolio BJ, Walumbwa FO, Weber TJ. Leadership: Current Theories, Research, and Future Directions. Annu Rev Psychol [Internet]. 2009 [Cited 2014 Apr 15]; 60:421-49. Avaible from: www.annualreviews.org.

113. Ghafoor A, Qureshi TM., Khan MA, Hijazi ST. Transformational leadership, employee engagement and performance: Mediating effect of psychological ownership. African Journal of Business Management. 2011 Sep; 17:7391-403.

114. Sorensen E. Transformational Leadership in Nursing. From Expert Clinician to Influencial Leader. Springer Publishing Company. New York, USA; 2011.

115. Castle NG, Decker, FH. Top Management Leadership Style and Quality of Care in Nursing Homes. Gerontologist. 2011 May;51(5):630-42.

116. Firth-Cozens J. Cultures for improving patient safety through learning: the role of teamwork. Qual Health Care. 2001 Dec; 10(Suppl 2):ii26-ii31.

117. De Lima Trindade L, Coelho Amestoy S, Adyles Muniz L, Biolchi T, Pires de Pires DE, Schubert Backes VM. Influência dos estilos de Liderança do Enfermeiro nas relações interpessoais da Equipe de Enfermagem. [Internet]. 2011 Apr [cited 2014 Mar 20]; 22:1-9. Avaible from: http://scielo.isciii.es/pdf/eg/v10n22/pt_administracion3.pdf.

118. Hetland H, Mjeldheim G, Backer T. Burnout in the information technology sector: ¿Does leadership matter? European Journal of Work and Organizational Psychology. 2007 Mar; 16(1):58-75. 
119. Zhu W, Avolio BJ, Walumbwa FO. Moderating role of follower characteristics with transformational leadership and follower work engagement. Group Organ Manag. 2009 Oct; 34(5):590-619.

120. Kean S, Haycock-Stuart, E. Understanding the relationship between followers and leaders. Nurs Manag (Harrow). 2011 Dec; 18(8):31-5.

121. Walumbwa FO, Lawler JJ, Avolio BJ, Wang P, Kan S. Transformational Leadership and Work-Related Attitudes: The Moderating Effects of Collective and Self-Efficacy Across Cultures. J Leaders Organ Stud. 2005 Spring; 11(3):2-16

122. Kuvaas B, Buch R, Dysvik A, Haerem T. Economic and social leader-member exchange relationships and follower performance. Leadership Q. 2012; 23(5): 756-65

123. Clark E, Squire S, Heyme A, Mickle ME, Petrie E. The PACT Project: Improving communication at handover. Med J Aust. 2009 Jun; 190(11 Suppl):S125-7.

124. Blegen MA, Vaughn T, Vojir CP. Nurse staffing levels: Impact of organizational characteristics and registered nurse supply. Health Serv Res. 2008 Feb; 43(1 Pt 1):154-73.

125. Avolio BJ. Promoting More Integrative Strategies for LeadershipTheory-Building. Am Psychol. 2007 Jan; 62(1):25-33.

126. Wong CA, Cummings GG. The relationship between nursing leadership and patient outcomes: a systematic review. J Nurs Manag. 2007 Jul; 15(8):508-21

127. Dierckx de casterlé B, Willemse A, Verschueren M, Milisen K. Impact of clinical leadership development on the clinical leader, nursing team and care-giving process: a case study. J Nurs Manag. 2008 Sep; 16(6):753-63.

128. Tomlinson J. Exploration of transformational and distributed leadership. Nursing Manag (Harrow). 2012 Jul;19(4):30-4.

129. Cameron S, Harbison J, Lambert V, Dickson C. Exploring leadership in community nursing teams. J Adv Nurs. 2012 Jul; 68(7):1469-81. 
130. Cummings G, MacGregor T, Davey M, Lee H, Wong CA, Lo E, Muise M. Leadership styles and outcome patterns for the nursing workforce and work environment: a systematic review. Int J Nurs Stud. 2010; 47(3): 363-85.

131. Blau JR, Goodman N. Social Roles and Social Institutions. San Francisco: Westview Press. c1991. Multigroup affiliations and complex role-sets.

132. Scott J, Tallia A, Crosson JC et al. Social network analysis as an analytic tool for interaction patterns in primary care practices. Ann Fam Med. 2005 Sep-Oct;3(5):443-8.

133. Samarth CN, Gloor PA. Process efficiency. Redesigning social networks to improve surgery patient flow. J Healthc Inf Manag. 2009; 23(1): 20-26.

134. Borgatti, Stephen, P; Everett, Martin, G; Jeffrey C Johnson .Analyzing Social Networks; 2013, SAGE publications. London, England.

135. Borgatti SP, Foster, PC. The Network Paradigm in Organizational Research: A Review and Typology. Journal of Management. 2003; 2(6):991-1013.

136. Lozares C, Verd JM., Martí J et all. Relaciones, redes y discurso: revisión y propuestas en torno al análisis reticular de datos textuales. Revista hispana para el análisis de redes sociales. 2003 Jan; 1(2):175-200.

137. Homans GC. Social behavior: Its elementary forms. New York: Harcourt Brace; 1961.

138. Farrell D, Rusbult CE. Exchange variables as predictors of job satisfaction, job commitment, and turnover: The impact of rewards, costs, alternatives, and investments. Organ Behav Hum Perform. 1981; 28:78-95.

139. Lozares C. Bases socio-metodológicas para el Análisis de Redes Sociales, ARS. Revista Metodológica de Ciencias Sociales. 2005 July-Dec; 10:9-35.

140. Barrera, D, Van de Bunt, G. Learning to Trust: Networks Effects Through Time. Eur Sociol Rev. 2009 Jan; 25(6):709-21.

141. Vincent CA, Wears RL. Communication in the emergency department: separating the signal from the noise. Medical Journal of Australia. 2002; 176: 409-410. 
142. Fieldin N. Triangulation and mixed methods designs: Data integration with new research technologies. J Mix Methods Res. 2012; 6(2):124-36.

143. Creswell, John, W. A concise Introduction to Mixed methods Research, SAGE publications, California USA; 2015.

144. Mixed methods in Health Science Research, A practical Primer. Leslie Curry \& Marcella Nunez-Smith. SAGE, California USA;2015.

145. Ivankova NV, Creswell JW, Stick SL. Using Mixed-Methods Sequential Explanatory Design: From Theory to Practice. Field Methods. 2006 Feb; 18:13-20.

146. Vega C, Zavala G. Adaptación del cuestionario multifactorial de liderazgo (MLQ forma $5 \mathrm{x}$ corta) de b. Bass y b. Avolio al contexto organizacional chileno [master's thesis]. Santiago; Universidad de Chile; 2004. p.295.

147. Curral L, Forrester R, Dawson J, West M. It's what you do and the way that you do it: Team task, team size and innovation-related group processes. European J Work Organ Psychol. 2001; 10(2):187-204.

148. Wasserman S, Faust K. Social Network Analysis. Cambridge: Cambridge University Press; 1994. p.116.

149. Borgatti S, Everett M, Freeman L. Ucinet for Windows: Software for social network analysis. Analytic Technologies; 2002.

150. Freeman L. Centrality in Social Networks Conceptual Clarification. Social Networks. 1978-1979: 1(3);215-39.

151. Sales A, Estabrooks C, Valente T. The impact of social networks on knowledge transfer in long-term care facilities: protocol for a study. Implement Sci. 2010 Jan; 5(49).

152. Jacour M, Mayer R. A obsevacao direta e a pesquisa qualitativa. 3rd Ed. Petrópolis_Rj: Vozes; c2012. A pesquisa qualitative: enfoques epitemológicos e metodológicos; 2012. p.254-293.

153. Sandelowski M, Barroso J. Finding the Findings in Qualitative Studies. J Nurs Scholarsh. 2004; 34 3):213-19. 
154. Koch T. Establishing rigour in qualitative research: the decision trail. Journal of Advanced Nursing. Jan 2006; 53(1): 91-100.

155. Graneheim U, Ludman B. Qualitative content analysis in nursing research: concepts, procedures and measures to achieve trustworthiness. Nurse Education Today. Freb 2004; 24 (2):105-12.

156. Burla L, Knierim B, Barth KL, Duetz M, Abel T. From the text to coding: Intercoder reliability assessment in qualitative content analysis. Nurs Res. 2008; 57: 113-17.

157. Emanuel EJ, Wender D, Grady C. What make Clinical Research Ethical. JAMA. 2000; $283(20): 2701-11$.

158. Resolução 466 do ano de 2012, Conselho Nacional de Pesquisa, Conselho Nacional de Saúde, Ministério a Saúde Brasil. Rescatado en Julio 2014 desde: http://conselho.saude.gov.br/resolucoes/2012/Reso466.pdf.

159. Vaus D. Analyzing Social Science Data 50 key problems in data analyzis ( $1^{\mathrm{a}}$ edition). Brisbana. Australia. SAGE Publications Ltda; 2002. 


\section{ANEXOS}

\subsection{Anexo $\mathrm{N}^{\circ} 1$ Cálculo de Muestra}

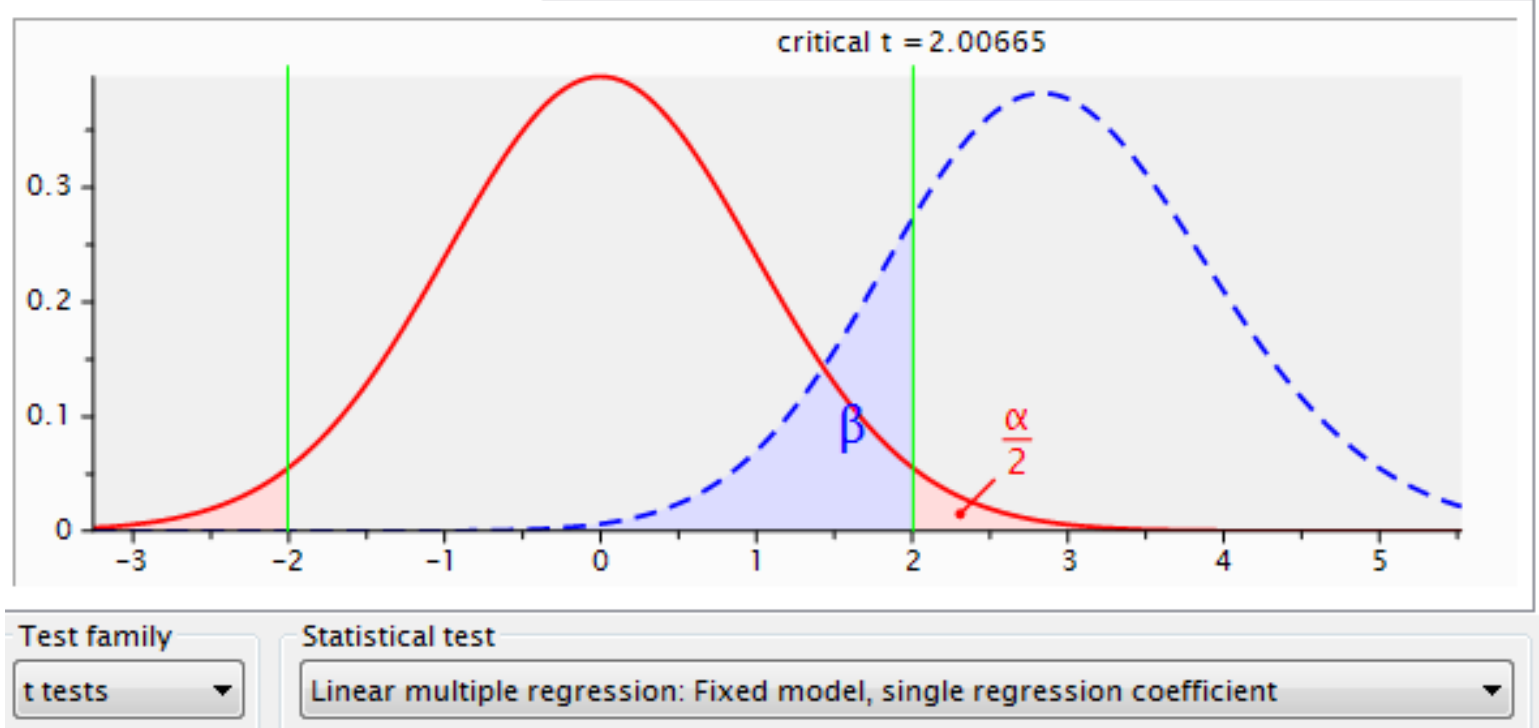

Type of power analysis

A priori: Compute required sample size - given $\alpha$, power, and effect size

Input Parameters

Tail(s)

Determine $=>$

Effect size $\mathrm{f}^{2}$ $\alpha$ err prob

Power ( $1-\beta$ err prob)

Number of predictors

Two $\quad-15$

0.15

0.05

0.80

2
Output Parameters

Noncentrality parameter $\delta$

Critical t

2.8722813

2.0066468

Df 52

Total sample size 55

Actual power 


\subsection{Anexo $\mathrm{N}^{\circ} 2$ Aprobación de Investigación Comités de Ética Brasil}

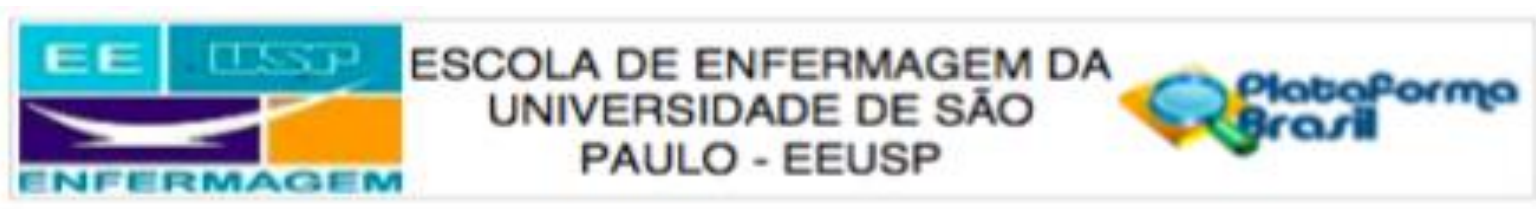

\section{PARECER CONSUBSTANCIADO DO CEP}

\section{DADOS DO PROJETO DE PESQUISA}

Titulo da Pesquisa: Satisfaçâo no trabaino, liderança transformacional e clima de equipes multiprofissionais: relaçös $00 \mathrm{~m}$ a comunicaça e interaçăo entre profissionais em um hospital de Santiago, Chile

Pesquisador: Marina Peduzzi

Area Tematica:

Versab: 1

CAAE: 41041215.2 .0000 .5392

Instituiçăo Proponente: Escola de Enfermagem da Univeraidade de Så Paulo - EEUSP

Patrocinador Principal: Financiamento Proprio

\section{DADOS DO PARECER}

Número do Parecer: 1.024.131

Data da Helatoria: 14/04/2015

\section{Apresentaçäo do Projeto:}

As organizaçōes de saúde săo cada vez mais sofisticadas, complexas e especializadas. Os oonhecimentos e habilidades necessarios para cumprir efetivamente suas metas mudam e aumentam constantemente. Trata-se de um projeto de doutorado de aluna chilena e a coleta de dados se realizara em hospital no Chile. O estudio tem por finalidade analisar os intercambios sociais, o clima, a relaçáo com o lider e a satistaçăo no trabalho dos membros de equipes multidisciplinares no contexto hospitalar. Estudo transversal exploratorio com uma fase quanti e outra qualitativa. A etapa quantitativa utilizara o Questionário Multifatorial de Liderança (16 itens), escala Clima de equipe na versalo reduzida em espanhol (14 itens), Questionário de satisfaçäo com a equipe ( 5 itens). Questionario das redes sociais no trabalho ( 6 perguntas). A etapa qualitativa - observaçăo direta com base em roteiro (atividades desenvolvidas, comunicaçăo e interaçăo). Os membros da equipe seráo acompanhados em observaçao durante periodos de 2 a 4 horas no turno da manha e tarde em diferentes dias da semana e será utilizado critério de saturaça para finalizar a observạ̧ă. Tambem serảo realizadas entrevistas semiestruturadas com profissionais considerados intormantes chave que serăo selecionados a partir dos resultados da analise de fedes sociais da primeira fase do estudo. As entrevistas seralo gravadas e realizadas com base em roteiro (5 questöes sobre trabaho em equipe) para conhecer as relaçóes que se estabelecem na

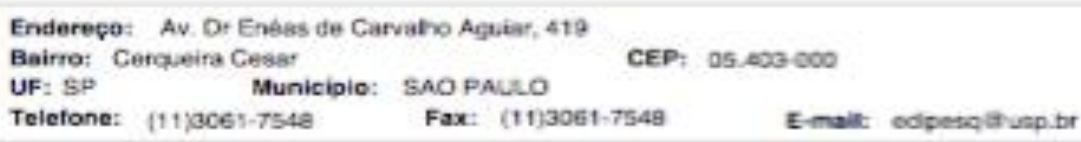




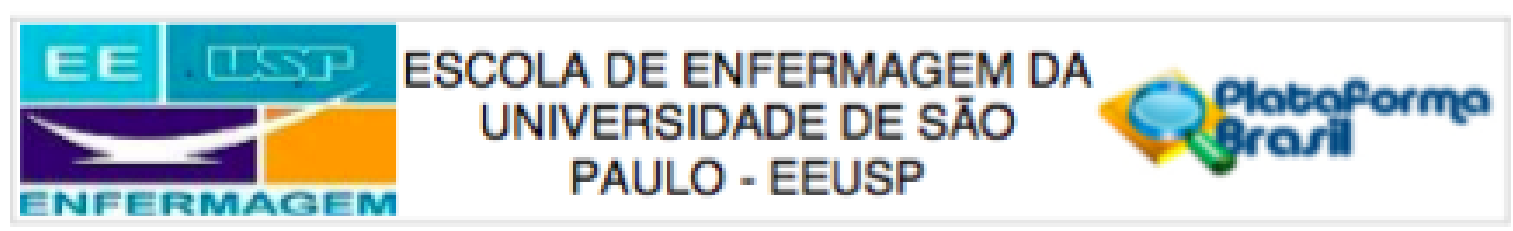

Certinuscalo do Pareser 1.004 .131

organizaçắ e as caracteristicas da comunicaçăo entre os profissionais de diferentes całegorias no cotidiano de trabalho no hospital estudado. Critério de Inclusảo: Profissionais com formaçấo universitária e auxliares/técniocs de enfermagem de todos os serviços (aculto e pedátrico) que tenham no mínimo um ano de trabalho no hospital. Critério de Exclusáo: Estudantes em estágios clínicos ou que de cursos de especializaçăo, bem como médicos bolsistas. Todo o pessoal administrativo que năo atua no cuidado direto ao paciente.

Objetivo da Pesquisa:

Objetivo primário

Analisar os intercâmbios sociais, a relaçăo com o líder e a satisfaçäo no trabalho dos membros de equipes multidisciplinares no contexto hospitalar

Objetivos secundários

- Analisar a relação entre liderança transformacional, clima de equipe e satisfaçăo no trabalho, bem como as redes sociais que se constituem entre os membros de equipes multidisciplinares em um hospital de Santiago, Chile. (decomposto em 6 objetivos especificos)

- Compreender os padrobes de comportamento, as relaçbes inter-pessoais e a comunicaçăo entre os membros de equipes multidisciplinares e seus respectivos lideres em um hospital de Santiago, Chile. (decomposto em 5 objetivos especificos)

\section{Avaliaçăo dos Riscos e Beneficios:}

Fiscos:o estudo apresenta riscos minimos, se ocorrerem serbio relacionados ao desconforto que a etapa de observaçäo da equipe profissional em atividade poderá ocasionar. O TCLE detalhe bem todas as etapas da coleta de dados, o que permitirá ao participante reconhecer o desconforto que poderá advir na sua participaçăo.

Beneficios:Estratégias baseadas em ferramentas organizacionais de comprovada efetividade podem melhorar as relą̧6es interpessoais das equipes de saúde e o cuidado aos pacientes do hospital estudado.

\section{Comentários e Consideraçōes sobre a Pesquisa:}

O estudo apresenta uma série de hipóteses a serem testadas: 1 - Melhor Satisfaçăo do Trabalho percebida pelos membros da equipe multidisciplinar de saúde associa-se a: a) Melhor percepçāo das diferentes dimensōes de Liderança Transformacional.b) Percepçăo positiva das diferentes dimensóes do Clima de Equipe.c) Alta densidade da rede de relap̧bes dos membros da equipe.d) Presença de centralidade na rede de relaçбes dos membros da

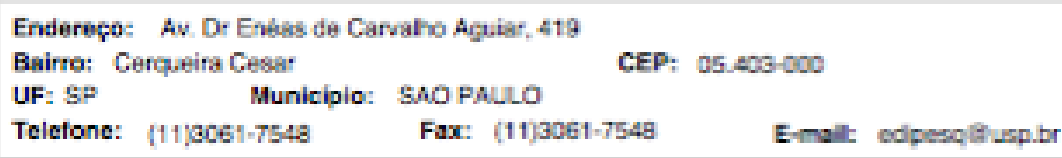




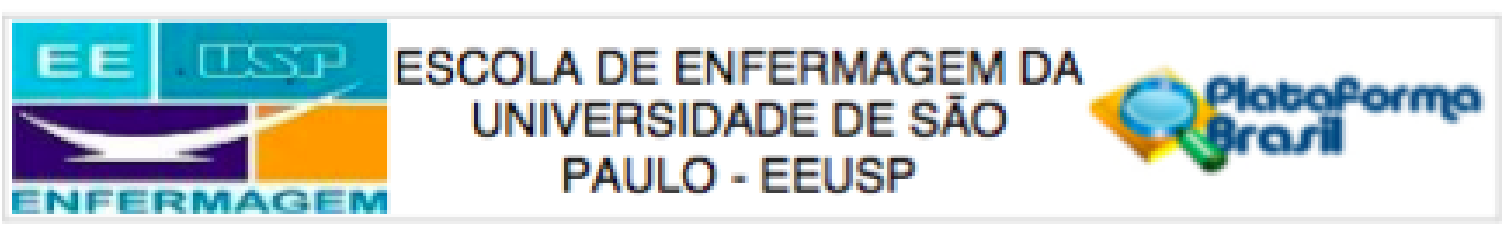

Cortinuache do Parecer: 1.024 .131

equipe.2 - Melhor percep̧̧ăo das diferentes dimensbes da Liderança Transformacional associa-se a:a) Percepçăo positiva das diferentes dimensóes do Clima de Equipe.b) Alta densidade da rede de relaçóes dos membros da equipe.c) Presença de centralidade na rede de relap̧es dos membros da equipe.3 - Uma melhor percepçăo das diferentes dimensobes do Clima de Equipe associa-se a:a) Alta densidade da rede de relaçóes entre os membros da equipe.b) Presença de centralidade na rede de relaçóes dos membros da equipe.

\section{Consideraçôes sobre os Termos de apresentaçāo obrigatória:}

O pesquisador apresenta dois TCLES: uma para a parte quantitativa do estudo que requer a participaçäo por meio do preenchimento de um instrumento pelos profissionais. O segundo TCLE será utilizado para a fase de observaçăo da equipe profissional e entrevista.

\section{Recomendaçôes:}

Näo há.

Conclusōes ou Pendências e Lista de Inadequaçōes:

Nåo apresenta b́bices éticos. O TCLE poderia ser mais sucinto e necessita ser rubricada em todas as páginas.

Situação do Parecer:

Aprovado

Necessita Apreciaçấo da CONEP:

Näo

Consideraçōes Finais a critério do CEP:

Este CEP informa a necessidade de registro dos resultados parciais e finais na Plataforma Brasil.

Esta aprovaçăo năo substitui a autorizaçăo da instituiçăo coparticipante, antes do inicio da coleta de dados.

Endereçe: Av. Dr Eness de Carvaho Aptiar, 419

Bairro: Cerqueira Cesar

CEP: 05.409 .000

UF: SP

Municipio: SAO PALLO

Telefone: (11),3661-7548

Fax: (11)3061-7548

Emalt: edpesgliusp.br 


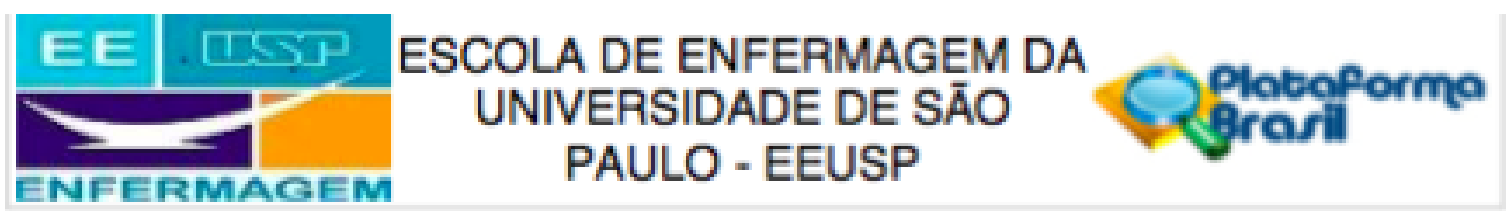

Cortinuagas do Parecer 1,024.134

\author{
SAO PAULO, 15 de Abril de 2015
}

Assinado por:

Marcelo José dos Santos

(Coordenador)

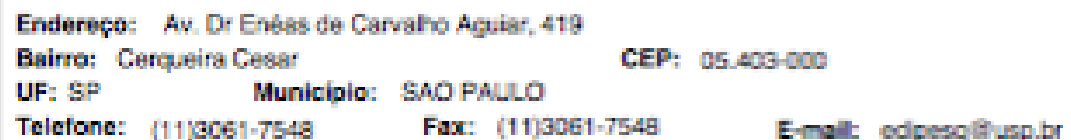




\subsection{Anexo $\mathrm{N}^{\circ} 3$ Aprobación de Investigación Comité de Ética Escuela de Enfermería} $\mathrm{UC}$

\section{Escuela de Enfermería UC}

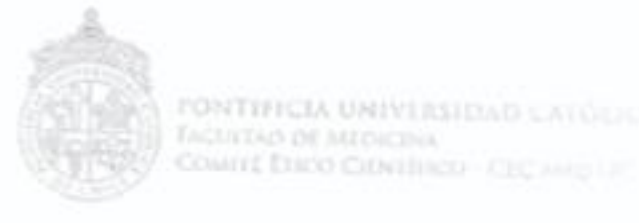

SE APROBO EL SIGUIENTE PROYECTO

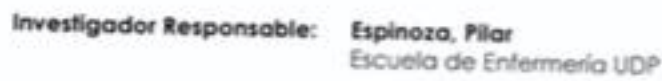

Financiamiento: no requiere financiamiento

Titulo: Prorecto: Sotistocción

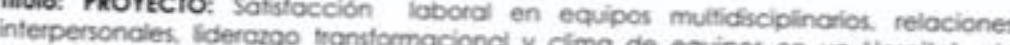
Santiogo.

\section{Se acusa recibo de los siguientes documentos}

Carta del investigadar responsable solicitando la revisión y aprobación de nuevo

Carta de respaldo del Jefe de Departamento de Salud dei Adulto y Senescente. Sra.
Sivia Barios. Corta de Dr, Ricardo Robogliat

Documentos revisados y aprobados por el comité:

Protocolo de investigación.

Documento de consentimiento informodo de etapa 1 y 2 dei provecto.

Cuestionario para los miembros de equipos mulsidisciplinorios.

\section{Resolución del CEC Med UC:}

Este proyecto ha sido aprobado

oflo. A contor del 04 de Moyo con fecho 05 de Mayo de 2015 y Siene vigencia de un Comité de Etica la renovación de 2016 el investigador responsable deberd solicitar of

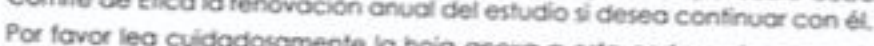

ers responsabilodes comente la hoja crexa a esta carta en la que se incfican todas us fesponsabildodes como investigodor responsable de este estudio. Se le solicita en toda futura correspondencia hocer referencia al número det Proyecto
asignado 15.059

Le saluda atentamente,

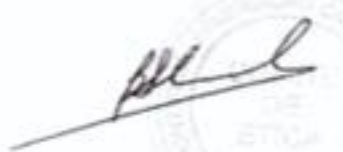

DRA. BEATRI SHAND KLAGGES

Presidente CEC-MeduC 


\subsection{Anexo $\mathrm{N}^{\circ} 4$ Documento de Consentimiento informado}

Lo invitamos a participar del proyecto de investigación titulado: "Satisfacción Laboral en Equipos Multidisciplinarios: Relaciones Interpersonales, Liderazgo Transformacional y Clima de Equipos en un Hospital de Santiago, Chile", proyecto de tesis doctoral bajo la responsabilidad de la investigadora Sra Pilar Espinoza, de la Escuela de Enfermería de la Pontificia Universidad Católica Chile, en Santiago y desarrollado en la Escuela de Enfermería de la Universidad de São Paulo ( EEUSP ) en Brasil .

El objetivo principal de esta investigación es analizar como las relaciones profesionales y sociales entre los miembros de equipos multidisciplinarios y su relación con el líder, se relacionan con la satisfacción que ellos experimentan de trabajar con ese equipo. Para lograrlo el estudio se llevará a cabo en dos etapas, primero a través de un cuestionario auto administrado y la segunda etapa que consiste en observar las rutinas de trabajo del equipo y entrevistas con algunos de sus miembros. Usted y su equipo está invitado a participar de esta primera etapa, que tiene como objetivo identificar si existe una relación entre liderazgo, clima y satisfacción laboral todo esto dentro del equipo multidisciplinarios, además de conocer las redes de interacciones sociales (formales e informales) entre sus miembros.

Si acepta participar, le pediremos que complete un cuestionario, que contiene preguntas sobre estilo de liderazgo, clima y satisfacción dentro del equipo de trabajo, además de identificar la red de relaciones interpersonales dentro del mismo. Este cuestionario será respondido de manera individual y los datos serán agrupados por equipo y luego analizados. Esta investigación nos ayuda a obtener información que nos permita contribuir a mejorar la satisfacción de las personas con su trabajo en los equipos de salud, a través de actividades que promuevan la comunicación, colaboración entre los miembros y relaciones interpersonales satisfactorias, además de programas de formación de futuros profesionales con énfasis en competencias relacionales y liderazgo.

Este cuestionario se aplicará a los miembros de aproximadamente 50 equipos multi disciplinarios de distintos servicios del hospital elegidos al azar de entre todos los equipos del hospital.

Se considera que No hay riesgos asociados a su participación en este estudio, teniendo en cuenta que: 
- La participación será por medio de responder el cuestionario descrito anteriormente, y se llevará a cabo de manera individual y privada en un lugar preparado para este fin dentro del hospital, en fecha y hora acordada.

- Responder el cuestionario le tomará alrededor de 20 a 25 minutos.

- La información que obtenemos a través suyo será estrictamente confidencial; no habrá ningún nombre, número o código que puede identificarlo, ni cualquier otra persona que participe .

- Sólo el investigador responsable del proyecto revisará sus respuestas al cuestionario, que permanecerá, junto con todo el material relacionado con esta investigación, bajo el cuidado de la Escuela de Enfermería de la Pontificia Universidad Católica de Chile en Santiago, Chile .

- Su participación en el estudio es completamente voluntario y su negativa a participar no afectará sus relaciones actuales o futuros en su lugar de trabajo o con la Universidad Católica.

- Usted puede optar por no responder a cualquier pregunta del cuestionario y puede decidir retirar su información en cualquier momento, incluso después de la final de la entrevista, sin ningún tipo de penalización.

Por favor, tenga en cuenta que al terminó de esta primera fase de la investigación, su equipo podría ser invitado a participar en la segunda fase, sin embargo, se le garantiza que será libre de participar o no de esta etapa, sin ningún tipo de penalización.

Usted recibirá la primera copia de este Consentimiento, para que permanezca en su poder.

Si tiene alguna pregunta acerca del cuestionario, incluso después que lo responda, puede comunicarse con la Sra Pilar Espinoza en el teléfono: 23547024 o por correo electrónico : pespinoq@uc.cl.

Si tiene preguntas acerca de sus derechos como participante en una investigación médica, usted puede llamar al Dra. Beatriz Shand Klagges., Presidente del Comité Ético Científico de la Facultad de Medicina, Pontificia Universidad Católica de Chile, al teléfono 2354-8173, o enviar un correo electrónico a: etica.investigacion@med.puc.cl.

En Brasil, el Comité de Ética de Investigación que evaluó el proyecto fue la Escuela de Enfermería de la Universidad de Sao Paulo y puede ser contactado por teléfono al (55 11) 3061-7652 o por correo electrónico edipesq@usp.br 
Tome el tiempo que requiera para decidirse, lea cuidadosamente este documento y hágale las preguntas que desee al equipo investigador.

Tiene alguna pregunta o duda?

$\mathrm{Si}$

No

Acepta participar voluntariamente del estudio?

$\mathrm{Si}$

No

Firme este documento voluntariamente, sin ser forzado/forzada a hacerlo.

Firma del participante

Lugar y Fecha

Nombre, firma y fecha del investigador

Nombre, firma y fecha del Director de la Institución o su Delegado: nombre, firma y fecha 


\section{Documento de Consentimiento informado}

Lo invitamos a participar del proyecto de investigación titulado: "Satisfacción Laboral en Equipos Multidisciplinarios: Relaciones Interpersonales, Liderazgo Transformacional y Clima de Equipos en un Hospital de Santiago, Chile", proyecto de tesis doctoral bajo la responsabilidad del investigador Sra Pilar Espinoza, de la Escuela de Enfermería de la Pontificia Universidad Católica de Chile y desarrollado en la Escuela de Enfermería de la Universidad de São Paulo en Brasil .

El objetivo principal de esta investigación es analizar como los intercambios profesionales y sociales entre los miembros de equipos multidisciplinarios y su relación con el líder, se relacionan con la satisfacción que ellos experimentan de trabajar con ese equipo. Para lograrlo el estudio se llevará a cabo en dos etapas, primero a través de un cuestionario auto administrado y la segunda etapa que incluye observar las rutinas de trabajo del equipo y entrevistas con algunos de sus miembros. Usted y su equipo está invitado a participar de esta segunda etapa, que tiene como objetivo observar y comprender en que contexto se manifiestan las relaciones interpersonales (formales e informales) y la comunicación entre los miembros de los equipos y con sus lideres.

El propósito de esta información es ayudarle a tomar la decisión de participar o no de esta investigación. Si acepta participar, le solicito que permita la observación del trabajo de su equipo en su servicio y que acepte participar en las entrevistas individuales. Esta investigación nos ayudara a obtener información que nos permita contribuir a mejorar la satisfacción de las personas con su trabajo en los equipos de salud, a través de actividades que promuevan la comunicación, colaboración entre los miembros y relaciones interpersonales satisfactorias, además de programas de formación de futuros profesionales con énfasis en competencias relacionales y liderazgo.

Este proyecto de investigación incluye a los miembros de aproximadamente 50 equipos multidisciplinarios de distintos servicios del hospital elegidos al azar de entre todos los equipos del hospital.

Se considera que no hay riesgos asociados a su participación en este estudio, teniendo en cuenta que:

- La participación será con su consentimiento, para observar el trabajo desarrollado por su equipo en la unidad donde se inserta dentro del hospital. 
- La participación también será a través de entrevistas, que se realizarán en un lugar preparado para este fin dentro del hospital o en otro lugar que usted indique, en fecha y hora acordados de antemano. La entrevista tendrá una duración aproximada de media hora y será grabada en audio, por lo que tiene todo el derecho de revisar la grabación y excluirla totalmente o en parte, si así lo desea.

- La información que obtenemos a través suyo será estrictamente confidencial; no habrá ningún nombre, número o código que puede identificarle, ni a ninguna otra persona que participe.

- El investigador a cargo del proyecto realizará la observación en su lugar de trabajo y su entrevista, que seguirá estando, junto con todo el material relacionado con esta investigación, bajo el cuidado de la Escuela de Enfermería de la Pontificia Universidad Católica de Chile en Santiago, Chile.

- Su participación en el estudio es completamente voluntaria y su negativa a participar no afectará sus relaciones actuales o futuras con su lugar de trabajo o con la Universidad Católica de Chile.

- Usted puede decidir no responder a cualquier pregunta durante la entrevista y puede decidir retirar la información proporcionada en cualquier momento, incluso después finalizada la entrevista y la observación, sin ninguna penalidad para usted.

Usted recibirá la primera copia de este Consentimiento, para que permanezca en su poder.

Si tiene alguna pregunta acerca del cuestionario, incluso después que lo responda, puede comunicarse con la Sra Pilar Espinoza en el teléfono: 23547024 o por correo electrónico : pespinoq@uc.cl.

Si tiene preguntas acerca de sus derechos como participante en una investigación médica, usted puede llamar al Dra. Beatriz Shand Klagges., Presidente del Comité Ético Científico de la Facultad de Medicina, Pontificia Universidad Católica de Chile, al teléfono 2354-8173, o enviar un correo electrónico a: etica.investigacion@med.puc.cl.

En Brasil, el Comité de Ética de Investigación que evaluó el proyecto fue la Escuela de Enfermería de la Universidad de Sao Paulo y pueden ser contactados por teléfono al (55 11) 3061-7652 o por correo electrónico edipesq@usp.br 
Tome el tiempo que requiera para decidirse, lea cuidadosamente este documento y hágale las preguntas que desee al equipo investigador.

Tiene alguna pregunta o duda?

$\mathrm{Si}$

No

Acepta participar voluntariamente del estudio?

$\mathrm{Si}$

No

Firme este documento voluntariamente, sin ser forzado/forzada a hacerlo.

Participante nombre, firma y fecha

Nombre, firma y fecha del investigador

Nombre, firma y fecha del Director de la Institución o su Delegado: nombre, firma y fecha 


\subsection{Anexo ${ }^{\circ} 5$ Instrumento}

\section{Cuestionario para los miembros de Equipos Multidisciplinarios}

Solicitamos unos minutos de su valioso tiempo y disposición para contestar el siguiente cuestionario, no le tomara mas de 20 minutos.

Este tiene por objetivo conocer su percepción, acerca de cuatro importante variables del comportamiento organizacional: Clima de equipos, Liderazgo, Satisfacción laboral y relaciones interpersonales, todo esto dentro de sus equipos de trabajo.

Cabe señalar, que este instrumento es anónimo, de carácter confidencial cuya finalidad es meramente académica. Los resultados particulares sólo los conocerán los investigadores responsables

Por favor no deje ningún ítem sin contestar... Desde ya agradecemos su valiosa colaboración...

Edad:

Sexo:

Femenino Masculino

Rol profesional dentro del equipo:

- a) Técnico en Enfermería

b) Enfermera

c) Médico

d) Kinesiólogo

e) Matrona

. f) Nutricionista

Tiempo trabajando en el Hospital: Tiempo trabajando con su actual equipo:

\section{1.-Cuestionario de Clima de Equipos}

\section{Instrucciones:}

Este cuestionario busca identificar los integrantes de su equipo de trabajo, tal como usted lo percibe. 
Para eso se presenta la siguiente definición de Equipo de Trabajo: “el grupo al cual las personas son asignadas, se identifican e interactúan con regularidad, con el fin de realizar tareas comunes"

1.a.- Según su opinión y de acuerdo a la definición anterior ¿Quiénes de los siguientes profesionales son miembros de su equipo de trabajo?

\begin{tabular}{|l|l|}
\hline Profesionales del Equipo & \\
\hline Técnico en Enfermería & \\
\hline Enfermera & \\
\hline Médico & \\
\hline Kinesiólogo & \\
\hline Matrona & \\
\hline Nutricionista & \\
\hline Ninguno de los anteriores & \\
\hline
\end{tabular}

1.a.-Ahora se le pedirá que reflexione en el clima que percibe dentro de su equipo de trabajo, y por favor responda las siguientes afirmaciones basado en esa reflexión.

\begin{tabular}{|l|l|l|l|l|}
\hline $\begin{array}{l}\text { Completamente } \\
\text { en desacuerdo }\end{array}$ & Desacuerdo & $\begin{array}{l}\text { Ni acuerdo ni } \\
\text { desacuerdo }\end{array}$ & De acuerdo & $\begin{array}{l}\text { Completamente } \\
\text { de acuerdo }\end{array}$ \\
\hline 1 & 2 & 3 & 4 & 5 \\
\hline
\end{tabular}

\begin{tabular}{|l|l|l|l|l|l|}
\hline $\begin{array}{l}\text { 1.-¿En qué medida estás de acuerdo con los objetivos que comparten? } \\
\text { 2.-¿Hasta que punto consideras que los miembros de tu equipo tienen } \\
\text { claro los objetivos del equipo? }\end{array}$ & $\mathbf{1}$ & $\mathbf{2}$ & $\mathbf{3}$ & $\mathbf{4}$ & $\mathbf{5}$ \\
\hline $\begin{array}{l}\text { 3.-¿Hasta qué punto crees que verdaderamente se pueden alcanzar los } \\
\text { objetivos de tu equipo? }\end{array}$ & $\mathbf{1}$ & $\mathbf{2}$ & $\mathbf{3}$ & $\mathbf{4}$ & $\mathbf{5}$ \\
\hline $\begin{array}{l}\text { 4.-¿En que medida crees que estos objetivos son beneficiosos para la } \\
\text { organización? }\end{array}$ & $\mathbf{1}$ & $\mathbf{2}$ & $\mathbf{3}$ & $\mathbf{4}$ & $\mathbf{5}$ \\
\hline $\begin{array}{l}\text { 5.-Tenemos una actitud solidaria: “en esto estamos juntos" } \\
\text { 6.-Las personas del equipo se mantienen mutuamente informadas } \\
\text { acerca de temas relacionados con el trabajo. }\end{array}$ & $\mathbf{1}$ & $\mathbf{2}$ & $\mathbf{3}$ & $\mathbf{4}$ & $\mathbf{5}$ \\
\hline
\end{tabular}




\begin{tabular}{|l|l|l|l|l|l|}
\hline 7.-La gente se siente comprendida y aceptada por los demás & $\mathbf{1}$ & $\mathbf{2}$ & $\mathbf{3}$ & $\mathbf{4}$ & $\mathbf{5}$ \\
\hline $\begin{array}{l}\text { 8.-En el equipo hay un intento real de compartir información } \\
\text { 9.-Están preparados los miembros del equipo para cuestionar el } \\
\text { fundamento de lo que el equipo esta haciendo? }\end{array}$ & $\mathbf{1}$ & $\mathbf{2}$ & $\mathbf{3}$ & $\mathbf{4}$ & $\mathbf{5}$ \\
\hline $\begin{array}{l}\text { 10.-¿Valora el equipo críticamente potenciales y debilidades en lo que } \\
\text { está haciendo para lograr los mejores resultados posibles? }\end{array}$ & $\mathbf{1}$ & $\mathbf{2}$ & $\mathbf{3}$ & $\mathbf{4}$ & $\mathbf{5}$ \\
\hline $\begin{array}{l}\text { 11.-iConstruyen los miembros del equipo sobre las ideas de los } \\
\text { demás para conseguir los mejores resultados posibles? }\end{array}$ & $\mathbf{1}$ & $\mathbf{2}$ & $\mathbf{3}$ & $\mathbf{4}$ & $\mathbf{5}$ \\
\hline $\begin{array}{l}\text { 12.-Las personas del equipo están siempre buscando nuevas formas } \\
\text { de ver los problemas. }\end{array}$ & $\mathbf{1}$ & $\mathbf{2}$ & $\mathbf{3}$ & $\mathbf{4}$ & $\mathbf{5}$ \\
\hline $\begin{array}{l}\text { 13.-En el equipo nos tomamos el tiempo necesario para desarrollar } \\
\text { nuevas ideas. }\end{array}$ & $\mathbf{1}$ & $\mathbf{2}$ & $\mathbf{3}$ & $\mathbf{4}$ & $\mathbf{5}$ \\
\hline $\begin{array}{l}\text { 14.-Las personas del equipo cooperan para ayudar a desarrollar y } \\
\text { aplicar nuevas ideas. }\end{array}$ & $\mathbf{1}$ & $\mathbf{2}$ & $\mathbf{3}$ & $\mathbf{4}$ & $\mathbf{5}$ \\
\hline
\end{tabular}

\section{2.-Cuestionario MLQ de Liderazgo Forma Corta}

\section{Instrucciones:}

Este cuestionario busca identificar la presencia de un líder en su equipo de trabajo y su estilo de liderazgo, tal como usted lo percibe.

Para eso se presenta una definición de liderazgo: “El Líder comparte las metas con los integrantes del equipo y reconoce el potencial de cada uno estimulando un mejor desempeño. Para el Líder son importante las relaciones interpersonales y la comunicación, además apoya, valora y respeta a todos los integrantes del equipo."

1.a.- Según su opinión ¿Quién de los siguientes miembros de su equipo de trabajo responde a la definición anterior? (Marque 1)

- a) Técnico en Enfermería

. b) Enfermera

. c) Médico

d) Kinesiólogo

e) Matrona 
- f) Nutricionista

. f) Ninguno

2.a. -Si su respuesta fue ninguno, por favor continúe con el punto 3.Cuestionario de Satisfacción con el Equipo.

- Si identifico un líder en su equipo!! por favor responda las siguientes afirmaciones pensando en el/ella y juzgue cuán frecuentemente se ajusta a cada una de las afirmaciones.

\begin{tabular}{|l|l|l|l|l|}
\hline NUNCA & RARA VEZ & A VECES & A MENUDO & SIEMPRE \\
\hline 0 & 1 & 2 & 3 & 4 \\
\hline
\end{tabular}

\begin{tabular}{|c|c|c|c|c|c|}
\hline 1.-Me siento orgulloso de trabajar con el/ella & $\mathbf{0}$ & 1 & 2 & 3 & 4 \\
\hline 2.-Por el bienestar de equipo es capaz de ir mas allá de sus intereses & $\mathbf{0}$ & 1 & 2 & 3 & 4 \\
\hline 3.-Actúa de un modo que se gana mi respeto & $\mathbf{0}$ & 1 & 2 & 3 & 4 \\
\hline 4.-Se muestra confiable y seguro & $\mathbf{0}$ & 1 & 2 & 3 & 4 \\
\hline 5.-Expresa sus valores y creencias mas importantes & $\mathbf{0}$ & 1 & 2 & 3 & 4 \\
\hline 6.-Considera importante tener un objetivo claro en lo que hace & $\mathbf{0}$ & 1 & 2 & 3 & 4 \\
\hline $\begin{array}{l}\text { 7.-Toma en consideración las consecuencias morales y éticas en las } \\
\text { decisiones adoptadas. }\end{array}$ & $\mathbf{0}$ & 1 & 2 & 3 & 4 \\
\hline $\begin{array}{l}\text { 8.-Enfatiza en la importancia de tener una misión cumplida y } \\
\text { compartida. }\end{array}$ & $\mathbf{0}$ & 1 & 2 & 3 & 4 \\
\hline 9.-Trata de mostrar el futuro de manera optimista & $\mathbf{0}$ & 1 & 2 & 3 & 4 \\
\hline 10.-Tiende a hablar con optimismo sobre las metas & $\mathbf{0}$ & 1 & 2 & 3 & 4 \\
\hline 11.-Construye una visión motivante del futuro & $\mathbf{0}$ & 1 & 2 & 3 & 4 \\
\hline 12.-Expresa confianza en que se alcanzarán las metas & $\mathbf{0}$ & 1 & 2 & 3 & 4 \\
\hline $\begin{array}{l}\text { 13.-Acostumbra a evaluar críticamente creencias y supuestos para } \\
\text { ver si son apropiados. }\end{array}$ & $\mathbf{0}$ & 1 & 2 & 3 & 4 \\
\hline 14.-Cuando resuelve problemas trata de verlos de distintas formas. & $\mathbf{0}$ & 1 & 2 & 3 & 4 \\
\hline 15.-Me ayuda a mirar los problemas desde distintos puntos de visto. & $\mathbf{0}$ & 1 & 2 & 3 & 4 \\
\hline 16.-Sugiere nuevas formas de hacer el trabajo. & $\mathbf{0}$ & 1 & 2 & 3 & 4 \\
\hline 17.-Dedica tiempo a enseñar y orientar. & $\mathbf{0}$ & 1 & 2 & 3 & 4 \\
\hline 18.-Me trata como individuo y no solo como miembro de un grupo. & $\mathbf{0}$ & 1 & 2 & 3 & 4 \\
\hline $\begin{array}{l}\text { 19.-Considera que tengo necesidades, habilidades y aspiraciones que } \\
\text { son únicas }\end{array}$ & $\mathbf{0}$ & 1 & 2 & 3 & 4 \\
\hline 20.-Me ayuda a desarrollar mis fortalezas. & $\mathbf{0}$ & 1 & 2 & 3 & 4 \\
\hline
\end{tabular}




\section{3.- Cuestionario de Satisfacción con el Equipo}

Este cuestionario busca identificar la satisfacción que usted siente con el trabajo en equipo, tal como usted lo percibe.

\section{Instrucciones:}

Valore en una escala de 1 a 7 su grado de acuerdo o desacuerdo con las siguientes afirmaciones relacionadas con su valoración sobre el trabajo en su equipo, donde 1 es completamente en desacuerdo y 7 es completamente de acuerdo.

\begin{tabular}{|c|c|c|c|c|c|c|c|}
\hline $\begin{array}{llllllll}\text { ompletamente en desacuerdo } & =1 & 2 & 3 & 4 & 5 & 6 & 7=\text { Com }\end{array}$ & ta & & & & & & \\
\hline $\begin{array}{l}\text { 1.- Si tuviera que elegir un equipo, estaría encantado/a de mantener } \\
\text { el mismo equipo de trabajo. }\end{array}$ & 1 & 2 & 3 & 4 & 5 & 6 & 7 \\
\hline $\begin{array}{l}\text { 2.-Estoy muy satisfecho/a con las decisiones adoptadas por este } \\
\text { equipo. }\end{array}$ & 1 & 2 & 3 & 4 & 5 & 6 & 7 \\
\hline 3.-La forma de trabajar de mi equipo me parece la más apropiada. & 1 & 2 & 3 & 4 & 5 & 6 & 7 \\
\hline $\begin{array}{l}\text { 4.-Mis expectativas son muy positivas sobre los resultados } \\
\text { favorables que resultara de la decisión tomada por el equipo. }\end{array}$ & 1 & 2 & 3 & 4 & 5 & 6 & 7 \\
\hline $\begin{array}{l}\text { 5.- El desarrollo del trabajo por parte de mi equipo ha sido muy } \\
\text { poco adecuado }\end{array}$ & 1 & 2 & 3 & 4 & 5 & 6 & 7 \\
\hline
\end{tabular}

\section{4.- Cuestionario de Redes Sociales en el trabajo}

Este cuestionario busca identificar las redes de interacción y comunicación dentro de su equipo de trabajo, tal como usted lo percibe

preguntas para determinar las redes sociales formales e informales dentro de los equipos Multidisciplinarios.

1.- ¿A quien acude cuando tiene alguna necesidad laboral? y con que frecuencia relativa en una semana de 1 a 5

\begin{tabular}{|l|l|l|l|l|l|}
\hline Profesionales del Equipo & 1 & 2 & 3 & 4 & $\begin{array}{l}5 \text { y } \\
\text { más. }\end{array}$ \\
\hline Técnico en Enfermería & & & & & \\
\hline Enfermera & & & & & \\
\hline Médico & & & & \\
\hline Kinesiólogo & & & & & \\
\hline Matrona & & & & & \\
\hline Nutricionista & & & & & \\
\hline Ninguno de los anteriores & \\
\hline
\end{tabular}


2.-¿A quien(s) acude cuando tiene algún problema personal? Marque con una $\mathbf{X}$

\begin{tabular}{|l|l|}
\hline Profesionales del Equipo & \\
\hline Técnico en Enfermería & \\
\hline Enfermera & \\
\hline Médico & \\
\hline Kinesiólogo & \\
\hline Matrona & \\
\hline Nutricionista & \\
\hline
\end{tabular}




\subsection{Anexo $\mathrm{N}^{\circ} 6$ Guía de entrevista con profesionales de los equipos Interdisciplinarios}

A - ¿Puedes compartir tu percepción en torno al trabajo en equipo en tu servicio?

B - En lo posible interdisciplinario y en las profesiones que tú consideres que participan......

$\mathrm{C}-$ ¿Como se organizan para trabajar en equipo?

a.-y la participación de los miembros?

b.- y apoyo a la innovación?

c.-tienen objetivos compartidos'

d.-Como se orientan para realizar las tarea?

D - ¿Que resultados esperas del trabajo en tu equipo?

E - ¿Como percibes el liderazgo dentro de tu equipo o equipos en general? un ejemplo? Alguna situación en que se observa? ¿las relaciones entre el líder y equipo y entre los miembros del equipo?

F - ¿Como te sientes en relación al liderazgo dentro de tu equipo? En este liderazgo:

a.-participan los miembros?

b.-apoya la innovación?

c.-los objetivos son compartidos?

d.-los orienta a la tarea?

$\mathrm{G}-$ ¿Como te sientes siendo parte de un equipo de salud? 